\title{
Integrating Biodiversity into Biosphere-Atmosphere Interactions Using an Individual-Based Model (IBM)
}

\author{
Bin Wang \\ Charlottesville, Virginia \\ A DISSERTATION PRESENTED TO THE GRADUATE FACULTY \\ OF THE UNIVERSITY OF VIRGINIA IN CANDIDACY FOR THE DEGREE OF \\ DOCTOR OF PHILOSOPHY
}

Department of Environmental Sciences

University of Virginia

December 2017 


\begin{abstract}
Biosphere-atmosphere interactions (BAIs) are integral to the functioning of the whole Earth System. The complexity of ecological systems profoundly determines these complex, nonlinear, and dynamic interactions. This complexity fundamentally originates from the high degree of biodiversity, resulting in complex interactions among individuals constituting a system and thus emergent system level behaviors. However, biodiversity has long been overlooked either intentionally or unintentionally largely because of methodological limitations. In particular, the currently widely used ecosystem model frameworks of aggregate representation of vegetation using plant functional types (PFTs) have severe deficiencies in integration of biodiversity and ecosystem functions. To address this grand issue, this dissertation primarily focuses on the development of an individual-based forest volatile organic compounds emission model, UVAFME-VOC (v1.0), and applications of this IBM (individual-based model) to addressing questions revolving around the roles of forest system diversity in influencing forest dynamics, biomass production, and isoprene (the most abundant VOC species) emissions responding to climate warming and ozone pollution. Specifically, this dissertation found that ozone may not suppress forest productivity and that climate warming does not necessarily always stimulate isoprene emissions all because of an explicit integration of species diversity and ecological interactions. These findings challenge long-held paradigms that are established on a linear scaleup of plant leaf physiology to the ecosystem level circumventing the community scale. This dissertation is concluded with discussing the deficiencies of IBMs and pointing out the challenges/directions, and advocates the development of IBM in truly integrating biodiversity into biosphere-atmosphere interactions in the Anthropocene Epoch.
\end{abstract}




\section{Acknowledgement}

How time flies! At this very moment of dissertation completion, so many memories, either sweet or a little bit bitter, spring up in retrospect the past four and half years. Most of them will probably fade away, but what will be remembered clearly forever is the scientific training of such a great quality I have received from my advisors, Professor Manuel Lerdau and Professor Herman Shugart. They are creative, giving me huge guidance when my project got stuck in key steps. They are patient, spending tremendous time in answering my questions and revising my manuscripts. They are kind, offering me great help and advices for my future career development. These are all great qualities that I have learned from them, which will definitely benefit for my future career development. However, the warmest thanks must go to Professor Manuel Lerdau who generously offered me this chance to purse a doctoral degree here in this department.

I also appreciate the invaluable inputs from my dissertation committee members, Professor Todd Scanlon and Professor John Pepper. With Professor Todd Scanlon I have gained a hydrological perspective to see the whole earth system.

Dr. Jackie Shuman is greatly acknowledged for her patience in guiding me to use the model, which opens a whole new methodology world for me. Dr. Megan McGroddy must be particularly acknowledged for her super kind support throughout my whole $\mathrm{PhD}$ life from the very beginning back in the 2013 fall to the very end now in 2017 winter.

So many more people, including those from terrestrial ecology group meeting, should be acknowledged, without whom I would not have been able to complete this dissertation at all. I wish all the best to all those who have helped me throughout this process.

Lastly, I thank my parents for their endless love and support. 


\section{Contents}

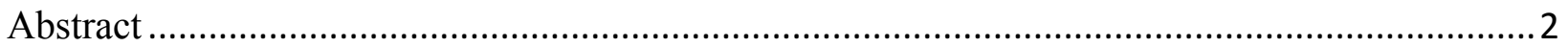

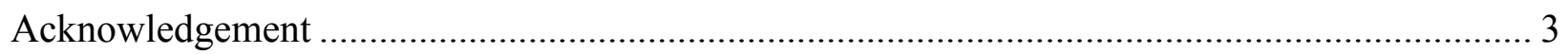

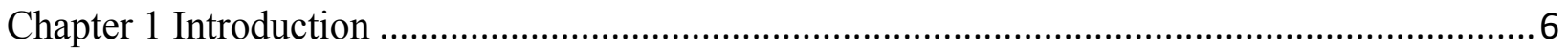

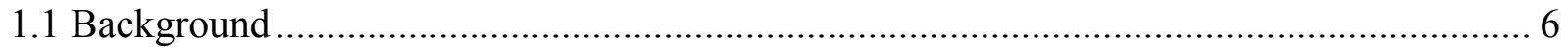

1.2 Feedbacks between vegetation and atmospheric chemical processes............................. 9

1.3 Importance of plant diversity in vegetation and atmospheric chemistry feedbacks .......... 12

1.4 Deficiencies of aggregate modelling strategy ......................................................... 14

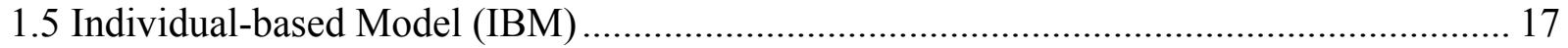

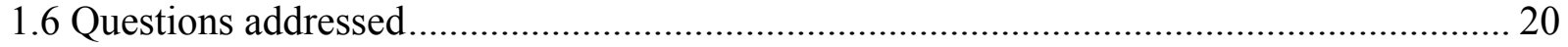

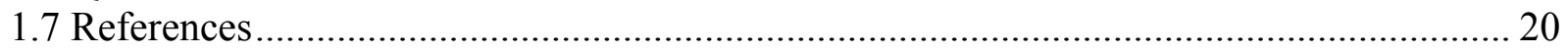

Chapter 2 Sensitivity of global greenhouse gas budgets to tropospheric ozone pollution mediated

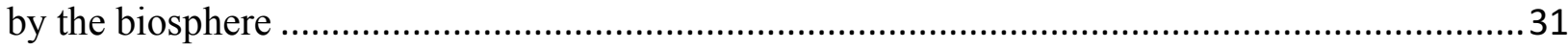

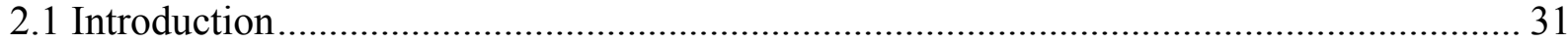

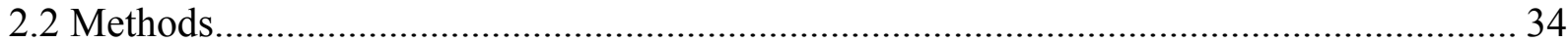

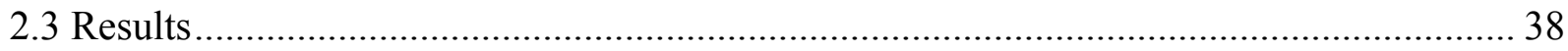

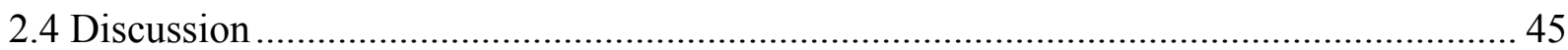

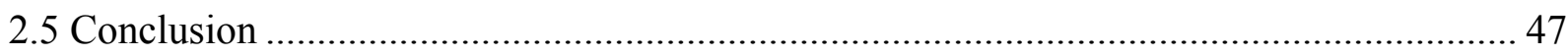

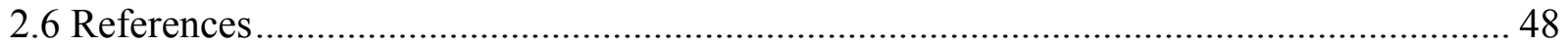

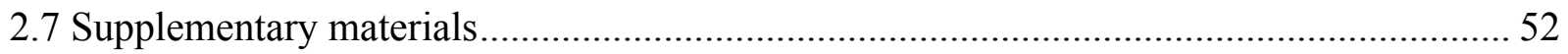

Chapter 3 An individual-based model of forest volatile organic compound emissions -

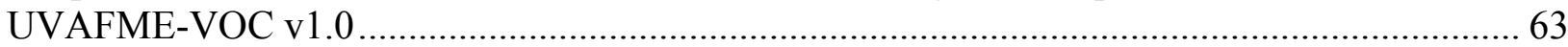

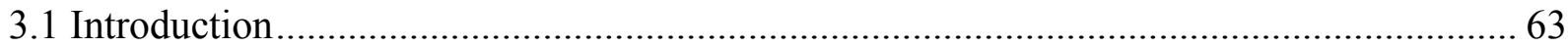

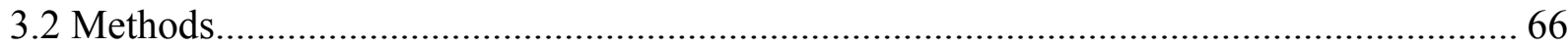

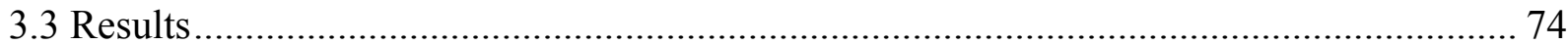

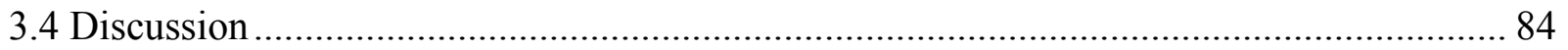

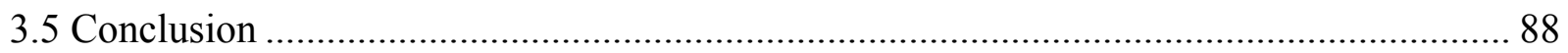

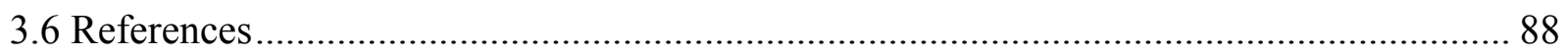

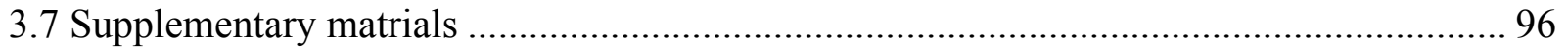

Chapter 4 Forests and ozone: productivity, carbon storage, and feedbacks .........................123

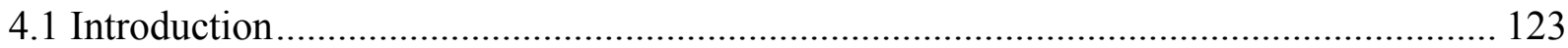

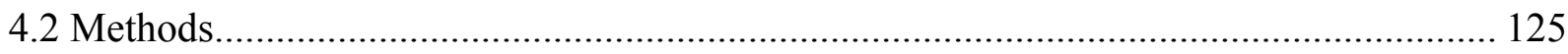

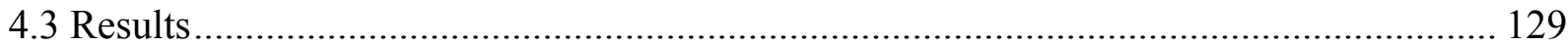

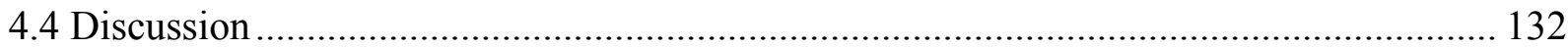

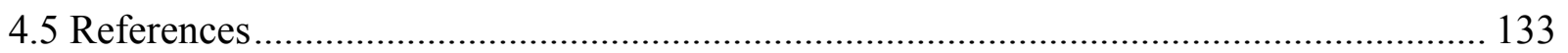

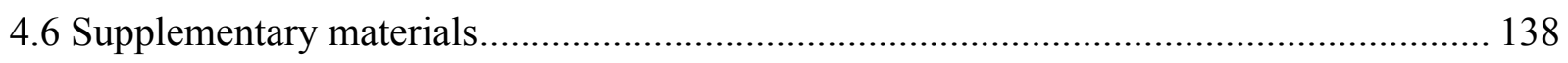

Chapter 5 The importance of biodiversity in mediating climate change-air quality feedbacks..144

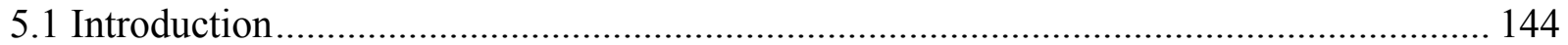

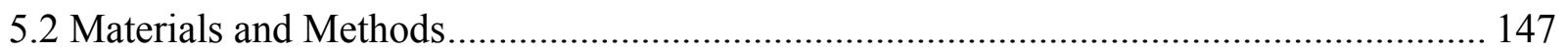

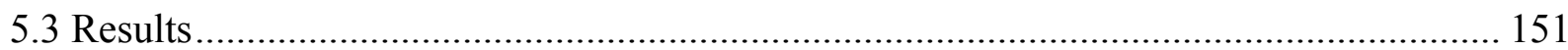

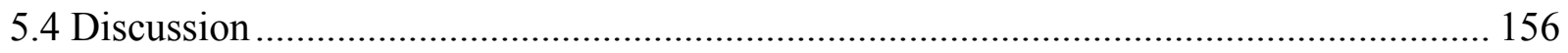

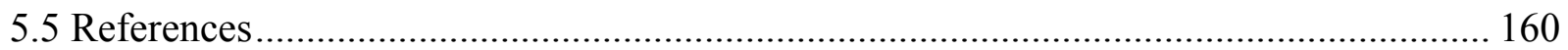




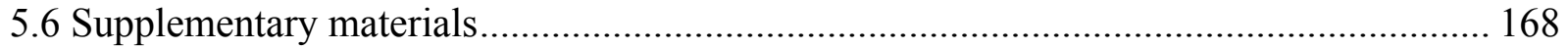

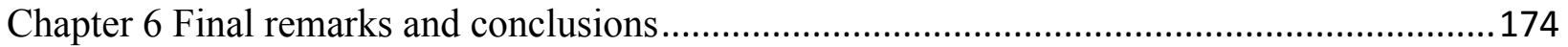

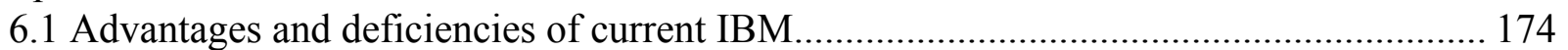

6.2 Challenges of IBM-based BAIs research............................................................. 178

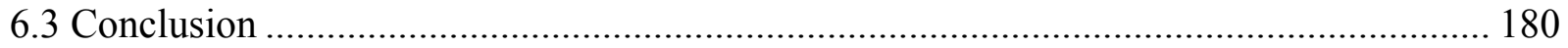

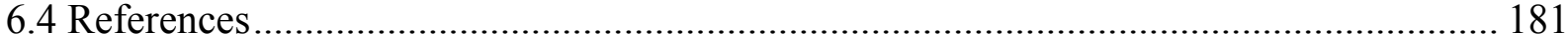




\section{Chapter 1 Introduction}

\subsection{Background}

The Earth system functions through the complex, dynamic interactions among a variety of component systems, to which the biosphere-atmosphere interactions (hereafter referred to as BAIs) are integral. BAIs play a central role in regulating the Earth system in terms of atmospheric components, physical climate, organism distribution, composition, structure and function, and beyond through an extremely complex array of biogeochemical and biophysical pathways. BAIs are dynamically changing; with the Earth entering the Anthropocene epoch (Crutzen 2002), the equilibrium status of BAIs has been significantly broken by ever strong human perturbations with an emergence of ever new, complex feedback mechanisms and pathways (e.g., Thornton et al. 2017; Penuelas et al. 2017). The climate is warming, atmospheric $\mathrm{CO}_{2}$ level rising, and nitrogen input increasing, accompanying among others severe air pollution (e.g., surface ozone), intensifying drought, and frequent heat waves, all of which are daunting problems to the biosphere in the past, present, and future, resulting from almost exclusively human activities (Ciais et al. 2013). Over the past several decades, the terrestrial ecosystem productivity has been steadily increasing (Le Quéré et al. 2016) but accompanied with an enhanced water use efficiency (Keenan et al. 2013; Cheng et al. 2017; Keeling et al. 2017); the Earth's land surface has been greening (Zhu et al. 2016); and the land carbon sink has also been increasing (Le Quéré et al. 2016). Increasing carbon uptake and land sink feed back both to determine the recent pause in the $\mathrm{CO}_{2}$ growth rate (Keenan et al. 2016) and to offset the 'carbon-13 Suess effect' (Keeling et al. 2017); warming forms a positive feedback loop with carbon (Cox et al. 2000; Mellio et al. 2017); and biophysical feedbacks of the Earth greening partly mitigates the climate warming (Zeng et al. 
2017). A glimpse of these feedbacks between terrestrial ecosystems and the atmosphere clearly suggests that BAIs research has been becoming unprecedentedly important and complex to ensure a sustainable and effective development of the natural systems and human society, as well as the whole Earth system.

Physicist Stephen Hawking asserted that 'the $21^{\text {st }}$ century will be the century of complexity' when responding the question: 'Some say that while $20^{\text {th }}$ century was the century of physics, we are now entering the century of biology. What do you think of this?'. Echoing Hawking's statement, theoretical physicist Geoffrey West contends that 'it is necessary to build a science of complex, adaptive systems to resolve the extraordinarily challenging societal problems we face' (West 2017). In fact, these statements are broadly true for BAIs research as well. From the biosphere side, lying in the heart of BAIs are the responses and feedbacks of the biosphere across the Earth to the physical and chemical components of the atmosphere, which is fundamentally determined by systems' functions. For simplicity, we could view the whole biosphere as a super-organism, of which functions are eventually determined by its metabolisms. However, the biosphere in reality is comprised of a tremendous number of organisms spanning from microorganisms through plants to animals. Such individuals with striking metabolism differences are the basic agents forming a super rich diversity of different hierarchical natural systems from the ocean to land and from aboveground to belowground across the globe (O'Neill et al. 1986; Levin 1998). The responses of these different ecosystems in terms of various biogeochemical and biophysical functions are determined by, but far more than a linear combination of, the responses of individuals (determined by the physiological metabolisms) comprising these systems, because system behaviors can emerge from the complex interactions among individuals (i.e., synergism of systems). Identically, we must have a system view of and 
build a science of complex, adaptive systems for the biosphere, which can offer us understandings of the past, present, and, more importantly, future state of the biosphere of clear composition, structure, and function. The beginning of this grand goal is biodiversity.

Because of this fundamental importance of diversity, the biodiversity-ecosystem functioning relationship in fact has largely drawn the attention from ecologists since 1990s (Loreau 2001, 2010). When biodiversity being discussed, two interweaved facets are implied: diversity differences across systems and temporal diversity changes (or system compositional changes). Over two decades of research has revealed that biodiversity in general is a significant driver of ecosystem functioning and a key component of ecosystem resilience to environmental perturbation (Loreau et al. 2001; Oliver et al. 2015). However, the systems and ecosystem functions studied are still extremely limited. The most impressive studies are probably the BEF studies in grassland ecosystems because of feasible experimental setup (Weisser et al. 2017). By contrast, more and more studies on forest ecosystems are only emerging in recent decade (Liang et al. 2016), while the belowground microbial systems are not studied until very recently (e.g. Allison and Martiny 2008). Moreover, the ecosystems functions studied are limited to carbon uptake (biomass) and ecosystem stability. Reasons leading to such scarcity of biodiversity consideration probably lie in, on the one hand, the extremely high biodiversity of terrestrial ecosystems, and, on the other hand, the long time scale and logistical difficulties for field experiments. Predicted changes in ecosystem composition, structure, and function play out over decades and centuries, making direct experimentation impossible and empirical observation challenging (Moorcroft et al. 2006). For example, to our best knowledge the longest FACE experiment manipulating environmental drivers is only 11 years; moreover, the number of species that can be included in such manipulated experiments is extremely limited (Zak et al. 2011). The understanding of BAIs thus largely rely 
on the predictions of large, complex models that make predictions at scales far larger than we are typically able to make measurements. However, a fundamental deficiency of those models is the aggregate way of vegetation being represented (e.g., Purves \& Pacala 2008; Scheiter et al. 2013). Therefore, the current condition is that we still do not widely see true integration of biodiversity and ecosystem function in BAIs research, which is ignored both intentionally and unintentionally and thus in its infancy.

By contrast, individual-based model (IBM), a bottom-up modelling strategy that has been existing for almost half of a century, can unify the theory of ecosystem and biodiversity by explicitly modelling each individual's behavior, interactions among individuals, and system level behavior emerged (Shugart 1984; Huston et al. 1988; Grimm et al. 2017). Instead of the paradigm of aggregate modelling strategy I propose that the strategy of IBM could be applied to integrate the diversity into system functions and hence address more broad questions regarding BAIs. The overarching purpose of this dissertation is to develop an individual-based forest volatile organic compounds emission model-UVAFEM-VOC — to study the responses and feedbacks of forest system composition dynamics, biomass, and emissions of isoprene (the single most abundant hydrocarbon species) to the atmosphere changes of climate warming and tropospheric ozone pollution.

\subsection{Feedbacks between vegetation and atmospheric chemical processes}

One major category of feedback mechanisms between the biosphere and atmosphere is the biogeochemistry pathway involving various biogeochemical processes associated with plant physiological metabolisms and soil microbial metabolisms in terrestrial ecosystems [but see Wang et al. (2017a) for an emerging new paradigm of non-microbial GHG production]. Terrestrial 
ecosystems and the atmospheric components and chemistry are closely associated through a wide variety of biogeochemical processes in the biosphere. Specifically, the impacts of terrestrial ecosystems on the atmospheric components/chemistry are attributed to the volatile organic compounds (VOCs) produced by and emitted from the vegetation through secondary metabolisms and other trace gases including $\mathrm{CO}_{2}, \mathrm{CH}_{4}, \mathrm{~N}_{2} \mathrm{O}$, and $\mathrm{NOx}$ which are primarily emitted from the soil systems. These processes and the underlying reactions are in turn simultaneously subject to strong alterations of air quality and climate changes.

As early as in 1960s, Haagen-Smit, Went, and colleagues first discovered that plant-derived organic compounds can contribute to ozone $\left(\mathrm{O}_{3}\right)$ and haze formation (Haagen-Smit and Fox, 1954; Went 1960). Over a half century of research has accumulated a good knowledge of biogenic VOCs production and emissions and their direct implications for atmospheric chemical processes and indirect effects on physical climate. VOCs production and emissions are strongly regulated by light intensity and temperature variations among a variety of other abiotic (e.g., warming, rising $\mathrm{CO}_{2}, \mathrm{O}_{3}$ pollution, and drought) and biotic factors (e.g., herbivory) (Lerdau et al. 1997; Vickers et al. 2009; Sharkey and Monson 2017). Every year a huge amount of VOCs is produced and emitted from the land surface vegetation into the biosphere (Guenther et al. 1995, 2006). These plantderived VOCs, together with anthropogenic emissions of VOC and $\mathrm{NO}_{\mathrm{X}}$, are oxidized by hydroxyl radical $(\mathrm{OH})$, nitrate radical $\left(\mathrm{NO}_{3}\right)$, and, to a smaller extent, $\mathrm{O}_{3}$ to form $\mathrm{O}_{3}$ and secondary organic aerosols (SOAs), which profoundly affects the air quality and physical climate (Atkinson and Arey 2003). Via VOCs the biosphere closely bridges the climate and air quality. Climate warminginitiated effects that cascade through the climate-biosphere-atmospheric chemistry chain have received the most attention (e.g., Weaver et al. 2009; Ito et al. 2009; Pacifico et al. 2012; Fu et al. 2015). Currently, it is widely accepted that warming can enhance vegetation VOC emissions 
because of warming-enhancement effects on leaf production (e.g., Sanderson 2003; Heald et al. 2009; Pacifico et al. 2012) and thus aggravate $\mathrm{O}_{3}$ pollution (Sanderson 2003; Fu et al. 2015) and SOA formation (Kulmala et al. 2004; Paasonen et al. 2013).

The air quality changes in turn exert strong impacts on the activities of terrestrial ecosystems, which eventually influences VOCs and other gases exchange. Air pollutants effects on plants has drawn attention from researchers for a long term. The earliest report of air pollutant affecting plants can be dated back to 1922 when O'Gara reported that $\mathrm{SO}_{2}$ negatively influenced plants. However, the $\mathrm{SO}_{2}$ pollution has been significantly ameliorated decades ago (Hand et al. 2012). Rather, $\mathrm{O}_{3}$ and and aerosols are the most severe air pollution problems confronted by the biosphere, affecting vegetation in both direct and indirect ways. First, $\mathrm{O}_{3}$, the most important secondary air pollutant, poses a strong oxidative pressure over the biosphere. The earliest finding of negative effects on plant date back to 1950s when researchers observed foliage damage and attributed it to $\mathrm{O}_{3}$ pollution. Over a half of century's research, we have basically elucidated the underlying physiological mechanisms, and $\mathrm{O}_{3}$ effects are manifested at a wide range of coarser levels beyond the cellular metabolism. At the cellular and leaf level, $\mathrm{O}_{3}$ inhibits photosynthesis and decreases the stomatal conductance by entering the intercellular space via the stomata, where $\mathrm{O}_{3}$ damages the cell functioning (Ainsworth et al. 2012). Additionally, $\mathrm{O}_{3}$ can also exert strong influences on the belowground biogeochemical processes (Anderson 2003). Overall, it is concluded that $\mathrm{O}_{3}$ largely induces feedbacks of the biosphere to the atmosphere by altering the exchange of greenhouse gases and water cycling globally. In detail, the $\mathrm{CO}_{2}$ has been significantly accumulated in the atmosphere resulting from suppressed vegetation productivity (Sitch et al. 2007), although suppressed $\mathrm{CH}_{4}$ and $\mathrm{N}_{2} \mathrm{O}$ emissions from terrestrial ecosystems can offset a small portion (Wang et al. 2017b). 
Aerosols can affect vegetation activity directly by supplying nutrients via deposition and/or indirectly by altering the physical environment (Mahowald 2011; Kanniah et al. 2012). The most discussed deposition of nitrogen deposition, supplying nitrogen nutrient to the biosphere, profoundly influences the whole biosphere. Nitrogen deposition has been shown to stimulate vegetation growth, inhibit $\mathrm{CO}_{2}$ emissions form land surface, and drive the increase of land carbon sink (Janssens et al. 2010; Penuelas et al. 2017). Aerosols can also indirectly affect the vegetation photosynthesis by altering the solar radiation reaching the surface in terms of both of total amount and proportion of diffuse light (Kanniah et al. 2012). Regionally, the tropical forest seasonal GPP variations are mostly determined by diffuse radiation (Yan et al. 2017); the severe haze in China enhanced the the diffuse radiation and largely stimulate photosynthesis (Yue et al. 2017). Globally, the changes in diffuse light are estimated to have increased terrestrial ecosystem uptake of carbon between 1960 and 1980 by $0.44 \mathrm{PgC}$ per year globally (Mercado et al. 2009).

\subsection{Importance of plant diversity in vegetation and atmospheric chemistry feedbacks}

The role of diversity in influencing the feedbacks discussed above is almost completely ignored in current and previous research; however, a rich accumulation of evidence suggests its great importance and warrant an inclusion. First of all, plant species in a system are having intrinsically heterogeneous primary and secondary metabolisms, producing striking interspecific differences responding to a variety of global and regional environmental changes including among others climate warming, drought, $\mathrm{O}_{3}$ pollution, nitrogen deposition, elevated $\mathrm{CO}_{2}$, and species invasion. As for the representative secondary metabolites VOCs, one of the longest known and most robust results is that their production and emissions are strongly contingent on species (e.g., Lerdau et al., 1997; Monson et al. 2013). Across global biomes a mixture of emitters and non- 
emitters of different VOC species in an ecosystem is ubiquitous (Loreto and Fineschi 2015). For instance, major tree species in the south eastern US is showing varying sensitivity to $\mathrm{O}_{3}$ and differing isoprene emission capacity. In addition to the intrinsic inter-specific differences, a high diversity of individuals in a system produce complex interactions, especially competition for resources of light, water, and nutriment. Moreover, changes in species diversity, which occurs at relatively long time scales especially in forest systems (induced by primary metabolism differences and interactions among individuals), can be caused by disturbances arising from global environmental changes (Franklin et al. 2015). Therefore, it is not simply a linear scale-up of an individual's response [usually obtained from studying one or just a few representative isolated individuals (with an average afterwards)] by assuming all the individuals comprising a system are same, as mostly done by previous studies. As regards VOCs, the changes in species diversity in terms of producers and non-producers have the potential to significantly influence the system-level emission capacity and even dominate physiological effects (Lerdau \& Slobodkin 2002; Lerdau 2007; Valolahti et al. 2015). We have scarce case studies that directly show the broad importance of diversity in affecting the biosphere-atmospheric chemistry interactions. The compositional change effect is best exemplified by the work by Hickman et al. (2010) who reported Kuzdo (Pueraria montana) invasion-induced $\mathrm{O}_{3}$ aggravation because of enhanced $\mathrm{NO}$ emissions in south eastern US, while a decline of $\mathrm{O}_{3}$ level induced by reduced isoprene emissions resulting from the red maple (Acer rubrum) expansion at the cost of oak (Quercus spp.) shrinkage in the eastern US was uncovered by Drewniak et al. (2014).

Therefore, it is essential to explicitly incorporate the species diversity and demographic processes when studying the effects of various environmental changes on forest functioning (e.g., productivity and VOC emissions). This requires long term studies and even a building of predictive 
science of ecosystem ecology, as advocated by an editorial of the journal Nature Ecology and Evolution to study 'long-term relationships' (https://www.nature.com/articles/s41559-017-03064) and evidenced by a few long term studies. For instance, the 11-year FACE study by Zak et al. (2011) found unsurprised forest productivity under $\mathrm{O}_{3}$ enrichment by including both $\mathrm{O}_{3}$-tolerant and-sensitive species/genotypes; the 27-year soil warming study by Mellilo et al. (2017) reported various phases of soil $\mathrm{CO}_{2}$ efflux response and indicated the important role of soil microbial community dynamics.

\subsection{Deficiencies of aggregate modelling strategy}

The very first concern when building a biosphere model is how to represent the vegetation of extremely high biodiversity. To simplify the representation, a strategy mimicking vegetation in an aggregate approach, i.e., plant functional types (PFTs), has thereby been proposed and widely applied to simulation of ecosystem processes, which has a rich history and can be traced back to Alexander von Humboldt who recognized at least 16 species-based structural classes having different physiognomies or plant growth forms in explorations of Europe, Africa and the Americas in the late 1770s (Ustin and Gamon 2010). This approach of lumping species together into PFTs is a non-phylogenetic classification system representing the highly diverse plants across the biosphere based on structural, phenological, functional, and biogeographical similarities (Ustin and Gamon 2010). Thus, a varying number of PFTs including, e.g., natural and managed grasses with either $\mathrm{C} 3$ or $\mathrm{C} 4$ photosynthetic pathways, shrubs, broadleaf or needleleaf trees with deciduous, evergreen or "rain green" phenology, and tropical versus temperate are created (Poulter et al. 2015). Accordingly, even for the most diverse Amazon tropical rainforest, only seven PFTs in total represent the plants in models (Fisher et al. 2010). Both advantages and problems in current 
large-scale terrestrial ecosystem mode frameworks emerge from this paradigm of vegetation representation.

With this approach current model frameworks represent vegetation in a climatological grid cell (usually 100-2500 $\mathrm{km}^{2}$, a habitat for a large number of species with varying ages and sizes) in the form of different PFTs which are assumed to be a single plant writ large experiencing spatially averaged resource conditions, i.e., 'big-leaf' (Moorcroft 2003). This 'big-leaf' representation of vegetation is the common practice in almost all of the terrestrial ecosystem models (TEM) and earth system models (ESM), e.g., TEM, IBIS, BIOME, and TRIFFID (Walker 1994; Purves and Pacala, 2008; Shugart and Woodward 2011). Recently, there are also a few model frameworks that deviate from these area-based ones and are simulated in 'individual-based' mode that can incorporate different ages and sizes (Smith et al. 2001; Ma et al. 2017), which, however, are still using the PFTs. Such an aggregate modelling approach shows overwhelming advantages, for example, reducing computational complexity of ESMs but also maintaining a feasible framework for hypothesis testing, and providing a practical solution to the problem that many of the plant traits required to parameterize a model at a species level are difficult to obtain (thereby fixed by averaging over a few representative species).

This aggregate modelling methodology, however, has severe weaknesses, fundamentally resulting from its abstraction of ecosystems that are of great complexity. This overwhelming simplification of ecosystem composition and structure is manifested by the missing of inter- and intra-specific variations of species, size, and age (Scheiter et al. 2013). This results in vertical and horizontal homogeneity, leading to the missing of mutual interactions and emergent properties; for example, the extremely important process of radiative transfer within the canopy is ignored (Scheiter et al. 2013). Thus, efforts to assess the stability and resilience of ecosystem-atmosphere 
interactions over long time scales using these models and other similar models are clearly hampered (Moorcroft et al. 2003, 2006; Purves and Pacala 2008). All in all, PFT-way representation induces apparent scaling problems in extrapolating system level processes from an individual's knowledge.

Here we take for example two widely used models (with fairly high citations, both exceeding 2000 times) that are capable of investigating BAIs to illustrate more details. LPJGUESS (Lund-Potsdam-Jena) is a flexible DGVM (Dynamics Global Vegetation Model) framework that is widely applied to study the regional and global vegetation dynamics and implications for carbon sequestration and climate (Sitch et al. 2003). Ten PFTs are defined in LPJ, of which eight are woody and two herbaceous. As regards woody plants, each individual belongs to a PFT (which is treated as an 'average individual'), while for grasses, just fractional coverage is defined. A spatial grid cell is treated as a mosaic divided into fractional coverages of different PFTs and bare ground; moreover, these PFTs do not occupy discrete blocks (Sitch et al. 2003). Without a mechanistic simulation of the competition among individuals, averages over these groups of PFTs for the demographic processes of growth, regeneration, and mortality enable a highly efficient modelling of vegetation dynamics (Sitch et al. 2003). Furthermore, with modification VOCs can also be simulated in a process-based way (Arneth et al. 2006; Hantson et al. 2017). In contrast to LPJ, MEGAN (Model of Emissions of Gases and Aerosols from Nature) is a popular, widely used model specifically for simulating biogenic VOCs emissions, which adopts the CLM4 scheme including 15 PFTs (Guenther et al. 2006). Unlike the LPJ and many other models, its vegetation representation per se is static, whereas dynamic vegetation distribution information can be obtained from other DGVMs such as LPJ and CLM (Oleson et al. 2013). Standard emission factor of VOC is assigned to different PFTs. 
It is undeniable that LPJ has been widely applied to study ecosystem functions (i.e. productivity, water cycling, and VOCs emissions) responding to global environmental changes including climate change and atmospheric components change $\left(\mathrm{CO}_{2}\right.$ level rise and air pollution) and that MEGAN has made great contributions to the understanding of spatial and temporal heterogeneities of VOC emissions, quantification of the magnitude, and implications for atmospheric chemistry. These are directly indicated by their fairly high citations. However, these models fundamentally ignore the ecological processes of ecosystems, in particular for MEGAN which has a static vegetation and lacks the ability of prediction (though dynamic vegetation can be fed by outputs from other vegetation dynamic models). Nevertheless, either static or dynamic, these two representative models are PFT-based, making the system dynamics one of the greatest sources of uncertainty (Purves and Pacala 2008). This is arguably evidenced by the LPJ-based modelling work by Schurgers et al. (2011) who compared simulations of isoprene and monoterpene with two different modes of vegetation representation and suggested that PFT-based simulations lose important information concerning the species heterogeneity.

\subsection{Individual-based Model (IBM)}

IBM is a bottom-up modelling methodology that can explicitly simulate the behaviors of each individual constituting a system, their interactions within this system, and system-level behaviors emerged (Huston et al. 1988). In contrary to the aggregate modelling strategy which lumps similar individuals together (but actually fairly different), as discussed above, this approach of modelling can integrate the hierarchical structure of ecological systems with processes at levels from the individual and population through community to ecosystem, each a separate discipline. In other words, IBM can simulate a system behaving the way it does. Therefore, IBM is capable 
of linking ecosystem functions and community ecology (biodiversity) (Grimm et al. 2017). This capability would facilitate the building of a true predictive science of the biosphere to predict the future state of ecological systems and thereby to inform management policies in the Anthropocene Era (Moorcroft 2003; Evans et al. 2012; Stillman et al. 2015; Houlahan et al. 2016, Dietze 2017).

Apparently, the fundamental advantage of IBM lies in its capability in simulation of variations among individuals constituting a system. A recognition of the importance of simulating such differences down to the individual level broadly in natural systems to determine a system's composition, dynamics, and functions can be dated back to at least the 1960s [according to the review by DeAngelis and Mooij (2005), and note that the early works do not necessarily use the term IBM]. A landmark work is that in 1988 Huston et al. gave the first formal endorsement of the great significance of IBMs in unifying ecological theory by synthesizing past theoretical and model development. Additionally, Huston et al. (1988) also predicted the rapid development of this approach by writing: "Within the next decade we expect to see a rapid development of this approach and a concomitant increase in the mechanistic understanding of ecological systems". Unexpectedly, such rapid development did not happen, though successively a series of synthesis work have been published to advocate the role of IBM in integrating ecosystem ecology and community ecology (e.g., Judson 1994; DeAngelis and Mooij 2005; DeAngelis and Grimm 2014). With four decades passing by, IBM toward elucidating the mechanisms of ecosystem across scales is still in this infancy and mostly stays at a stage of articulating its 'individual-based philosophy' (Grimm et al. 2017), though overall big achievements have been made in understanding forest systems' dynamics (Shugart and Woodward 2011). It is noteworthy that IBM development in ecological systems parallels the growth of related "agent-based" models (ABM, a different term but same with IBM) of economics, social science, and artificial intelligence and of particle-based 
models in physics (Huston et al. 1988; DeAngelis and Mooij 2005). However, a stark contrast is that the IBM (or ABM) approach has been developed with a much higher maturity and seen successful applications in the social and physical sciences to tackle social and economic problems (Epstein and Axell 1996; Auyang 1998; Grimm et al. 2005).

In retrospect, forest-based IBM is basically the earliest type among the various IBM in different systems. IBM for forest systems has been existing for about four decades, since the first individual-based forest model for a temperate forest in north eastern US, JABOWA, was developed by Botkin and colleagues in 1972. The occurrence of such a forest model can be traced deeply back into the forest yield table [see Shugart et al. (2017 in review) for a deeper history]. Following the formulation strategy of JABOWA, Shugart and West in 1977 developed the second forest IBM, FORET. Successively, Shugart and West (1980) introduced the term 'Gap Model' to describe this class model, which is widely applied in the community. Such a gap model designation emphasized that a principal simplifying assumption in these models (the assumption that the competition among individual trees on a small patch of land was homogeneous in the horizontal over a small area but spatially explicit in the vertical dimension) comported well with the classic "gap dynamics" concept of A.S. Watt $(1925,1947)$. Implied in this formulation was an underlying idea that a small plot, near the size of the influence zone of a large tree was an appropriate scale to include the gap generation and recovery seen in Watt's classic work. With these pioneering models, a diverse array of such individual-based forest gap models has been developed in different forest systems and has made huge contributions to the understanding of forest dynamic development responding to climate change and human disturbances (e.g., Bugmann 2001; Shugart and Woodward. 2011; Fischer et al. 2016; Shugart et al. in review). 


\subsection{Questions addressed}

Specifically, in this dissertation four questions (chapters) are addressed (presented):

1) How does tropospheric $\mathrm{O}_{3}$ affect the soil-atmosphere exchange of greenhouse gases including $\mathrm{CO}_{2}, \mathrm{CH}_{4}$, and $\mathrm{N}_{2} \mathrm{O}$ ? (Chapter 2)

2) An individual-based forest volatile organic compounds emission model, UVAFME-VOC (1.0) was developed, validated, and applied to address the following questions. (Chapter 3)

3) How does tropospheric $\mathrm{O}_{3}$ pollution affects forest composition, biomass, and isoprene emissions with an explicit representation of species-specific sensitivity to $\mathrm{O}_{3}$ ? (Chapter 4)

4) How does climate warming affect forest isoprene emissions when explicitly incorporating system biological diversity? (Chapter 5)

\subsection{References}

Ainsworth, E. A., Yendrek, C. R., Sitch, S., Collins, W. J., \& Emberson, L. D. (2012). The effects of tropospheric ozone on net primary productivity and implications for climate change. Annual Review of Plant Biology, 63, 637-661.

Allison, Steven D., and Jennifer BH Martiny (2008) Resistance, resilience, and redundancy in microbial communities. Proceedings of the National Academy of Sciences 105: 1151211519.

Andersen, C. P. (2003). Source-sink balance and carbon allocation below ground in plants exposed to ozone. New Phytologist, 157, 213-228.

Arneth, A., Niinemets Ü., Pressley S., Bäck J., Hari P., Karl T., Noe S., Prentice I.C., Serça D., Hickler T., Wolf A., Smith B., 2007. Process-based estimates of terrestrial ecosystem isoprene emissions: incorporating the effects of a direct $\mathrm{CO}_{2}$-isoprene interaction. Atmos. 
Chem. Phys. 7, 31-53.

Atkinson, R., \& Arey, J. (2003). Gas-phase tropospheric chemistry of biogenic volatile organic compounds: a review. Atmospheric Environment, 37, 197-219.

Auyang, S. Y. Foundations of Complex System Theories in Economics, Evolutionary Biology, and Statistical Physics (Cambridge Univ. Press, New York, 1998).

Botkin, D. B., Janak, J. F., \& Wallis, J. R. (1972). Some ecological consequences of a computer model of forest growth. Journal of Ecology, 60, 849-872.

Bugmann, H., 2001a. A review of forest gap models. Clim. Change 51, 259-305.

Cox, P. M., Betts, R. A., Jones, C. D., Spall, S. A., \& Totterdell, I. J. (2000). Acceleration of global warming due to carbon-cycle feedbacks in a coupled climate model. Nature, 408, 184-187.

Crutzen, P. J. (2002). Geology of mankind. Nature, 415(6867), 23-23.

Cheng, L., Zhang, L., Wang, Y. P., Canadell, J. G., Chiew, F. H., Beringer, J., ... \& Zhang, Y. (2017). Recent increases in terrestrial carbon uptake at little cost to the water cycle. Nature Communications, 8 .

Ciais P, Sabine C, Bala G, et al. (2013) Carbon and Other Biogeochemical Cycles. In: Climate Change 2013: The Physical Science Basis. Contribution of Working Group I to the Fifth Assessment Report of the Intergovernmental Panel on Climate Change (eds. Stocker TF, Qin D, Plattner G-K, Tignor M, Allen SK, Boschung J, Nauels A, Xia Y, Bex V \& Midgley PM), pp. 465-570, Cambridge University Press Cambridge, United Kingdom and New York, NY, USA.

DeAngelis, D. L., \& Mooij, W. M. (2005). Individual-based modeling of ecological and evolutionary processes. Annu. Rev. Ecol. Evol. Syst., 36, 147-168.

DeAngelis, D. L., \& Grimm, V. (2014). Individual-based models in ecology after four decades. 
F1000prime Reports, 6 .

Dietze, M. C. (2017). Prediction in ecology: a first-principles framework. Ecol Appl, 27: 20482060.

Drewniak, B. A., Snyder, P. K., Steiner, A. L., Twine, T. E., \& Wuebbles, D. J. (2014). Simulated changes in biogenic VOC emissions and ozone formation from habitat expansion of Acer Rubrum (red maple). Environmental Research Letters, 9, 014006.

Evans, M. R. (2012). Modelling ecological systems in a changing world. Phil. Trans. R. Soc. B, $367,181-190$.

Epstein, J. and Axtell, R. Growing Artificial Societies. Social Science from the Bottom Up (Brookings Institution/MIT Press, Washington, DC, 1996).

Fisher, R., McDowell, N., Purves, D., Moorcroft, P., Sitch, S., Cox, P., ... \& Ian Woodward, F. (2010). Assessing uncertainties in a second-generation dynamic vegetation model caused by ecological scale limitations. New Phytologist, 187, 666-681.

Franklin, J., Serra-Diaz, J. M., Syphard, A. D., Regan, H. M., (2016). Global change and terrestrial plant community dynamics. Proc. Natl. Acad. Sci. U. S. A. 201519911.

Fu T.M., Zheng Y., Paulot F., Mao J. \& Yantosca R.M. (2015). Positive but variable sensitivity of August surface ozone to large-scale warming in the southeast United States. Nature Climate Change. 5, 454-458.

Guenther, A., Hewitt C.N., Erickson D., Fall R., Geron C., Graedel T., Harley P., Klinger L., Lerdau M., McKay W., 1995. A global model of natural volatile organic compound emissions. J. Geophys. Res. 100, 8873-8892.

Guenther, A., Karl T., Harley P., Wiedinmyer C., Palmer P.I., Geron C., 2006. Estimates of global terrestrial isoprene emissions using MEGAN, Model of Emissions of Gases and Aerosols 
from Nature. Atmos. Chem. Phys. 6, 3181-3210.

Grimm, V., Revilla E., Berger U., Jeltsch F., Mooij W.M., Railsback S.F., Thulke H.-H., Weiner J., Wiegand T., DeAngelis D.L., 2005. Pattern-oriented modeling of agent-based complex systems: lessons from ecology. Science 310, 987-991.

Grimm, V., Ayllón, D., \& Railsback, S. F. (2017). Next-generation individual-based models integrate biodiversity and ecosystems: yes we can, and yes we must. Ecosystems, 20, 229236.

Haagen-Smit, A. J., \& Fox, M. M. (1954). Photochemical ozone formation with hydrocarbons and automobile exhaust. Air Repair, 4, 105-136.

Hantson, S., Knorr, W., Schurgers, G., Pugh, T. A., \& Arneth, A. (2017). Global isoprene and monoterpene emissions under changing climate, vegetation, $\mathrm{CO}_{2}$ and land use. Atmospheric Environment, 155, 35-45.

Heald, C. L., Wilkinson, M. J., Monson, R. K., Alo, C. A., Wang, G., \& Guenther, A. (2009). Response of isoprene emission to ambient $\mathrm{CO} 2$ changes and implications for global budgets. Global Change Biology, 15, 1127-1140.

Houlahan, J. E., McKinney, S. T., Anderson, T. M. and McGill, B. J. (2017), The priority of prediction in ecological understanding. Oikos, 126, 1-7.

Huston M., DeAngelis D. \& Post W. (1988). New Computer Models Unify Ecological Theory. Bioscience, 38, 682-691.

Ito A., Sillman S. \& Penner J.E. (2009). Global chemical transport model study of ozone response to changes in chemical kinetics and biogenic volatile organic compounds emissions due to increasing temperatures: Sensitivities to isoprene nitrate chemistry and grid resolution. Journal of Geophysical Research: Atmospheres (1984-2012), 114. 
Janssens, I. A., Dieleman, W., Luyssaert, S., Subke, J. A., Reichstein, M., Ceulemans, R., ... \& Papale, D. (2010). Reduction of forest soil respiration in response to nitrogen deposition. Nature Geoscience, 3, 315.

Judson, O. P. (1994). The rise of the individual-based model in ecology. Trends in Ecology \& Evolution, 9, 9-14.

Kanniah, K. D., Beringer, J., North, P., \& Hutley, L. (2012). Control of atmospheric particles on diffuse radiation and terrestrial plant productivity: A review. Progress in Physical Geography, 36, 209-237.

Keeling, R. F., Graven, H. D., Welp, L. R., Resplandy, L., Bi, J., Piper, S. C., ... \& Meijer, H. A. (2017). Atmospheric evidence for a global secular increase in carbon isotopic discrimination of land photosynthesis. Proceedings of the National Academy of Sciences, 114, 10361-10366.

Keenan, T. F., Hollinger, D. Y., Bohrer, G., Dragoni, D., Munger, J. W., Schmid, H. P., \& Richardson, A. D. (2013). Increase in forest water-use efficiency as atmospheric carbon dioxide concentrations rise. Nature, 499, 324.

Keenan, T. F., \& Niinemets, Ü. (2016). Global leaf trait estimates biased due to plasticity in the shade. Nature plants, 3 .

Keenan, T. F., Prentice, I. C., Canadell, J. G., Williams, C. A., Wang, H., Raupach, M., \& Collatz, G. J. (2016). Recent pause in the growth rate of atmospheric CO2 due to enhanced terrestrial carbon uptake. Nature communications, 7.

Kulmala, M., Suni, T., Lehtinen, K. E. J., Dal Maso, M., Boy, M., Reissell, A., Rannik, Ü., Aalto, P., Keronen, P., Hakola, H., Bäck, J., Hoffmann, T., Vesala, T., and Hari, P. (2004) A new feedback mechanism linking forests, aerosols, and climate, Atmos. Chem. Phys., 4, 557- 
562.

Le Quéré, C., Andrew, R. M., Canadell, J. G., Sitch, S., Korsbakken, J. I., Peters, G. P., ... \& Keeling, R. F. (2016). Global carbon budget 2016. Earth System Science Data, 8, 605.

Lerdau M., Guenther A. \& Monson R. (1997). Plant production and emission of volatile organic compounds. Bioscience, 373-383.

Lerdau, M., \& Slobodkin, L. (2002). Trace gas emissions and species-dependent ecosystem services. Trends in Ecology \& Evolution, 17, 309-312.

Lerdau, M. 2007. A positive feedback with negative consequences. Science 316, 212-213.

Levin, S. A. (1998). Ecosystems and the biosphere as complex adaptive systems. Ecosystems, $1,431-436$.

Liang, J., Crowther, T. W., Picard, N., Wiser, S., Zhou, M., Alberti, G., ... \& de-Miguel, S. (2016). Positive biodiversity-productivity relationship predominant in global forests. Science, 354 , aaf8957.

Loreau, M. (2010). Linking biodiversity and ecosystems: towards a unifying ecological theory. Philosophical Transactions of the Royal Society of London B: Biological Sciences, 365, 49-60.

Loreau, M., Naeem, S., Inchausti, P., Bengtsson, J., Grime, J. P., Hector, A., ... \& Tilman, D. (2001). Biodiversity and ecosystem functioning: current knowledge and future challenges. Science, 294, 804-808.

Loreto, F., Fineschi S., 2014. Reconciling functions and evolution of isoprene emission in higher plants. New Phytol. 206, 578-572

Ma, J., Shugart, H. H., Yan, X., Cao, C., Wu, S., \& Fang, J. (2017). Evaluating carbon fluxes of global forest ecosystems by using an individual tree-based model FORCCHN. Science of 
The Total Environment, 586, 939-951.

Mahowald, N. (2011). Aerosol indirect effect on biogeochemical cycles and climate. Science, 334, 794-796.

Melillo, J. M., Frey, S. D., DeAngelis, K. M., Werner, W. J., Bernard, M. J., Bowles, F. P., ... \& Grandy, A. S. (2017). Long-term pattern and magnitude of soil carbon feedback to the climate system in a warming world. Science, 358, 101-105.

Mercado, L. M., Bellouin, N., Sitch, S., Boucher, O., Huntingford, C., Wild, M., \& Cox, P. M. (2009). Impact of changes in diffuse radiation on the global land carbon sink. Nature, 458, 1014-1017.

Monson, R.K., Jones R.T., Rosenstiel T.N., Schnitzler J. P., 2013. Why only some plants emit isoprene. Plant Cell Environ. 36, 503-516.

Moorcroft, P. R. (2003). Recent advances in ecosystem-atmosphere interactions: an ecological perspective. Proceedings of the Royal Society of London B: Biological Sciences, 270, $1215-1227$.

Moorcroft, P. R. (2006). How close are we to a predictive science of the biosphere? Trends in Ecology \& Evolution, 21, 400-407.

Oleson, K. W., Lawrence, D. M., Gordon, B., Flanner, M. G., Kluzek, E., Peter, J., ... \& Heald, C. L. (2010). Technical description of version 4.0 of the Community Land Model (CLM).

Oliver, T. H., Heard, M. S., Isaac, N. J., Roy, D. B., Procter, D., Eigenbrod, F., ... \& Proença, V. (2015). Biodiversity and resilience of ecosystem functions. Trends in Ecology \& Evolution, 30, 673-684. 
Paasonen, P., Asmi, A., Petäjä, T., Kajos, M. K., Äijälä, M., Junninen, H., ... \& van der Gon, H. D. (2013). Warming-induced increase in aerosol number concentration likely to moderate climate change. Nature Geoscience, 6, 438-442.

Pacifico, F., Folberth, G. A., Jones, C. D., Harrison, S. P., and Collins, W. J. (2012). Sensitivity of biogenic isoprene emissions to past, present, and future environmental conditions and implications for atmospheric chemistry, J. Geophys. Res., 117, D22302.

Peñuelas, J., Ciais, P., Canadell, J. G., Janssens, I. A., Fernández-Martínez, M., Carnicer, J., ... \& Sardans, J. (2017). Shifting from a fertilization-dominated to a warming-dominated period. Nature Ecology \& Evolution, 1, 1438.

Peñuelas, J., Ciais, P., Canadell, J. G., Janssens, I. A., Fernández-Martínez, M., Carnicer, J., ... \& Sardans, J. (2017). Shifting from a fertilization-dominated to a warming-dominated period. Nature Ecology \& Evolution, 1, 1438.

Poulter, B., MacBean, N., Hartley, A., Khlystova, I., Arino, O., Betts, R., Bontemps, S., Boettcher, M., Brockmann, C., Defourny, P., Hagemann, S., Herold, M., Kirches, G., Lamarche, C., Lederer, D., Ottlé, C., Peters, M., and Peylin, P. (2015). Plant functional type classification for earth system models: results from the European Space Agency's Land Cover Climate Change Initiative, Geosci. Model Dev., 8, 2315-2328

Purves, D., \& Pacala, S. (2008). Predictive models of forest dynamics. Science, 320, 1452-1453.

Sanderson M.G. (2003). Effect of climate change on isoprene emissions and surface ozone levels. Geophysical Research Letters, 30.

Scheiter, S., Langan, L., \& Higgins, S. I. (2013). Next-generation dynamic global vegetation models: learning from community ecology. New Phytologist, 198, 957-969.

Schurgers, G., A. Arneth, and T. Hickler (2011), Effect of climate-driven changes in species 
composition on regional emission capacities of biogenic compounds, J. Geophys. Res., 116, D22304

Sharkey T.D. \& Monson R.K. (2014) The future of isoprene emission from leaves, canopies and landscapes. Plant, Cell \& Environment 37, 1727-1740.

Shugart, H.H., West D.C., 1980 Forest succession models. BioScience 30, 308-313.

Shugart, H. H. (1984). A theory of forest dynamics. The ecological implications of forest succession models. Springer-Verlag.

Shugart, H.H., Woodward F.I., 2011. Global change and the terrestrial biosphere: achievements and challenges. John Wiley \& Sons, UK.

Shugart, H. H., Bin Wang, Andreas Huth, Rico Fischer, Xiaodong Yan, Amanda Armstrong (under review). Gap models and their individual-based relatives in the assessment of the consequences of global change. Environmental Research Letters

Sitch, S., Smith, B., Prentice, I. C., Arneth, A., Bondeau, A., Cramer, W., Kaplan, J. O., Levis, S., Lucht, W., Sykes, M. T., Thonicke, K. and Venevsky, S., 2003. Evaluation of ecosystem dynamics, plant geography and terrestrial carbon cycling in the LPJ dynamic global vegetation model. Glob. Change Biol. 9, 161-185.

Sitch S, Cox P, Collins W and Huntingford C (2007) Indirect radiative forcing of climate change through ozone effects on the land-carbon sink. Nature, 448, 791-794

Smith, B., Prentice, I. C., \& Sykes, M. T. (2001). Representation of vegetation dynamics in the modelling of terrestrial ecosystems: comparing two contrasting approaches within European climate space. Global Ecology and Biogeography, 10, 621-637.

Stillman, R. A., Railsback, S. F., Giske, J., Berger, U., \& Grimm, V. (2015). Making predictions in a changing world: the benefits of individual-based ecology. Bioscience, 65, 140-150. 
Ustin, S. L., \& Gamon, J. A. (2010). Remote sensing of plant functional types. New Phytologist, $186,795-816$.

Valolahti, H., Kivimaenpaa M., Faubert P., Michelsen A., Rinnan R., 2015. Climate changeinduced vegetation change as a driver of increased subarctic biogenic volatile organic compound emissions. Glob. Change Biol. 21, 3478-3488

Vickers, C. E., Gershenzon, J., Lerdau, M. T., Loreto, F., 2009. A unified mechanism of action for volatile isoprenoids in plant abiotic stress. Nature Chem. Biol. 5, 283-291.

Walker, B. H. (1994). Landscape to regional-scale responses of terrestrial ecosystems to global change. Ambio, 23.

Wang B, Lerdau M, He Y. (2017). Widespread production of nonmicrobial greenhouse gases in soils. Glob Change Biol., 23, 4472-4482.

Watt, A. S. 1925. On the ecology of British beech woods with special reference to their regeneration. II. The development and structure of beech communities on the Sussex Downs. Journal of Ecology 13, 27-73.

Watt, A.S. 1947. Pattern and process in the plant community. Journal of Ecology 35:1-22.

Weaver C., Cooter E., Gilliam R., Gilliland A., Grambsch A., Grano D., Hemming B., Hunt S., Nolte C. \& Winner D. (2009). A preliminary synthesis of modeled climate change impacts on US regional ozone concentrations. Bulletin of the American Meteorological Society, 90, 1843-1863.

Weisser, W. W., Roscher, C., Meyer, S. T., Ebeling, A., Luo, G., Allan, E., ... \& Engels, C. (2017). Biodiversity effects on ecosystem functioning in a 15-year grassland experiment: Patterns, mechanisms, and open questions. Basic and Applied Ecology, 23, 1-73.

Went, F.W., 1960. Blue hazes in the atmosphere. Nature 187, 641-643. 
West, G. (2017). Scale: The Universal Laws of Growth, Innovation, Sustainability, and the Pace of Life in Organisms, Cities, Economies, and Companies. Penguin.

Thornton, P. E., Calvin, K., Jones, A. D., Di Vittorio, A. V., Bond-Lamberty, B., Chini, L., ... \& Thomson, A. (2017). Biospheric feedback effects in a synchronously coupled model of human and Earth systems. Nature Climate Change, 2017.

Yan, H., Wang, S.-Q., Yu, K.-L., Wang, B., Yu, Q., Bohrer, G., ... Shugart, H. H. (2017). A novel diffuse fraction-based two-leaf light use efficiency model: An application quantifying photosynthetic seasonality across 20 AmeriFlux flux tower sites. Journal of Advances in Modeling Earth Systems, 9, doi.org/10.1002/2016MS000886

Yue, X., Unger, N., Harper, K., Xia, X., Liao, H., Zhu, T., Xiao, J., Feng, Z., and Li, J. (2017) Ozone and haze pollution weakens net primary productivity in China, Atmos. Chem. Phys., $17,6073-6089$.

Zak, D. R., Pregitzer, K. S., Kubiske, M. E. \& Burton, A. J. (2011) Forest productivity under elevated $\mathrm{CO}_{2}$ and $\mathrm{O}_{3}$ : positive feedbacks to soil $\mathrm{N}$ cycling sustain decade-long net primary productivity enhancement by $\mathrm{CO}_{2}$. Ecol. Lett. 14, 1220-1226.

Zeng, Z., Piao, S., Li, L. Z., Zhou, L., Ciais, P., Wang, T., ... \& Mao, J. (2017). Climate mitigation from vegetation biophysical feedbacks during the past three decades. Nature Climate Change, 7, 432-436. 


\section{Chapter 2 Sensitivity of global greenhouse gas budgets to tropospheric ozone pollution mediated by the biosphere}

\subsection{Introduction}

Tropospheric ozone $\left(\mathrm{O}_{3}\right)$ is formed from the photochemical oxidation of carbon monoxide (CO) and volatile organic compounds (VOCs), typically initiated by the hydroxyl radical (OH), in the presence of nitrogen oxides $\left(\mathrm{NOx} \equiv \mathrm{NO}+\mathrm{NO}_{2}\right)$ (Leighton, 1961). Its concentration has significantly increased since the industrial revolution and is projected to either continue to rise or to decline over the course of this century with considerable spatial variability, driven largely by trends in fossil fuel combustion (source of NOx) and vegetation growth (source of VOCs) (Myhre et al., 2013; Young et al., 2013; Cooper et al., 2014). Aside from severe damage to human health, what makes $\mathrm{O}_{3}$ particularly important as a pollutant in the troposphere is its reactivity with biochemical systems - it can alter the metabolisms involved with the production and/or consumption of radiatively significant gases such as $\mathrm{CO}_{2}, \mathrm{CH}_{4}$, and $\mathrm{N}_{2} \mathrm{O}$ (McLaughlin et al., 2007; Zak et al., 2011; Ainsworth et al., 2012; Agathokleous et al., 2016). All of these could largely contribute to changes in the atmospheric GHGs budgets and affect climate (Sitch et al., 2007). This paper provides the first assessment of the sensitivity of global budgets of $\mathrm{CO}_{2}, \mathrm{CH}_{4}$, and $\mathrm{N}_{2} \mathrm{O}$ to tropospheric $\mathrm{O}_{3}$ abundance resulting from the alterations of land-atmosphere exchange based on a meta-analysis of published experimental studies of $\mathrm{O}_{3}$ impacts on the exchange of these three gases from varying ecosystems.

There are a myriad of mechanisms at different organizational levels by which the oxidizing capacity of $\mathrm{O}_{3}$ affects terrestrial ecosystems. Ozone can directly depress photosynthesis by disturbing cellular biochemistry or indirectly by damaging stomatal function; in either case it alters 
carbon and water exchange (Ainsworth et al., 2012; Grantz et al., 2012). Ozone can also change secondary metabolism and tissue chemistry, which can affect carbon mineralization (Findlay et al., 1996; Loya et al., 2003; Valkama et al., 2007). At the community level, $\mathrm{O}_{3}$ exerts indirect effects on species composition through mediation of competitive relations (Wang et al., 2016). Since $\mathrm{O}_{3}$ does not penetrate soil (Blum et al., 1977), impacts on the processes responsible for the production and/or consumption of $\mathrm{CO}_{2}, \mathrm{CH}_{4}$, and $\mathrm{N}_{2} \mathrm{O}$ in soils are mediated by these aboveground changes (Fig.1). Changes in organic matter production, composition, and allocation, in turn, affect decomposition and carbon and nitrogen cycling, and alter rates of $\mathrm{CO}_{2}$ and $\mathrm{N}_{2} \mathrm{O}$ production and $\mathrm{CH}_{4}$ production/consumption (Agathokleous et al., 2016).

Independent empirical studies from different ecosystems around the world have been conducted to measure changes in the sources or sinks of GHGs in response to elevated $\mathrm{O}_{3}$. These experiments feature different designs with regards to ecosystem type, fumigation method and duration, $\mathrm{O}_{3}$ manipulation level, and other experimental factors (e.g., atmospheric $\mathrm{CO}_{2}$ level). Such differences likely contribute to inconsistencies among different studies and complicate efforts to synthesize and interpret the results. Here, we conducted a meta-analysis (Hedges et al., 1999; Gurevitch et al., 2001) of the published literature to statistically synthesize and analyze all reported empirical findings and determine the sensitivity of $\mathrm{CO}_{2}, \mathrm{CH}_{4}$, and $\mathrm{N}_{2} \mathrm{O}$ exchange between terrestrial ecosystems and the atmosphere to changes in $\mathrm{O}_{3}$ pollution. These results allow for the first systematic assessment of the sensitivity in the budgets of GHGs to tropospheric $\mathrm{O}_{3}$ concentration elevation that are based on empirical data. 


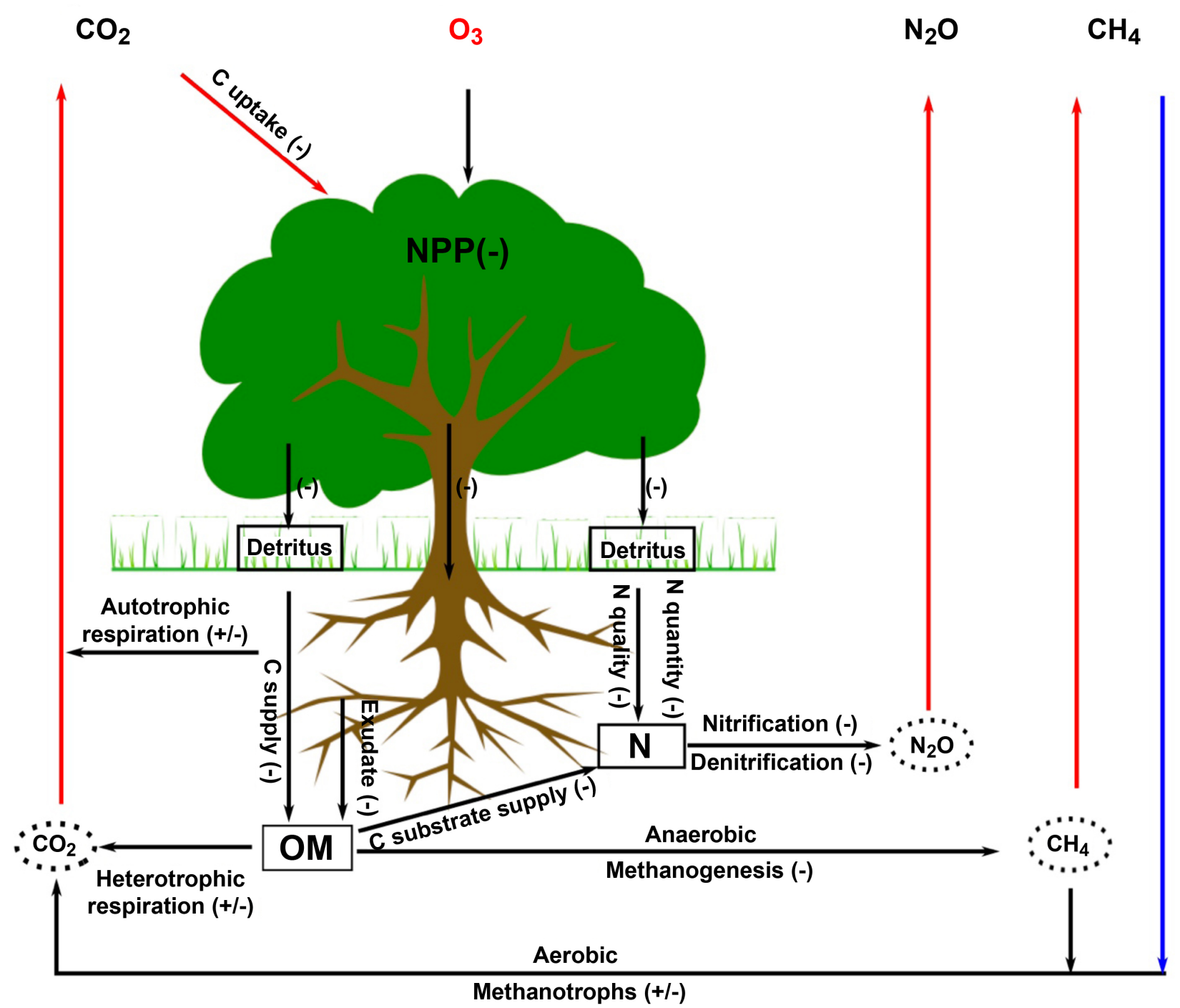

Figure 1 Schematic of processes by which $O_{3}$ influences GHG production and/or consumption. +/-signs denote positive and negative effect reported by different studies, respectively. The blue and red lines denote $\mathrm{CH}_{4}$ consumption and emissions of $\mathrm{CO}_{2}, \mathrm{~N}_{2} \mathrm{O}$, and $\mathrm{CH}_{4}$, respectively. 


\subsection{Methods}

\subsubsection{Data collection}

A search of published literature concerning $\mathrm{O}_{3}$ influences on belowground processes was initially conducted in both the ISI Web of Science (Thomson Reuters, New York, NY, USA) and Google Scholar (Google, Mountain View, CA, USA) with a range of search terms. Only those studies that reported results on soil respiration, $\mathrm{CH}_{4}$ uptake/emission, and/or $\mathrm{N}_{2} \mathrm{O}$ emission were selected. For example, the oft-cited study by Findlay et al. (1996) examined litter decomposition, but was not included here because $\mathrm{CO}_{2}$ emission values were not reported. Similarly, studies that only measured the respiration of soil surrounding roots or root respiration were not included. We did not include lab incubation studies, except for $\mathrm{CH}_{4}$ uptake with a lack of field measurements. These three GHGs show seasonal variations in their fluxes that appear to be independent of $\mathrm{O}_{3}$ impacts. Therefore, to avoid the potential variability and bias caused by a limited number of sampling dates, only those studies that repeatedly measured the fluxes at least one year (growing season) are included. In these cases, we either extracted the annual sum, or calculated the mean values for a whole year.

For effect size calculations, data including mean, standard deviation or standard error, and number of replicate for both control and treatment were extracted from text, tables, or graphs. The basic principles for data extraction from each individual study were as follows: To keep the independence of each observation, continuous observations within a single study were subjectively excluded to extract only one observation (i.e., the last year or growing season). However, different treatments (e.g., multiple manipulated levels of $\mathrm{O}_{3}$, different plant community, and elevated $\mathrm{CO}_{2}$ level) in one study were treated as independent observations (Gurevitch et al., 2001), and thus were included. The papers with data presented only as graphs were digitized using Engauge Digitizer 
(http://digitizer.sourceforge.net/). In addition, the control and treatment $\mathrm{O}_{3}$ level (ppb) were extracted either directly if reported or indirectly by converting the cumulative $\mathrm{O}_{3}$ exposure measures (e.g., accumulative ozone exposure above a threshold of 0 and $40 \mathrm{ppb}$ : AOT0 and AOT40). Categorical variables included ecosystem type (forest, cropland, rice paddy, grassland, and peat land), fumigation method (Free Air Concentration Enrichment-FACE and Open Top Chambers-OTCs), fumigation duration, and $\mathrm{CO}_{2}$ elevation. The categorical variables and the corresponding levels used by different response variables (soil respiration, $\mathrm{CH}_{4}$ flux, and $\mathrm{N}_{2} \mathrm{O}$ flux) depended on the data availability. The detailed information of these compiled data and the corresponding literatures are listed in supporting information S1.

\subsubsection{Meta-analysis and meta-regression}

First, the RR (Response Ratio) of $\mathrm{O}_{3}$ elevation for each individual observation was calculated by response ratio:

$$
R R=\ln \frac{X_{t}}{X_{c}}
$$

of which the sampling variance was computed by:

$$
v=\frac{(S D c)^{2}}{N c(X c)^{2}}+\frac{(S D t)^{2}}{N t(X t)^{2}}
$$

where $X c$ is the control mean, $X t$ is the treatment mean, $S D c$ is the control standard deviation, $S D t$ is the treatment standard deviation, $N_{C}$ is the control replication number, and $N_{T}$ is the treatment replication number.

The normalization of effect sizes under different $\mathrm{O}_{3}$ manipulation levels to a same $\Delta \mathrm{O}_{3}$ followed a linear transformation procedure:

$$
X_{N T}=X_{c}+\left(\frac{X_{t}-X_{c}}{\Delta O_{3}}\right) \Delta 03 *
$$


where $X_{N T}$ is the normalized value, $X c$ is the control mean, $X t$ is the treatment mean, $\Delta \mathrm{O}_{3}$ is the $\mathrm{O}_{3}$ level difference between the treatment and control, and $\Delta \mathrm{O}_{3}{ }^{*}$ represents the $\mathrm{O}_{3}$ level difference to which the effect sizes are normalized (i.e. a certain $\mathrm{O}_{3}$ concentration interval between the current troposphere $\mathrm{O}_{3}$ level and an elevated $\mathrm{O}_{3}$ level: 10, 20, 30 and $40 \mathrm{ppb}$ ).

Meta-analysis of RR was performed by fitting to the random-effects model via the restricted maximum-likelihood (REML) method. The inverse-variance weighted mean of RRs and the standard error of the weighted mean were calculated. The detailed calculation procedures are fully described in references Hedges et al. (1999) and Koricheva et al. (2013). The unlogged mean RR and corresponding 95\% confidence interval (CI) were further obtained. Percentage change due to elevated $\mathrm{O}_{3}$ was calculated from the unlogged mean $\mathrm{RR}$. The $\mathrm{O}_{3}$ effect on a response variable was considered significant if the $95 \% \mathrm{CI}$ did not overlap 1 .

The meta-regression of RR with moderators was performed by fitting to the mixed-effects model via the REML method as well. An omnibus test with a chi-square distribution $\left(Q_{M}\right)$ (Koricheva et al., 2013) was conducted to show whether the moderator has a significant contribution to the total heterogeneity. For categorical moderator with a significant $Q_{M}$, the categorical group was subdivided and the inverse-variance weighted mean RR for each level was calculated. An omnibus test was further conducted, with a significance of $Q_{M}$ indicating that the mean RR were different among the levels of this categorical moderator.

In addition, during the meta-analysis publication bias was tested by funnel plots (Rosenberg et al., 2013), and Egger's regression test was further performed to test the plot asymmetry (Egger et al., 1997). Q-Q normal plots were created to test whether the effect sizes fulfill the normality requirement (Wang et al., 1998). All calculation procedures described above were executed by R language using the 'metafor' package (Viechtbauer et al., 2010). 


\subsubsection{Estimation of global GHGs budget sensitivity}

The meta-analysis results provide the average changes of each gas across the terrestrial ecosystems over the planet under a certain $\mathrm{O}_{3}$ concentration interval between the current troposphere $\mathrm{O}_{3}$ level and an elevated $\mathrm{O}_{3}$ level (i.e. $\Delta \mathrm{O}_{3}{ }^{*}$ in $\mathrm{ppb}$ ). We can give an approximate sensitivity estimate of the global GHGs changes in response to this tropospheric $\mathrm{O}_{3}$ level increase relative to today in a way as follows:

$$
\Delta \mathrm{F}=\mathrm{F}_{\mathrm{C}} * \Delta \mathrm{A}
$$

where $\Delta \mathrm{F}$ change $\left(\right.$ year $\left.^{-1}\right)$ represents the average change of each flux; Fc (year ${ }^{-1}$ ) represents the strength of each flux under the current $\mathrm{O}_{3}$ level; and $\Delta \mathrm{A}(\%)$, obtained from meta-analysis and dependent on $\mathrm{O}_{3}$ level, denotes the average percentage change of each flux. The current strengths of the different fluxes are listed in Table S1 in supporting information S2. It is noteworthy that the upscaling here has integrated the major ecosystem types, though still not yet a complete representation, across the land surface. This representativeness is much better than the previous global modelling studies that parameterized $\mathrm{O}_{3}$ effects in global ecosystem models with strikingly limited $\mathrm{O}_{3}$ response data. For example, in the study of $\mathrm{O}_{3}$ impacts on global carbon cycling by Sitch et al. (2007) $\mathrm{O}_{3}$ response data for only a few European and North America species were extrapolated to represent all global vegetation types.

As for the determination of net flux of $\mathrm{CO}_{2}$ into the atmosphere, our work only conducted a meta-analysis of soil respiration and thus the change in carbon uptake by terrestrial vegetation is necessary to complete the analysis. Previous meta-analysis of plant photosynthesis response to $\mathrm{O}_{3}$ elevation for trees (Wittig et al., 2007), wheat (Feng et al., 2008), and soybeans (Morgan et al., 2003), and studies comparing plants from multiple functional groups find a consistent $20 \%$ reduction (Reich and Amundson, 1985; Volin et al., 1998; Lombardozzi et al., 2013). Moreover, 
the synthesis work by Lombardozzi et al. (2013) did not find a significant correlation between photosynthesis response and $\mathrm{O}_{3}$ level and agreed with the average $20 \%$ effect. Therefore, a constant $20 \%$ value is applied to constrain the global net primary productivity (NPP) to quantity the reduction of vegetation carbon uptake caused by different $\mathrm{O}_{3}$ elevation levels. It is noteworthy that our meta-analysis of soil respiration also includes the autotrophic respiration by plant roots, which, however, is not included in the NPP term. This represents a small uncertainty. Note that for the $\mathrm{CO}_{2}$ flux change a $50 \%$ reduction is further applied assuming $50 \%$ percent of the net accumulation of $\mathrm{CO}_{2}$ from the terrestrial biosphere is sequestered by the ocean (Sabine et al., 2004).

To describe the global GHGs budget change, GWP (global warming potential) was used to calculate the GHG balance in units of $\mathrm{CO}_{2}$ equivalents as follows:

$$
\mathrm{GHG}=\mathrm{F}_{\mathrm{CO} 2-\mathrm{C}} * 44 / 12+\mathrm{F}_{\mathrm{CH} 4-\mathrm{C}} * 16 / 12 * \mathrm{GWP}_{\mathrm{CH} 4}+\mathrm{F}_{\mathrm{N} 2 \mathrm{O}-\mathrm{N}} * 44 / 28 * \mathrm{GWP}_{\mathrm{N} 2 \mathrm{O}}
$$

where $\mathrm{F}_{\mathrm{CO} 2-\mathrm{C}}, \mathrm{F}_{\mathrm{CH} 4-\mathrm{C}}$, and $\mathrm{F}_{\mathrm{N} 2 \mathrm{O}-\mathrm{N}}$ are annual changes of total soil $\mathrm{CO}_{2}$ efflux, $\mathrm{N}_{2} \mathrm{O}$, and $\mathrm{CH}_{4}$ as calculated by the above equation. The fractions $44 / 12,16 / 12$ and $44 / 28$ were used to convert the mass of $\mathrm{CO}_{2}-\mathrm{C}, \mathrm{CH}_{4}-\mathrm{C}$ and $\mathrm{N}_{2} \mathrm{O}-\mathrm{N}$ into $\mathrm{CO}_{2}, \mathrm{CH}_{4}$, and $\mathrm{N}_{2} \mathrm{O}$. GWP $\mathrm{GH}_{4}\left(\mathrm{Pg} \mathrm{CO}_{2}\right.$ equiv. per $\mathrm{Pg} \mathrm{CH}$ ) and $\mathrm{GWP}_{\mathrm{N} 2 \mathrm{O}}\left(\mathrm{Pg} \mathrm{CO}_{2}\right.$ equiv. per $\left.\mathrm{Pg} \mathrm{N}_{2} \mathrm{O}\right)$ are constants indicating integrated radiative forcing of $\mathrm{CH}_{4}(28)$ and $\mathrm{N}_{2} \mathrm{O}(265)$ in terms of a $\mathrm{CO}_{2}$ equivalent unit over a period of 100 years (Ciais et al., 2013).

\subsection{Results}

Collectively, 96 effect sizes [Response Ratios (RR)] for soil respiration ( $\mathrm{CO}_{2}$ emission), $\mathrm{N}_{2} \mathrm{O}$ emission, and $\mathrm{CH}_{4}$ emission and uptake were compiled from peer-reviewed studies (supporting information S1). These studies were conducted in the Northern Hemisphere for 
ecosystems including forest, grassland, agricultural land, and peat land (Fig.S1 in supporting information S2). The data do not show publication bias based on funnel plots and Egger's tests (Fig.S2 supporting information S2) and fulfill the requirement of normality according to Q-Q plots (Fig.S3 in supporting information S2). Moreover, methodological differences, i.e., fumigation method and duration, among studies do not make a significant contribution to RR variability, with the exception of fumigation method for $\mathrm{CH}_{4}$ emission (Table $\mathrm{S} 2$ in supporting information $\mathrm{S} 2$ ). For these reasons, we conducted the analyses across the entire dataset.

Differing $\mathrm{O}_{3}$ manipulation levels were adopted by different studies. We choose the absolute difference in experimental $\mathrm{O}_{3}$ concentration between the treatment and control (hereafter referred to as $\left.\Delta \mathrm{O}_{3}\right)$ as a variable to describe the different studies. Meta-regressions between $\Delta \mathrm{O}_{3}$ and $\mathrm{RR}$ of different gases indicate that the $\mathrm{RR}$ of $\mathrm{CO}_{2}$ and $\mathrm{CH}_{4}$ (both emission and uptake) hold a significantly positive and negative linear relationship with $\Delta \mathrm{O}_{3}$, respectively, while the $\mathrm{RR}$ of $\mathrm{N}_{2} \mathrm{O}$ is uncorrelated with $\Delta \mathrm{O}_{3}$ (Fig. 2). These results suggest that the magnitude of $\mathrm{CO}_{2}$ and $\mathrm{CH}_{4}$ responses depend on $\mathrm{O}_{3}$ levels in the lower atmosphere. As for $\mathrm{N}_{2} \mathrm{O}$, based on limited data we can not exclude its dependence on $\mathrm{O}_{3}$ levels. In this study, we temporarily treat $\mathrm{N}_{2} \mathrm{O}$ response as being independent $\mathrm{O}_{3}$ level. Therefore, to assess the sensitivity of terrestrial ecosystems in terms of GHG exchange to $\mathrm{O}_{3}$ pressure, we test four $\Delta \mathrm{O}_{3}$ levels-10, 20,30, and $40 \mathrm{ppb}$ - to which RR were linearly normalized, except for $\mathrm{N}_{2} \mathrm{O}$. Meta-analyses were further conducted on these normalized RR. 

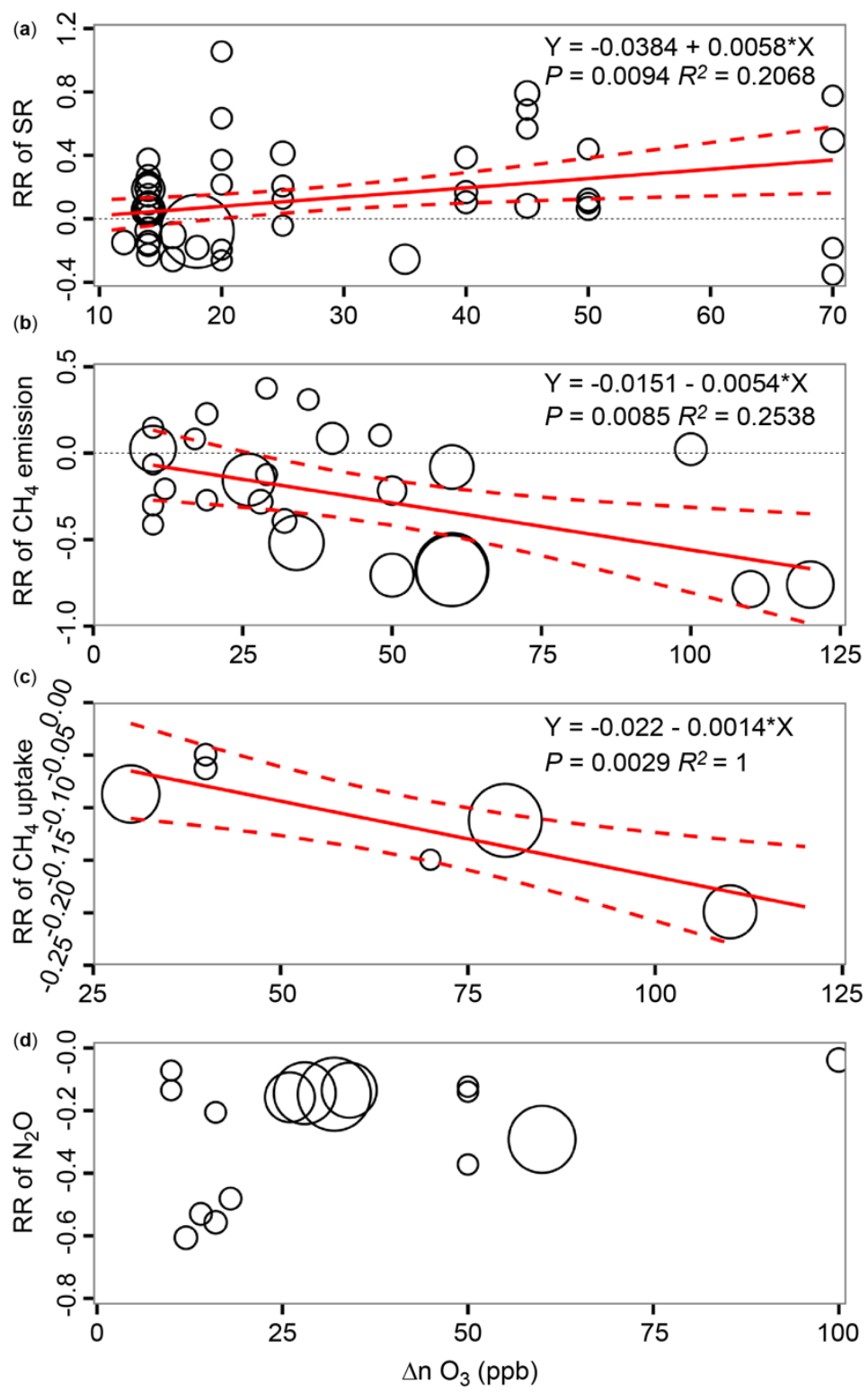

Figure 2 Meta-regression between $\mathrm{RR}$ and $\Delta \mathrm{O}_{3} .(a)-(d)$ denote soil respiration, $\mathrm{CH}_{4} \mathrm{emission}$, $\mathrm{CH}_{4}$ uptake, and $\mathrm{N}_{2} \mathrm{O}$ emission, respectively. The $\mathrm{RR}$ of $\mathrm{N}_{2} \mathrm{O}$ is not statistically correlated with $\Delta O_{3}(d)$. The size of the bubble is the relative weight of the $R R$ in the random-effects meta-regression. Larger bubbles indicate study outcomes that contributed a greater overall weight in meta-regressions. 
First, GHGs from different ecosystems present differing sensitivities to changes in $\mathrm{O}_{3}$ (Table $\mathrm{S} 3$ in supporting information $\mathrm{S} 2$ ). The $\mathrm{CO}_{2}$ effluxes from soils in both cropland and peat land, though with a similar magnitude, show a low sensitivity to increased $\mathrm{O}_{3}$ (Fig.S4 in supporting information S2). By contrast, $\mathrm{CO}_{2}$ effluxes from grassland soils display strong sensitivity to elevated $\mathrm{O}_{3}$, with $\mathrm{CO}_{2}$ flux diminished by from more than $10 \%(10 \mathrm{ppb})$ to more than $60 \%(20$ $\mathrm{ppb}$ ), and the forest shows a smaller but still significant response of 5\% (10 ppb) to $30 \%$ (40 ppb) (Fig.S4 in supporting information S2). For $\mathrm{CH}_{4}$ emissions, rice paddies present a significant reduction from almost $7 \%$ (10 ppb) to $25 \%$ (40 ppb), while the peat land does not show significant responses to $\mathrm{O}_{3}$ elevation (Fig. $\mathrm{S} 5$ in supporting information $\mathrm{S} 2$ ). Similarly, $\mathrm{O}_{3}$ enrichment shows a significantly different effect on the $\mathrm{N}_{2} \mathrm{O}$ flux among the three ecosystems as well. Elevated $\mathrm{O}_{3}$ results in a reduction of $\mathrm{N}_{2} \mathrm{O}$ emissions by an average of $19 \%$ (statistically not significant), $16 \%$, and $41 \%$ for cropland, rice paddies, and grassland, respectively (Fig.S6 in supporting information S2). Additionally, this meta-analysis indicates that $\mathrm{O}_{3}$ and $\mathrm{CO}_{2}$ elevations in combination have a larger influence on $\mathrm{CO}_{2}$ and $\mathrm{N}_{2} \mathrm{O}$ effluxes than $\mathrm{O}_{3}$ alone (Fig. S4, S6 in supporting information S2). This may result from a carbon fertilization effect and associated protection of carbon fixation against elevated $\mathrm{O}_{3}$ via stomatal closure (Sitch et al., 2007; Valkama et al., 2007). 

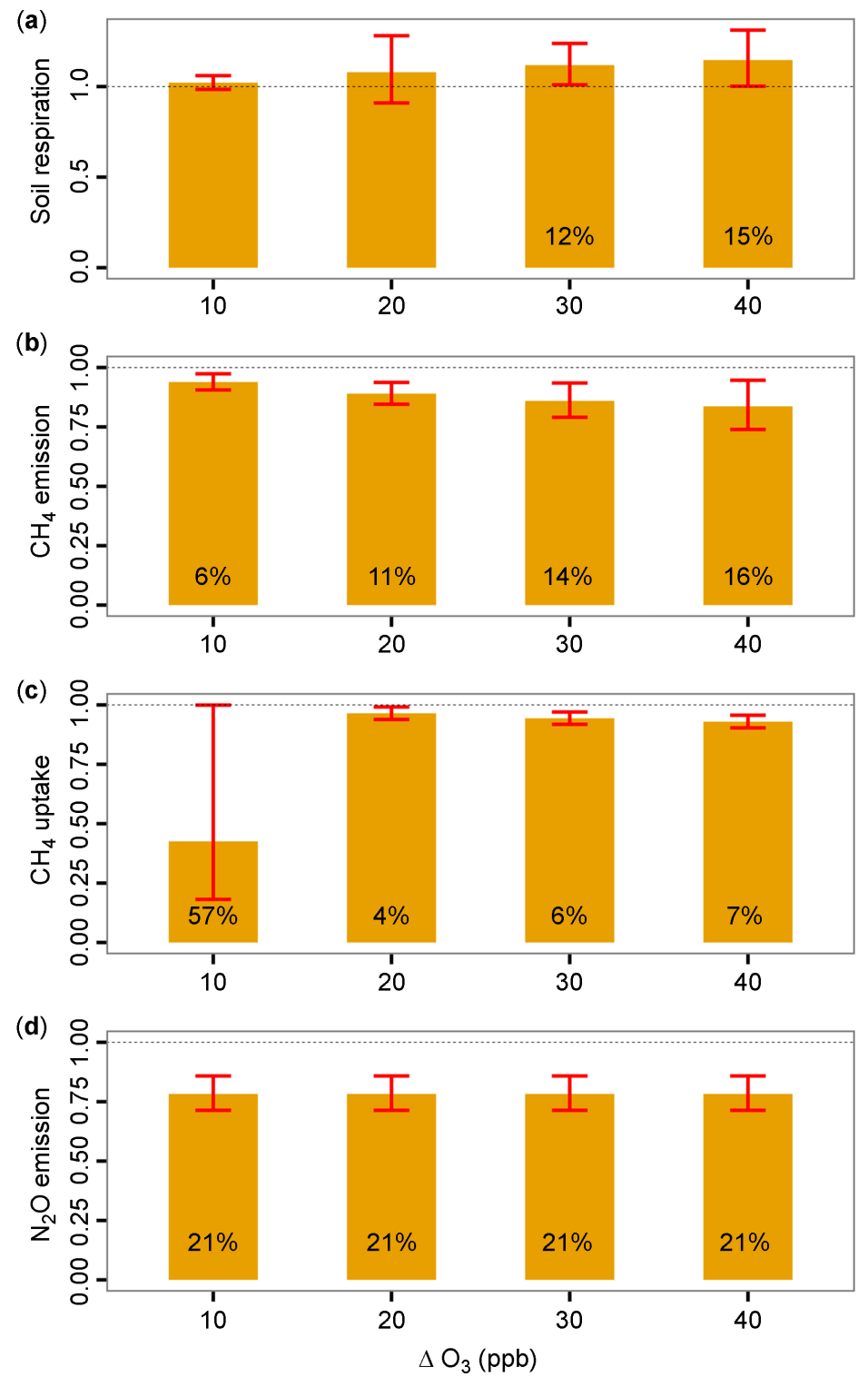

Figure 3 Meta-analysis of GHGs exchange across different ecosystems. (a)-(d) shows the meta-analysis results of soil respiration (a), $\mathrm{CH}_{4}$ emission (b), $\mathrm{CH}_{4}$ uptake (c), and $\mathrm{N}_{2} \mathrm{O}$ emission $(d)$ respectively, with mean and $95 \%$ confidence interval. The values are backtransformed from the RRs. The response is significant if the interval does not overlap 1(denoted by the dashed line). Values presented in this figure minus 1 multiplied by 100 correspond to the \% change, with the negative and positive suggesting a decrease and an increase, respectively. Values listed on the bar are the mean of significant responses. 
Integrating the responses across these different ecosystems, we derived the average responses for each gas. For soil $\mathrm{CO}_{2}$ efflux, the $\mathrm{RR}$ of $\mathrm{CO}_{2}$ is positively correlated with $\mathrm{O}_{3}$ level (Fig.2a), but does not show a significant sensitivity to $\mathrm{O}_{3}$ enrichment until $\Delta \mathrm{O}_{3}$ of 30 and $40 \mathrm{ppb}$, when soil respiration is stimulated by an average of about $12 \%$ and $15 \%$, respectively (Fig. 3a). By contrast, $\mathrm{CH}_{4}$ emissions are sensitive to $\mathrm{O}_{3}$ across the full range of treatments, with an average of 6\% (10 ppb), 11\% (20 ppb), 14\% (30 ppb), and 16\% (40 ppb) (Fig. 3b). Similarly, $\mathrm{CH}_{4}$ uptake is sensitive to the dose of elevated $\mathrm{O}_{3}$ with a large reduction seen initially but with low sensitivity to further increases in $\mathrm{O}_{3}$ (Fig. 3c). Finally, the RR of $\mathrm{N}_{2} \mathrm{O}$ emissions does not depend on $\mathrm{O}_{3}$ manipulation level (Fig. 2d); elevated $\mathrm{O}_{3}$ significantly decreases $\mathrm{N}_{2} \mathrm{O}$ emission by an average of $22 \%$ regardless of the $\Delta \mathrm{O}_{3}$ level (Fig. 3d). Our meta-analysis suggests that the soil respiration of terrestrial ecosystems is rather insensitive to $\mathrm{O}_{3}$ pressure, stimulating $\mathrm{CO}_{2}$ release to the atmosphere only after large $\mathrm{O}_{3}$ changes. These responses of $\mathrm{CO}_{2}, \mathrm{CH}_{4}$, and $\mathrm{N}_{2} \mathrm{O}$ exchange occur primarily because of reduced carbon availability from inhibited photosynthesis and slower decomposition and nitrogen return from altered detritus quality (Findlay et al., 1996; Anderson et al., 2003; Grantz et al., 2006; Kanerva et al., 2006). However, it has also been postulated that $\mathrm{O}_{3}$ pressure may stimulate mycorrhizal formation in fine roots and root nutrient acquisition and turnover (Scagel et al., 1997; Kasurinen et al., 2004) or greater consumption of the carbon formed since the $\mathrm{O}_{3}$ pressure because of changes in microbial activity and carbon quality (Loya et al., 2003), which cause unsuppressed and even enhanced $\mathrm{CO}_{2}$ efflux from soils. 
(a)

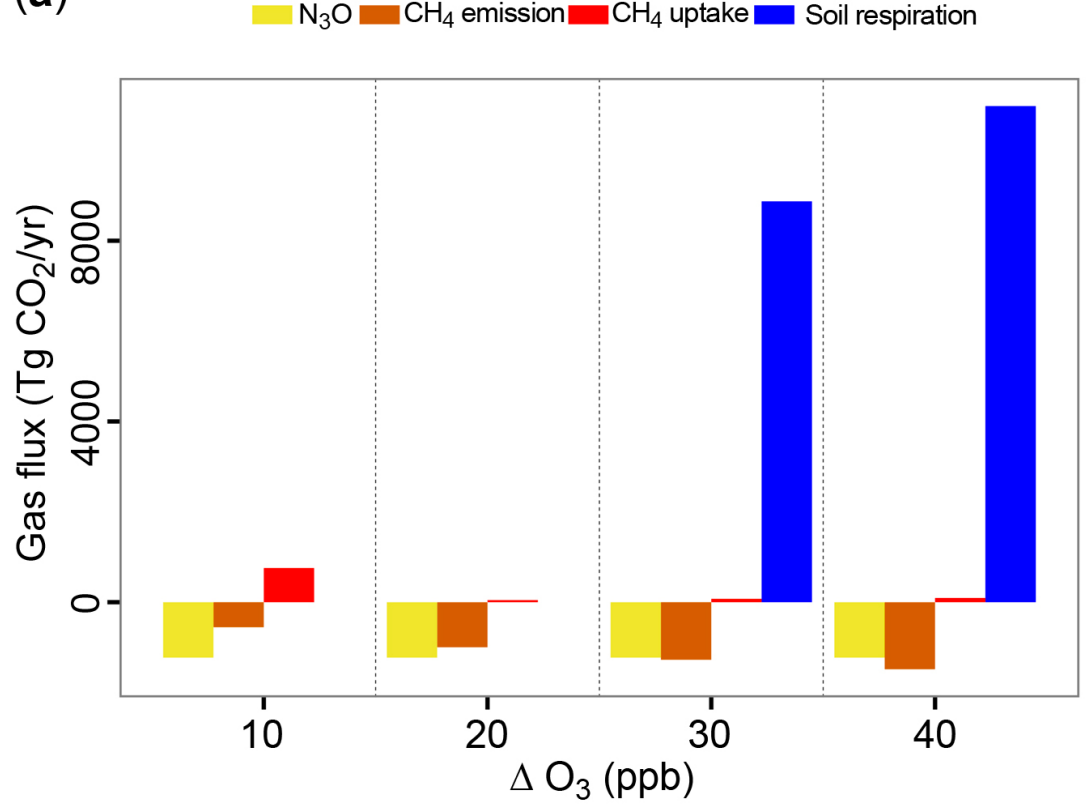

(b)

Net change $=$ Percent

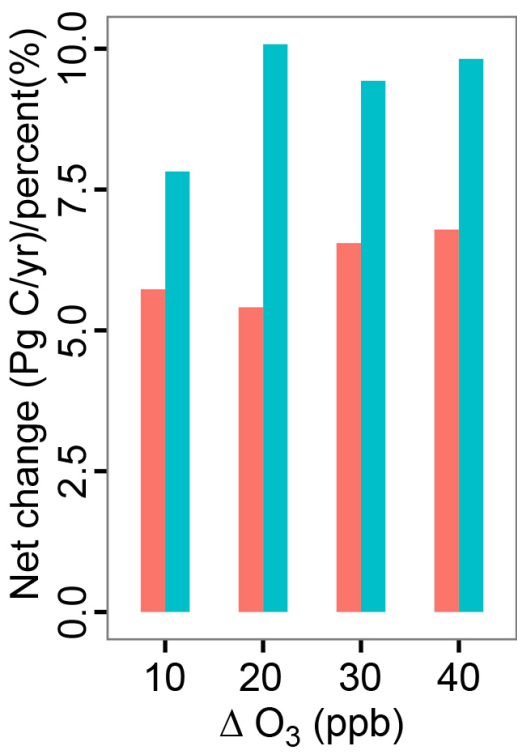

Figure 4 Sensitivity of global GHG budget change to $\mathrm{O}_{3}$ change. (a) Shows the positive (enhanced soil respiration and suppressed $\mathrm{CH}_{4}$ uptake) and negative contributions (suppressed $\mathrm{N}_{2} \mathrm{O}$ and $\mathrm{CH}_{4}$ emissions) to the atmospheric GHGs. (b) Shows the net global budget change and the percent of positive contributions offset by the negative contributions by accounting for the positive contribution from suppressed vegetation carbon uptake (that

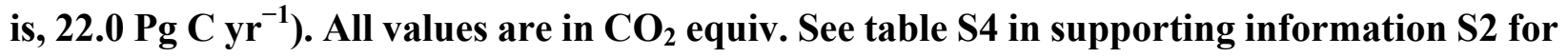
specific calculation and data source.

Scaling up these average ecosystem-scale responses, we estimate the sensitivity of global budget of the three gases to enhanced $\mathrm{O}_{3}$ (Fig.4) As shown in Fig.4a, the contribution by suppressed $\mathrm{N}_{2} \mathrm{O}$ flux to the global budget is consistently $\sim 1.23 \mathrm{Pg} \mathrm{CO}_{2}$ equiv. $\mathrm{yr}^{-1}$. Increased $\mathrm{O}_{3}$ of 10 and $20 \mathrm{ppb}$ induce a decline of the current terrestrial natural $\mathrm{CH}_{4}$ emission flux by an average of $6 \%$ and $11 \%$, which contributes to a reduced balance of 0.6 and $1.0 \mathrm{Pg} \mathrm{CO}_{2}$ equiv. $\mathrm{yr}^{-1}$, while 
suppressed $\mathrm{CH}_{4}$ uptake positively contributes 0.8 and $0.05 \mathrm{Pg} \mathrm{CO}_{2}$ equiv. $\mathrm{yr}^{-1}$. Global soil $\mathrm{CO}_{2}$ efflux is insensitive to these small changes in $\mathrm{O}_{3}\left(\Delta \mathrm{O}_{3}=10\right.$ and $\left.20 \mathrm{ppb}\right)$. By contrast, in response to larger increases in $\mathrm{O}_{3}\left(\Delta \mathrm{O}_{3}=30\right.$ and $\left.40 \mathrm{ppb}\right)$ stimulated soil $\mathrm{CO}_{2}$ emissions contribute an average of 4.4 and $5.5 \mathrm{Pg} \mathrm{CO}_{2} \mathrm{yr}^{-1}$, respectively (Fig. 4a). At the same $\Delta \mathrm{O}_{3}$, suppressed $\mathrm{CH}_{4}$ emissions contribute 1.3 and $1.5 \mathrm{Pg} \mathrm{CO}_{2}$ equiv. $\mathrm{yr}^{-1}$, while suppressed $\mathrm{CH}_{4}$ uptake contributes only 0.07 and $0.09 \mathrm{Pg} \mathrm{CO}_{2}$ equiv. $\mathrm{yr}^{-1}$ (Fig. 4a). This sensitivity analysis clearly shows that the soil system can be transformed from a sink into a source with $\mathrm{O}_{3}$ level continuously increasing because of enhanced soil $\mathrm{CO}_{2}$ emissions outweighing suppressed $\mathrm{CH}_{4}$ and $\mathrm{N}_{2} \mathrm{O}$ emissions. Taking into consideration $\mathrm{O}_{3}$-suppressed $\mathrm{CO}_{2}$ uptake by vegetation (which is about $44.0 \mathrm{Pg} \mathrm{CO}_{2} \mathrm{yr}^{-1}$ ), plus the oceans' $\mathrm{CO}_{2}$ sequestration, the $\mathrm{O}_{3}$-induced net global GHGs budget change on average is

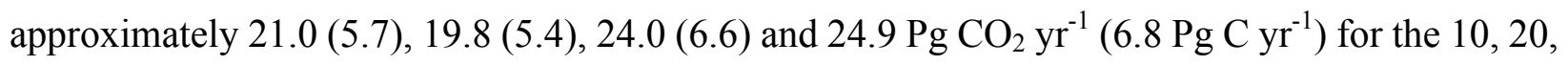
30 , and 40 ppb change in $\mathrm{O}_{3}$, respectively (Fig. 4b; Table $\mathrm{S} 4$ in supporting information S2). These changes correspond to an annual increase of $12.73 \%, 12.00 \%, 14.55 \%$, and $15.10 \%$ relative to the current net global budget (Table S4 in supporting information S2). Additionally, under the four $\mathrm{O}_{3}$ change levels the reduction in $\mathrm{N}_{2} \mathrm{O}$ and $\mathrm{CH}_{4}$ emissions offset at most about $10 \%$ of the $\mathrm{O}_{3}$-induced net increase of $\mathrm{CO}_{2}$ (Fig. 4b). Therefore, the sensitivity of terrestrial vegetation productivity to elevated $\mathrm{O}_{3}$ predominate the global GHG budget change sensitivity.

\subsection{Discussion}

The overall exchange of GHGs between terrestrial ecosystems and the atmosphere are sensitive to tropospheric $\mathrm{O}_{3}$ pollution, and significantly contributes to the atmospheric GHGs accumulation. This matches the conclusion of a large buildup of $\mathrm{CO}_{2}$ in the atmosphere derived from the modelling study by Sitch et al. (2007), which, however, only considered the $\mathrm{CO}_{2}$. For 
understanding the full range of interactions between the atmosphere and terrestrial processes, we need an integrative perspective (e.g., Tian et al. 2016). Our results also suggest that suppressed $\mathrm{CH}_{4}$ and $\mathrm{N}_{2} \mathrm{O}$ emissions can offset a portion of the increased $\mathrm{CO}_{2}$ emissions. This study clearly pinpoints the necessity for assessing surface-atmosphere exchange processes comprehensively in air quality-climate feedback analyses. Therefore, other possible feedback pathways mediated by biogenic volatile organic compounds (BVOCs) and soil nitrous oxides (NOx) emissions should be investigated and fully incorporated into assessment of $\mathrm{O}_{3}$-climate feedbacks (e.g. Hickman et al. 2010).

However, these estimates of global GHGs flux sensitivities come with uncertainties. First, GHGs from different ecosystems present differing sensitivities to changes in $\mathrm{O}_{3}$ due to fundamental differences in vegetation composition. However, this study, as a pioneering work, integrates the different systems in an aggregate way. Ecosystem-specific assessments are expected for following studies. Meanwhile, during these assessments different measures of $\mathrm{O}_{3}$ dosage should be differentiated. Second, the studied ecosystem types and independent observations that can be included in this meta-analysis are limited. For example, upland forest ecosystems generally act as a sink of $\mathrm{CH}_{4}$ (e.g. Yavitt et al., 1990), but no study is currently available of the $\mathrm{O}_{3}$ sensitivities of these ecosystems. There is also a striking lack of experimental data from the Southern Hemisphere (Fig. S1 in supporting information S2). This problem is particularly important because many regions in the Southern Hemisphere are predicted to industrialize in the future, which could lead to higher $\mathrm{O}_{3}$ levels in the near field of cities and hemisphere wide. Clearly, more field measurements on $\mathrm{CO}_{2}, \mathrm{~N}_{2} \mathrm{O}$, and $\mathrm{CH}_{4}$ fluxes around the world should be undertaken. Third, exchange of GHGs between the atmosphere and terrestrial ecosystems can be simultaneously influenced by other global change agents. To more fully and realistically evaluate 
$\mathrm{O}_{3}$ impacts on GHGs, the combined impacts with other global change agents, e.g., nitrogen deposition and climate warming, need additional investigation.

\subsection{Conclusion}

By fully accounting for the three gases simultaneously, we find that with $\mathrm{O}_{3}$ level continuously increasing the whole soil system would be transformed from a sink into a source of GHGs. With an increase of $\mathrm{O}_{3}$ concentration by $10 \mathrm{ppb}$, the global annual net atmospheric budgets

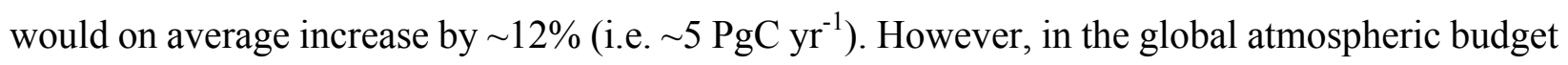
suppressed $\mathrm{CH}_{4}$ and $\mathrm{N}_{2} \mathrm{O}$ emissions can offset a small portion (at most $10 \%$ ) of the net $\mathrm{CO}_{2}$ increase derived from changes in soil respiration and vegetation carbon fixation in terms of $\mathrm{CO}_{2}-$ equivalent. The sensitivity of global net GHGs budgets is still predominantly determined by the high sensitivity and thus a large magnitude of $\mathrm{O}_{3}$-induced reduction in terrestrial vegetation carbon sequestration capability.

Natural systems with a high biodiversity, however, are increasingly suggested to be resilient to $\mathrm{O}_{3}$ pressure. For example, the productivity and carbon stock of the temperate deciduous forest in the Eastern United States are shown to be unsuppressed by $\mathrm{O}_{3}$ pressure (Wang et al., 2016). The FACE study by Zak et al. (2011), which included both $\mathrm{O}_{3}$-tolerant and $\mathrm{O}_{3}$-sensitive species or genotypes, also indicated unsuppressed net primary productivity after a long-term fumigation (11 years). Grassland ecosystems including temperate (Volk et al., 2011), calcareous (Thwaites et al., 2006), and alpine types (Bassin et al., 2007) have also shown that the productivity is insensitive to elevated $\mathrm{O}_{3}$. Hence, we postulate that the indirect role of $\mathrm{O}_{3}$ (that is via altering the land-atmosphere exchange) on the Earth's radiative balance might be most significant on those managed systems that are of low diversity, e.g., agricultural and forest plantation systems. This 
means agricultural production practices would play a key role in mitigating $\mathrm{O}_{3}$ 's indirect effects on global climate, reinforcing the conclusion that adoption of best practices in human-impacted ecosystems could mitigate climate change (Paustian et al., 2016; Tian et al., 2016).

\subsection{References}

Agathokleous E, Saitanis C J, Wang X, Watanabe M and Koike T 2016 A review study on past 40 years of research on effects of tropospheric $\mathrm{O}_{3}$ on belowground structure, functioning, and processes of trees: a linkage with potential ecological implications Water Air Soil Poll. 227 $1-28$

Ainsworth E A, Yendrek C R, Sitch S, Collins W J and Emberson L D 2012 The effects of tropospheric ozone on net primary productivity and implications for climate change Annu. Rev. Plant Biol. 63 637-661

Andersen C P 2003 Source-sink balance and carbon allocation below ground in plants exposed to ozone New Phytol. 157 213-228

Bassin S, Volk M, Suter M, Buchmann N and Fuhrer J 2007 Nitrogen deposition but not ozone affects productivity and community composition of subalpine grassland after $3 \mathrm{yr}$ of treatment New Phytol. 175 523-534

Blum U and Tingey D T 1977 A study of the potential ways in which ozone could reduce root growth and nodulation of soybean. Atmos. Environ. 11 737-739

Ciais P et al in Climate Change 2013: The Physical Science Basis. Contribution of Working Group I to the Fifth Assessment Report of the Intergovernmental Panel on Climate Change (eds T.F. Stocker et al.) Ch. 6, 465-570 (Cambridge University Press, 2013) 
Cooper O R et al 2014 Global distribution and trends of tropospheric ozone: An observation-based review Elementa: Science of the Anthropocene 2000029

Egger M, Smith G D, Schneider M and Minder C 1997 Bias in meta-analysis detected by a simple, graphical test $B m j 315$ 629-634

Feng Z, Kobayashi K and Ainsworth E A 2008 Impact of elevated ozone concentration on growth, physiology, and yield of wheat (Triticum aestivum L.): a meta-analysis Glob. Change Biol. $142696-2708$

Findlay S, Carreiro M, Krischik V and Jones C G (1996) Effects of damage to living plants on leaf litter quality Ecol. Appl. 6 269-275

Gurevitch J, Curtis P S and Jones M H 2001 Meta-analysis in ecology Adv. Ecol. Res. 32 199-24

Grantz D, Gunn S and VU H B $2006 \mathrm{O}_{3}$ impacts on plant development: a meta-analysis of root/shoot allocation and growth Plant Cell Environ. 29 1193-1209

Hedges L V, Gurevitch J and Curtis P S (1999) The meta-analysis of response ratios in experimental ecology Ecology 80 1150-1156

Hickman J E, Wu S, Mickley L J, and Lerdau M T 2010 Kudzu (Pueraria montana) invasion doubles emissions of nitric oxide and increases ozone pollution P. Natl. Acad. Sci. 107 $10115-10119$

Kanerva $\mathrm{T}$ et al $2006 \mathrm{~A}$ 3-year exposure to $\mathrm{CO}_{2}$ and $\mathrm{O}_{3}$ induced minor changes in soil $\mathrm{N}$ cycling in a meadow ecosystem Plant Soil 286 61-73

Kasurinen A, Kokko-Gonzales P, Riikonen J, Vapaavuori E and Holopainen T 2004 Soil $\mathrm{CO}_{2}$ efflux of two silver birch clones exposed to elevated $\mathrm{CO}_{2}$ and $\mathrm{O}_{3}$ levels during three growing seasons Glob. Change Biol. 10 1654-1665 
Koricheva J, Gurevitch J and Mengersen K 2013 Handbook of Meta-analysis in Ecology and Evolution Princeton University Press Princeton

Leighton P A 1961 Photochemisty of Air Pollution Academic Press New York

Lombardozzi D, Levis S, Bonan G, Hess P and Sparks J 2015 The influence of chronic ozone exposure on global carbon and water cycles J. Climate 28 292-305

Lombardozzi D, Sparks J P and Bonan G 2013 Integrating $\mathrm{O}_{3}$ influences on terrestrial processes: photosynthetic and stomatal response data available for regional and global modeling Biogeosciences 10 6815-683

Loya W M, Pregitzer K S, Karberg N J, King J S and Giardina C P 2003 Reduction of soil carbon formation by tropospheric ozone under increased carbon dioxide levels Nature $\mathbf{4 2 5}$ 705707

McLaughlin S B, Wullschleger S D, Sun G and Nosal M 2007 Interactive effects of ozone and climate on water use, soil moisture content and streamflow in a southern Appalachian forest in the USA New Phytol. 174 125-136

Morgan P, Ainsworth E and Long S 2003 How does elevated ozone impact soybean? A metaanalysis of photosynthesis, growth and yield Plant Cell Environ. 26 1317-1328

Myhre G et al 2013 Anthropogenic and Natural Radiative Forcing. Climate Change 2013: The Physical Science Basis. Contribution of Working Group I to the Fifth Assessment Report of the Intergovernmental Panel on Climate Change (Stocker, T.F., D. Qin, G.-K. Plattner, M.Tignor, S.K. Allen, J. Boschung, A. Nauels, Y. Xia, V. Bex and P.M. Midgley (eds.)). Cambridge University Press, Cambridge, United Kingdom and New York, NY, USA, pp. $659-740$

Paustian K et al 2016 Climate-smart soils Nature 532 49-57 
Reich P B and Amundson R G 1985 Ambient levels of ozone reduce net photosynthesis in tree and crop species Science $230566-570$

Jennions M D, Lortie C J, Rosenberg M S and Rothstein H R 2013 Publication and related biases Handbook of Meta-analysis in Ecology and Evolution ed J Koricheva, J Gurevitch and K Mengersen (Princeton and Oxford, USA: Princeton University Press) pp 207-236

Sabine C L et al 2004 The oceanic sink for anthropogenic $\mathrm{CO}_{2}$ Science 305 367-371

Scagel C F and Andersen C P 1997 Seasonal changes in root and soil respiration of ozone-exposed ponderosa pine (Pinus ponderosa) grown in different substrates New Phytol. 136 627-643

Sitch S, Cox P, Collins W and Huntingford C 2007 Indirect radiative forcing of climate change through ozone effects on the land-carbon sink Nature 448 791-794

Thwaites R, Ashmore M, Morton A and Pakeman R 2006 The effects of tropospheric ozone on the species dynamics of calcareous grassland Environ. Pollut. 144 500-509

Tian $\mathrm{H}$ et al 2016 The terrestrial biosphere as a net source of greenhouse gases to the atmosphere Nature $\mathbf{5 3 1} 225-228$

Valkama E, Koricheva J and Oksanen E 2007 Effects of elevated $\mathrm{O}_{3}$, alone and in combination with elevated $\mathrm{CO}_{2}$, on tree leaf chemistry and insect herbivore performance: a metaanalysis Glob. Change Biol. 13 184-201

Viechtbauer W 2010 Conducting meta-analyses in R with the metafor package J. Stat. Software $361-48$

Volin J C, Reich P B and Givnish T J 1998 Elevated carbon dioxide ameliorates the effects of ozone on photosynthesis and growth: species respond similarly regardless of photosynthetic pathway or plant functional group New Phytol. 138 315-325 
Volk M et al 2011 Subalpine grassland carbon dioxide fluxes indicate substantial carbon losses under increased nitrogen deposition, but not at elevated ozone concentration Glob. Change Biol. 17 366-376

Wang B, Shugart H H, Shuman J K and Lerdau M T 2016 Forests and ozone: productivity, carbon storage, and feedbacks Sci. Rep. 622133

Wang M C and Bushman B J 1998 Using the normal quantile plot to explore meta-analytic data sets Psychological Methods 346

Wittig V E, Ainsworth E A and Long S P 2007 To what extent do current and projected increases in surface ozone affect photosynthesis and stomatal conductance of trees? A meta-analytic review of the last 3 decades of experiments Plant Cell Environ. 30 1150-1162

Yavitt J B, Downey, D M, Lang G E and Sexstone A J 1990 Methane consumption in two temperate forest soils Biogeochemistry 9 39-52

Young P J et al 2013 Pre-industrial to end $21^{\text {st }}$ century projections of tropospheric ozone from the Atmospheric Chemistry and Climate Model Intercomparison Project (ACCMIP) Atmos. Chem. Phys. 13 2063-2090

Zak D R, Pregitzer K S, Kubiske M E and Burton A J 2011 Forest productivity under elevated $\mathrm{CO}_{2}$ and $\mathrm{O}_{3}$ : positive feedbacks to soil $\mathrm{N}$ cycling sustain decade-long net primary productivity enhancement by $\mathrm{CO}_{2}$ Ecol. Lett. 14 1220-1226

\subsection{Supplementary materials}


Table S1 Data sources of current annual fluxes of GHGs from the terrestrial ecosystems.

\begin{tabular}{|c|c|c|c|c|}
\hline Gas & Source/Sink & Strength (yr $\left.{ }^{-1}\right)$ & Total annual flux* & Reference \\
\hline \multirow[t]{2}{*}{$\mathrm{CO}_{2}$} & Soil respiration & $75 \mathrm{Pg} \mathrm{CO}_{2}$ & $75,000 \mathrm{Tg} \mathrm{CO}_{2} \mathrm{yr}^{-1}$ & Schlesinger and Andrews, 2000 \\
\hline & NPP & $60 \mathrm{Pg} \mathrm{C}-\mathrm{CO}_{2}$ & $22,0200 \mathrm{Tg} \mathrm{CO}_{2} \mathrm{yr}^{-1}$ & Beer et al., 2010 \\
\hline \multirow[t]{2}{*}{$\mathrm{N}_{2} \mathrm{O}$} & Agriculture & $1.7-4.8 \mathrm{Tg} \mathrm{N}-\mathrm{N}_{2} \mathrm{O}$ & $21.67 \mathrm{Tg} \mathrm{N}_{2} \mathrm{O} \mathrm{yr}^{-1}$ & Ciais et al., 2013 \\
\hline & Natural vegetation & $3.3-9.0 \mathrm{Tg} \mathrm{N}-\mathrm{N}_{2} \mathrm{O}$ & & Ciais et al., 2013 \\
\hline \multirow[t]{2}{*}{$\mathrm{CH}_{4}$ emission } & Rice paddy & $33-40 \mathrm{Tg} \mathrm{CH}_{4}$ & $324 \mathrm{Tg} \mathrm{CH}_{4} \mathrm{yr}^{-1}$ & Ciais et al., 2013 \\
\hline & Wetland & $177-284 \mathrm{Tg} \mathrm{CH}_{4}$ & & Ciais et al., 2013 \\
\hline $\mathrm{CH}_{4}$ uptake & Upland & $9-47 \mathrm{Tg} \mathrm{CH}_{4}$ & $47 \mathrm{Tg} \mathrm{CH}_{4} \mathrm{yr}^{-1}$ & Ciais et al., 2013 \\
\hline
\end{tabular}

* For the total annual fluxes of $\mathrm{CH}_{4}$ and $\mathrm{N}_{2} \mathrm{O}$, the upper end values of the estimated range is applied. 
Table S2 Test of fumigation methodology to effect sizes variation.

\begin{tabular}{lllll}
\hline Variable & & $\mathrm{CO}_{2}$ & $\mathbf{N}_{\mathbf{2}} \mathbf{O}$ & $\mathbf{C H}_{\mathbf{4}}$ emission \\
\hline Fumigation method & $\mathrm{Q}_{\mathrm{M}}$ & 0.0719 & 1.2198 & 8.9298 \\
& $P$ & 0.7886 & 0.2694 & $\mathbf{0 . 0 1 1 5}$ \\
Fumigation duration & $\mathrm{Q}_{\mathrm{M}}$ & 0.0093 & 0.0094 & 0.0362 \\
& $P$ & 0.9233 & 0.9228 & 0.8491 \\
\hline
\end{tabular}

Only fumigation method (FACE and OTC) significantly contributes to the variations of effect sizes of $\mathrm{CH}_{4}$ emission. 
Table S3 Effect of $\mathrm{O}_{3}$ enrichment on between group heterogeneity $\left(Q_{M}\right)$ for each response variable.

\begin{tabular}{|c|c|c|c|c|c|c|c|c|c|c|c|c|c|}
\hline \multirow{3}{*}{$\begin{array}{l}\text { Response } \\
\text { variable }\end{array}$} & \multirow{3}{*}{$\begin{array}{l}\text { Categorical } \\
\text { variable }\end{array}$} & \multicolumn{12}{|l|}{ Delta $\mathrm{O}_{3}$} \\
\hline & & \multicolumn{3}{|l|}{$10 \mathrm{ppb}$} & \multicolumn{3}{|l|}{$20 \mathrm{ppb}$} & \multicolumn{3}{|l|}{$30 \mathrm{ppb}$} & \multicolumn{3}{|l|}{$40 \mathrm{ppb}$} \\
\hline & & $Q_{M}$ & $d f$ & $P$-value & $Q_{M}$ & $d f$ & $P$-value & $Q_{M}$ & $d f$ & $P$-value & $Q_{M}$ & $d f$ & $P$-value \\
\hline \multirow[t]{2}{*}{$\mathrm{CO}_{2}$} & Ecosystem & 10.1436 & 4 & 0.0381 & 33.3984 & 4 & $<0.0001$ & 31.018 & 4 & $<0.0001$ & 32.7520 & 4 & $<0.0001$ \\
\hline & $\mathrm{CO}_{2}$ elevation & 6.7263 & 2 & 0.0346 & 2.8304 & 2 & 0.2429 & 6.5426 & 2 & 0.038 & 5.4281 & 2 & 0.0663 \\
\hline $\mathrm{CH}_{4}$ emission & Ecosystem & 12.4856 & 2 & 0.0019 & 25.2659 & 2 & $<0.0001$ & 20.6876 & 2 & 0.0001 & 19.4727 & 2 & $<0.0001$ \\
\hline \multirow[t]{2}{*}{$\mathrm{N}_{2} \mathrm{O}$} & Ecosystem & 76.5853 & 3 & $<0.0001$ & 76.5853 & 3 & $<0.0001$ & 76.5853 & 3 & $<0.0001$ & 76.5853 & 3 & $<0.0001$ \\
\hline & $\mathrm{CO}_{2}$ elevation & 62.4640 & 2 & $<0.0001$ & 62.4640 & 2 & $<0.0001$ & 62.4640 & 2 & $<0.0001$ & 62.4640 & 2 & $<0.0001$ \\
\hline
\end{tabular}

Note: Four tests on $\mathrm{N}_{2} \mathrm{O}$ across the four delta $\mathrm{O}_{3}$ levels are totally same as meta-regression shows $\mathrm{N}_{2} \mathrm{O}$ response is independent of $\mathrm{O}_{3}$ level. 
Table S4 Estimation of annual GHGs flux change induced by $\mathrm{O}_{3}$ level elevation.

\begin{tabular}{|c|c|c|c|c|c|c|c|c|c|}
\hline \multirow[b]{2}{*}{ Gas } & \multirow{2}{*}{$\begin{array}{l}\text { Current flux* } \\
\left(\operatorname{Tg~yr}^{-1}\right)\end{array}$} & \multicolumn{2}{|c|}{ DeltaO3 = $10 \mathrm{ppb}$} & \multicolumn{2}{|c|}{$\operatorname{DeltaO}_{3}=20 \mathrm{ppb}$} & \multicolumn{2}{|c|}{ DeltaO3 $=\mathbf{3 0} \mathbf{p p b}$} & \multicolumn{2}{|c|}{ DeltaO $_{3}=40 \mathrm{ppb}$} \\
\hline & & Average changet $(\%)$ & $\begin{array}{l}\text { GWP change } \\
\left(\mathrm{Tg} \mathrm{CO}_{2} \mathrm{yr}^{-1}\right)\end{array}$ & Average changet $(\%)$ & $\begin{array}{l}\text { GWP change } \\
\left(\mathrm{Tg} \mathrm{CO}_{2} \mathrm{yr}^{-1}\right)\end{array}$ & Average change† (\%) & $\begin{array}{l}\text { GWP change (Tg } \\
\text { CO2 } \mathrm{yr}-1)\end{array}$ & Average change (\%) & $\begin{array}{l}\text { GWP change } \\
\left(\mathrm{Tg} \mathrm{CO}_{2} \mathrm{yr}^{-1}\right)\end{array}$ \\
\hline NPP & $220,200 \mathrm{CO}_{2}$ & 20.00 & 22,020 & 20.00 & 22,020 & 20.00 & 22,020 & 20.00 & 22,020 \\
\hline Soil respiraton & $75,000 \mathrm{CO}_{2}$ & 0 & 0 & 0.00 & 0 & 11.83 & 4,436 & 14.64 & 5,490 \\
\hline $\mathrm{N}_{2} \mathrm{O}$ emission & $16.7 \mathrm{~N}_{2} \mathrm{O}$ & -21.37 & $-1,227$ & -21.37 & $-1,227$ & -21.37 & $-1,227$ & -21.37 & $-1,227$ \\
\hline $\mathrm{CH}_{4}$ emission & $324 \mathrm{CH}_{4}$ & -6.11 & -554 & -10.99 & -997 & -14.04 & -1274 & -16.36 & $-1,484$ \\
\hline $\mathrm{CH}_{4}$ uptake & $47 \mathrm{CH}_{4}$ & 57.44 & 756 & 3.53 & 46 & 5.62 & 74 & 7.04 & 93 \\
\hline \multicolumn{2}{|c|}{$\begin{array}{l}\text { Global net change induced by } \\
\text { future } \mathrm{O}_{3} \text { pollution }\end{array}$} & \multicolumn{2}{|c|}{$20,995 \mathrm{Tg}$ CO2 yr-1/5.7 Pg C yr-1 } & \multicolumn{2}{|c|}{$19,842 \mathrm{Tg} \mathrm{CO}_{2} \mathrm{yr}^{-1} / 5.4 \mathrm{Pg} \mathrm{C} \mathrm{yr}^{-1}$} & \multicolumn{2}{|c|}{$24,029 \mathrm{Tg} \mathrm{CO} 2 \mathrm{yr}-1 / 6.55 \mathrm{Pg}$ Cyr-1 } & \multicolumn{2}{|c|}{$24,891 \mathrm{Tg} \mathrm{CO}_{2} \mathrm{yr}^{-1} / 6.8 \mathrm{Pg} \mathrm{C} \mathrm{rr}^{-1}$} \\
\hline \multicolumn{2}{|c|}{$\begin{array}{l}\% \text { of positive contribution offset } \\
\text { by negative contribution }\end{array}$} & \multicolumn{2}{|l|}{$7.82 \%$} & \multicolumn{2}{|l|}{$10.08 \%$} & \multicolumn{2}{|c|}{$9.43 \%$} & \multicolumn{2}{|l|}{$9.82 \%$} \\
\hline
\end{tabular}

${ }^{*}$ See Table S1 for specific calculation and data source. $\uparrow$ Negative sign (-) denotes negative contribution to the atmosphere budget. 


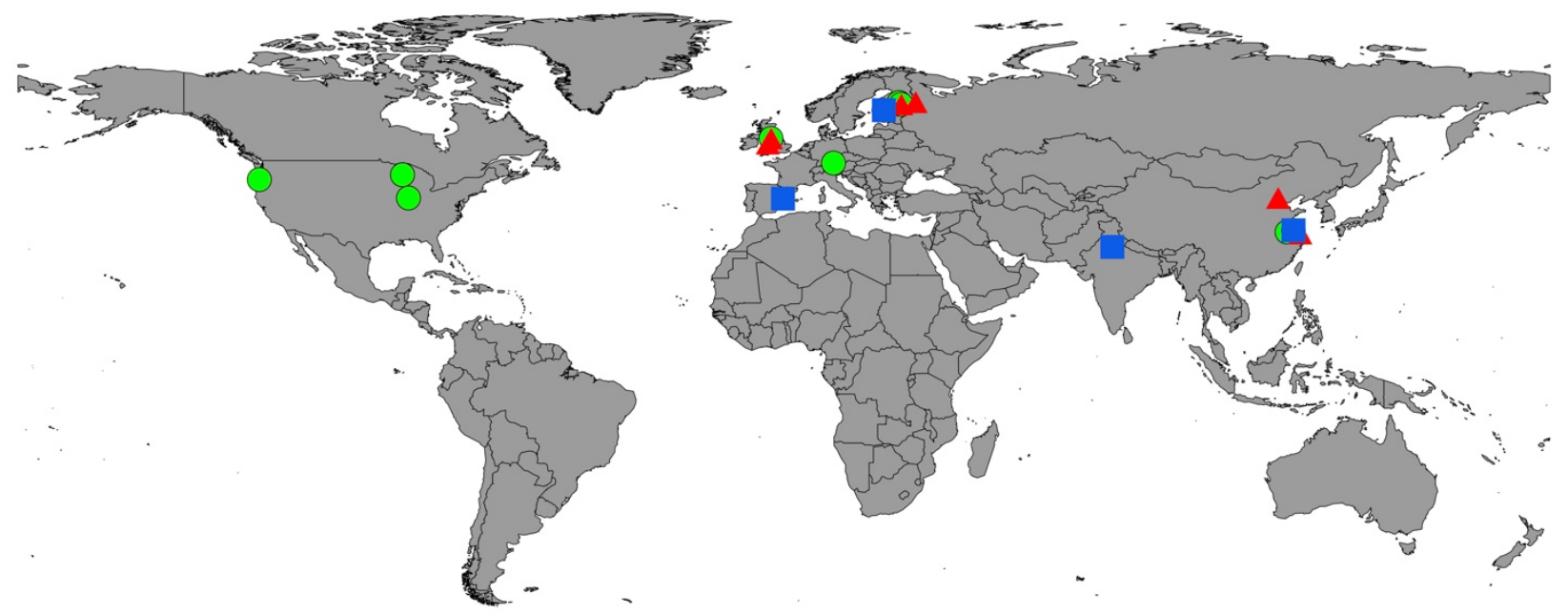

Fig.S1 Distribution of sites where measurements on soil respiration, $\mathrm{CH}_{4}$ flux, and $\mathrm{N}_{2} \mathrm{O}$ flux were conducted. The green, blue, and red denotes soil respiration, $\mathrm{CH}_{4}$, and $\mathrm{N}_{2} \mathrm{O}$, respectively. 

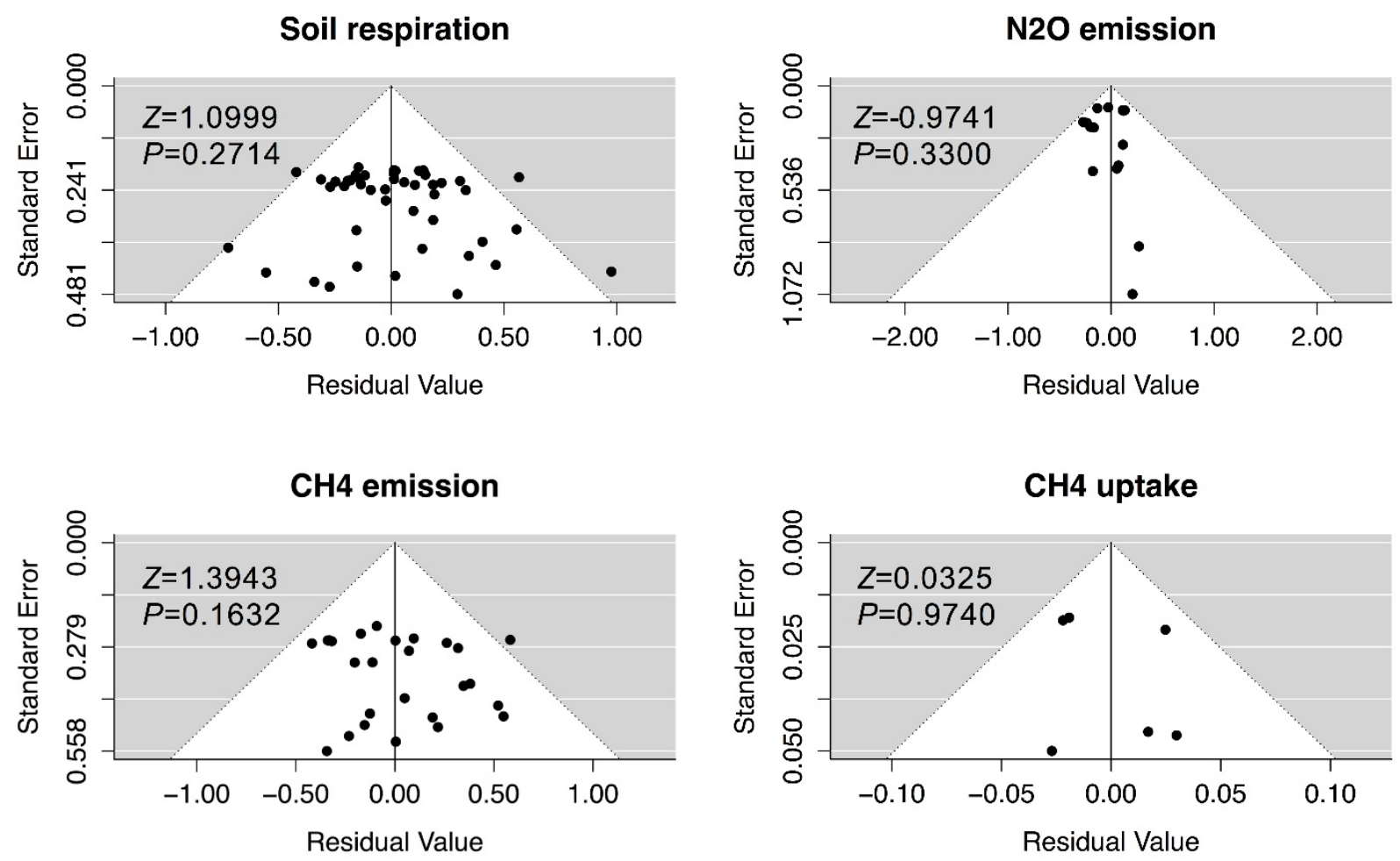

Fig.S2 Funnel plots and Egger's regression test detecting the publication bias. The corresponding Egger's regression test is shown in each panel. A $P>0.0 .5$ indicates the asymmetry of the funnel plot, suggesting the absence of publication bias. 

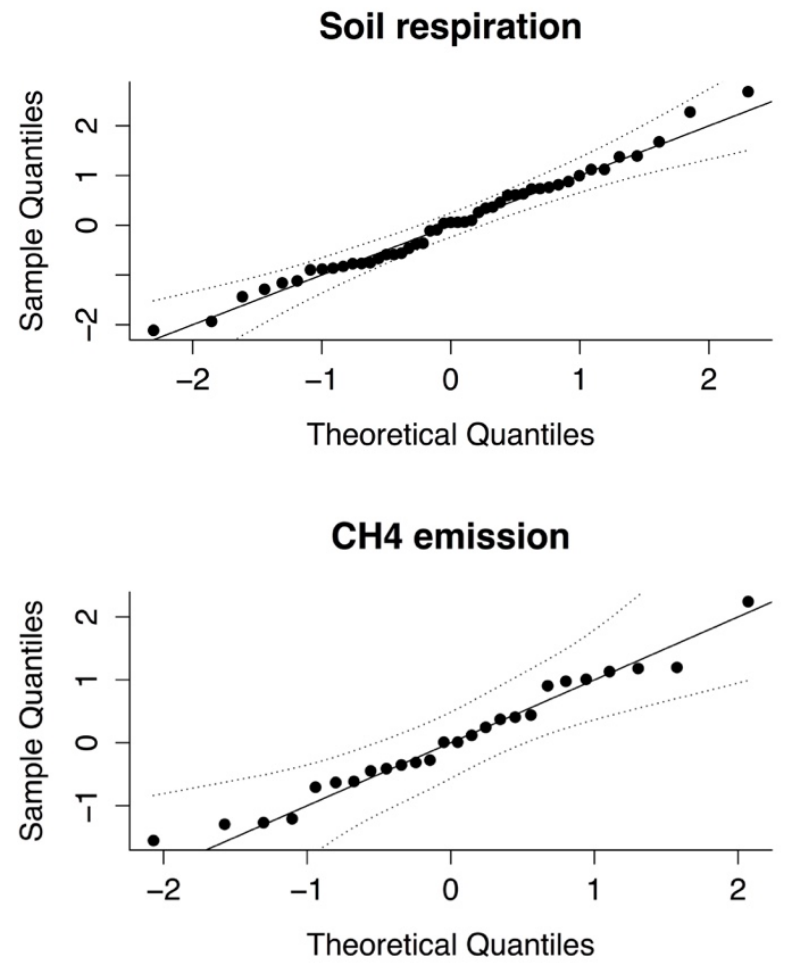
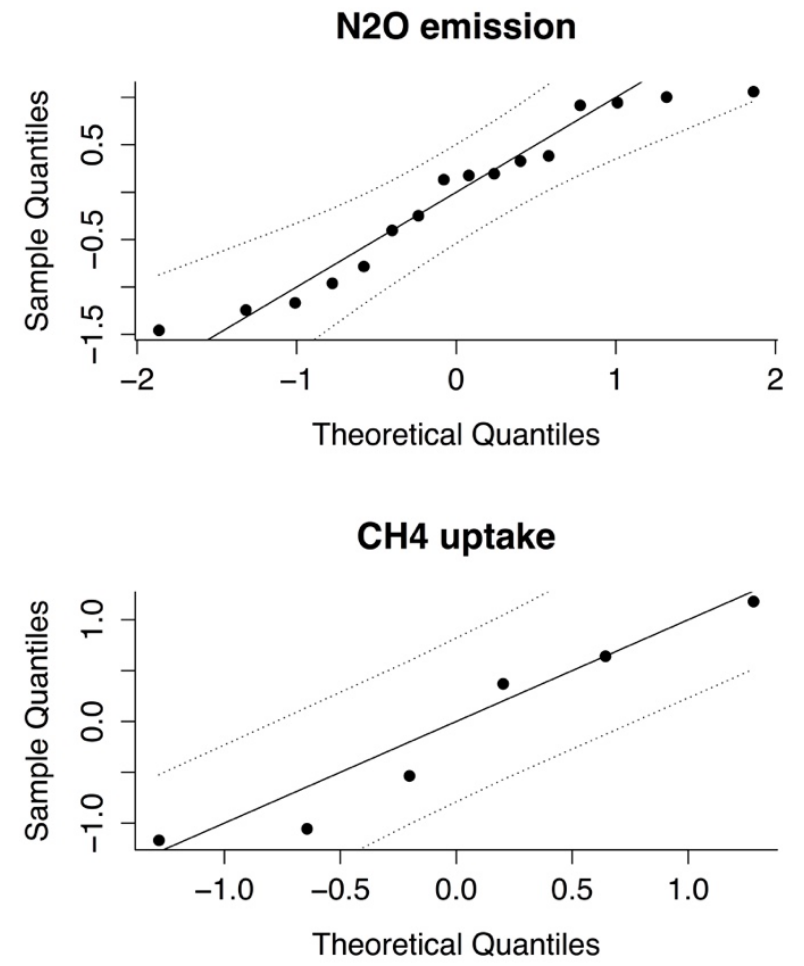

Fig.S3 Normality test of the effect sizes by $Q-Q$ plot. All the four flux items fulfill the normality requirement. 

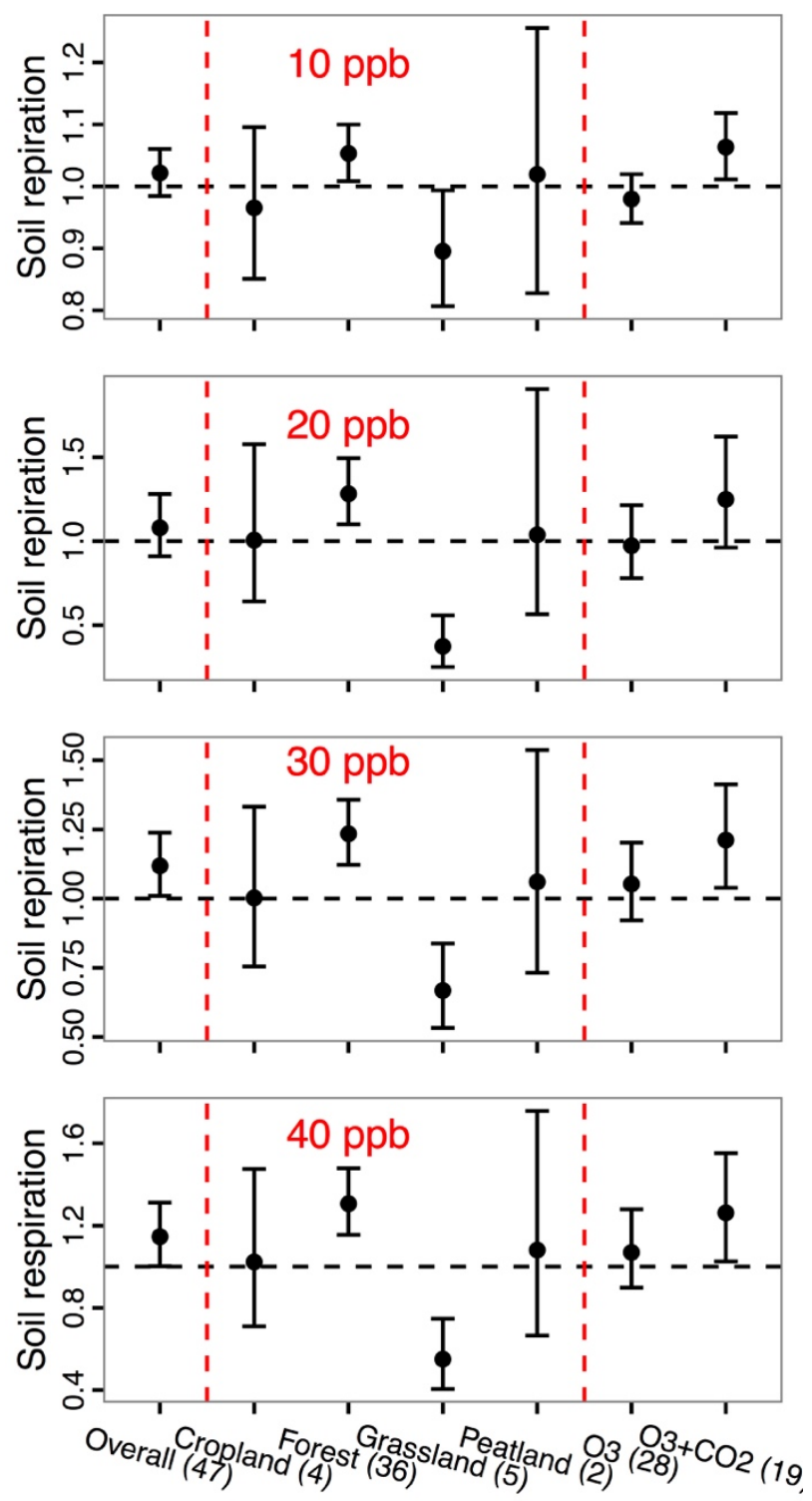

Fig.S4. Meta-analysis results of soil $\mathrm{CO}_{2}$ emissions from different ecosystems. The combined effects of $\mathrm{O}_{3}$ and $\mathrm{CO}_{2}$ are always stronger than the $\mathrm{O}_{3}$ effects alone. 

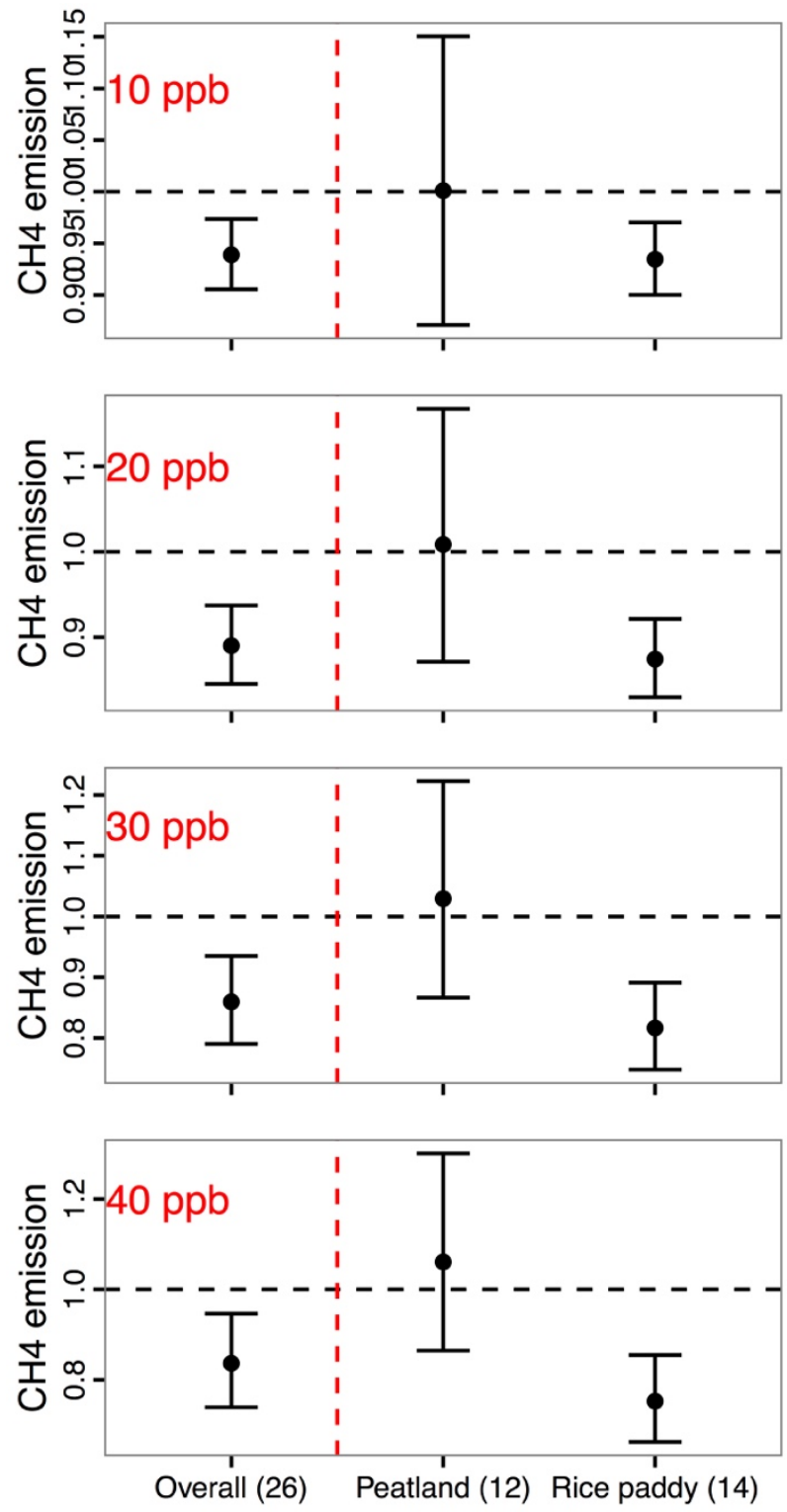

Fig.S5. Meta-analysis results of $\mathrm{CH} 4$ emissions from different ecosystems. 


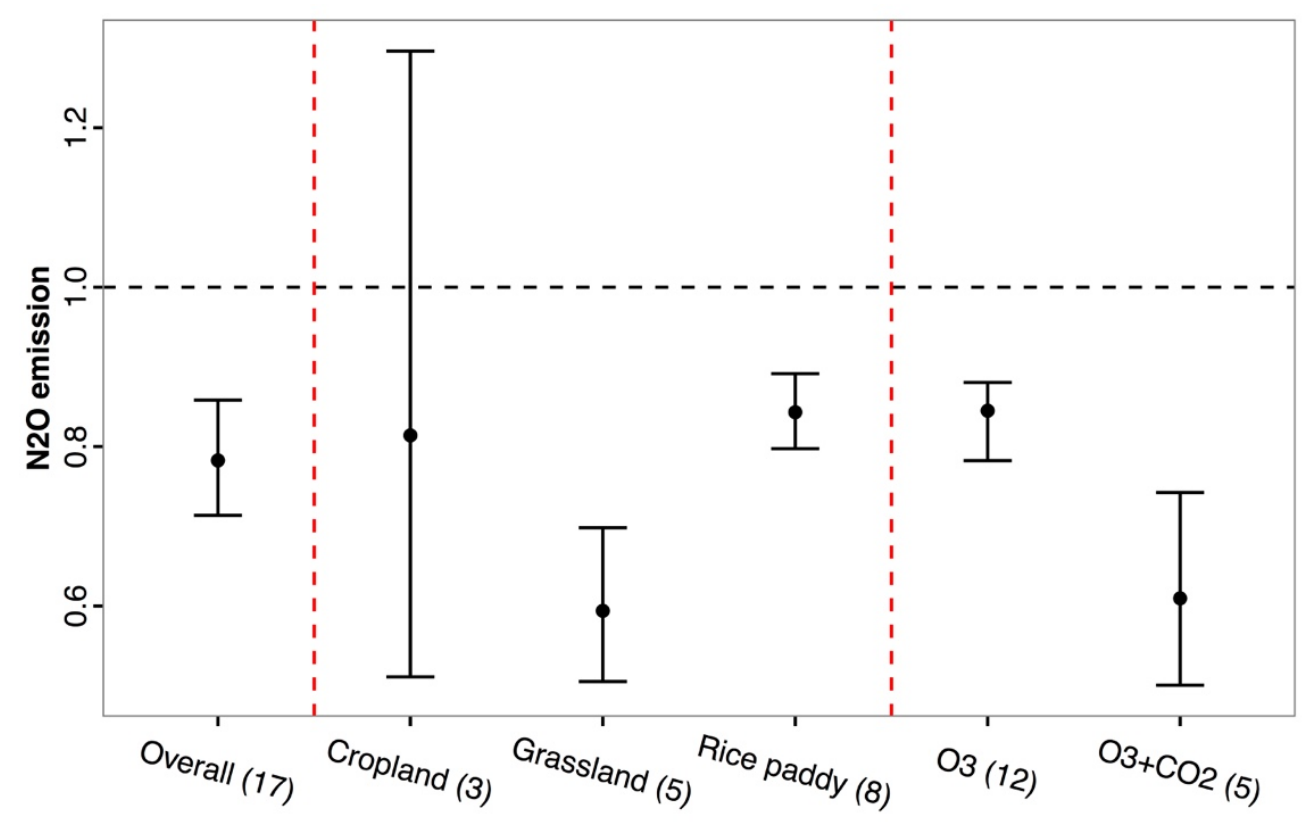

Fig.S6 Meta-analysis results of $\mathrm{N}_{2} \mathrm{O}$ emissions from different ecosystems. The combined effects of $\mathrm{O}_{3}$ and $\mathrm{CO}_{2}$ are stronger than $\mathrm{O}_{3}$ alone. 


\section{Chapter 3 An individual-based model of forest volatile organic compound emissions - UVAFME-VOC v1.0}

\subsection{Introduction}

Since the discovery by Haagen-Smit, Went, and colleagues that plant-derived organic compounds can contribute to $\mathrm{O}_{3}$ and haze formation (Haagen-Smit and Fox, 1954; Went, 1960) over half a century of research has shown the myriad ways that biogenic volatile organic compound (VOC) emissions from plants can influence both atmospheric chemistry and physical climate. Vegetation-derived VOCs enter the troposphere and are oxidized by reactions with hydroxyl radical $(\mathrm{OH})$, nitrate radical $\left(\mathrm{NO}_{3}\right)$, and to a smaller extent, $\mathrm{O}_{3}$ (Atkinson and Arey, 2003). These reactions affect the growth rate of methane $\left(\mathrm{CH}_{4}\right)$ and produce chemical products including $\mathrm{O}_{3}$, secondary organic aerosol (SOA), and various forms of oxidized nitrogen, which profoundly affect the air quality and physical climate at regional and global scales, in particular the forested areas (e.g., Atkinson and Arey, 2003; Fuentes et al., 2000; Jacob and Wofsy, 1988).

A good understanding of the biochemical mechanisms and the eco-physiology of production and emission of abundant VOCs species has been developed with over half a century of research (e.g. Monson et al., 1995; Lerdau et al., 1997; Lerdau and Gray, 2003; Vickers et al., 2009). VOCs production and emissions are strongly regulated by light intensity and temperature variations among many other abiotic (e.g., rising $\mathrm{CO}_{2}, \mathrm{O}_{3}$ pollution, and drought) and biotic factors (e.g., herbivory) (e.g., Niinemets et al., 2013). These confine our understanding only to the low order levels, i.e., leaf and individual of the hierarchical ecosystems on short time scales. 
However, how ecosystem-level VOCs emissions behave, in particular at decade-to-century time scales, is almost unknown. Changes in species composition could have profound impacts on phytogenic VOCs emissions because of the strongly species-dependent nature of VOCs production (e.g., Lerdau et al., 1997; Loreto and Fineschi, 2014; Monson et al., 2013; Zimmerman et al., 1979). For example, in the eastern United States about one-third of tree species produce isoprene (Lerdau, 2007). Tropical systems have a similar proportion of emitting species, and even low diversity ecosystems, such as boreal forests, contain a mixture of emitting and non-emitting species (Lerdau, 2007). This inter-specific variability in VOCs production means that community dynamics (i.e., changes in species composition and abundance) could significantly affect an ecosystem's VOCs emission capacity (Lerdau and Slobodkin, 2002). Furthermore, recent work has shown that impacts of VOCs on the atmosphere can alter the trajectory of these community dynamics, feeding back to affect VOC emissions (Wang et al., 2016). A good understanding of VOCs emissions and controls at the community/ecosystem levels are critical for more accurate quantification of their impacts on global change-atmospheric chemistry feedbacks at larger temporal scales.

Investigating these issues, however, poses intrinsic challenges. Long tree generation times and slow forest dynamics mean that experimental studies would have to occur on time-scales of decades. Substituting space for time, a common practice in ecological studies of long-lived organisms, is difficult because of the spatial heterogeneity of tropospheric chemistry (Atkinson and Arey, 2003; Fuentes et al., 2000). Logistic difficulties with empirical studies dictate the need for predictive models. However, previous modelling studies examining long-term vegetation VOCs emissions dynamics in response to global changes have not explicitly considered species compositional dynamics within ecosystems. Current modelling frameworks mostly represent 
vegetation in an aggregate way without a consideration of species-specific changes (e.g., Purves and Pacala, 2008; Scheiter et al., 2013). This is the case from the earliest regional model, BEIS (Pierce and Waldruff, 1991), to the widely used global model, MEGAN (Guenther et al., 2006, 2012). Operating from regional through global scales, these models represent vegetation in coarse resolutions, genus to PFT statically with the emission factors empirically constrained by environmental fluctuations. In addition, built on DGVMs (Dynamc Global Vegetation Models; see review by Shugart and Woodward, 2011) process-based models that can explicitly consider the biochemistry and eco-physiology of VOCs production and emissions have also been developed (Sanderson, 2003; Arneth et al., 2007). Nonetheless, these dynamic models, with a representation of vegetation in the PFTs fashion, still cannot explicitly predict communities' compositional dynamics. Without an explicit consideration of ecosystems' compositional change, great uncertainties are intrinsic to these models in estimating the magnitude of VOCs emissions.

Forest gap models (Shugart and West, 1980) are a type of individual-based model (IBM) in use for over 40 years. They simulate forest compositional and structural dynamics through an explicit consideration of life cycles of individual trees, their interactions, and emergent behaviors at the ecosystem level (Shugart, 1984; Bugmann, 2001a; Grimm et al., 2005; Shugart and Woodward, 2011). IBMs provide a framework to develop an individual-based VOC emission model that can predict emissions at the ecosystem scale over time-scales relevant for community dynamics — decades to centuries. Our primary objectives are:

1) To introduce the development of a forest VOC emissions model initiated with the individual-based gap model of University of Virginia Forest Model Enhanced, UVAFME-UVAFME-VOC v1.0; 
2) To evaluate this model's performance by implementing it for a temperate deciduous forest in the southeastern United States and then by comparing model outputs with independent field data. An additional test involves an application testing the hypothesis that the Chestnut Blight (Cryphonectria parasitica), which essentially eliminated American Chestnut, (Castanea dentate) as a dominant canopy tree in eastern North America, resulted in the oak-dominance and increased isoprene emission; and

3) Finally, to discuss the model's applicability and implications in addressing the feedbacks between global change and atmospheric chemistry bridged by the vegetation community ecology.

\subsection{Methods}

\subsubsection{Description of UVAFME}

UVAFME (Fig.1) simulates the annual growth, death, and regeneration of each individual tree on a 1/20 ha plot. These processes are constrained by temperature, light, and soil moisture and nutrients at the individual-tree level, as well as by wind and fire disturbances at the stand level. Trees compete for light, nutrient, and water resources. The community dynamics and composition, including tree numbers of each species, basal area, leaf area, biomass carbon and nitrogen, and litter carbon and nitrogen can be derived from the sizes and species of individual trees, which are computed annually in the model. The soil carbon, nitrogen, and water dynamics, along with soil carbon and nitrogen storage, soil respiration, and evapotranspiration, are calculated as state variables. The input data include species-related parameters, quantifying species' fundamental silvics and responses to environmental factors and site conditions, local soil physiochemical 
properties and meteorological temperature and precipitation. For details concerning the model algorithms, please refer to Yan and Shugart (2005).

\subsubsection{Model development}

Two principles guided the development of this individual-based VOCs emissions model. First, starting with the individual-based forest gap model, UVAFME, the overarching principle during model development was to keep the internal structure and functions of UVAFME unaltered. Second, in the simulation of VOCs emissions we applied the extensively used empirically based methodology (Guenther et al., 1995, 2006): that is, species-specific standard emission rate of different VOCs constrained by the leaf area of each individual tree and modified by environmental factors, e.g., light and temperature through the forest canopy profile with the central governing equation:

$$
E_{V O C}=E_{S} * A_{L} * C_{L} * C_{T}
$$

where Es represents the standard leaf-level emission rate of VOCs, $A_{L}$ represents leaf area, and $C_{L}$ and $\mathrm{C}_{\mathrm{T}}$ accounts for light- and temperature-induced variability, respectively. As will be discussed immediately below, the direct and diffuse light onto the leaf profile of each tree, in five canopy layers is simulated allowing the computation of each tree's VOCs emission as a summation of sunlit and shaded leaves production. Model structure and development are outlined in Fig.1. Note the specific inclusion of the simulation of isoprene emissions. See Appendix A for the simulation methodology of other VOCs species (e.g., monoterpenes). 


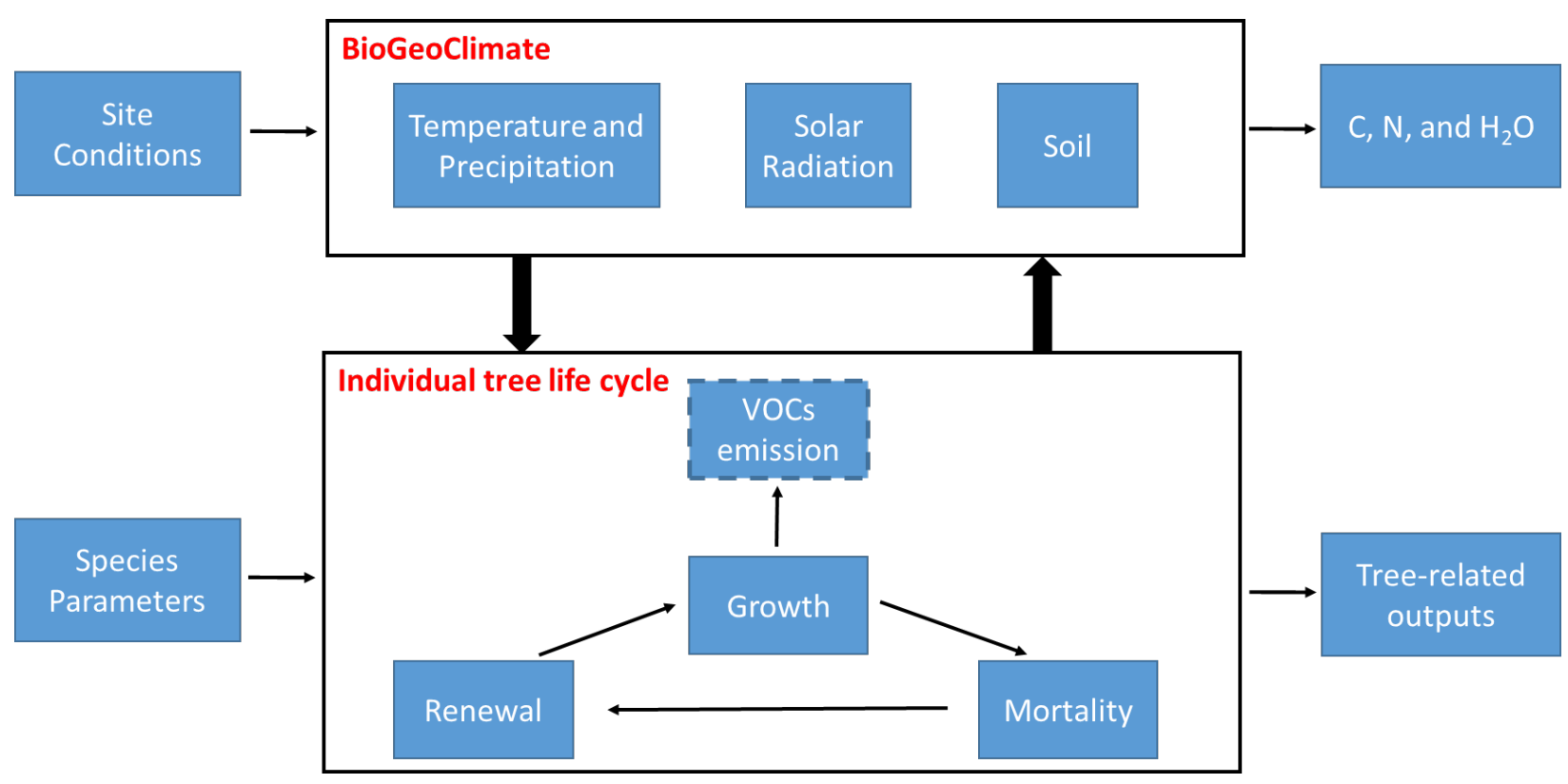

Fig.1 A schematic of the main structure and components of UVAFME-VOC v1.0.

The leaf area is assumed to be uniformly distributed throughout the crown of each tree [as with all the other vegetation models (Bugmann, 2001a; Sitch et al., 2003)] and updated annually. We assume that the leaf area in July of each year equals this year-step leaf area. To account for the light variation within the forest stand, the canopy of each tree is divided into five layers. Each layer is further subdivided into sunlit and shaded leaves. Isoprene emissions from the sunlit and shaded leaves of each layer of each tree are calculated $\left(\mathrm{mg} \mathrm{m}^{-2} \mathrm{~h}^{-1}\right)$ under constraints of air temperature and leaf-level PPFD (photosynthetic photon flux density) for both sunlit and shaded leaves with an hourly time step, as shown below. The sunlit-leaves flux and the shaded-leaves flux from each tree's five layers sum to the daily flux for each tree $\left(\mathrm{mg} \mathrm{m}^{-2}\right.$ day $\left.^{-1}\right)$. The sum of isoprene emission over all trees represents the stand canopy isoprene flux $\left(\mathrm{mg} \mathrm{m}^{-2} \mathrm{day}^{-1}\right)$. 
Light-dependency algorithm follows Guenther et al., (1995):

$$
C_{L}=\frac{\alpha C_{L 1} \mathrm{~L}}{\sqrt{1+\alpha^{2} \mathrm{~L}^{2}}}
$$

where $\mathrm{L}$ is leaf level PPFD, $\mu \mathrm{mol} \mathrm{m} \mathrm{m}^{-2}, \alpha=0.0027$, and $\mathrm{C}_{\mathrm{L} 1}=1.066$. The hourly leaf-level PPFD at each canopy layer for sunlit and shaded leaves of each isoprene-emitting tree is obtained by three steps of calculation (Fig. 2):

First, the direct beam and diffuse PPFD above the forest stand is calculated from incoming total solar radiation. Second, considering the shading by taller and surrounding trees, the light intensity including total beam (unintercepted beam plus down scattered beam), beam (unintercepted beam), and diffuse PPFD above each individual tree canopy within the forest stand is then calculated. Third, the leaf area of sunlit and shaded leaves and the corresponding PPFD for each canopy layer are calculated. The sunlit leaf fraction and different flux densities are determined at each canopy layer using an exponential function of leaf area depth but with differing extinction coefficients based on a spherical leaf angle of $60^{\circ}$. The light intensity on shaded leaves is from both incoming diffuse light and scattered light from the direct beam inside the canopy, which plus the absorbed beam radiation equals the intensity on sunlit leaves surface. These calculations are described in Goudriaan and Van Laar (1994). See Appendix A for more details concerning simulation of the sunlit and shaded leaf area and PPFD level. 


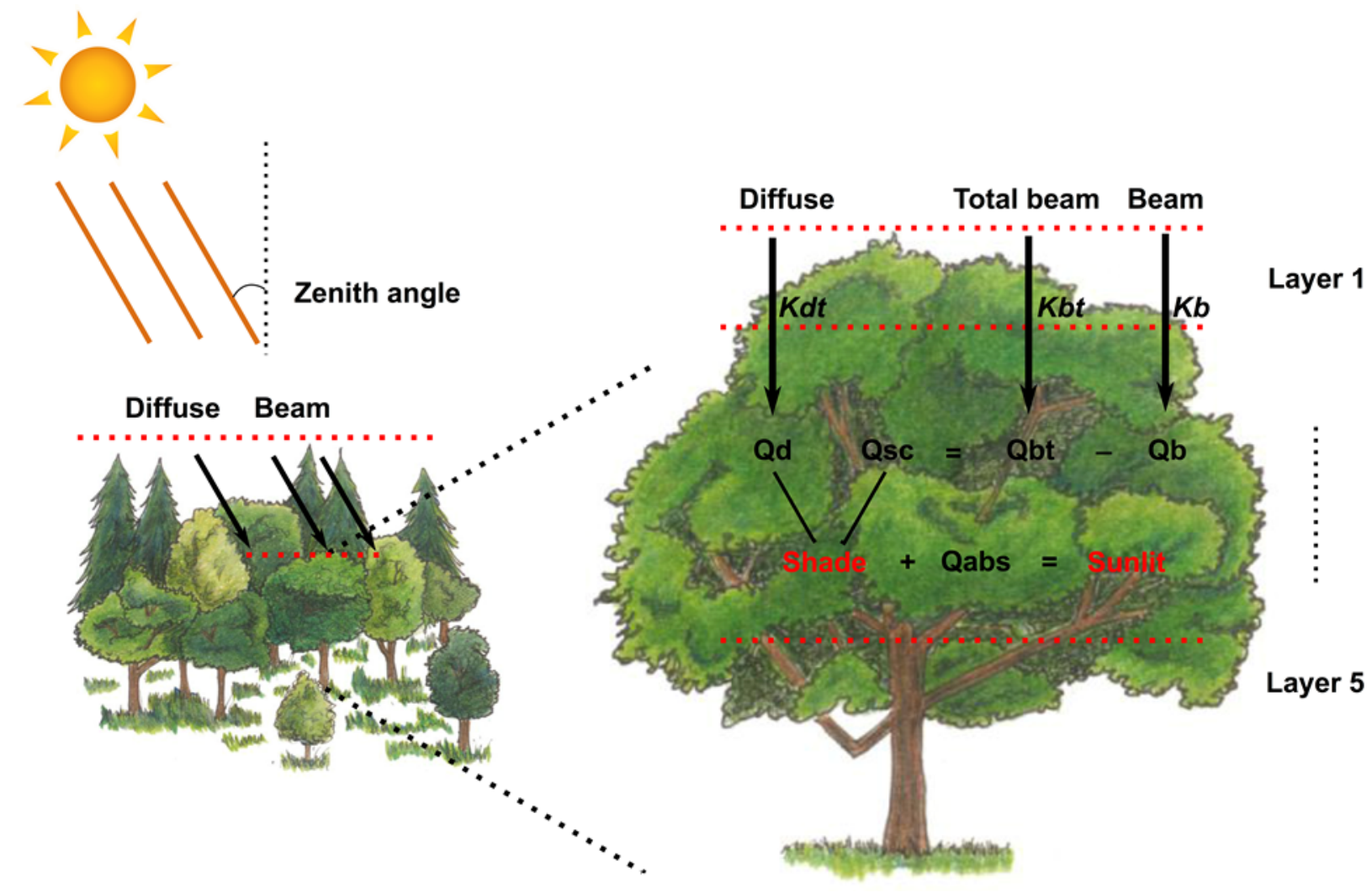

Fig.2 A schematic of simulation of light transmission within stand and individual tree canopy. $K d t, K b t$, and $K b$ represent the extinction coefficient for diffuse, total beam, and beam respectively. Qsc and Qabs denote the scattered and absorbed beam radiation, respectively.

The temperature-dependency algorithm of isoprene emission (Guenther et al., 1995) is:

$$
C_{T}=\frac{\exp \frac{\mathrm{C}_{\mathrm{T} 1}\left(\mathrm{~T}-T_{S}\right)}{\mathrm{R} T_{S} \mathrm{~T}}}{1+\exp \frac{C_{T 2}\left(\mathrm{~T}-\mathrm{T}_{\mathrm{M}}\right)}{\mathrm{R} T_{S} \mathrm{~T}}}
$$

where $\mathrm{R}=8.314 \mathrm{~J} \mathrm{~K}^{-1} \mathrm{~mol}^{-1}, \mathrm{C}_{\mathrm{T} 1}=95,000 \mathrm{~J} \mathrm{~mol}^{-1}, \mathrm{C}_{\mathrm{T} 2}=230,000 \mathrm{~J} \mathrm{~mol}^{-1}, \mathrm{~T}_{\mathrm{M}}=314 \mathrm{~K}$, and $\mathrm{T}_{\mathrm{S}}=$ $303 \mathrm{~K}$. T is leaf temperature, which is assumed to be equal to hourly air temperature and constant through the canopy. Hourly temperature is calculated from daily minimum and maximum temperature, the previous-day maximum temperature, and the following-day minimum 
temperature (Goudriaan and Van Laar, 1994). See Appendix A for detailed procedures to calculate the hourly temperature.

\subsubsection{Model performance evaluation}

To evaluate the performance of UVAFME-VOC v1.0, we implemented it to simulate the forest successional dynamics and VOCs (isoprene) emission in the southern Appalachian Mountains region located in the southeastern United States. This region has an extensive field record of forest inventory data (e.g., Fowells, 1965; Hardin et al., 2001), and, in particular, extensive research on VOCs production and emissions make species-specific information readily available (e.g., Geron et al., 2000, 2001). Historically, the Chestnut blight (Cryphonectria parasitica), a fungus parasite introduced from Asia (Braun, 1950; Woods and Shanks, 1959) of the late $19^{\text {th }}$ and early $20^{\text {th }}$ centuries caused a massive change in forest composition in the eastern United States. American Chestnut (Castanea dentate), which had comprised as much as 50\% of East Coast lowland forests, disappeared almost completely and was replaced to a large extent by oaks (Braun, 1950). Unlike oak, American Chestnut does not emit isoprene (Guenther et al., 1996) and it has been hypothesized that the Chestnut Blight has produced an approximate doubling of the biomass of isoprene-emitting species and a significant increase of isoprene emission (Lerdau et al., 1997). To date, however, this hypothesis has not been tested. A community/ecosystem-scale IBM is an ideal vehicle for explicitly testing the question of how changes in species composition might alter VOC emissions.

\subsubsection{Model parameterization}

Thirty-two species including both deciduous and coniferous trees native to the southern Appalachian region in the southeastern US, plus chestnut, are included in the simulation (Appendix B). Twenty-five parameters describing silvical properties of each species required as inputs were 
drawn from the literature. Specifically, wood bulk density values were from global wood density data compiled by Zanne et al. (2009). Species response to nutrient availability is according to Weinstein (1982). All the remaining parameters are estimated according to Fowells (1965) and Hardin et al. (2001). Major isoprene-emitting species and their standard emission rates were according to Geron et al. (2001).

Thirty years of meteorological data for monthly precipitation, $\mathrm{mm}$ and monthly maximum and minimum temperature $\left({ }^{\circ} \mathrm{C}\right)$ ranging from 1981 to 2010 were obtained from the NOAA (National Oceanic and Atmospheric Administration) meteorological station at Oak Ridge ATDD, Tennessee, USA (GHCND: USW00003841; Latitude/Longitude: 36.0028\%-84.2486º Elevation: $275.8 \mathrm{~m}$ ) to compute monthly average precipitation, monthly maximum and minimum temperature, and their standard deviations. Soil-related parameters including organic layer carbon and nitrogen, active layer carbon and nitrogen, and base soil layer carbon are estimated according to Johnson and Van Hook (2012). Values of $25 \mathrm{~cm}$ and $12.5 \mathrm{~cm}$ were used for soil field capacity and soil permanent wilting point, respectively.

\subsubsection{Simulation methodology}

We applied a Monte Carlo simulation of a landscape of indeterminate size sampled with a system of independent sample plots with the same climate and soil conditions. Therefore, the average of the simulation corresponds to a shifting-mosaic steady-state landscape (Bormann and Likens, 1979). An analysis of convergence of average species-specific biomass values indicated that $150-200$ replicate plots are needed to provide a sample which approximates a statistically quasi-stable landscape response of the forest landscape (Bugmann et al., 1996). The model was run for a plot size of $500 \mathrm{~m}^{2}$ starting from bare ground (i.e. gaps with ample active seeds where secondary succession occurs, and which in field such gaps can be created from the death of a 
canopy-dominant tree resulting from wind, fire, or other disturbances) and lasting for 500 years for 200 independent plots. All the results presented are the average of 200 such runs. Specifically, the simulation without and with the chestnut tree was defined as 'Present' and 'Pre-blight', respectively.

\subsubsection{Validation criteria}

As recommended by Grimm et al. (2006), the validation of an IBM should include individual, community, and system level inspections emphasizing the hierarchical structure of an ecological system. We compared simulation results with a series of independent observations involving community composition, basal area, stand density, biomass, productivity, and isoprene emission. Several criteria were applied to demonstrate the reliability of this model:

(1) 'Present' simulation outputs including composition, stand basal area, stem density, biomass, productivity, and soil respiration generally match empirical data;

(2) 'Pre-blight' forest composition is similar to the historical record;

(3) Proportion of isoprene-emitting species within the forest community was much lower in 'Preblight' than in 'Present'; and

(4) Correspondingly, isoprene emission is much higher from 'Present' forest than from the 'Preblight' forest. 


\subsection{Results}

3.3.1 Forest successional dynamics in the southeastern United States

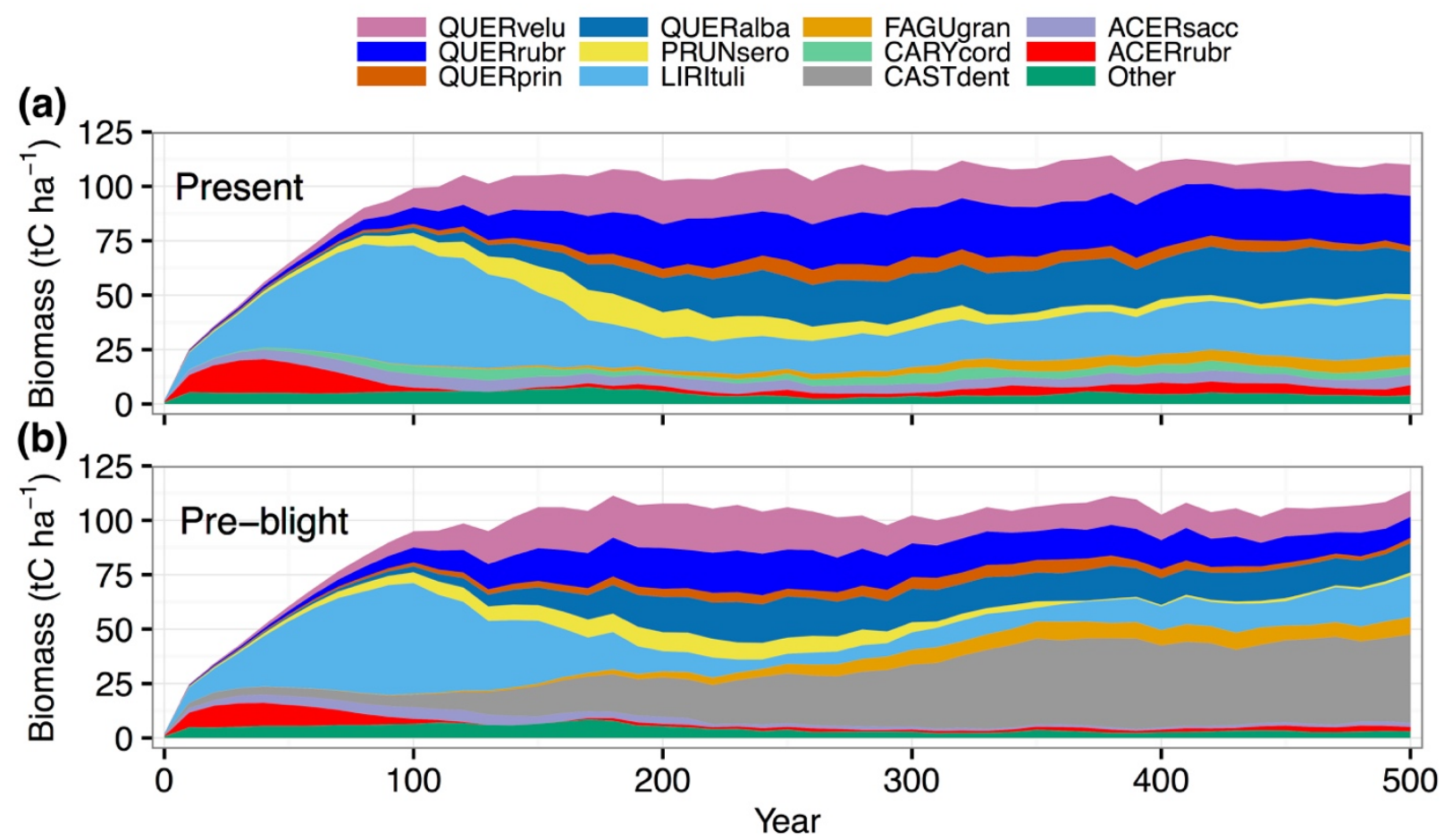

Fig. 3 Simulated forest dynamics in terms of biomass over 500 years for (a) the 'present' forest (i.e., without Chestnut) and (b) the 'pre-blight' forest (i.e., with Chestnut). The width of each color band represents the biomass $\left(\mathrm{tC} \mathrm{ha}^{-1}\right)$ of different species at a specific year. QUERvelu: black oak; QUERrubr: red oak; QUERprin: Chestnut oak; QUERalba: white oak; PRUNsero: black cherry; LIRItuli: yellow poplar; FAGUgran: American beech; CARYcord: bitternut hickory; CASTdent: American Chestnut; ACERsacc: sugar maple; ACERrubr: red maple; and Other: all the following species simulated (see Appendix B). 

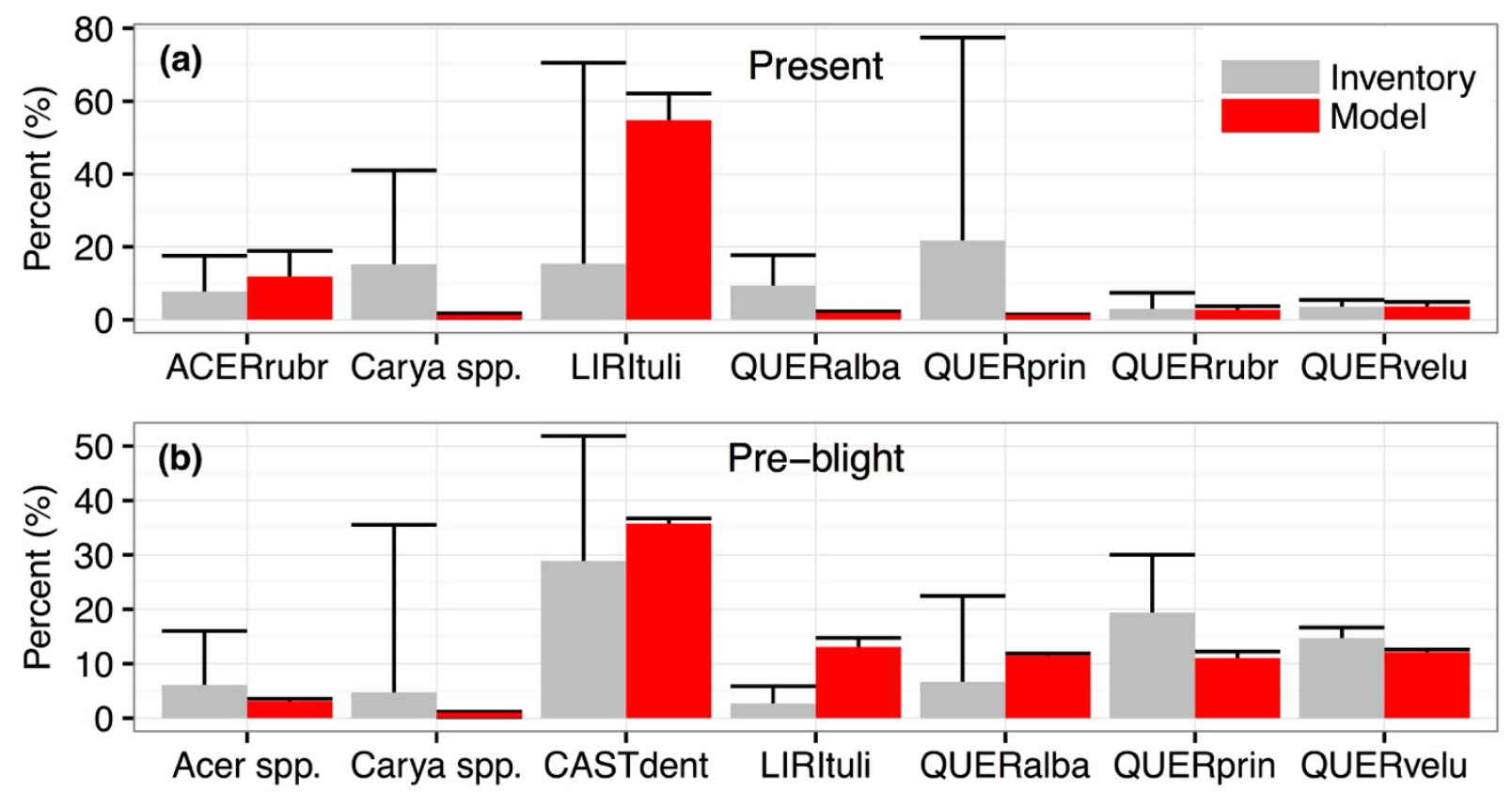

Fig.4 Comparisons between model simulation and field survey in terms of percent species composition in basal area $\left(\mathrm{m}^{2} \mathrm{ha}^{-1}\right)$. (a) Comparison of major species in the present forest between the average of model simulation output from 10-90 year and field data describing the forest composition at a successional age of about 40 year at Walker Branch Watershed in eastern Tennessee (35'58' N; 84'17' W) acquired from Grigal and Goldstein (1971); (b) Comparison of major species in the pre-blight forest between the simulation (average of 400500 year output) and field data describing the composition of eastern Tennessee before the outbreak of chestnut blight acquired from Shugart and West (1977). The error bars show the upper $95 \%$ confidence interval. Species code is same with Figure 3. 

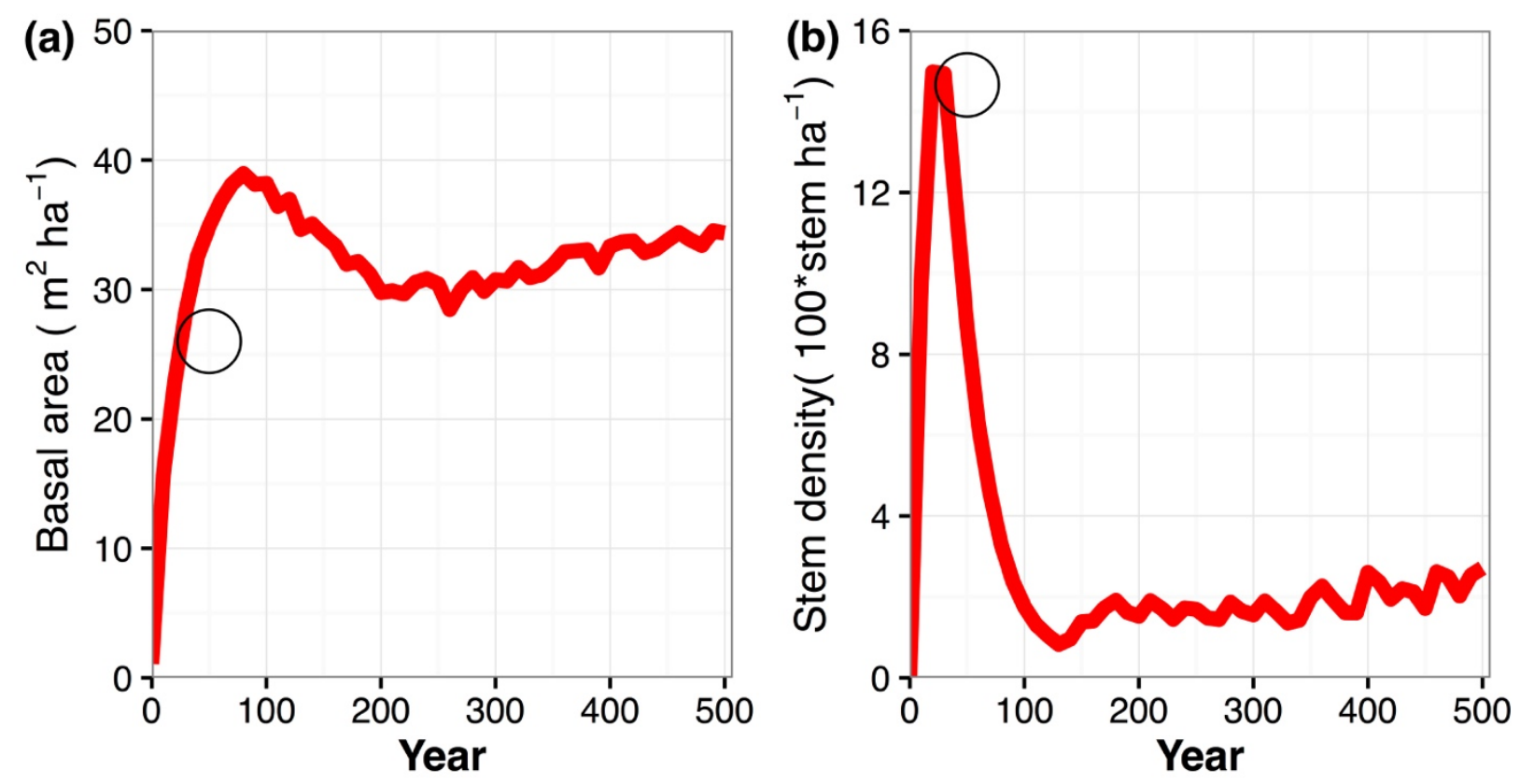

Fig.5 Stand basal area (a) and stem density (b) dynamics over the 500-year simulation of the present forest. The open circle represents a value of basal area $\left(26 \mathrm{~m}^{2} \mathrm{ha}^{-1}\right)$ and stem density $\left(1466\right.$ stem ha $\left.{ }^{-1}\right)$ at a successional age of 50 years at Walker Branch Watershed in eastern Tennessee (35'58' $\mathrm{N}$ and 84'17' W) acquired from Lafon et al. (2000) and Bugmann et al. (2001b), respectively. Trees with a diameter larger than $2.5 \mathrm{~cm}$ are included.

Successional dynamics of the 'Present' forest over 500 years involves changes in 10 abundant species and 22 other species (Fig.3a). Initially for a forest succession from an open plot, the 'other' species category, mostly composed of pioneer species, dominates the forest with approximately $50 \%$ of the total biomass. Soon, both Acer rubrum and Liriodendron tulipifera become increasingly important, but $A$. rubrum eventually loses to the larger, faster-growing $L$. tulipifera trees, which persist and become dominant. After L. tulipifera declines over time, trees of four late successional oak species (Quercus alba, Q. velutina, Q. rubra, and $Q$. prinus) become 
increasingly important, together accounting for approximately $75 \%$ of the stand biomass at year 500. The composition of the forest stabilizes and is eventually dominated by aforementioned oaks, along with L. tulipifera and two maples (A. rubrum and A. saccharum). This simulated composition matches the description in southeastern United States qualitatively (Shugart, 1984). Moreover, the average percent composition over the first 100 years of simulation was compared with available field species survey data (Fig.4a). Generally, composition was statistically not different with field inventory data (overlap between 95\% confidence intervals). These results suggest that the model can capture the forest succession composition.

Similar to the species composition changes, total biomass becomes relatively less variable, beginning around year 100 (Fig.3a). Over succession, the total basal area and stand density quickly reached a maximum of almost $40 \mathrm{~m}^{2} \mathrm{ha}^{-1}$ and 1400 stem ha $^{-1}$ within 100 years, respectively (Fig.5). Subsequently, total basal area declined until around the 200 year to about $30 \mathrm{~m}^{-2}$ year $^{-1}$, and then stayed relatively stable with a slight increasing trend (Fig.5a). The stem density sharply declines and then keeps relatively stable at about 200 stems ha $^{-1}$ (Fig.5b). These patterns result from the initial rapid stand establishment, followed by thinning from competition. The simulation matches very well with the available field survey data at a succession age of around 50 years (Fig.5). Further, three principal carbon cycling processes, net primary productivity, soil respiration, and net ecosystem production and the forest carbon stock through dynamic development show reasonable resemblance over successional time (see Appendix A for details).

With the American Chestnut included, i.e., 'Pre-blight' forest, the successional dynamics were quite different in forest composition from the 'Present' forest (Fig.3b). Chestnut was dominant in 'Pre-blight' forests and oaks (Quercus spp.) dominant in the 'Present' forest. Chestnut was a canopy-dominant, shade-tolerant tree in these forests (Braun, 1950). These simulated 
changes in forest composition accord well with the description of forest change in response to the chestnut blight in the southeastern United States (Keever, 1975; Nelson, 1955; Woods and Shanks, 1959). Moreover, such dominance and the composition of other species by the model simulation matched the historical field survey data quantitatively. As shown in Fig.4b, the percentage of each species in the simulation at the later successional stage were not statistically different with field survey data except for only L. tulipifera [see Shugart and West (1977) for more details on historical forest composition]. 
3.3.2 VOCs, isoprene emission dynamics

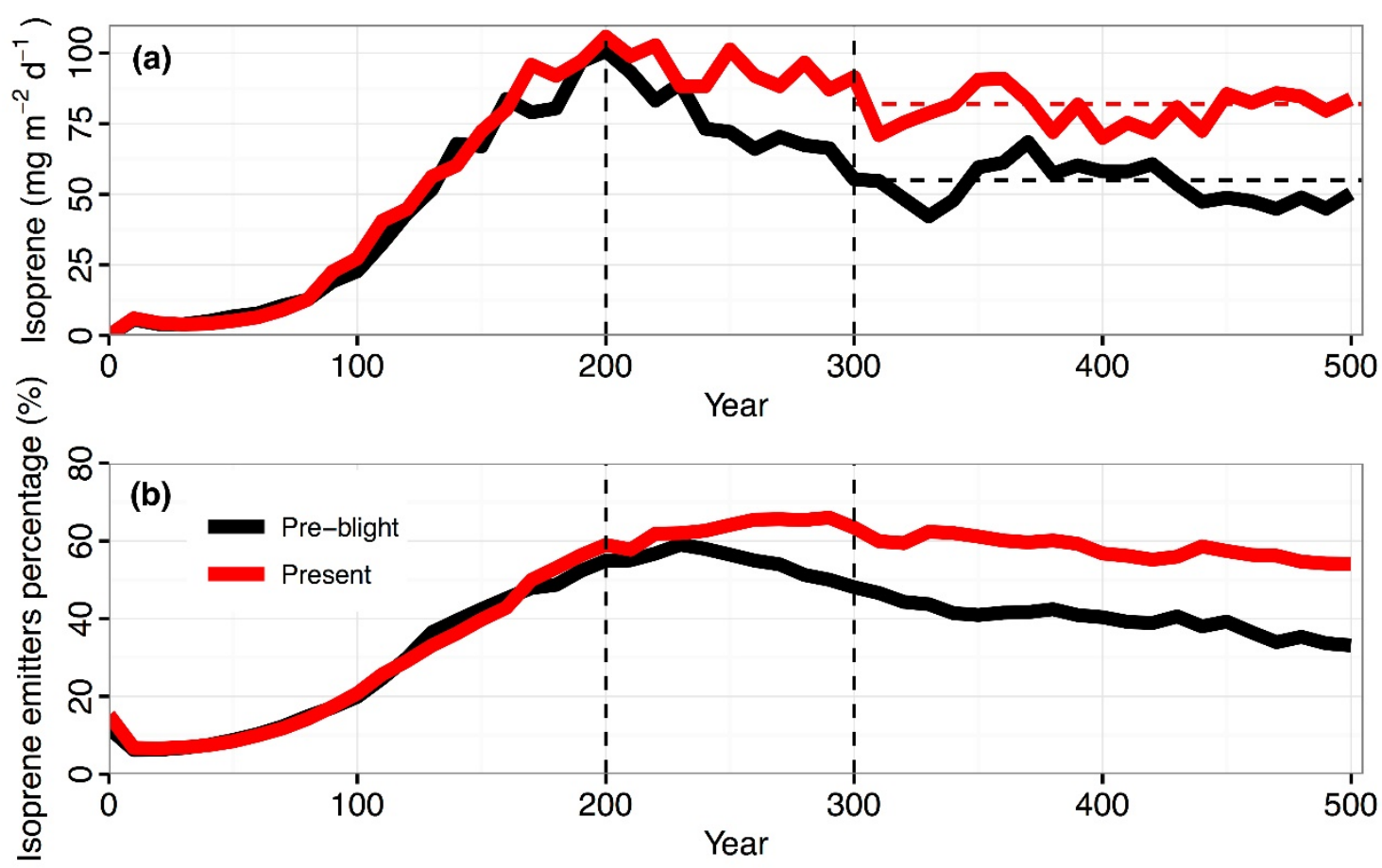

Fig.6 Comparisons of isoprene emission rate (a) and percentage of isoprene-emitting species' biomass within the forest stand (b) between the 'Present' (red) and 'Pre-blight' forest (black) over the 500-year simulation. The isoprene emission rate represents the average of daily isoprene emission rate from July of each year. 
(a)

QUERalba $\square$ QUERprin $\square$ QUERrubr $\square$ QUERvelu $\square$ Others
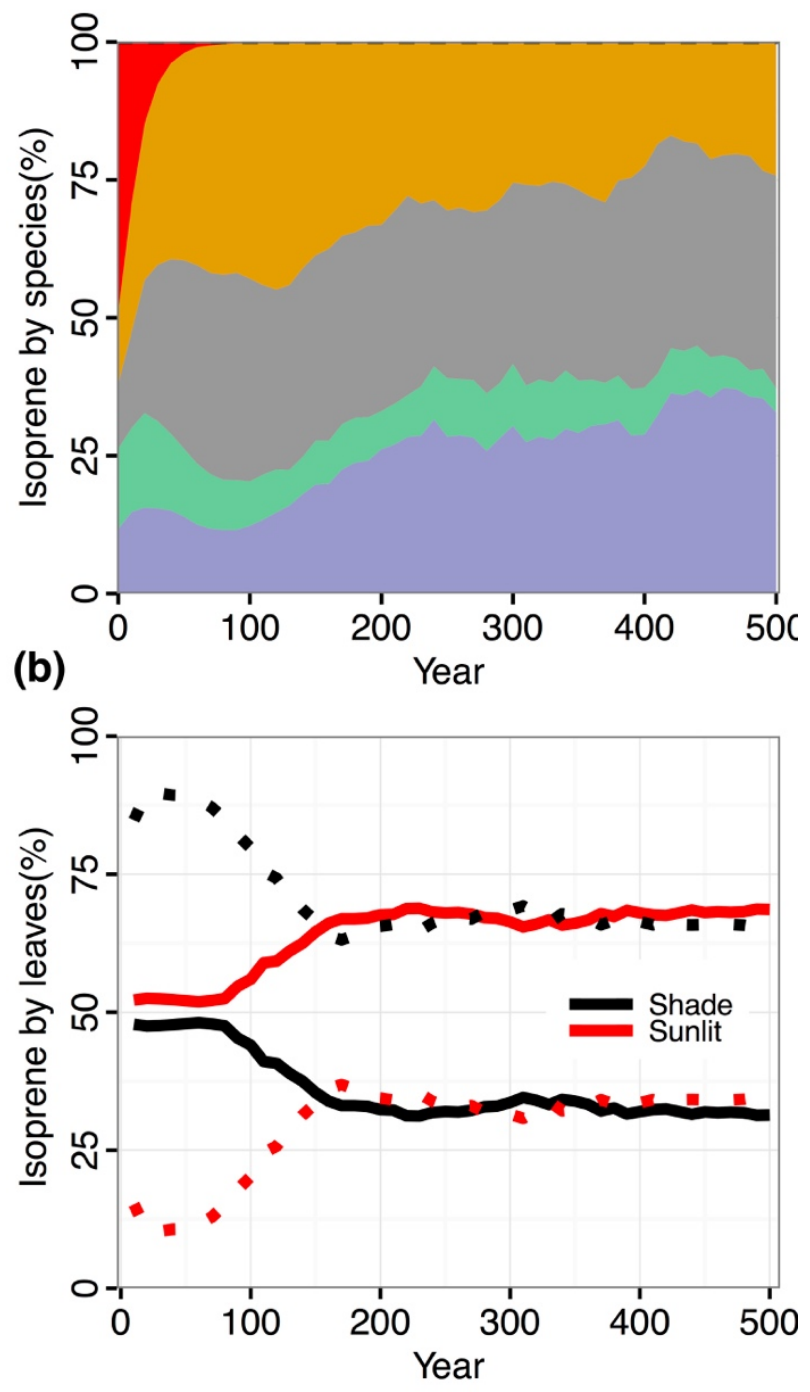

Fig. 7 Total isoprene emissions contributed by species and leaf type (sunlit and shade leaf).

(a) Total isoprene emissions comprised by different species, among which the 'others' refer to the isoprene emitters besides the four oak species. (b) Percent contribution to total isoprene emissions (solid lines) and to total leaf area (dashed lines) from sunlit (red) and shaded leaves (black). Note the dynamics presented in (b) starts from the year 10. See species code in Figure 3 and the leaf area in units of $\mathrm{m}^{2} \mathrm{~m}^{-2}$ in Appendix A. 

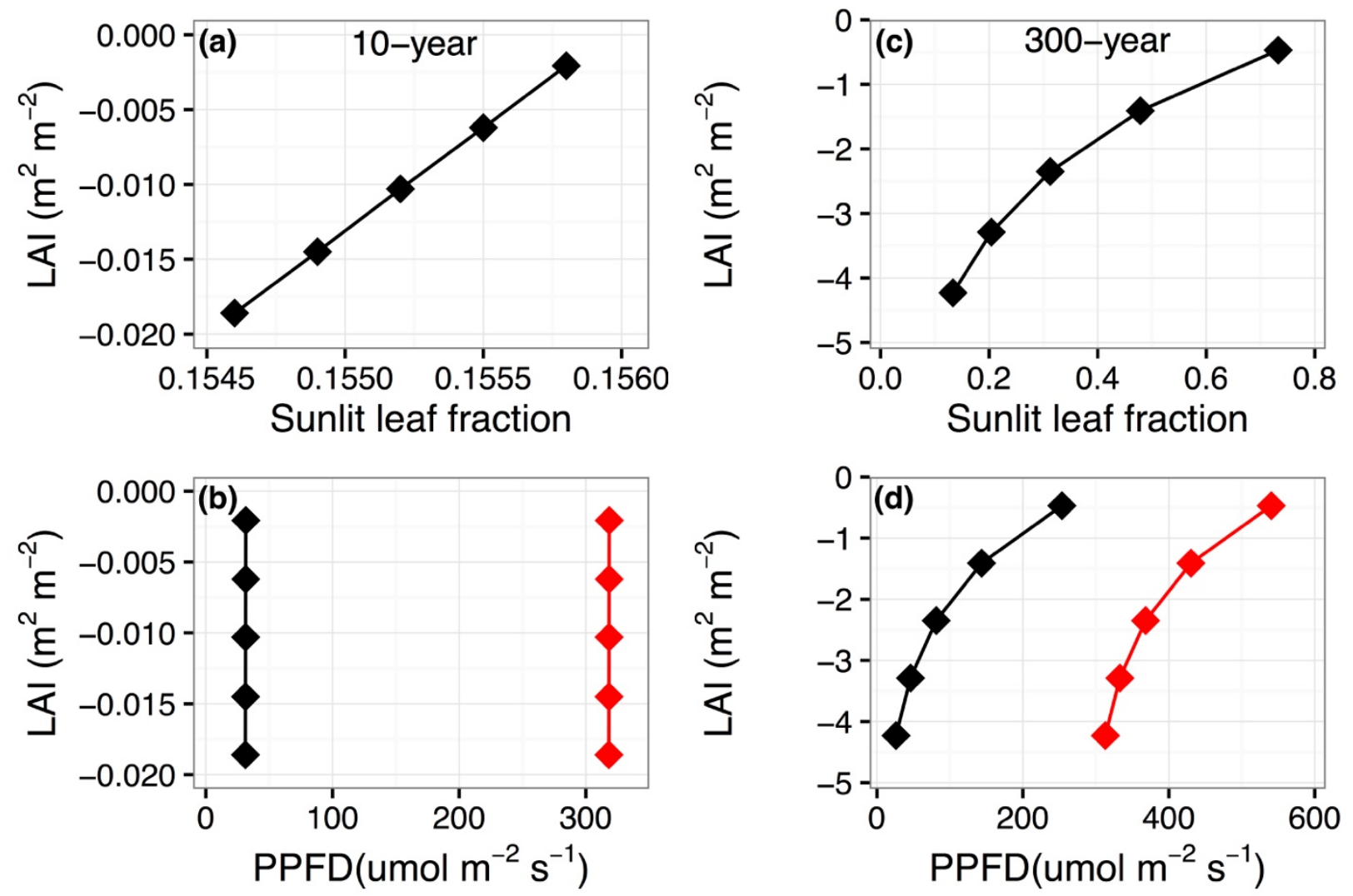

Fig.8 An example of profile of fraction of sunlit leaf area and PPFD on the sunlit and shaded leaves across a white oak $(Q$. alba) tree canopy within the stand. The white oak tree was randomly chosen from the simulated forest stand at a successional age of $10(\mathrm{a}, \mathrm{b})$ and 300 (c.d). A spherical leaf angle of 60 degrees is assumed. The negative values on $\mathrm{Y}$-axis indicate an increasing canopy depth. Red lines denote the light intensity on sunlit leaves. 
Isoprene emissions following the 'Present' forest dynamics (Fig.6) showed an initial increase with the isoprene producers gradually accumulating in the forest. After the plateau at around the year 200 with an emission rate of about $100 \mathrm{mg} \mathrm{m}^{-2} \mathrm{~d}^{-1}$, isoprene emission rate slightly declined until around year 300 when the emission settled at around $85 \mathrm{mg} \mathrm{m}^{-2} \mathrm{~d}^{-1}$ with the stabilization of forest composition and structure (for diurnal dynamics, see Appendix A).

The magnitude of isoprene emissions simulated here was a little lower than was found in the simulation by MEGAN in the southeastern US (Guenther et al., 2006). MEGAN and other models (e.g., BEIS) assign an emission factor to each plant functional type or genus (Guenther et al. 2006; Pierce and Waldruff, 1991). By contrast, the UVAFME-VOC v1.0 uses species-specific emission factor, which could contribute to this difference in simulated isoprene emission.

The ecosystem level emissions are comprised of emissions from different species and leaf types (sunlit and shaded) with differing proportions (Fig.7). Initially, the total isoprene emissions attributed to the 'others' reached nearly $50 \%$ percent, but this contribution source declined in importance very quickly and was nearly zero after about 60 years. The eventual contribution, ranked by the percentage, was from $Q$. prinus, $Q$. alba, $Q$. velutina, and $Q$. rubra (Fig.7a). This dynamic change was accompanied by change in leaf area of sunlit and shaded leaves over the succession. The total isoprene emissions were also separated into sunlit leaf- and shaded leafderived production, hereafter called sunlit and shaded flux, respectively (Fig.7b). During the early successional stage, the sunlit flux and shaded flux remained stable and contributed almost equally $(\sim 50 \%)$ with the sunlit flux being slightly higher. The contribution by sunlit leaves relative to shaded leaves gradually increased, and eventually increased to about $75 \%$, sunlit leaves against $25 \%$, shaded leaves at the later successional stage. 
This dynamic change pattern of ecosystem level isoprene emissions originated from the compositional and structural changes of the simulated forest over natural succession. The annual growth environment, including air temperature and in-coming radiation which were primary controlling factors for isoprene production, did not change during the 500-year succession (see Appendix A for diurnal and annual temperature and radiation cycles). However, the within-canopy environment experienced significant modifications resulting from the compositional and structural changes, which can affect isoprene production and emission (e.g., Bryan et al., 2015). This model explicitly simulated shaded and sunlit leaf area and the corresponding leaf-level PPFD variations of each individual tree within the canopy. Here an individual white oak, $Q$. alba tree within the forest stand is used to illustrate the changes (Fig. 8). At 10 year, when succession just started from bare ground, the white oak tree is still small and shaded by other trees (as indicated by the leaf area and PPFD in Fig.8a,b), which results in an almost linear decline of sunlit leaf area fraction (Fig.8a) and light extinction within the canopy (Fig.8b). By contrast, at 300 year the white oak (Q.alba) tree has grown much bigger and become canopy dominant (as indicated by the leaf area of $>4 \mathrm{~m}^{2}$ $\mathrm{m}^{-2}$ and above-canopy PPFD of nearly $600 \mathrm{umol} \mathrm{m}^{-2} \mathrm{~s}^{-1}$ ). At this point the sunlit leaf area proportion (Fig.8c) and sunlit and shaded leaf level PPFD exponentially decline within the canopy (Fig.8d).

When the American Chestnut was included (i.e., 'Pre-blight'), the isoprene emission followed similar successional dynamics, but the magnitude is much lower than the 'Present' forest (Fig.6a). At a later successional stage (300-500 year), the 'Pre-blight' forest isoprene emission was lower than the 'Present' forest by as much as $50 \%$. This is mostly from isoprene-emitting species in the 'Pre-blight' forest being much less common than in the 'Present' forest (Fig. 6b). The presence of American Chestnut significantly suppresses the growth and dominance of 
isoprene-emitting species (mostly Quercus spp.) in the pre-blight forest, as shown in Fig.2. These results are congruent with the hypothesis that the Chestnut blight increased the dominance of Quercus spp. and isoprene emissions (Lerdau et al., 1997).

\subsection{Discussion}

\subsubsection{Forest compositional dynamics simulation in southeastern United States}

The simulated successional changes resemble expected changes in forest composition, basal area, and stem density in the southeastern United States. The model's reconstruction of historical forest composition with American Chestnut also reasonably reproduced the historical forest compositional change in the eastern United States caused by the Chestnut Blight. These results suggest that UVAFME-VOC v1.0 is able to simulate the dynamic changes of secondary temperate deciduous forests in the southeastern United States. This motivates applications of this model to simulate the temperate forest dynamics in the southeastern United States in response to anthropogenic disturbances [e.g., impacts of pollutant ozone on forest diversity change by Wang et al. (2016)].

As is often the case, more detailed model tests are limited by the lack of detailed long-term (century time-scale) forest records with the associated weather records. In addition, the forests in the eastern United States regenerated from farmlands that were abandoned after disturbance by European colonists (McEwan et al., 2011). However, it is seldom a simple succession process because of human disturbances and climate change (McEwan et al., 2011; Oliver, 1980; Pederson et al., 2014). This is a common challenge in the evaluation not only of this specific model but of individual-based models in general (Harrison and Shugart, 1990; MacPherson and Gras, 2016). 


\subsubsection{VOCs emissions simulation in southeastern United States}

Results presented suggest that UVAFME-VOCs 1.0 can simulate forest isoprene emission capacity change in the eastern United States. Simulation by this model offered a clear dynamic pattern of isoprene emission capacity over long-term forest succession. This ecosystem behavior is totally determined by forest community change in terms of species composition and structure, indicating the essential role of forest systems themselves in determining VOCs emission capacity. Moreover, the application with this model - a test of the hypothesis of significantly enhanced isoprene emissions from the present forest compared with the forest prior to the Chestnut Blightclearly shows that ecosystem composition change plays an important role in determining ecosystems' VOCs emissions. This conclusion to some extent is supported by the postulation from the current short-term field surveys or experimental studies (Purves et al., 2004; Valolahti et al., 2015). The current widely used global and regional vegetation VOCs emissions model frameworks, e.g., MEGAN (Guenther et al., 2006, 2012), could benefit from including this community dynamical perspective.

Clearly, uncertainties still exist. First, long-term empirical data on VOCs emissions dynamics following ecosystem successional development are rare. Very recently, a simple, stable, and affordable method toward ecosystem-level long-term VOCs flux measurements was proposed (Rinne et al., 2016), potentially providing long-term data to better evaluate this model. Second, algorithms used in this current version of model for simulating light- and temperature-induced variations can be further improved (Guenther et al., 2009; Sharkey et al., 1999). Other factors influencing VOCs production, e.g., drought, nitrogen deposition, and $\mathrm{CO}_{2}$ elevation, could be useful future additions, as would consideration of VOCs chemistry within the stand canopy. 
Certainly, the latter has been suggested to be important in quantification of actual forest VOCs emissions capacity (Bryan et al., 2015; Fuentes et al., 2000).

\subsubsection{Generality and implications of UVAFME-VOC}

We did not fine-tune model parameters to meet the field observation. Rather, general silvical properties and standard VOCs emission rate of the North America temperate tree species were used to implement the simulation. Although the evaluation of performance of this model was currently limited to the temperate deciduous forest in the southeastern United States, it could apply to other forests around the world. Individual-based gap models have been extensively verified, validated, and applied to simulate local-, landscape-, and regional-level forest dynamics in many environments (Shugart and Woodward, 2011). With the recent technical advances in computer and remote-sensing infrastructures, a large-scale testing of individual-based forest models has become feasible (Shugart et al., 2015). Additionally, although this model currently only introduces the isoprene emission simulation, it provides a convenient framework to conduct simulations on other species of VOCs (e.g., monoterpenes). This is facilitated by the accumulating and readily available species-specific emission data of various VOC species around the world (e.g., Geron et al., 2000).

This individual-based model can be a powerful tool in studying the VOCs emissions dynamics by integrating individual metabolism differences, community, and ecosystem ecology. These are potentially important contributions to the over half a century of research on vegetation VOCs emissions. Global change agents, including, for example, rising $\mathrm{CO}_{2}$ level, climate change, nitrogen deposition, ozone pollution, biotic invasions, altered disturbance regimes, and land-use change, have modified and will continue to modify ecosystems' composition and species diversity (Franklin et al., 2016). How these changes can affect vegetation VOCs emissions because of 
diversity change has only rarely been studied. For example, UVAFME-VOC v1.0 has been applied to study forest-isoprene-ozone feedbacks (Wang et al., 2016). A positive feedback loop between tropospheric ozone pollution and forests is simulated, which is mediated by favoring isoprene-emitting species because of their overall stronger resistance to ozone's oxidative pressure (Wang et al., 2016). This feedback mechanism could maintain the ecosystem-level carbon fixation capacity in the face of increased ozone in the eastern United States (Wang et al., 2016).

Further, the sort of massive community-scale changes seen in the case of American Chestnut because of Chestnut Blight invasion are not uncommon in mid- and high-latitude forest systems. For instance, eastern hemlocks (Tsuga Canadensis), oaks (Quercus spp.), and other species have also been heavily impacted by pathogens and/or herbivores in North America (Orwig et al., 2002; Rizzo and Garbelloto, 2003). In particular, a similar change is ongoing in both North America and Europe as the emerald ash borer (Agrilus planipennis) and, in Europe, the chalara fungus, (Hymenoscyphus fraxineus) wreak havoc on ash (Fraxinus spp.) populations (Poland et al., 2014; Thomas, 2016). Fraxinus does not emit large amounts of VOCs, while several of the species likely to replace it, e.g., Populus spp. in higher latitudes and Quercus spp. in lower ones, are large emitters of isoprene (Harley et al., 1999; Lerdau and Gray, 2003). Any replacement of Fraxinus by these genera will likely lead to large increases in system-level VOCs emissions and thus a large change in the troposphere's redox potential. Fraxinus also is more sensitive to ozone damage than Populus and Quercus (Landolt et al., 2000), which creates the possibility for a positive feedback where increases in these two genera lead to higher levels of VOCs emissions to the atmosphere and higher ozone concentrations, which, in turn, can accelerate the decline of Fraxinus. Estimating the extent, magnitude, and impacts of these changes requires a formal 
modeling approach that explicitly considers species identity, and the model developed here should be considered.

Therefore, individual-based model, UVAFME-VOC v1.0, should be applied in studying global environmental change effects on forest VOCs emissions and the complex mechanisms underlying climate change-air quality feedbacks mediated by the vegetation, in particular the role of forest composition dynamics in influencing ecosystem-scale VOCs emissions.

\subsection{Conclusion}

This work introduces the development, evaluation, and application of an individual-based forest VOCs emission model-UVAFME-VOC 1.0. With an explicit consideration of individual metabolic and functional differences and their interactions, this model simulates forest succession impacts on isoprene emissions in the southeastern United States. Results of this model imply that the disappearance of American Chestnut as a canopy tree from the Chestnut Blight resulted in a dominance of oak trees (Quercus spp.) and increased isoprene emissions in today's forests. UVAFME-VOC provides a flexible framework to simulate not only isoprene but also other phytogenic volatile compounds from forests, and as an experimental system, could see widespread applications in studying feedbacks among global change, forest diversity, and atmospheric chemistry.

\subsection{References}

Atkinson, R., Arey J., 2003. Gas-phase tropospheric chemistry of biogenic volatile organic compounds: a review. Atmos. Environ. 37, 197-219. 
Arneth, A., Niinemets Ü., Pressley S., Bäck J., Hari P., Karl T., Noe S., Prentice I.C., Serça D., Hickler T., Wolf A., Smith B., 2007. Process-based estimates of terrestrial ecosystem isoprene emissions: incorporating the effects of a direct $\mathrm{CO}_{2}$-isoprene interaction. Atmos. Chem. Phys. 7, 31-53.

Bormann, F. H., Likens, G. E., 1979. Catastrophic disturbance and the steady state in northern hardwood forests. Am. Scientist 67, 660-669.

Braun, E.L., 1950. Deciduous forests of eastern North America. Blakiston, Philadelphia.

Bryan, A.M., Cheng S.J., Ashworth K., Guenther A.B., Hardiman B.S., Bohrer G., Steiner A.L., 2015. Forest-atmosphere BVOC exchange in diverse and structurally complex canopies: 1-D modeling of a mid-successional forest in northern Michigan. Atmos. Environ. 120, 217-226.

Bugmann, H., 2001a. A review of forest gap models. Clim. Change 51, 259-305.

Bugmann, H., Fischlin A., Kienast F., 1996. Model convergence and state variable update in forest gap models. Ecol. Model. 89, 197-208.

Bugmann, H. K., Wullschleger, S. D., Price, D. T., Ogle, K., Clark, D. F., Solomon, A. M., 2001b. Comparing the performance of forest gap models in North America. Clim. Change 51, 349388.

Fowells, H.A., 1965. Silvics of forest trees of the United States. Agric. Handb. US Dep. Agric. 271

Franklin, J., Serra-Diaz, J. M., Syphard, A. D., Regan, H. M., 2016. Global change and terrestrial plant community dynamics. Proc. Natl. Acad. Sci. U. S. A. 201519911. 
Fuentes, J.D., Gu, L., Lerdau, M., Atkinson, R., Baldocchi, D., Bottenheim, J.W., Ciccioli, P., Lamb, B., Geron, C., Guenther, A. and Sharkey, T.D., 2000. Biogenic hydrocarbons in the atmospheric boundary layer: a review. Bull. Amer. Meteorol. Soc. 81,1537-1575.

Geron, C., Harley P., Guenther A., 2001. Isoprene emission capacity for US tree species. Atmos. Environ. 35, 3341-3352.

Geron, C., Rasmussen R., R Arnts R., Guenther A., 2000. A review and synthesis of monoterpene speciation from forests in the United States. Atmos. Environ. 34, 1761-1781.

Goudriaan, J., Van Laar H.H., 1994. Modelling potential crop growth processes: textbook with exercises. Springer, Netherlands.

Grigal, D. F., Goldstein, R. A., 1971. An integrated ordination-classification analysis of an intensively sampled oak-hickory forest. J. Ecol. 481-492.

Grimm, V., Berger U., Bastiansen F., Eliassen S., Ginot V., Giske J., Goss-Custard J., Grand T., Heinz S.K. ,Huse G., 2006. A standard protocol for describing individual-based and agentbased models. Eco. Model. 198, 115-126.

Grimm, V., Revilla E., Berger U., Jeltsch F., Mooij W.M., Railsback S.F., Thulke H.-H., Weiner J., Wiegand T., DeAngelis D.L., 2005. Pattern-oriented modeling of agent-based complex systems: lessons from ecology. Science 310, 987-991.

Guenther, A., Greenberg J., Harley P., Helmig D., Klinger L., Vierling L., Zimmerman P., Geron C., 1996. Leaf, branch, stand and landscape scale measurements of volatile organic compound fluxes from US woodlands. Tree Physiol. 16, 17-24.

Guenther, A., Hewitt C.N., Erickson D., Fall R., Geron C., Graedel T., Harley P., Klinger L., Lerdau M., McKay W., 1995. A global model of natural volatile organic compound emissions. J. Geophys. Res. 100, 8873-8892. 
Guenther, A., Karl T., Harley P., Wiedinmyer C., Palmer P.I., Geron C., 2006. Estimates of global terrestrial isoprene emissions using MEGAN, Model of Emissions of Gases and Aerosols from Nature. Atmos. Chem. Phys. 6, 3181-3210.

Guenther, A.B., Jiang X., Heald C.L., Sakulyanontvittaya T., Duhl T., Emmons L.K., Wang X., 2012. The Model of Emissions of Gases and Aerosols from Nature version 2.1, MEGAN2.1: an extended and updated framework for modeling biogenic emissions. Geosci. Model Dev. 5, 1471-1492.

Haagen-Smit, A., Fox M., 1954. Photochemical ozone formation with hydrocarbons and automobile exhaust. Air Repair 4, 105-136.

Hardin, J.W., Leopold D.J., White F.M., 2001. Harlow and Harrar's textbook of dendrology. McGraw-Hill ,New York.

Harley, P. C., Monson, R. K.,, Lerdau, M. T., 1999. Ecological and evolutionary aspects of isoprene emission from plants. Oecologia 118, 109-123.

Harrison, E., Shugart H., 1990. Evaluating performance of an Appalachian oak forest dynamics model. Vegetatio 86, 1-13.

Jacob, D. J., Wofsy, S. C., 1988. Photochemistry of biogenic emissions over the Amazon forest. J. Geophys. Res. Atmos. 93, 1477-1486.

Johnson, D.W., Van Hook R.I., 2012. Analysis of biogeochemical cycling processes in Walker Branch Watershed. Springer Verlag, New York.

Keever, C. 1975. Present composition of some stands of the former oak-chestnut forest in the southern Blue Ridge Mountains. Ecology 33, 44-54.

Lafon, C. W., Huston, M. A.,, Horn, S. P., 2000. Effects of agricultural soil loss on forest succession rates and tree diversity in east Tennessee. Oikos 90, 431-441. 
Landolt, W., Bühlmann, U., Bleuler, P., \& Bucher, J. B., 2000. Ozone exposure-response relationships for biomass and root/shoot ratio of beech (Fagus sylvatica), ash (Fraxinus excelsior), Norway spruce (Picea abies) and Scots pine (Pinus sylvestris). Environ. Pollut. $109,473-478$.

Lerdau, M. 2007. A positive feedback with negative consequences. Science 316, 212-213.

Lerdau, M., Gray D., 2003. Ecology and evolution of light-dependent and light-independent phytogenic volatile organic carbon. New Phytol. 157, 199-211.

Lerdau, M., Guenther A., Monson R., 1997. Plant production and emission of volatile organic compounds. Bioscience 47, 373-383.

Lerdau, M., Slobodkin L., 2002. Trace gas emissions and species-dependent ecosystem services. Trends Ecol. Evol. 17, 309-312.

Loreto, F., Fineschi S., 2014. Reconciling functions and evolution of isoprene emission in higher plants. New Phytol. 206, 578-572

MacPherson, B., Gras R., 2016. Individual-based ecological models: Adjunctive tools or experimental systems? Eco. Model. 323, 106-114.

McEwan, R.W., Dyer J.M., Pederson N., 2011. Multiple interacting ecosystem drivers: toward an encompassing hypothesis of oak forest dynamics across eastern North America. Ecography $34,244-256$.

Monson, R.K., Jones R.T., Rosenstiel T.N., Schnitzler J. P., 2013. Why only some plants emit isoprene. Plant Cell Environ. 36, 503-516.

Monson, R.K., Lerdau M.T., Sharkey T.D., Schimel D.S., Fall R., 1995. Biological aspects of constructing volatile organic compound emission inventories. Atmos. Environ. 29, 29893002. 
Nelson, T.C. 1955. Chestnut replacement in the southern highlands. Ecology 36, 352-353.

Niinemets, Ü., Kännaste, A.,, Copolovici, L., 2013. Quantitative patterns between plant volatile emissions induced by biotic stresses and the degree of damage. Front. Plant Sci. 4, 262.

Oliver C.D., 1980. Forest development in North America following major disturbances. For. Ecol. Manage. 3, 153-168.

Orwig, D. A., Foster, D. R.,, Mausel, D. L., 2002. Landscape patterns of hemlock decline in New England due to the introduced hemlock woolly adelgid. J. Biogeogr. 29, 1475-1487.

Pederson, N., D'Amato A.W., Dyer J.M., Foster D.R., Goldblum D., Hart J.L., Hessl A.E., Iverson L.R., Jackson S.T., Martin-Benito D., McCarthy B.C., McEwan R.W., Mladenoff D.J., Parker A.J., Shuman B., Williams J.W., 2014. Climate remains an important driver of postEuropean vegetation change in the eastern United States. Glob. Change Biol. 21, 21052110.

Pierce, T.E., Waldruff P.S., 1991. PC-BEIS: a personal computer version of the biogenic emissions inventory system. J. Air Waste Manage. Assoc. 41, 937-941.

Poland, T. M., Chen, Y., Koch, J.,, Pureswaran, D., 2015. Review of the emerald ash borer, Coleoptera: Buprestidae, life history, mating behaviours, host plant selection, and host resistance. Can. Entomol. 147, 252-262.

Purves, D., Pacala S., 2008. Predictive models of forest dynamics. Science 320, 1452-1453.

Purves, D.W., Caspersen J.P., Moorcroft P.R., Hurtt G.C., Pacala S.W., 2004. Human-induced changes in US biogenic volatile organic compound emissions: evidence from long-term forest inventory data. Glob. Change Biol. 10, 1737-1755.

Rinne, J., Karl, T. and Guenther, A., 2016. Simple, stable, and affordable: Towards long-term ecosystem scale flux measurements of VOCs. Atmos. Environ. 131, 225-227. 
Rizzo, D. M., Garbelotto, M., 2003. Sudden oak death: endangering California and Oregon forest ecosystems. Front. Ecol. Environ. 1, 197-204.

Sanderson, M.G., 2003. Effect of climate change on isoprene emissions and surface ozone levels. Geophys. Res. Lett. 30, 18

Scheiter, S., Langan L., Higgins S.I., 2013. Next-generation dynamic global vegetation models: learning from community ecology. New Phytol. 198, 957-969.

Shugart, H.H., 1984. A theory of forest dynamics. The ecological implications of forest succession models. Springer Verlag, New York.

Shugart, H.H., Asner G.P., Fischer R., Huth A., Knapp N., Le Toan T., Shuman J.K., 2015. Computer and remote-sensing infrastructure to enhance large-scale testing of individualbased forest models. Front. Ecol. Environ. 13, 503-511.

Shugart, H.H., West D.C., 1977. Development of an Appalachian deciduous forest succession model and its application to assessment of the impact of the chestnut blight. J. Environ. Manage. 5, 161-179.

Shugart, H.H., West D.C., 1980 Forest succession models. BioScience 30, 308-313.

Shugart, H.H., Woodward F.I., 2011. Global change and the terrestrial biosphere: achievements and challenges. John Wiley \& Sons, UK

Sitch, S., Smith, B., Prentice, I. C., Arneth, A., Bondeau, A., Cramer, W., Kaplan, J. O., Levis, S., Lucht, W., Sykes, M. T., Thonicke, K. and Venevsky, S., 2003. Evaluation of ecosystem dynamics, plant geography and terrestrial carbon cycling in the LPJ dynamic global vegetation model. Glob. Change Biol. 9, 161-185.

Thomas, P. A., 2016. Biological Flora of the British Isles: Fraxinus excelsior. J. Ecol. 104, 11581209. 
Valolahti, H., Kivimaenpaa M., Faubert P., Michelsen A., Rinnan R., 2015. Climate changeinduced vegetation change as a driver of increased subarctic biogenic volatile organic compound emissions. Glob. Change Biol. 21, 3478-3488

Vickers, C. E., Gershenzon, J., Lerdau, M. T., Loreto, F., 2009. A unified mechanism of action for volatile isoprenoids in plant abiotic stress. Nature Chem. Biol. 5, 283-291.

Wang, B., Shugart H.H., Shuman J.K., Lerdau M.T., 2016. Forests and ozone: productivity, carbon storage, and feedbacks. Sci Rep 6, 22133.

Weinstein, D.A., 1982. The long-term nutrient retention properties of forest ecosystems: a simulation investigation. University of Tennessee.

Went, F.W., 1960. Blue hazes in the atmosphere. Nature 187, 641-643.

Woods, F.W. and R.D. Shanks. 1959. Natural replacement of chestnut by other species in the Great Smoky Maintains National Park. Ecology 40, 349-361.

Yan, X., Shugart H., 2005. FAREAST: a forest gap model to simulate dynamics and patterns of eastern Eurasian forests. J. Biogeogr. 32, 1641-1658.

Zanne, A.E., Lopez-Gonzalez G., Coomes D.A., Ilic J., Jansen S., Lewis S.L., Miller R.B., Swenson N.G., Wiemann M.C., Chave J., 2009. Data from: Towards a worldwide wood economics spectrum. Dryad Data Repository. http://dx.doi.org/10.5061/dryad.234.

Zimmerman, P. R., 1979. Testing of hydrocarbon emissions from vegetation, leaf litter and aquatic surfaces, and development of a methodology for compiling biogenic emission inventories. Office of Air Quality Planning and Standards. 


\subsection{Supplementary matrials}

\subsubsection{Appendix A}

\section{Dynamics of forest carbon cycling processes}

This model also simulated two major processes determining the carbon balance of forest systems, NPP (net primary production) and SR (soil respiration) (Fig.A.1). The forest NPP increased sharply to a plateau of around $8 \mathrm{tC} \mathrm{ha}^{-1}$ year $^{-1}$ in about 50 years, after which it declined and eventually stabilized at around $6 \mathrm{tC} \mathrm{ha}^{-1} \mathrm{year}^{-1}$. The soil respiration followed a similar trajectory, increasing to about $7 \mathrm{tC} \mathrm{ha}^{-1}$ year $^{-1}$ at approximate year 100, and then declining and remaining at a level that was lower than the NPP. Therefore, the net ecosystem productivity (NEP) remained positive (though approaching nearly zero) during the 500-year simulation, which enabled the accumulation of forest carbon (Fig. A. 2). These simulated results were compared with rare independent field observation data. Empirical information gave a range of NPP from 3.8 to 7.9 tC $\mathrm{ha}^{-1} \mathrm{year}^{-1}$ at around the year 40, which overlapped the simulation (Huston et al., 2013). Further, the soil respiration observation with a value of $6.1 \mathrm{tC} \mathrm{ha}^{-1} \mathrm{year}^{-1}$ matched the simulation as well. These comparisons with field observations suggest that this model captures the magnitude of forest system carbon cycling processes including NPP and SR. Moreover, the long-term dynamics of NPP, SR, and NEP are congruent with the hypothesis proposed by Odum (1969) and with experimental studies (e.g., Gough et al. 2008; Tang et al. 2014). The positive NEP in this work suggests the secondary forests in southeastern US act as a carbon sink. This is congruent with other studies showing the North America forests act as a carbon sink (Goodale et al. 2002; Pan et al. 2011). All these evidence indicate UVAFME-VOC 1.0 demonstrates capability of linking the carbon biogeochemical processes with forest dynamics in the southeastern US. 


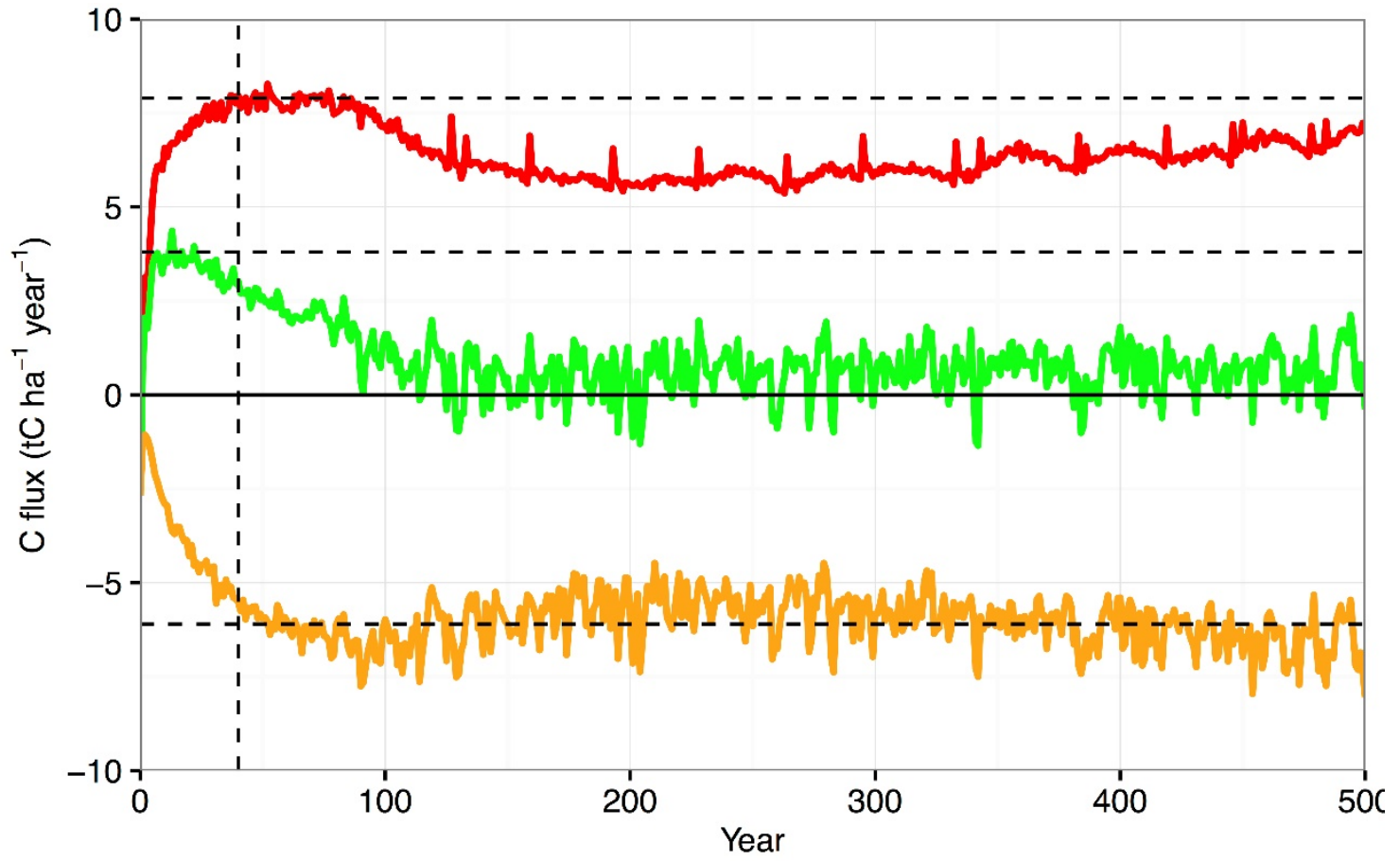

Fig. A.1 Simulated carbon cycling processes-net primary productivity (NPP), soil respiration (SR), and net ecosystem productivity (NEP)—over 500-year simulation. Dotted lines denote empirical values of NPP and SR observed at around 40 year from Huston et al. (2013). 


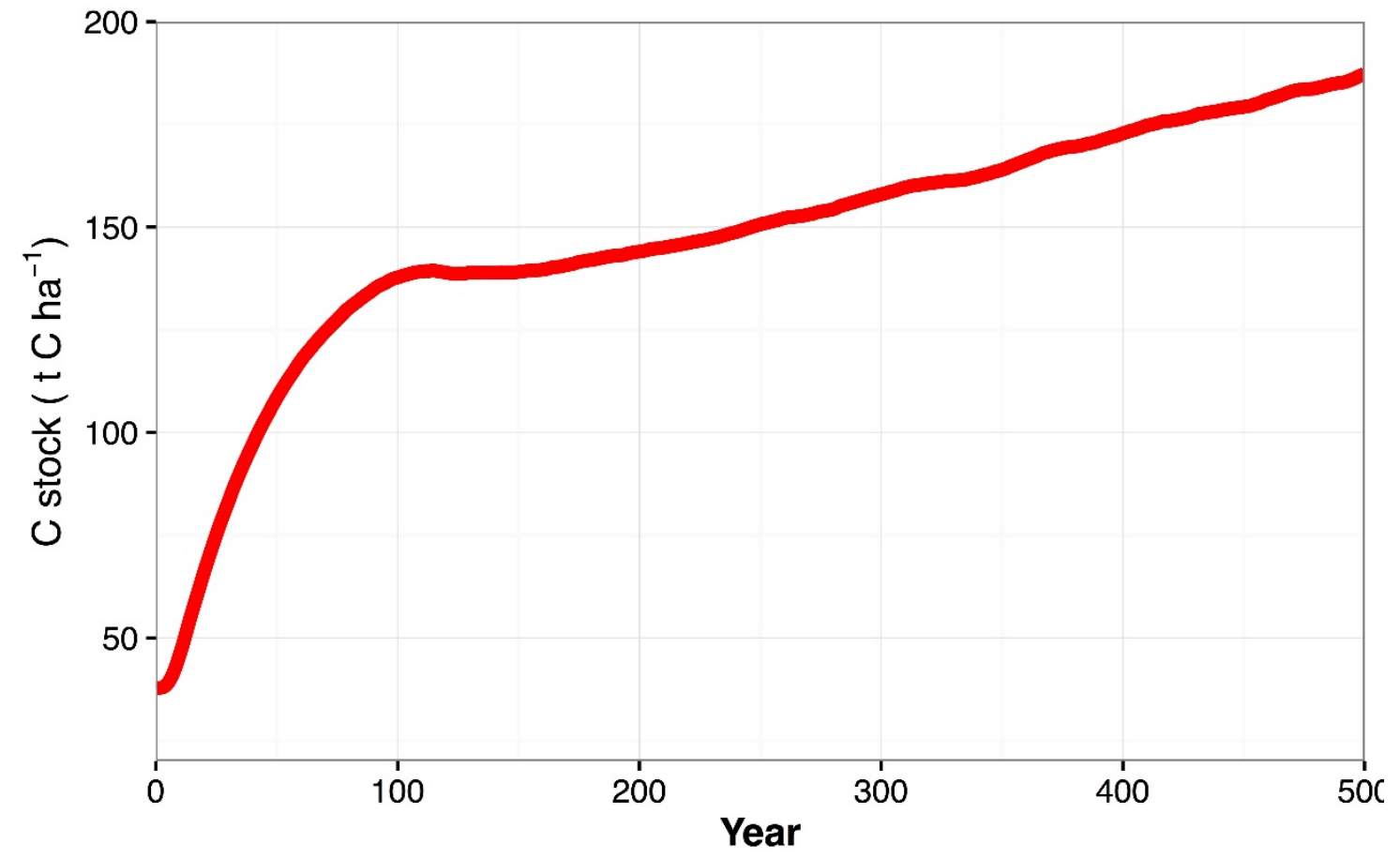

Fig. A.2 Total carbon stock (tC ha-1) dynamics of the forest system over the 500-year simulation. 

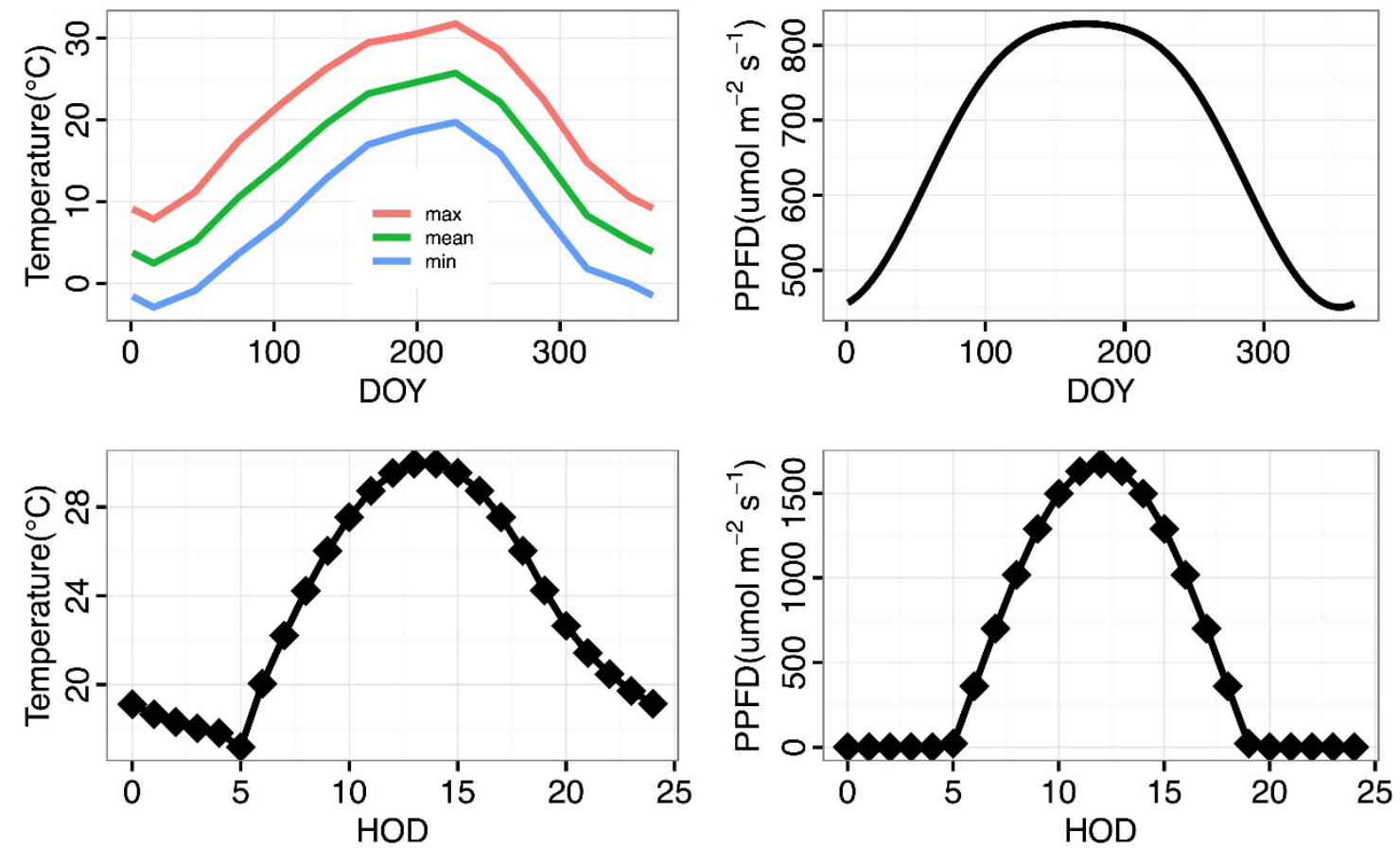

Fig.A.3 Temperature and PPFD dynamics at daily and diurnal scales throughout the 500year simulation. 


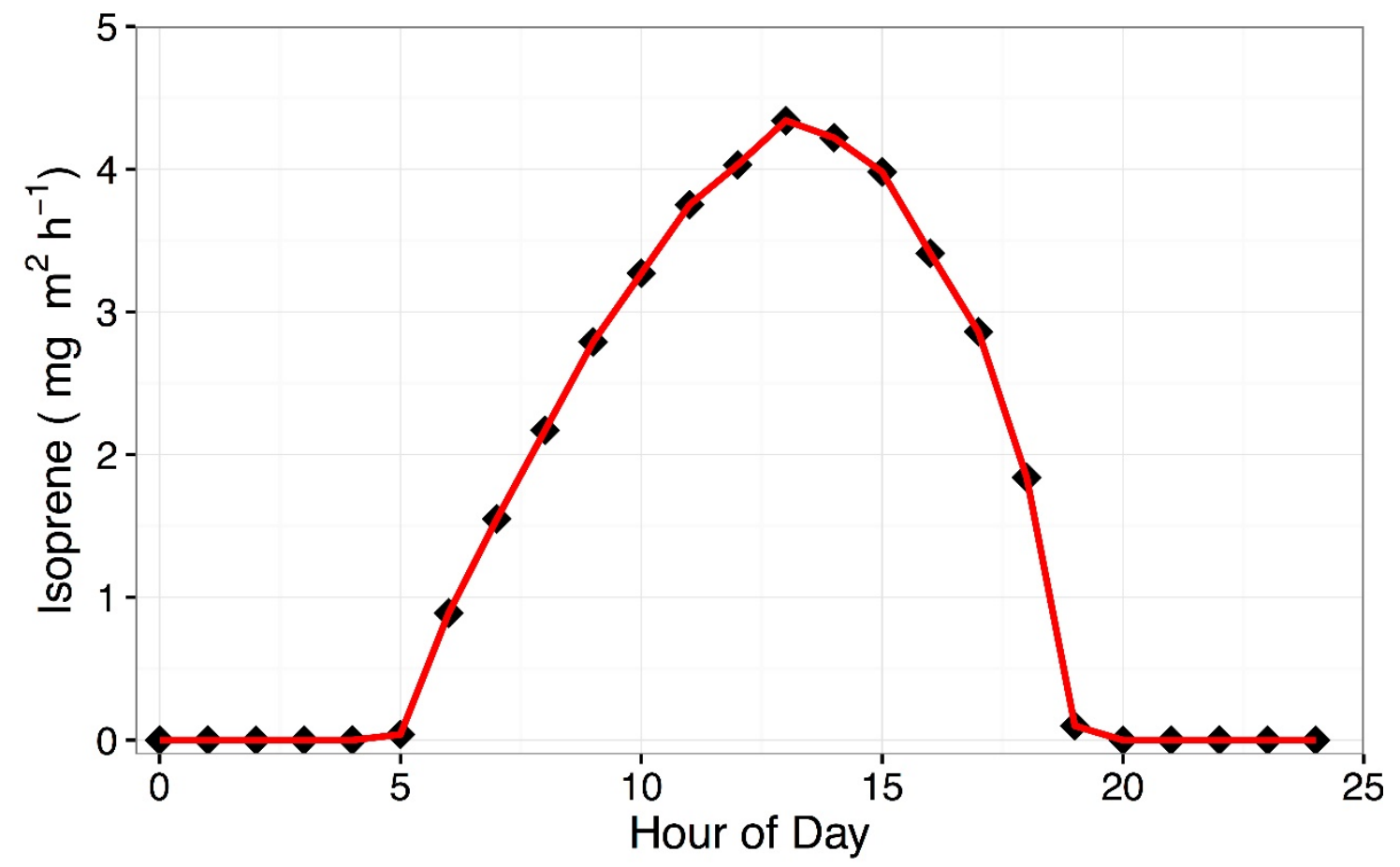

Fig.A.4 Diurnal isoprene emission dynamics from the simulated present forest at day 201 of the 300 year. 


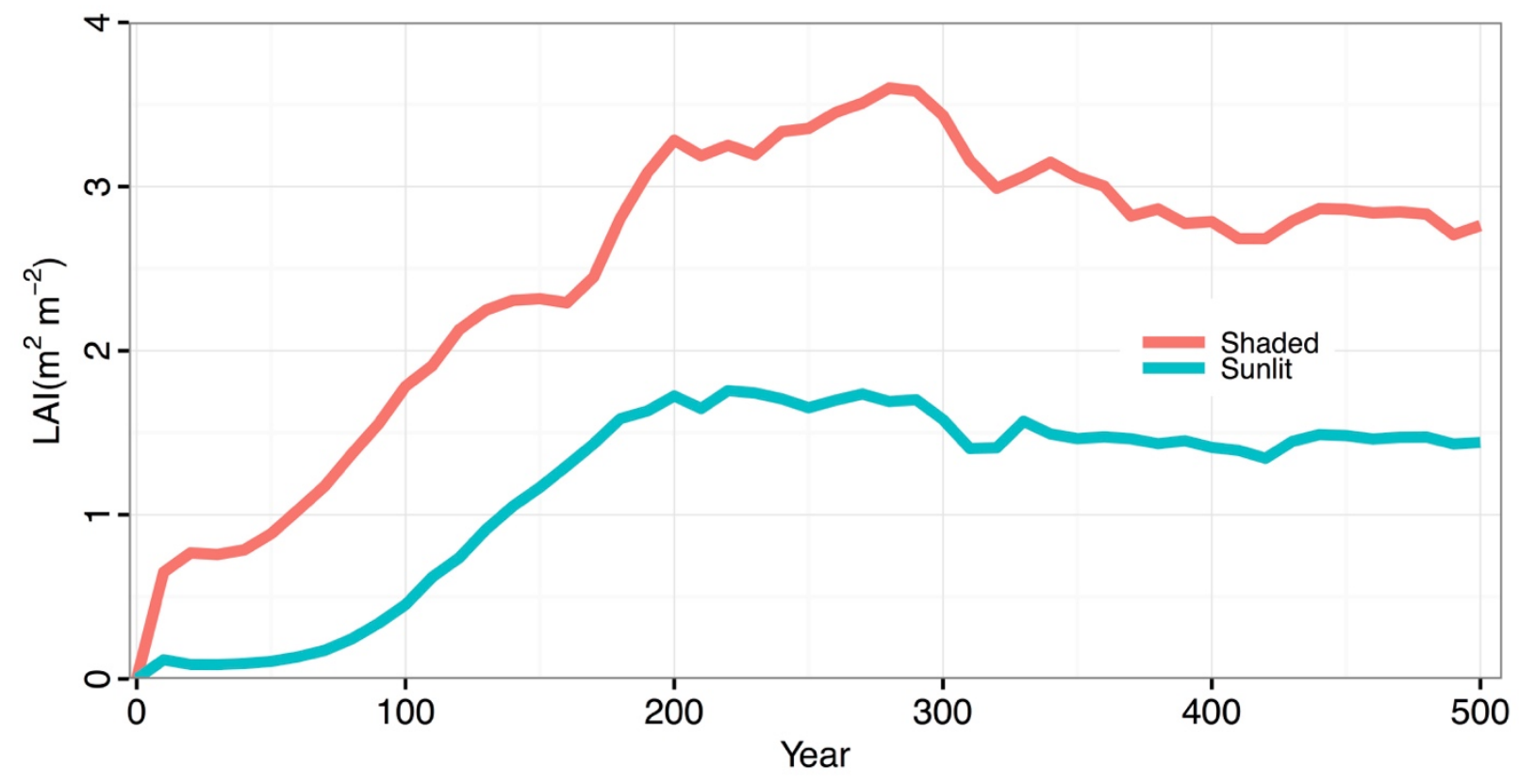

Fig.A.5 Sunlit and shaded leaf area changes over the 500-year simulation at day 201 of each year. 


\subsubsection{Full model documentation}

\section{Model Structure}

UVAFME-VOC is an individual-based forest volatile organic compounds emission model build up on the state-of-the-art forest gap model UVAFME (University of Virginia Forest Model Enhanced) which can be traced back to the FORET gap model developed by Shugart and West in 1977 (Shugart and West 1977). UVAFME-VOC is capable of simulating forest compositional and structural dynamics at a yearly time step by explicitly simulate each individual tree's growth, mortality, and regeneration, competition among these individuals, and emergent system behaviors (e.g., carbon productivity and VOCs emissions) under the constraints of light, temperature, and soil water and nutrition on a range of spatial scales over long time periods. A simplified model structure is shown in Fig.1. Inputs required include species-specific parameters (primarily silvicultural traits quantifying tree geometry, growth, mortality, establishment, and responses to environment), site-specific information, and climate of precipitation and temperature. Major components of this model include modules of growth, mortality, and regeneration, as well as soil hydrology and biogeochemistry and climate. Outputs of tree number categorized into groups of different sizes, species-specific and total basal area and biomass $(\mathrm{C} \& \mathrm{~N})$, productivity, and soil respiration are usually used. 


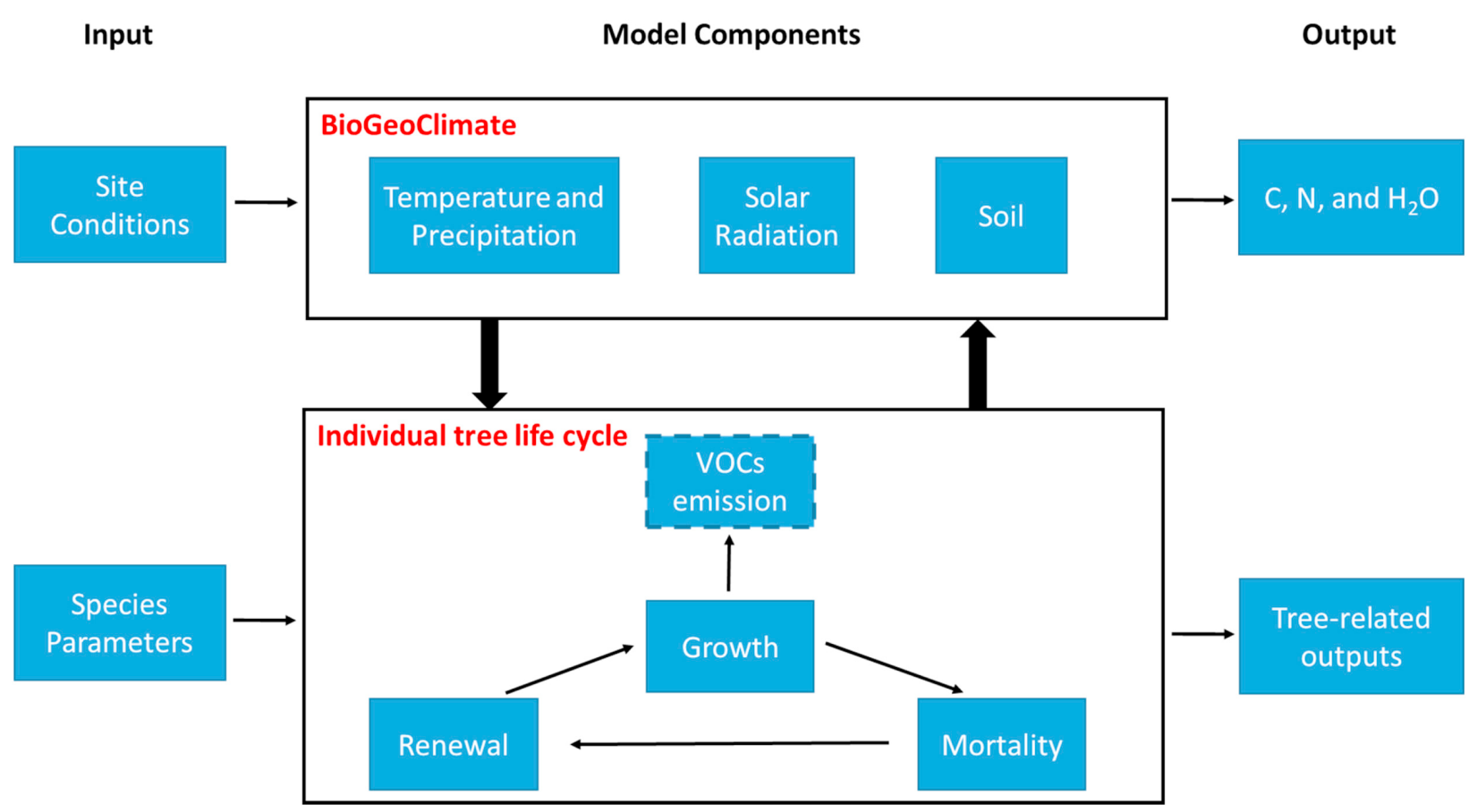

Fig.1 Schematic of model structure in terms of major model components and inputs and outputs.

\section{Individual tree structure}

In UVAFME-VOC (and almost all other individual-based forest gap models), the geometry of an individual tree follows the assumptions as follows: The stem bole shape is assumed to be a simple cone, the branch volume above the clear branch bole height $(\mathrm{CH})$ is assumed to be a cubic cone, the foliage is assumed uniformly distributing across the branch, the lateral root volume is assumed to be half of the branch amount, and the primary root volume is computed by extending the cone used to compute bole volume to the depth of the soil rooting zone. Moreover, these structural units are quantitatively linked by allometric relationships. Tree height $(\mathrm{H})$ is a function 
of the diameter at the breast height (DBH), which are used to calculate diameter at canopy height (DCH), while leaf area (LAI) is a function of DCH. See formulations in the following section.

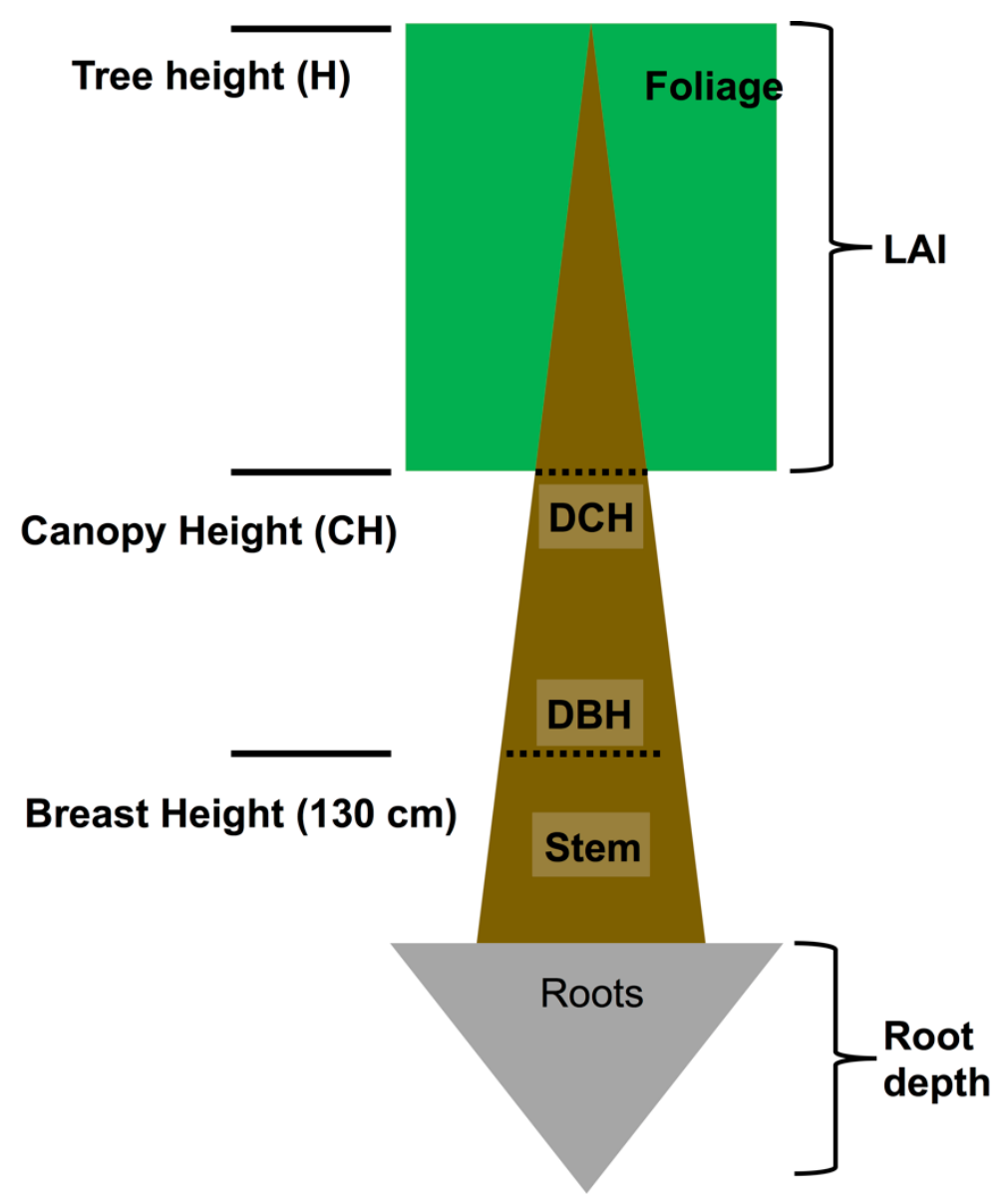

Fig.2 Individual tree geometric structure simulated in UVAFME.

\section{Simulated Processes}

\subsection{Growth}

UVAFME defines an individual tree's growth $(\mathrm{G})$ as an increment of the diameter at the breast height $(130 \mathrm{~cm})$, i.e. DBH $(\mathrm{cm})$, at a yearly time step, which is computed by multiplying the 
optimal growth (Gopt) by scalars of available light, temperature, nutrient, and soil moisture, following the FORSKA model (Leemans and Prentice, 1989):

$$
\begin{gathered}
G=G_{\text {opt }} * f_{L} f_{T} f_{D} f_{F} f_{N} \\
G_{o p t}=g * D B H *\left\{\frac{1.0-\frac{D B H * H}{D B H_{m} * H_{m}}}{2.0 * H+s * D B H * e^{\left(\frac{-s * D B H}{H m-1.3}\right)}}\right\}
\end{gathered}
$$

where $\mathrm{g}\left(\mathrm{cm} \mathrm{yr}^{-1}\right)$ is a species-specific scalar parameter of tree growth, $\mathbf{s}\left(\mathrm{m} \mathrm{cm}^{-1}\right)$ is speciesspecific parameter representing the slope of the linear regression between DBH and $\mathrm{H}$ at an initial height stage, $\mathrm{H}(\mathrm{m})$ is tree height, $\mathrm{DBHm}(\mathrm{cm})$ and $\mathrm{Hm}(\mathrm{m})$ is species-specific maximum tree diameter and maximum tree height, respectively, required as input, and $f_{L}, f_{T}, f_{D}, f_{F}$, and $f_{N}$ is light scalar, temperature scalar, drought scalar, flood scalar, and nutrient scalar, respectively. Tree height $(\mathrm{H})$ is calculated based on the allometric relationship between height and diameter using the formulation from the FORSKA model (Leemans and Prentice, 1989):

$$
H=1.3+(H m-1.3) *\left\{1.0-e^{\left(\frac{-s * D B H}{H m-1.3}\right)}\right\}
$$

The parameter $g$ is calculated following (Shugart 1984):

$$
\begin{aligned}
g=\frac{4 H m}{A G E m} *\{ & \ln \{2(2 * D B H m-1)\} \\
& +\frac{\alpha}{2} \ln \left(\frac{9 / 4+\alpha / 2}{4 D B H m^{2}+2 \alpha D B H m-\alpha}\right) \\
& \left.-\left(\frac{\alpha+\alpha^{2} / 2}{\sqrt{\alpha^{2}+4 \alpha}} * \ln \left\{\frac{\left(3+\alpha-\sqrt{\alpha^{2}+4 \alpha}\right)\left(4 D B H m+\alpha+\sqrt{\alpha^{2}+4 \alpha}\right)}{\left(3+\alpha+\sqrt{\alpha^{2}+4 \alpha}\right)\left(4 D B H m+\alpha-\sqrt{\alpha^{2}+4 \alpha}\right)}\right\}\right)\right\}
\end{aligned}
$$


The parameter $s$ is estimated by fitting the FORSKA H(DBH) formulation as listed above with the data calculated from FORET H(DBH), which is calculable because no similar parameter with $\mathrm{s}$ is required (Shugart 1984).

\subsubsection{Light scalar $\left(f_{L}\right)$}

Light scalar is calculated as:

$$
f_{L}(H)=c_{1} *\left\{1-e^{\left[-C_{2} *\left(I(H)-C_{3}\right)\right]}\right\}
$$

where $c_{1}, c_{2}$, and $c_{3}$ are species-specific parameters determining the shape of the productivity-light relationship, among which $c_{1}$ and $c_{2}$ involve the asymptote and increase of the productivity-light curve and $c_{3}$ is the shade-tolerance parameter from the ZELIG model (Urban et al., 1991) corresponding to the light compensation point. $\mathrm{C}_{1}$ is one value of 1.01, 1.04, 1.11, 1.24, and 1.49; $\mathrm{C}_{2}$ of $4.62,3.44,2.52,1.78,1.23$; and $\mathrm{C}_{3}$ of $0.05,0.06,0.07,0.08$, and 0.09 . The specific values of these three parameters correspond to species shade tolerance level from 1-5 (denoted by $\mathbf{s}$ and required as a species-specific, of course, input, and the lower level represents the stronger tolerance). $\mathrm{I}(\mathrm{H})$ denotes the available light at height $\mathrm{H}$ and is computed according to the LambertBeer law (Monsi and Saeki 1953):

$$
I(H)=I(0) * e^{-k L A I(H)}
$$

where $\mathrm{I}(0)$ is light intensity right above the tree, $\mathrm{k}$ is light extinction efficient $(0.4)$, and $L A I(H)$ is the integrated leaf area above the height $\mathrm{H}$. To calculate the available light for each individual tree, we first have to obtain the value of leaf area. One major assumption concerning leaf area is its 
uniform distribution across branch above the clear branch bole height $(\mathrm{CH}, \mathrm{m})$. Leaf area (LAI) is calculated according to the 'pipe model' proposed by Shinozaki et al. (1964):

$$
L A I=D_{L} * D C H^{2}
$$

where $\mathrm{D}_{\mathrm{L}}$ is a species-specific constant quantifying the relation between leaf area and squared diameter at the clear branch bole, and $\mathrm{DCH}(\mathrm{cm})$ is the stem diameter at $\mathrm{CH}$ and calculated following:

$$
D C H=D B H *\left(\frac{H-C H}{H-1.3}\right)
$$

Evergreen and deciduous species within the same physiological shade-tolerance class have different competition abilities for regeneration and growth, related to the utilization of light by evergreen tree species in the period before deciduous leaf expansion (Yan \& Zhao, 1995a,b). Based on Yan \& Zhao (1995a, b), UVAFME allows deciduous tree species to shade sub-ordinate evergreen tree species for $80 \%$ of the length of the growing season.

\subsubsection{Temperature scalar $\left(f_{T}\right)$}

Temperature scalar is calculated as:

$$
\begin{gathered}
f_{T}(d d)=\left(\frac{x-d d \min }{d d o p t-d d \min }\right)^{a}\left(\frac{d d \max -x}{d d \max -d d o p t}\right)^{b} \\
a=\frac{d d o p t-d d \min }{d d \max -d d \min } \\
b=\frac{d d \max -d d o p t}{d d \max -d d \min }
\end{gathered}
$$


where $\mathrm{dd}\left({ }^{\circ} \mathrm{C}\right)$ is effective growing degree-days, and $d d \max , d d m i n$, and $d d o p t$ are observed species-specific maximum, minimum, and optimum growing degree days, respectively. These growing degree-days are using a $5{ }^{\circ} \mathrm{C}$ base.

Note that an alternative algorithm of temperature scalar (an asymptotic curve rather than parabolic) has been proposed and used to account for the concern of high temperature-induced drought effects. The work by Bugmann and Solomon (2000) is referred to for details.

\subsubsection{Nutrient scalar $\left(f_{N}\right)$}

$$
\begin{gathered}
f_{N}(N V)=b_{1}+b_{2} * N V+b_{3} * N V^{2} \\
N V=\frac{N_{a v}}{N_{r q}}
\end{gathered}
$$

where $b 1, b 2$ and $b 3$ are species specific parameters determined by the species-specific nutrientlimitation tolerance level (i.e., input variable $\mathbf{n}$ ). from the $Z E L I G$ model of Urban et al. (1991). $N V$ is the ratio of nutrient supply ( $\mathrm{Nav}$, i.e., available nutrient, $\left.\mathrm{tN} \mathrm{ha}^{-1}\right)$ to potential maximum nutrient requirement $\left(\mathrm{Nrq}, \mathrm{tN} \mathrm{ha}{ }^{-1}\right)$.

Nitrogen requirement $(\mathrm{Nrq})$ is computed by:

$$
\begin{aligned}
N_{r q}=\sum \frac{\operatorname{wood}(D B H+d d)-\operatorname{wood}(D B H)}{W_{c / n}} \\
-\sum \frac{(\operatorname{leaf}(D C H+d d)-\operatorname{lea} f(D C H)) * \text { RATIO }}{L_{c / n}}
\end{aligned}
$$

where $\mathrm{Wc} / \mathrm{n}$ is wood biomass $\mathrm{C} / \mathrm{N}$ ratio, $\mathrm{Lc} / \mathrm{n}$ is the leaf $\mathrm{C} / \mathrm{N}$ ratio, $\mathrm{RATIO}$ is annual leaf and fine 
root renewal ratio, wood (DBH) is the wood biomass $\left(10^{3} \mathrm{~kg}\right.$ of C), leaf (DCH) is leaf and fine root biomass $\left(10^{3} \mathrm{~kg}\right.$ of $\left.\mathrm{C}\right)$, and, lastly, $d d$ denotes the $\mathrm{DBH}$ or $\mathrm{DCH}$ increment without nutrient limitation at an annual time step, which is calculated as:

$$
d d=\frac{d_{D B H}}{d_{t}} f_{L}(H) f_{T} f_{M}
$$

Available nitrogen (Nav) calculation is documented in section 3.6.3.

\subsubsection{Drought scalar $\left(f_{M}\right)$}

Drought scalar is calculated as:

$$
f_{M}(D)=\left\{\begin{array}{l}
\sqrt{\frac{D_{0}-D}{D_{O}}} ; \quad D<D_{0} \\
0 ; D \geq D_{0}
\end{array}\right.
$$

where $\mathrm{D}$ is relative drought days and $\mathrm{D}_{0}$ is a species-specific value dependent on the speciesspecific drought tolerance parameter, d. D is calculated during the growing season based on a simple three-layer bucket soil water model. Detailed methods are referred to the soil hydrology section. $\mathrm{D}_{0}$ is one value of $0.50,0.45,0.35,0.25,0.15$, and 0.05 , corresponding to the speciesspecific drought tolerance level (d) 1-6 (with a larger number denoting lower tolerance).

The flooding effect is neglected in the current version, although it does have corresponding input parameter and relevant codes (which, however, does not work).

\subsection{Mortality}


Tree death in UVAFME is a stochastic process, which is simulated by calculating the annual mortality probability taking into consideration of both intrinsic mortality and environmentinduced mortality.

As regards the intrinsic mortality, species simulated are categorized into three groups with an assumption of $1 \%, 0.1 \%$, or $0.01 \%$ of the individual trees being expected to reach their maximum life span (AGEmax), respectively. Using the maximum age, AGEmax, as a scaling parameter, the annual intrinsic death probability $(\partial)$ of a tree is computed as:

$$
\partial=\frac{\text { death }}{\text { AGEmax }}
$$

where death is a species-dependent parameter contingent on the species' group (4.605--1\%, 6.908$-0.1 \%$, and $11.5129-0.01 \%$ ). As regards how these values are obtained, please refer to Shugart (1984). In the model, a parameter named old with values 1-3 is used to index these values.

The likelihood of mortality is further increased for slow growing trees. UVAFME defines slow growth as DBH increment less than $0.5 \mathrm{~mm}$ or less than $10 \%$ of the average increment over the tree's life span. Species are categorized into five groups assuming a survival of 5,10,20,40, and 80 more years with a probability 5\%, respectively, once they become slow growing trees. Thus, the annual probability of death is $0.43,0.40,0.37,0.34$, and 0.31 . In the model, a parameter named stress with values $1-5$ is used to index these probability values.

\subsection{Establishment}

The annual establishment of new trees in terms of the number, size, and species is also a stochastic process. UVAFME randomly selects the species that establish in a given year from the candidate species pool which is comprised by the species that can survive in a given environment 
determined by the relative size of seedling bank (RSSB) of a species. RSSB (seedlings $\mathrm{m}^{-2}$ ) is calculated as:

$$
R S S B=\operatorname{seedlingbank} * f_{L} f_{T} f_{N} f_{D}
$$

where environmental multipliers reduce each species' seedling-bank size, and seedlingbank (seedlings $\mathrm{m}^{-2}$ ) is updated annually by computing the natural decline of seedlings with the parameter NDE (annual seedling survival coefficient) and adding new seedlings from seeds and sprouts:

$$
\text { seedlingbank }=\text { seedlingbank } * N D E+\text { sprouting }+ \text { seedbank } * f L f T f N f D
$$

where seedbank (seeds $\mathrm{m}^{-2}$ ) is also updated annually by adding new seeds from local tree seed production and any seeds for invading species from outside the plot and by decreasing the seeds with seed mortality (quantified by a parameter of annual seed survival coefficient--NDS):

$$
\text { seedbank }=\text { seedbank } * N D S+\text { invader }
$$

Parameters mentioned above, including invader (seeds $\mathrm{m}^{-2}$ ), seedbank (seeds $\mathrm{m}^{-2}$ ), sprouting (seedlings $\mathrm{m}^{-2}$ ), NDE, and NDS, can be defined and estimated according to speciesspecific functional traits including seed size, shape, production amount and frequency of seeding, as well as species adaptations to environmental stress by sprouting and seed banking.

Please note that UVAFME can also simulate the disturbances from wind and fire toward the 
seed bank and seedling bank, which, however, is usually not considered in our application of this model and not described here.

\subsection{Biomass Volume, Carbon and Nitrogen}

Tree biomass (C) is comprised of four parts: stem, twig, leaf, and root, of which the root consists of lateral root, root ball, and fine root.

Stem biomass $(\mathrm{tC})$ and twig biomass $(\mathrm{tC})$ are calculated as:

$$
\begin{gathered}
\text { Stem }_{\text {biomas }}=\frac{t C * B D}{3} * D C H^{2} * H * 0.9 \\
\text { Twig }_{\text {biomass }}=\frac{t C * B D}{0.34} * D C H^{2} *(H-C H)
\end{gathered}
$$

where $\mathrm{tC}=3.92699 \mathrm{e}-5$, BD is species-specific wood density $\left(\mathrm{tC} \mathrm{m}^{-3}\right)$, $\mathrm{H}$ is tree height, and $\mathrm{DCH}$ is the diameter at the clear branch height.

Leaf biomass is calculated as:

$$
\text { Lea } f_{\text {biomass }}=L A I * L M A
$$

where LAI is leaf rea calculated as above and LMA is species-dependent parameter of leaf biomass

per hector $\left(\mathrm{tC} \mathrm{ha}{ }^{-1}\right)$. Note in the model a different variable name, L_C (literally means leaf area to carbon), is used.

Fine root biomass is assumed to be equal to leaf biomass. Primary (seminal) root biomass is calculated as: 


$$
\text { Rootball }_{\text {biomass }}=\text { Stem }_{\text {biomass }} * \frac{\text { Root_depth }}{H}
$$

where Root_depth intuitively denotes the root depth and $\mathrm{H}$ denotes the tree height. The lateral root biomass is computed following:

$$
\text { Lateralroot }_{\text {biomass }}=0.5 * \text { Twi }_{\text {biomass }}
$$

Biomass $(\mathrm{N})$ calculations are totally based on the plant stoichiometry (i.e. $\mathrm{C} / \mathrm{N}$ ratio) but with a differentiation between leaf and all remaining parts (stem), and the leaf is further distinguished between conifer and deciduous trees. As for the stem and branch, a $\mathrm{C} / \mathrm{N}$ ratio of 450 is used throughout the model. Leaf $\mathrm{C} / \mathrm{N}$ is 40 and 60 for deciduous and conifer trees, respectively.

\subsection{Volatile organic compounds (VOCs) emissions}

Ecosystem-level isoprene emission, $F_{I S O}$, is calculated as a summation of the emissions from each individual tree at five canopy layers with a differentiation between sunlit and shaded leaves at an hourly time step according to the widely used empirical approach developed by Guenther et al. $(1995,2006)$ :

$$
F_{I S O}=\sum_{i=0}^{n} \sum_{j=1}^{5} E_{S}(i) C_{T}(i)\left[L_{\text {sun }}(i j) C_{L}(i j)+L_{\text {shade }}(i j) C_{L}(i j)\right](1)
$$

where $i$ denotes one of $n$ trees in the forest, $j$ denotes one of five layers of each individual tree's canopy, Es represents the species-specific standard leaf-level emission rate of isoprene, $L_{\text {sun }}$ and 
$L_{\text {shade }}$ represents sunlit and shaded leaf area, and $C_{T}$ and $C_{L}$ account for light- and temperatureinduced variability, respectively, which are calculated according to Guenther et al. (1995):

$$
\begin{gathered}
C_{T}=\frac{\exp \frac{\mathrm{C}_{\mathrm{T} 1}\left(\mathrm{~T}-T_{S}\right)}{\mathrm{R} T_{S} \mathrm{~T}}}{1+\exp \frac{C_{T 2}\left(\mathrm{~T}-\mathrm{T}_{\mathrm{M}}\right)}{\mathrm{R} T_{S} \mathrm{~T}}}(2) \\
C_{L}=\frac{\alpha C_{L 1} \mathrm{~L}}{\sqrt{1+\alpha^{2} \mathrm{~L}^{2}}}(3)
\end{gathered}
$$

where $\mathrm{R}=8.314 \mathrm{~J} \mathrm{~K}^{-1} \mathrm{~mol}^{-1}, \mathrm{C}_{\mathrm{T} 1}=95,000 \mathrm{~J} \mathrm{~mol}^{-1}, \mathrm{C}_{\mathrm{T} 2}=230,000 \mathrm{~J} \mathrm{~mol}^{-1}, \mathrm{~T}_{\mathrm{M}}=314 \mathrm{~K}, \mathrm{~T}_{\mathrm{S}}=303 \mathrm{~K}$, $\alpha=0.0027$, and $C_{L 1}=1.066$. $T$ is hourly leaf temperature, which is assumed to be equal to hourly air temperature and constant through the canopy. L is hourly leaf-level PPFD $\left(\mu \mathrm{mol} \mathrm{m} \mathrm{m}^{-2} \mathrm{~s}^{-1}\right)$ at each canopy layer for sunlit and shaded leaves of each individual tree obtained with an explicit computing of light behavior within the stand and tree crown with a distinction between direct beam and diffuse radiation considering the shading by taller and surrounding trees, interception, reflection, scattering, and absorption. Please refer to Wang et al. (2017) for details.

\subsection{Soil Hydrology and Biogeochemistry}

\subsubsection{Three-layer soil system}

In UVAFME, the soil system is simplified by assuming having three distinctive layers: organic layer (Ao), active layer (A), and base layer (BL) (Fig.3). Soil hydrological processes and soil organic matter turnover all occur in this three-layer system. With basic soil properties of field capacity, permanent wilting point, soil depth, and initial soil system conditions in terms of water content and carbon and nitrogen contents at these three different layers being determined by model 
inputs, the soil system conditions are successively influenced by rainfall and organic matter input from plant detritus (at a yearly step) and evapotranspiration and decomposition (at a daily step). See Pastor and Post (1985), Post and Paster (1996), Thornton (1998) for more details.

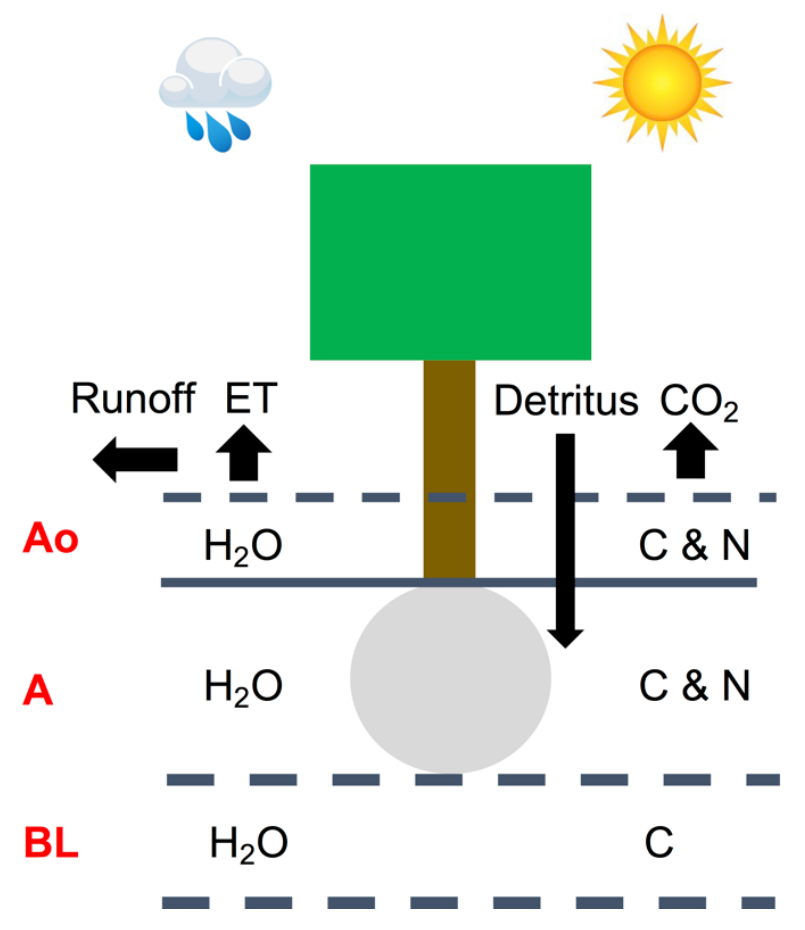

Fig.3. Schematic of UVAFME soil system and major processes simulated.

\subsubsection{Hydrology}

Soil hydrological processes are all calculated at a daily time step. Overall, water available to be allocated in the soil system is firstly calculated by subtracting from rainfall three items including potential evapotranspiration (PET), tree crown interception, and land surface runoff because of slope. Then, this available water is allocated across the three layers by the order of $\mathrm{AO}$, 
A, and BL based on soil field capacity of active layer (A) and maximum water content in the organic layer (Ao) and base layer (B). Water content of the three layers, actual evapotranspiration, and runoff are calculated.

First, potential evapotranspiration (PET) is fundamental in determining the soil hydrology, and is computed at a daily time step according to the 1985 Hargreaves equation (Hargreaves \& Allen, 2003) following:

$$
P E T=H_{\text {coeff }} * \sqrt{T_{\text {max }}-T_{\text {min }}} *\left(T_{\text {mean }}+H_{\text {addon }}\right) * R_{a}
$$

where Tmax, Tmin, Tmean are maximum, minimum, and average temperature, respectively, H_coeff $=0.000093876, \mathrm{H} \_$addon $=17.8$, and $R a$ is extraterrestrial radiation $\left(\mathrm{mj} / \mathrm{m}^{2} / \mathrm{day}\right)$.

The amount of rain intercepted by canopy $\left(\mathrm{LAI}_{\text {loss }}\right)$ is calculated as:

$$
L A I_{\text {loss }}=\min \left\{\left(L A I_{w \max }-L A I_{w 0}\right), \operatorname{rain}\right\}
$$

where LAIwmax is the maximum water that a tree canopy can hold, and is calculated as:

$$
L A I_{\text {wax }}=L A I * L A I_{\max }
$$

where LAI is the leaf area index and updated at an annual time step, and LAImax is a constant of 0.15 .

The amount of water loss resulting from a slope is calculated as:

$$
\text { slope }_{\text {loss }}=\left(\text { rain }-L A I_{\text {loss }}\right)\left(\frac{\text { slope }}{90}\right)^{2}
$$

where slope is the site slope required as an input.

Next, the rainfall after subtracting the canopy interception and slope-induced loss is compared with potential evapotranspiration. If larger, the net amount of water is allocated across the three layers, and the corresponding actual evapotranspiration and runoff are calculated. If smaller, the water already stored in the canopy and soil will lose, and corresponding actual 
evapotranspiration and runoff are calculated. Detailed procedures concerning the computation of soil water contents in the three layers are skipped. However, the soil active layer (A) field capacity $(\mathrm{cm})$ and permanent wilting point $(\mathrm{cm})$, which are required as model inputs, are used here for water content calculations. Please note the following is a detailed description of water table calculation and soil base layer water content before evapotranspiration occurs.

With known values of soil water content, drought days are further calculated by a simple comparison of soil active layer (A) water content with a soil maximum drying parameter (in the model, named max_dry_parm with a constant of 1.0001). Two categories of drought days, minimum drought days and maximum drought days, are calculated based on the active water content computed from permanent wilting point and field capacity, respectively.

\subsubsection{Litter and soil organic matter turnover}

Carbon and nitrogen pool sizes in each layer are balanced by output determined by organic matter decomposition and input from tree detritus (litter or fine roots) or downward transport across layers (Note that this model does not consider $\mathbf{N}$ in the base layer). Decomposition is simulated using first-order linear decay rates that are modified by environmental scalars (temperature and moisture). The amount of carbon decomposed into $\mathrm{CO}_{2}$ is assumed to be proportional to the soil $\mathrm{C}$ stock, and is calculated following:

$$
R_{c_{2}}=C_{0} * k * f_{T} * f_{M}
$$

where $\mathrm{C}_{0}$ is the carbon pool size, $\mathrm{k}$ is proportion of organic $\mathrm{C}$ that is respired as $\mathrm{CO}_{2}$, and $f_{T}$ and $f_{M}$ are temperature and moisture scalar, respectively, for which they are all layer-dependent. Nitrogen decomposed in the three layers is computed by dividing the $\mathrm{Rco}_{2}$ by the total soil $\mathrm{C} / \mathrm{N}$ ratio in the 
corresponding layer. See more details for such a modelling strategy (its derivation and underlying assumptions) in Jenkinson et al., (1987) and Parton et al., (1987).

Organic matter input into the soil system includes three fluxes: leaf and fine root turnover, branch litter fall, and individual tree death. Leaf and fine root return to litter layer (Ao). The increase in clear branch bole height $(\mathrm{CH})$ generates branch litter fall (and the associated relative decline of the diameter at the clear branch bole height, $\mathrm{DCH}$ ). These organic matter inputs do not affect the soil base layer.

The soil $\mathrm{CO}_{2}$ emission (respiration) is a summation of $\mathrm{CO}_{2}$ emissions from the three layers:

$$
R_{\text {soil }}=R_{\mathrm{CO}_{2}\left(\mathrm{~A}_{\mathrm{O}}\right)}+R_{\mathrm{Co}_{2}(A)}+R_{\mathrm{Co}_{2}(B L)}
$$

Organic layer (AO): $\mathrm{C}$ and $\mathrm{N}$ input in this layer are determined by the input of plant input.

$$
\begin{gathered}
\mathrm{k}_{\mathrm{Ao}}=5.24 \mathrm{e}-4 \\
f_{T}= \begin{cases}3^{\frac{T-1.0}{10}} ; T \geq 5^{\circ} \mathrm{C} \\
0 \quad ; \quad T<5{ }^{\circ} \mathrm{C}\end{cases} \\
f_{M}=\max \left\{1-\left(1-\frac{\text { moisture }}{0.3}\right)^{2}, 0.2\right\}
\end{gathered}
$$

Active layer (A): C and N input in this layer are dependent on both the plant input and the downward transport from the above Ao layer.

$$
\begin{gathered}
\mathrm{k}_{\mathrm{A}}=1.24 \mathrm{e}-5 \\
f_{T}= \begin{cases}2.5^{\frac{T-1.0}{10}} ; T \geq 5^{\circ} \mathrm{C} \\
0 \quad T<5{ }^{\circ} \mathrm{C}\end{cases} \\
f_{M}=\max \left\{1-\left(1-\frac{\text { moisture }}{0.8}\right)^{2}, 0.2\right\}
\end{gathered}
$$

Soil available nitrogen, as mentioned above for an eventual calculation of the nutrient scalar in section 3.1.5, refers to the nitrogen in this layer, and is calculated following: 


$$
N_{a v}=\frac{R_{C O_{2}(A)}}{A_{C / N}} * \max \left\{\frac{A_{C / N}-A_{C / N(0)}}{A_{C / N}}, 0.5\right\}
$$

where $A_{C / N}$ and $A_{C / N(0)}$ refer to the active layer total $\mathrm{C} / \mathrm{N}$ ratio and a constant of 4.0, respectively.

Base layer (BL): Carbon and nitrogen input into this layer are totally determined by the downward transport from the above layer A. Moreover, this layer's decomposition is independent of soil moisture.

$$
\begin{gathered}
\mathrm{k}_{\mathrm{BL}}=2.74 \mathrm{e}-7 \\
f_{T}=\left\{\begin{array}{cr}
2.5^{\frac{T-1.0}{10}} ; T \geq 5^{\circ} \mathrm{C} \\
0 \quad ; T<5{ }^{\circ} \mathrm{C}
\end{array}\right.
\end{gathered}
$$




\section{Input data}

\subsubsection{Site geospatial and soil information}

Table 1. Site geospatial and soil information required as inputs.

\begin{tabular}{|c|c|c|c|}
\hline Function & Symbole & Unit & Description \\
\hline \multirow[t]{9}{*}{ Site basic information } & site & 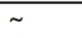 & Site id, i.e. $0,1,2,3 \ldots$ \\
\hline & latitude & degree & Site latitude \\
\hline & longitude & degree & Site longitude \\
\hline & wmo & $\sim$ & World Meterology Organization station name \\
\hline & name & $\sim$ & Site name, e.g., O'Hill \\
\hline & region & $\sim$ & Region, e.g., USA \\
\hline & elevation & $\mathrm{m}$ & Sea level altitude \\
\hline & slope & degree & Used for water runoff calculation \\
\hline & sigma & $\sim$ & Used for water table calculation \\
\hline \multirow{13}{*}{ Soil information } & soilA_field_cap & $\mathrm{cm}$ & Active layer field capacity \\
\hline & soilA_perm_wp & $\mathrm{cm}$ & Active layer permanent wilting point \\
\hline & soil_base_h & $\mathrm{cm}$ & Base layer soil depth \\
\hline & lai_w0 & $\mathrm{cm}$ & Crown water content \\
\hline & soilAO_w0 & $\mathrm{cm}$ & Organic layer water content \\
\hline & soilA_w0 & $\mathrm{cm}$ & Active layer water content \\
\hline & sbase_w0 & $\mathrm{cm}$ & Base layer water content \\
\hline & soilAO_c0 & $\mathrm{tC} / \mathrm{ha}$ & Organic layer $\mathrm{C}$ content \\
\hline & soilAO_no & $\mathrm{tN} / \mathrm{ha}$ & Organic layer $\mathrm{N}$ content \\
\hline & soilA_c0 & $\mathrm{tC} / \mathrm{ha}$ & Active layer $\mathrm{C}$ content \\
\hline & soilA_no & $\mathrm{tN} / \mathrm{ha}$ & Active layer $\mathrm{N}$ content \\
\hline & sbase_c0 & $\mathrm{tC} / \mathrm{ha}$ & Base layer $\mathrm{C}$ content \\
\hline & sbase_no & $\mathrm{tN} / \mathrm{ha}$ & Base layer $\mathrm{N}$ content \\
\hline \multirow[t]{12}{*}{ Temperature lapse rate } & tmp_lapse_jan & $\sim$ & 0.37 (example value) \\
\hline & tmp_lapse_feb & $\sim$ & 0.52 \\
\hline & tmp_lapse_mar & $\sim$ & 0.67 \\
\hline & tmp_lapse_apr & $\sim$ & 0.71 \\
\hline & tmp_lapse_may & $\sim$ & 0.68 \\
\hline & tmp_lapse_jun & $\sim$ & 0.62 \\
\hline & tmp_lapse_jul & $\sim$ & 0.57 \\
\hline & tmp_lapse_aug & $\sim$ & 0.57 \\
\hline & tmp_lapse_sep & $\sim$ & 0.59 \\
\hline & tmp_lapse_oct & $\sim$ & 0.57 \\
\hline & tmp_lapse_nov & $\sim$ & 0.53 \\
\hline & tmp_lapse_dec & $\sim$ & 0.3 \\
\hline \multirow[t]{12}{*}{ Precipitation lapse rate } & prcp_lapse_jan & $\sim$ & 0.19 (example value) \\
\hline & prcp_lapse_feb & $\sim$ & 0.16 \\
\hline & prcp_lapse_mar & $\sim$ & 0.73 \\
\hline & prcp_lapse_apr & $\sim$ & 1.61 \\
\hline & prcp_lapse_may & $\sim$ & 2.18 \\
\hline & prcp_lapse_jun & $\sim$ & 3.46 \\
\hline & prcp_lapse_jul & $\sim$ & 9.52 \\
\hline & prcp_lapse_aug & $\sim$ & 7.92 \\
\hline & prcp_lapse_sep & $\sim$ & 3.74 \\
\hline & prcp_lapse_oct & $\sim$ & 1.8 \\
\hline & prop_lapse_nov & $\sim$ & 1.04 \\
\hline & prcp_lapse_dec & $\sim$ & 0.3 \\
\hline \multirow[t]{2}{*}{ Disturbance } & fire_prob & $\sim$ & Fire probability \\
\hline & wind_prob & $\sim$ & Wind probability \\
\hline
\end{tabular}




\subsubsection{Species parameters}

Table 2 Species parameters (silvics) required as inputs.

\begin{tabular}{|c|c|c|c|}
\hline Category & Symbol & Unit & Description \\
\hline \multirow[t]{6}{*}{ Geometry } & evergreen & $\sim$ & Growth form: either evergreen (1) or deciduous (0) \\
\hline & AGEmax & $\mathrm{yr}$ & The maximum ages a species can reach \\
\hline & DBHmax & $\mathrm{cm}$ & The maximum diameter a species can reach \\
\hline & Hmax & $\mathrm{m}$ & The maximum height a species can reach \\
\hline & $\mathrm{s}$ & $\sim$ & The initial relationship between tree height and diameter \\
\hline & D_L & $\sim$ & The relationship between leaf area and the squared diamter at the clear branch height \\
\hline Growth & $\mathrm{g}$ & $\sim$ & Tree growth scalar \\
\hline Mortality & $\begin{array}{l}\text { old } \\
\text { stress }\end{array}$ & $\sim$ & $\begin{array}{l}\text { Parameter }(1-3) \text { assigning the species into three groups with differing intrinsic mortality probability } \\
\text { Index }(1-5) \text { referring to species with differing mortality probability when growth deficiency is reached }\end{array}$ \\
\hline \multirow[t]{4}{*}{ Establishment } & seed & seeds $m^{\wedge}-2$ & Annual number of seeds produced by a species in the plot \\
\hline & sprout & sprouts $m^{\wedge}-2$ & Annual number of sprouts produced by species in the plot \\
\hline & NDE & $\sim$ & Annual seed survival coefficient for the seed bank \\
\hline & $\begin{array}{l}\text { NDS } \\
\text { invader }\end{array}$ & $\sim$ seeds $m^{\wedge}-2$ & $\begin{array}{l}\text { Annual seedling survival coefficient for the seedling bank } \\
\text { Annual number of seeds entering the plot }\end{array}$ \\
\hline \multirow{8}{*}{$\begin{array}{l}\text { Response to } \\
\text { stress } \\
\text { factors }\end{array}$} & DEGDmax & ${ }^{\circ} \mathrm{C}$ & Defines the maximum growing degree days $\left(5^{\circ} \mathrm{C}\right.$ basis $)$ \\
\hline & DEGDopt & ${ }^{\circ} \mathrm{C}$ & The optimum growing degree days $\left(5^{\circ} \mathrm{C}\right.$ basis $)$ \\
\hline & DEGDmin & ${ }^{\circ} \mathrm{C}$ & The minimum growing degree days $\left(5^{\circ} \mathrm{C}\right.$ basis $)$ \\
\hline & I & $\sim$ & Shade tolerance level: tolerance decreases from 1-5 \\
\hline & d & $\sim$ & Drought tolerance level: tolerance decreases from 1-6 \\
\hline & f & $\sim$ & Flood tolerance level: tolerance decreases from 1-6 \\
\hline & $\mathrm{n}$ & $\sim$ & Nitrient tolerance level: tolerance decreases from 1-3 \\
\hline & fire & $\sim$ & Fire tolerance level: tolerance decreases from 1-6 \\
\hline \multirow[t]{2}{*}{ Biomass } & L_C & tC ha^-1 & Specific leaf area ratio used to calculate leaf biomass from leaf area \\
\hline & bulk & $\mathrm{tC} \mathrm{m}^{\wedge}-3$ & Stem bulk density used to calculate stem biomass from tree volume \\
\hline
\end{tabular}

\subsubsection{Climate data}

Mean precipitation, mean maximum and minimum temperature, and their standard deviations of each month are required. Therefore, historical data of monthly meteorological precipitation and temperature over the past several decades are usually acquired from, e.g., stations of World Meteorology Organization. For example, Wang et al. (2017) used thirty years of meteorological data for monthly precipitation $(\mathrm{mm})$ and monthly maximum and minimum temperature $\left({ }^{\circ} \mathrm{C}\right)$ ranging from 1981 to 2010 which were obtained from the NOAA (National Oceanic and Atmospheric Administration) meteorological station at Oak Ridge ATDD, Tennessee, USA (GHCND: USW00003841; Latitude/Longitude: 36.0028\%/84.2486º; Elevation: $275.8 \mathrm{~m}$ ) to compute monthly average precipitation, monthly maximum and minimum temperature, and their standard deviations. 


\section{Modelling protocol}

Because of the stochastic nature, UVAFME-VOC and all other individual-based gap models intrinsically simulate dynamics of a landscape of indeterminate size sampled with a system of independent sample plots(patches) with the same climate and soil conditions. An average of the simulation resulting from those independent plots corresponds to a shifting-mosaic steady-state landscape (Bormann and Likens, 1979).

According to the convergence analysis of gap model conducted by Bugmann et al. (1996), 150-200 replicate plots are needed to provide a sample which approximates a statistically quasistable landscape response of the forest landscape. Therefore, with a Monte Carlo simulation this model is usually run for 200 independent plots of a size of $500 \mathrm{~m}^{2}$ starting from bare ground (i.e. gaps with ample active seeds where secondary succession occurs, and in field such gaps can be created from the death of a canopy-dominant tree resulting from wind, fire, or other disturbances) and lasting for 500 years. The model results are usually analyzed with the average of these 200 runs. 


\section{Chapter 4 Forests and ozone: productivity, carbon storage, and feedbacks}

\subsection{Introduction}

Interactions between forests and the atmospheric pollutants are a crucial component of Earth System Science, but the impacts of changes in tree-species composition on ecosystems and the atmosphere are not yet well understood. Most long-term efforts to examine pollutant interactions with forests have relied on models based on process-level studies at biochemical and physiological scales (Sitch et al. 2007; Felzer et al. 2005; Lombardozzi et al. 2015). These models do not explicitly consider variability among species, notably the impacts that growth and competition among species can affect system-level metabolism. Using an individual-based ecosystem model, we examined how species-specific variability in responses to the most important atmospheric pollutant in North America, ozone $\left(\mathrm{O}_{3}\right)$ (Felzer et al. 2005), interacts with these higher-order processes and modifies functions at the community, ecosystem, and biogeochemical scales.

At cellular-to-organ scales, the impacts of $\mathrm{O}_{3}$ on plants are relatively well understood ozone causes cellular damage; induces reduced stomatal conductance; eventually decreases carbon dioxide $\left(\mathrm{CO}_{2}\right)$ assimilation rates and produces visible leaf injury (Wittig et al. 2007; Ainsworth et al. 2012; Lombardozzi et al. 2013). These effects often accelerate senescence, diminish leaf area and biomass, and reduce productivity (Wittig et al. 2007; Ainsworth et al. 2012; Reich et al. 1987; Wittig et al. 2009). These responses promote the inference that $\mathrm{O}_{3}$ pollution should reduce forest ecosystem productivity and suppress terrestrial carbon sequestration (Sitch et al. 2007; Felzer et al. 2005; Lombardozzi et al. 2015). 
This inference ignores the differences among tree species in their sensitivity to $\mathrm{O}_{3}$ (Wittig et al. 2007, 2009). These differences in sensitivities potentially mediate competitive interactions, giving $\mathrm{O}_{3}$-tolerant species that are competitively inferior in low- $\mathrm{O}_{3}$ environments advantages in high- $\mathrm{O}_{3}$ situations (Ainsworth et al. 2012; Matyssek et al. 2010; Zak et al. 2007). Understanding this complex problem requires consideration of both the diversity of species and sizes of trees in a forest, including their metabolic properties and competitive interactions. Such insights are particularly difficult to obtain in forests because of the long generational times that are associated with trees. Some studies have tried to conduct ecosystem-scale forest $\mathrm{O}_{3}$ experiments in the context of free-air carbon enrichment (FACE) experiments, but logistical limitations have required these studies to focus on a limited set of species and for a relatively short time period (Matyssek et al. 2010; Zak et al. 2011; Talhelm et al. 2014).

The forest response to ozone is a complex mixture of the responses of individual trees of different species and sizes. The homogenization of this complexity can be lost in the aggregation necessary to construct ordinary-differential-equation-based process-models of ecosystem dynamics. An approach to overcome this difficulty is to simulate each of the trees in a forest ecosystem using individual-based models (IBMs) (Shugart 1984; Grimm et al. 2005). Here, we use a class of IBMs known as gap models to study the complex relationships among species-level variability in growth, ozone sensitivity, and ecosystem processes.

Gap models are IBMs that simulate growth, mortality, and regeneration of all individual trees in a $\sim 0.10$ ha plot in a forest, as well as their competition for light and other resources (Shugart 1984). Such models have a rich history in community ecology (Shugart and Woodward 2011). Recent advances in computational power have allowed current versions of these models to explicitly simulate compositional and structural dynamics and to link these dynamics to ecosystem 
and biogeochemical processes. This study uses UVAFME-VOC (University of Virginia Forest Model Enhanced-Volatile Organic Compounds; Wang et al. 2017) to simulate the successional dynamics of species composition and structural change of a typical temperate deciduous forest in the southeastern USA, a region that is well studied in terms of forest succession and whose component species have been characterized with respect to their $\mathrm{O}_{3}$ sensitivity and competitive relations (McLaughlin et al. 2007).

\subsection{Methods}

\subsubsection{Description of UVAFME}

UVAFME-VOC simulates the growth, death, and regeneration of each individual tree annually on a 1/20 ha plot. Its dynamics are constrained by temperature, light, soil moisture, soil nutrient, wind, and fire conditions. Competition among trees for light, nutrient, and water resources are also included. The community dynamics and composition, including tree number of each species, basal area, leaf area, litter carbon and nitrogen, and biomass carbon and nitrogen, can be determined from processing the sizes and species of individual trees, which are computed annually in the model. The soil carbon, nitrogen, and water dynamics, along with soil carbon and nitrogen storage, soil respiration, and evapotranspiration, are calculated as state variables. These parameters

include species-related parameters (quantifying species' fundamental silvics and responses to environmental factors) and site conditions (i.e., local soil physiochemical properties and meteorological temperature and precipitation).

\subsubsection{Coupling with isoprene emission model}

The canopy of each tree of an isoprene-emitting species is divided into five layers. Hourly isoprene emissions from sunlit and shaded leaves of each layer are determined by leaf area and 
standard emission rate, and constrained by hourly air temperature and leaf-level PPFD (photosynthetic photon flux density). The sunlit-leaves flux and the shaded-leaves flux sum to the hourly flux, which can be added together to obtain the daily flux ( $\mathrm{mg} \mathrm{m}^{-2}$ day $\left.^{-1}\right)$ for each tree. The sum of isoprene emission of each tree is the canopy isoprene flux.

Emitting species and their standard emission rates are according to Geron et al. (2001) (Supplementary Table 1). Leaf area of UVAFME changes annually and we assume that the leaf area during July is constant. The leaf area is assumed to be uniformly distributed for each tree in the UVAFME.

Temperature-dependency algorithm of isoprene emission (Guenther et al. 1995) is:

$$
C_{T}=\frac{\exp \frac{\mathrm{C}_{\mathrm{T} 1}\left(\mathrm{~T}-T_{S}\right)}{\mathrm{R} T_{S} \mathrm{~T}}}{1+\exp \frac{C_{T 2}\left(\mathrm{~T}-\mathrm{T}_{\mathrm{M}}\right)}{\mathrm{R} T_{S} \mathrm{~T}}}
$$

where $\mathrm{R}=8.314 \mathrm{~J} \mathrm{~K}^{-1} \mathrm{~mol}^{-1}, \mathrm{C}_{\mathrm{T} 1}=95,000 \mathrm{~J} \mathrm{~mol}^{-1}, C_{T 2}=230,000 \mathrm{~J} \mathrm{~mol}^{-1}, \mathrm{~T}_{\mathrm{M}}=314 \mathrm{~K}$, and $T_{S}=$ $303 \mathrm{~K}$. T is leaf temperature, which is assumed to be equal to hourly air temperature and through the canopy. Hourly temperature is calculated from daily minimum and maximum temperature, the previous-day maximum temperature, and the following-day minimum temperature (see Supplementary Note) (Goudriaan 1994).

Light-dependency algorithm (Guenther et al. 1995) is:

$$
C_{L}=\frac{\alpha C_{L 1} \mathrm{~L}}{\sqrt{1+\alpha^{2} \mathrm{~L}^{2}}}
$$

where $\mathrm{L}$ is leaf level PPFD $\left(\mu \mathrm{mol} \mathrm{m} \mathrm{s}^{-1}\right), \alpha=0.0027$, and $C_{L 1}=1.066$. The hourly leaf-level PPFD at each canopy layer for sunlit and shaded leaves (the distribution of sunlit leaf area within a canopy can be described by an exponential model analogous to Beer's law with the extinction coefficient for direct beam but without the light intensity multiplier) of each isoprene-emitting tree 
is achieved by three steps of calculations: First, above-forest stand PPFD is obtained; second, considering the shading by taller and surrounding trees, the light intensity above each isopreneemitting tree within the forest stand is then calculated; and, third, the sunlit-leaf area, shaded-leaf area, and the corresponding PPFD on sunlit and shaded leaves at each canopy layer for each isoprene-emitting tree are calculated. In detail, direct beam and diffuse PPFD above the forest stand are calculated from incoming extraterrestrial solar radiation using an atmospheric transmissivity value of 0.6. Light intensity at each canopy layer within the canopy are determined by Beer's law with different extinction coefficients for direct beam and diffuse light based on an assumption of spherical leaf angle distribution with accounting for light reflection and scattering. Light intensity on a shaded leaf is from both incoming diffuse light and scattered light from the direct beam. For more details concerning calculation of the sunlit and shaded leaf area and PPFD level, please refer to MEGAN 2.1 (Guenther et al. 2012) and Goudriaan (1994).

\subsubsection{Input parameters estimation}

Thirty-two species native to the southern Appalachian region in USA, including both deciduous and coniferous trees, are simulated. Twenty-four parameters required as inputs for each species were estimated (Supplementary Data 1). Specifically, wood bulk density values were from a global wood density data compiled by Zanne (2009). Species response to nutrient availability is according to Weinstein (1982). All the remaining are estimated according to Fowell (1965) and Hardin et al. (2001). Thirty-year meteorological data of monthly precipitation (mm) and monthly maximum and minimum temperature $\left({ }^{\circ} \mathrm{C}\right)$ ranging from 1981 to 2010 were obtained from a nearby NOAA (National Oceanic and Atmospheric Administration) meteorological station, Oak Ridge ATDD, Tennessee, USA (GHCND: USW00003841; Latitude/Longitude: 36.0028\%-84.2486² Elevation: $275.8 \mathrm{~m}$ ) to compute monthly average precipitation, monthly maximum and minimum 
temperature, and their standard deviations. Additionally, soil-related parameters including organic layer carbon and nitrogen, active layer carbon and nitrogen, and base soil carbon are estimated according to Miegroet et al. (1994) and Iversen et al. (2012). Default values of $25 \mathrm{~cm}$ and $12.5 \mathrm{~cm}$ were used for soil field capacity and soil permanent wilting point, respectively.

\subsubsection{Modelling $\mathrm{O}_{3}$ effects on growth}

To incorporate the $\mathrm{O}_{3}$ effects on tree growth into UVAFME, we first classify the 32 species into three categories based on their relative sensitivity to $\mathrm{O}_{3}$ stress: resistant, intermediate, and sensitive (Supplementary Table 1). This categorization derives from the current literatures including review studies (Wittig et al. 2007; Reich 1987; Wittig et al. 2009; Krupa et al. 1989; Coulston et al. 2003) and reports on individual species (Davis et al. 1992; Tjoelker et al. 1993; Samuelson et al. 1994; Lawrence et al. 1996; Chappelka et al. 1997; Weinstein et al. 2001; Schaub et al. 2003). A growth reduction of $0,10 \%$, and $20 \%$ is exerted on resistant, intermediate and sensitive species, respectively (For a validity check of these specific reduction values, see Supplementary Fig. 5).

\subsubsection{Simulation methods}

We apply a Monte Carlo simulation of a landscape of indeterminate size sampled with a system of independent sample plots with the same climate and soil conditions. Therefore, the average of the simulation corresponds to a shifting-mosaic steady-state landscape. An analysis of convergence of average species-specific biomass values finds that 150-200 replicate plots are necessary to provide a sample which approximates the landscape response of the forest (Bugmann et al. 1996). Therefore, the model is run on a plot size of $500 \mathrm{~m}^{2}$ starting from bare ground and lasting for 500 years for 200 independent plots. All the results presented are the average of 200 such runs. 


\subsection{Results}

The simulated successional dynamics of this temperate deciduous forest over 500 years involve changes in 10 abundant species and 22 other species (Supplementary Fig. 1). Initially for a forest succession from an open plot, the 'other' species category, mostly composed of pioneer species, dominates the forest with approximately $50 \%$ of the total biomass (Figure 1). Soon, both Acer rubrum and Liriodendron tulipifera become increasingly important, but $A$. rubrum eventually loses to the larger, faster-growing $L$. tulipifera trees, which persist and become dominant. After $L$. tulipifera declines over time, trees of four shade-tolerant oak species (Quercus alba, Q. velutina, Q. rubra, and $Q$. prinus) become increasingly important, together accounting for approximately $75 \%$ of the stand biomass at year 500 . The composition of the forest stabilizes and is eventually dominated by aforementioned oaks, along with L. tulipifera, and two maples (A. rubrum and $A$. saccharum). Correspondingly, total biomass becomes relatively stable starting around year 100 (Figure 1). The simulated successional change resembles expected forest composition change in the southeastern USA (Shugart 1984).

When $\mathrm{O}_{3}$ impacts on growth and competitive ability are included, the compositional changes differ from the case when $\mathrm{O}_{3}$ impacts are absent (Figure 2). Generally, $\mathrm{O}_{3}$-sensitive species have lower biomass when exposed to $\mathrm{O}_{3}$ stress over succession (e.g., L. tulipifera and A. rubrum), but $A$. rubrum has almost same biomass at year 100 as the control case (Figure 1). For species with an intermediate $\mathrm{O}_{3}$ sensitivity (e.g., A. saccharum and Q. velutina), biomass can be enhanced rather than diminished early in the stand dynamics. For resistant species (e.g., Q. alba), biomass is significantly enhanced by $\mathrm{O}_{3}$. An individual's response to $\mathrm{O}_{3}$ is not absolutely 
determined by its intrinsic $\mathrm{O}_{3}$ sensitivity, and it can be modified through interactions with other species within the community (e.g., Matyssek et al. 2010).

The differential sensitivity to $\mathrm{O}_{3}$ and release from competitive suppression result in a compensatory response from $\mathrm{O}_{3}$-tolerant species, with the result that forest biomass does not decline over time under high $\mathrm{O}_{3}$ conditions, although it is lower initially (Figure 1). Forest carbon storage is also not suppressed by $\mathrm{O}_{3}$, and it gradually increases over time because of the unsuppressed net ecosystem productivity (Supplementary Fig. 2). These results differ from the logical inference emerging from coupled climate-biogeochemical cycling models (e.g., Felzer et al. 2005; Lombardozzi et al. 2015) that do not include the species-specific individual-based metabolism and competitive interactions.

An important source of metabolic variation with respect to $\mathrm{O}_{3}$ in forests is the occurrence of isoprene-emitting taxa. Isoprene from forest trees dominates the annual global volatile organic compounds (VOCs) flux into the atmosphere (Guenther et al. 2006, 2012). Isoprene contributes to tropospheric $\mathrm{O}_{3}$ formation and aggravates $\mathrm{O}_{3}$ pollution under conditions of moderate to high nitrogen oxides (Sharkey et al. 2014). Not all tree species, however, emit isoprene. About one third of tree species produce isoprene in both the eastern USA and tropical forests; low diversity boreal forests also consist of emitters (e.g., spruce and aspen) and non-emitters (e.g., pine) (Lerdau 2007). There are 10 isoprene-emitting species identified in this simulated forest (Supplementary Table 1).

We examined the species composition change in terms of isoprene-emitting species. Because isoprene-emitting species tend to be better protected against atmospheric oxidative pressure (e.g., Sharkey 1995; Vickers et al. 2009; Loreto and Velikova 2001), the proportion of isoprene-emitting species in the simulated forest increases significantly from $60 \%$ to $80 \%$ under 
$\mathrm{O}_{3}$ stress (Figure 3a). Among the emitting species, 'other' species represents a high percentage $(\sim 50 \%)$ at the beginning of the succession (Supplementary Fig. 4). However, these species are almost completely replaced at about 60 years by four isoprene-emitting oak species ( $Q$. alba, $Q$. velutina, Q. rubra, and Q. prinus). From these simulations, tropospheric $\mathrm{O}_{3}$ pollution modifies forest composition and favors isoprene-emitting species. At the same time, tropospheric $\mathrm{O}_{3}$ pollution engenders a decline of forest biodiversity as proposed earlier (Lerdau 2007).

We simulated the isoprene emission from this forest to investigate these implied feedbacks. Isoprene flux increases sharply within the first 200 years of compositional dynamics, and remains relatively stable with a slightly decline over the remaining simulation with some inter-annual variability (Figure 3b). Emitters are often shaded by non-emitting species (e.g., L. tulipifera) early in succession and are then more exposed to light when they eventually become canopy dominants, which is indicated by, for example, the change of sunlit leaf area proportion and light extinction for a $Q$. alba tree's canopy at 10 and 300 years. We also calculated the dynamics of sunlit versus shaded leaf area index (LAI), and the corresponding isoprene flux initially increases and then stabilizes. The sunlit LAI is small relative to shaded LAI, but the sunlit leaf-derived flux always dominates in its contribution to the total isoprene flux. It accounts for $\sim 70 \%$ of the isoprene flux in the later successional forest. The contribution to emission from early successional species is initially large but declines quickly (Supplementary Fig. 4). As succession progresses, the isoprene flux becomes dominated by the aforementioned four oaks (Q. alba, Q. velutina, Q. rubra, and $Q$. prinus). Dynamic change in forest composition significantly alters the simulated isoprene flux under elevated $\mathrm{O}_{3}$ conditions (Figure $3 b$ ). On average, the isoprene flux is increased by $50 \%$ (from $80 \mathrm{mg} \mathrm{m}^{-2} \mathrm{~d}^{-1}$ to $\left.120 \mathrm{mg} \mathrm{m}^{-2} \mathrm{~d}^{-1}\right)$ under $\mathrm{O}_{3}$ stress. 


\subsection{Discussion}

These simulations suggest that $\mathrm{O}_{3}$ pollution does not necessarily cause reduced forest productivity or carbon storage. The FACE study by Zak et al. (2011) which included both $\mathrm{O}_{3}$ tolerant and -sensitive species or genotypes and reported unsuppressed net primary productivity after long-term fumigation, supports this conclusion. In contrast, the earlier modeling studies that have found such reductions (Sitch et al. 2007; Felzer et al. 2005; Lombardozzi et al. 2015) have explicitly not included species-specific effects and thus have not produced these compensatory responses. One would expect agricultural systems, which lack the interspecific dynamics and plant-size differences simulated here, to feature the $\mathrm{O}_{3}$-generated productivity reductions (Ainsworth et al. 2012).

Previous comparative work on managed and unmanaged systems has measured the effects of forest composition on isoprene emissions ${ }^{27}$, and the results described here are congruent. In forests, enhanced isoprene emission arising from species-composition changes represents a potential positive feedback loop. If $\mathrm{O}_{3}$ tolerance is linked to isoprene production, as has been suggested (e.g., Sharkey 1995; Vickers et al. 2009; Loreto and Velikova 2001), these simulations of temperate deciduous forest in southeastern USA can be extended to other types of forests (tropical and boreal forests) with global-scale implications.

Three important implications emerge from this study. The first is that community dynamics, in particular compensatory responses and competitive release, suggest that $\mathrm{O}_{3}$ may not play a substantial role in depressing productivity and carbon storage at ecosystem and landscape scales. Second, many other large-scale environmental perturbations that are occurring today also have species-dependent effects, e.g., rising $\mathrm{CO}_{2}$ concentrations, increasing temperatures, and nitrogen deposition (Mooney et al. 1987; Bazzaz 1990; Lerdau and Slobodkin 2002; Rudd et al. 
2011). For large-scale environmental perturbations that modify interactions among individual plants, changes in competitive relations can induce compensatory (or, potentially, synergistic) responses not inferred from aggregated models. Moreover, how these factors act together to affect the terrestrial ecosystems are far more important. Third, the ozone-diversity-isoprene emission feedback suggests connectivity between species-specific metabolism and atmospheric chemistry. This has only rarely been demonstrated (Hickman et al. 2010), but it implies the possibilities for a diverse array of interactions between the biosphere and the atmosphere. Future ecological and biosphere-atmosphere research should examine explicitly, rather than ignore by design, the potential for such species-specific impacts.

\subsection{References}

Ainsworth, E. A., Yendrek, C. R., Sitch, S., Collins, W. J. \& Emberson, L. D. The effects of tropospheric ozone on net primary productivity and implications for climate change. Аnпu. Rev. Plant Biol. 63, 637-661 (2012).

Bazzaz, F. A. The response of natural ecosystems to the rising global $\mathrm{CO}_{2}$ levels. Annu. Rev. Ecol. Evol. Syst. 21, 167-196 (1990).

Bugmann, H., Fischlin, A. \& Kienast, F. Model convergence and state variable update in forest gap models. Ecol. Model. 89, 197-208 (1996).

Chappelka, A., Renfro, J., Somers, G. \& Nash, B. Evaluation of ozone injury on foliage of black cherry (Prunus serotina) and tall milkweed (Asclepias exaltata) in Great Smoky Mountains National Park. Environ. Pollut. 95, 13-18 (1997).

Coulston, J., Smith, G. \& Smith, W. Regional assessment of ozone sensitive tree species using bioindicator plants. Environ. Monit. Assess. 83, 113-127 (2003). 
Davis, D. D. \& Skelly, J. M. Growth response of four species of eastern hardwood tree seedlings exposed to ozone, acidic precipitation, and sulfur dioxide. J. Air Waste Manage. Assoc. 42, 309-311 (1992).

Felzer, B. et al. Future effects of ozone on carbon sequestration and climate change policy using a global biogeochemical model. Clim. Change 73, 345-373 (2005).

Fowells, H. A. Silvics of Forest Trees of the United States. Agricutural. Handbook. (US Dep. Agric., 1965).

Fowler, D. et al. Effects of land use on surface-atmosphere exchanges of trace gases and energy in Borneo: comparing fluxes over oil palm plantations and a rainforest. Phil. Trans. R. Soc. B. 366, 3196-3209 (2011).

Geron, C., Harley, P. \& Guenther, A. Isoprene emission capacity for US tree species. Atmos. Environ. 35, 3341-3352 (2001).

Guenther, A. et al., A global model of natural volatile organic compound emissions. J. Geophys. Res. 100, 8873-8892 (1995).

Goudriaan, J. \& Van Laar, H. H. Modelling Potential Crop Growth Processes: Textbook With Exercises. (Springer, Netherlands, 1994).

Grimm, V. et al. Pattern-oriented modeling of agent-based complex systems: lessons from ecology. Science 310, 987-991 (2005).

Guenther A. B. et al., Estimates of global terrestrial isoprene emissions using MEGAN (Model of Emissions of Gases and Aerosols from Nature). Atmos. Chem. Phys. 6, 3181-3210 (2006).

Guenther A. B. et al. The Model of Emissions of Gases and Aerosols from Nature version 2.1 (MEGAN2.1): an extended and updated framework for modeling biogenic emissions. Geosci. Model Dev. 5, 1471-1492 (2012). 
Hardin, J. W., Leopold, D. J. \& White, F. M. Harlow \& Harrar's Textbook of Dendrology. (McGraw-Hill, New York, 2001).

Hickman, J. E., Wu, S., Mickley, L. J. \& Lerdau, M. T. Kudzu (Pueraria montana) invasion doubles emissions of nitric oxide and increases ozone pollution. Proc. Natl. Acad. of Sci. USA 107, 10115-10119 (2010).

Iversen, C. M., Keller, J. K., Garten, C. T. \& Norby, R. J. Soil carbon and nitrogen cycling and storage throughout the soil profile in a sweetgum plantation after 11 years of $\mathrm{CO}_{2}$ enrichment. Glob. Change Biol. 18, 1684-1697 (2012).

Krupa, S. V. \& Kickert, R. N. The greenhouse effect: impacts of ultraviolet-B (UV-B) radiation, carbon dioxide $\left(\mathrm{CO}_{2}\right)$, and ozone $\left(\mathrm{O}_{3}\right)$ on vegetation. Environ. Pollut. 61, 263-393 (1989).

Kubiske, M., Quinn, V., Marquardt, P. \& Karnosky, D. Effects of elevated atmospheric $\mathrm{CO}_{2}$ and/or $\mathrm{O}_{3}$ on intra- and interspecific competitive ability of aspen. Plant Biol. 9, 342-355 (2007).

Laurence, J. A., Kohut, R. J., Amundson, R. G., Weinstein, D. A. \& MacLean, D. C. Response of sugar maple to multiple year exposures to ozone and simulated acidic precipitation. Environ. Pollut. 92, 119-126 (1996).

Lerdau, M. A positive feedback with negative consequences. Science 316, 212-213 (2007).

Lerdau, M. \& Slobodkin, L. Trace gas emissions and species-dependent ecosystem services. Trends Ecol. Evol. 17, 309-312 (2002).

Lombardozzi, D., Levis, S., Bonan, G., Hess, P. G. \& Sparks, J. P. The influence of chronic ozone exposure on global carbon and water cycles. J. Clim. 28, 292-305(2015).

Lombardozzi, D., Sparks, J. P. \& Bonan, G. Integrating $\mathrm{O}_{3}$ influences on terrestrial processes: photosynthetic and stomatal response data available for regional and global modeling. Biogeosciences 10, 6815-6831 (2013). 
Loreto, F. \& Velikova, V. Isoprene produced by leaves protects the photosynthetic apparatus against ozone damage, quenches ozone products, and reduces lipid peroxidation of cellular membranes. Plant Physiol. 127, 1781-1787 (2001).

Matyssek R. et al. Advances in understanding ozone impact on forest trees: messages from novel phytotron and free-air fumigation studies. Environ. Pollut. 158, 1990-2006 (2010).

Matyssek R. et al. Enhanced ozone strongly reduces carbon sink strength of adult beech (Fagus sylvatica) - Resume from the free-air fumigation study at Kranzberg Forest. Environ. Pollut. 158, 2527-2532 (2010).

McLaughlin, S. B., Nosal, M., Wullschleger, S. D. \& Sun, G. Interactive effects of ozone and climate on tree growth and water use in a southern Appalachian forest in the USA. New Phytol. 174, 109-124(2007).

Mooney, H. A., Vitousek, P. M. \& Matson, P. A. Exchange of materials between terrestrial ecosystems and the atmosphere. Science 238, 926-932 (1987).

Reich, P. B. Quantifying plant response to ozone: a unifying theory. Tree Physiol. 3, 63-91 (1987).

Rudd, M. A. et al. Generation of priority research questions to inform conservation policy and management at a national level. Conserv. Biol. 25, 476-484 (2011).

Shugart, H. H. A Theory of Forest Dynamics: The Ecological Implications of Forest Succession Models. (Springer-Verlag, New York, 1984).

Sitch, S., Cox, P., Collins, W. \& Huntingford, C. Indirect radiative forcing of climate change through ozone effects on the land-carbon sink. Nature 448, 791-794 (2007).

Schaub, M. et al. Physiological and foliar injury responses of Prunus serotina, Fraxinus americana, and Acer rubrum seedlings to varying soil moisture and ozone. Environ. Pollut. 124, 307-320 (2003). 
Sharkey T. D. Why plants emit isoprene. Nature 374, 769 (1995).

Sharkey, T. D. \& Monson, R. K. The future of isoprene emission from leaves, canopies and landscapes. Plant Cell Environ. 37, 1727-1740 (2014).

Shugart, H. H. \& Woodward, F. I. Global Change and the Terrestrial Biosphere: Achievements and Challenges. (John Wiley \& Sons, New York, 2011).

Shuman, J. K., Shugart, H. H. \& Krankina, O. N. Testing individual-based models of forest dynamics: Issues and an example from the boreal forests of Russia. Ecol. Model. 293, $102-$ $110(2013)$.

Samuelson, L. J. Ozone-exposure responses of black cherry and red maple seedlings. Environ. Exp. Bot. 34, 355-362 (1994).

Talhelm A. F. et al. Elevated carbon dioxide and ozone alter productivity and ecosystem carbon content in northern temperate forests. Glob. Change Biol. 20, 2492-2504 (2014).

Tjoelker, M. G., Volin, J. C., Oleksyn, J. \& Reich, P. B. Light environment alters response to ozone stress in seedlings of Acer saccharum Marsh. and hybrid Populus L. I. in situ net photosynthesis, dark respiration and growth. New Phytol. 124, 627-636 (1993).

Van Miegroet, H., Norby, R. J. \& Tschaplinski, T. J. Nitrogen fertilization strategies in a shortrotation sycamore plantation. Forest Ecol. and Manag. 64, 13-24 (1994).

Vickers, C. E., Gershenzon, J., Lerdau, M. T. \& Loreto, F. A unified mechanism of action for volatile isoprenoids in plant abiotic stress. Nat. Chem. Biol. 5, 283-291 (2009).

Wang, B, Shugart, H.H., Lerdau, M.T., (2017a). An individual-based forest volatile organic compounds emission model—UVAFME-VOC v1.0. Ecological Modelling, 350, 69-78

Weinstein, D. A. The Long-term Nutrient Retention Properties of Forest Ecosystems: A Simulation Investigation. (University of Tennessee, 1982). 
Weinstein, D. A., Gollands, B. \& Retzlaff, W. A. The effects of ozone on a lower slope forest of the Great Smoky Mountain National Park: simulations linking an individual tree model to a stand model. Forest Sci. 47, 29-42 (2001).

Wittig, V. E., Ainsworth, E. A. \& Long, S. P. To what extent do current and projected increases in surface ozone affect photosynthesis and stomatal conductance of trees? A meta-analytic review of the last 3 decades of experiments. Plant Cell Environ. 30, 1150-1162 (2007).

Wittig, V. E., Ainsworth, E. A., Naidu, S. L., Karnosky, D. F. \& Long, S. P. Quantifying the impact of current and future tropospheric ozone on tree biomass, growth, physiology and biochemistry: a quantitative meta-analysis. Glob. Change Biol. 15, 396-424 (2009).

Zak D. R. et al. Belowground competition and the response of developing forest communities to atmospheric $\mathrm{CO}_{2}$ and $\mathrm{O}_{3}$. Glob. Change Biol. 13, 2230-2238 (2007).

Zak, D. R., Pregitzer, K. S., Kubiske, M. E. \& Burton, A. J. Forest productivity under elevated $\mathrm{CO}_{2}$ and $\mathrm{O}_{3}$ : positive feedbacks to soil $\mathrm{N}$ cycling sustain decade-long net primary productivity enhancement by $\mathrm{CO}_{2}$. Ecol. Lett. 14, 1220-1226 (2011).

Zanne A. E. et al. Data from: Towards a Worldwide Wood Econimics Spectrum. (Dryad Data Repository, 2009).

\subsection{Supplementary materials}




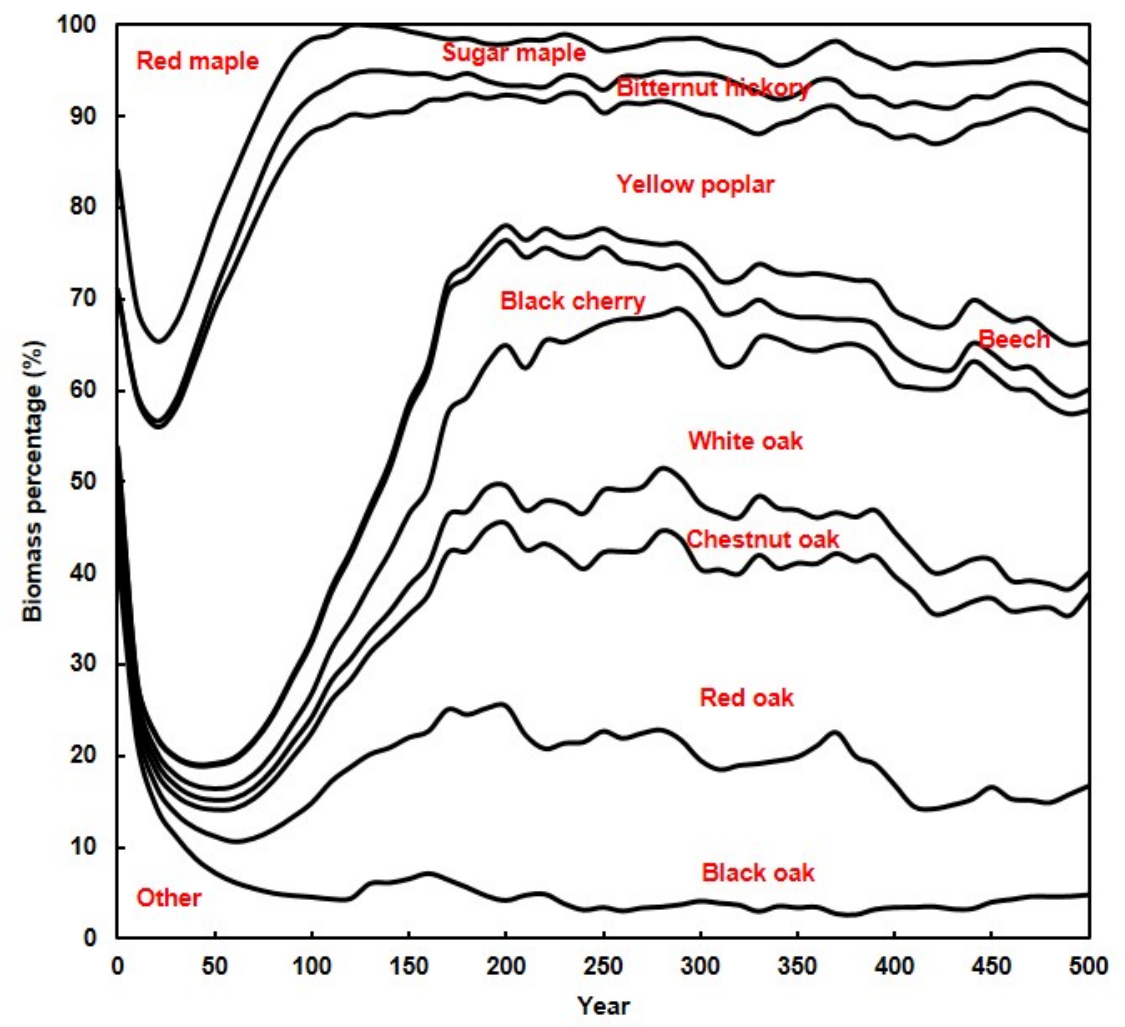

Supplementary Figure 1 Succession of the deciduous forest over 500 years without $\mathrm{O}_{3}$. The vertical distance between two lines represents the percentage of total biomass comprised by each species. The 'other' species refers to all the remaining 22 species except for the 10 listed. Red maple- Acer rubrum, sugar maple-Acer saccharum, Bitternut hickory-Carya cordiformis, Yellow poplar-Liriodendron tulipifera, beech-Fagus grandifolia, white oak-Quercus alba, chestnut oakQuercus prinus, red oak-Quercus rubra, and black oak-Quercus velutina. 


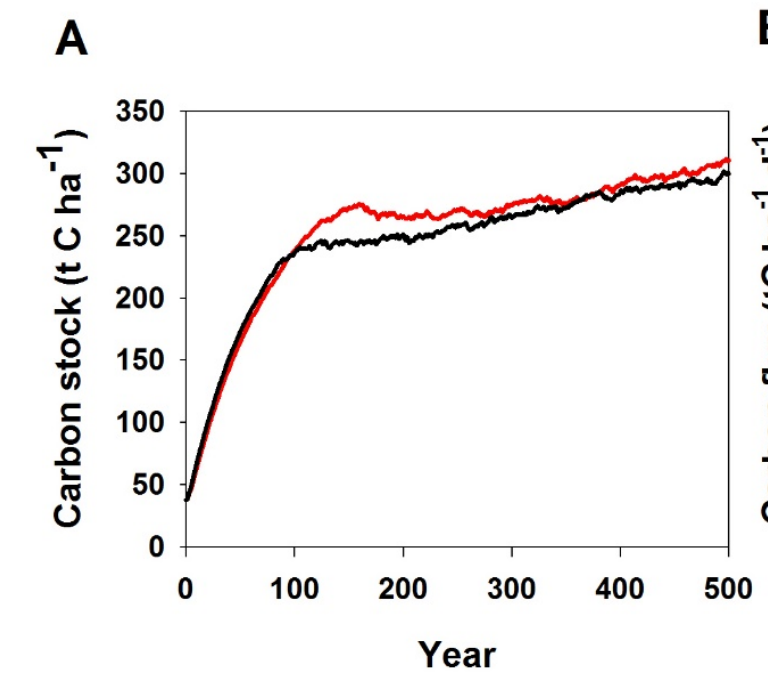

B

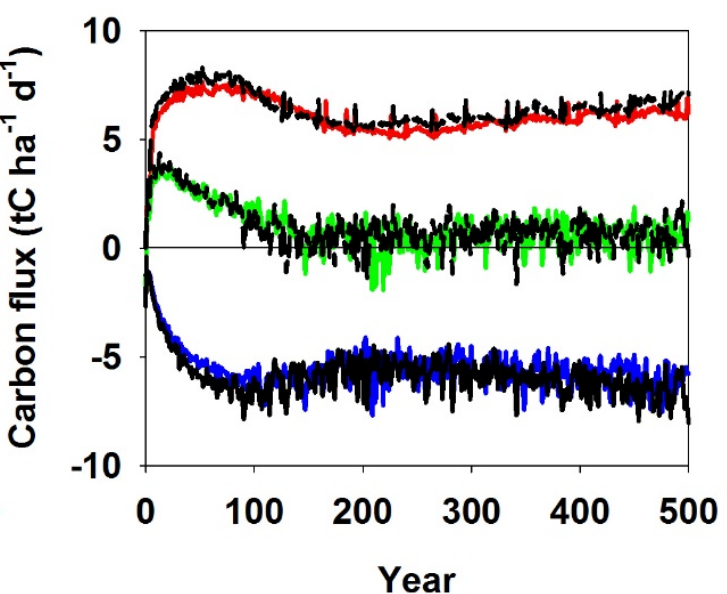

Supplementary Figure 2 Forest carbon stock and flux changes over succession due to $\mathrm{O}_{3}$. Forest carbon (biomass and soil carbon) dynamics over succession (dark and red line denote without $\mathrm{O}_{3}$ and with $\mathrm{O}_{3}$, respectively) (A). Forest NPP (net primary productivity, red), soil respiration (blue), and NEP (net ecosystem productivity, green) responses to $\mathrm{O}_{3}$ over the succession (B). 

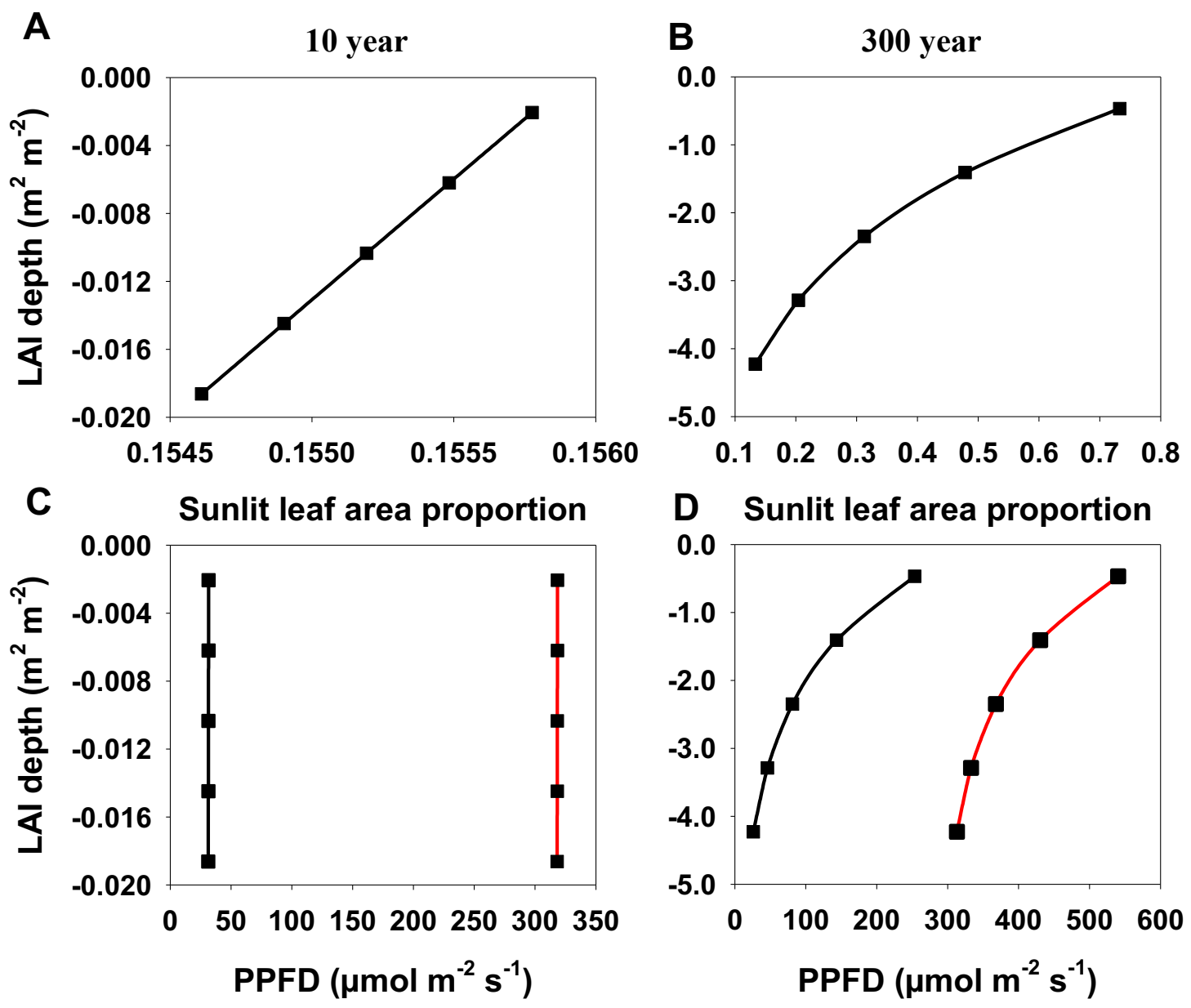

Supplementary Figure 3 Dynamics of sunlit leaf area fraction and sunlit and shaded leaf-level PPFD (photosynthetic photon flux density) profile. Sunlit leaf area fraction gradient (A, B) and sunlit leaf-level and shaded leaf-level PPFD changes $(\mathbf{C}, \mathbf{D})$ within the canopy of only one tree of Quercus alba, which is randomly chosen from the simulated forest stand at 10 year $(\mathbf{A}, \mathbf{C})$ and 300 year $(\mathbf{B}, \mathbf{D})$. Values represent the 13:00 of day 201 in each year. The negative axis values mean increased canopy depth. The light levels change shown by the two trees of the same species at two different stages of the forest stand development clearly shows that because of forest composition and structure change the shade-tolerant species (here Quercus alba) will become dominant in the forest, enabling them to receive more light. 


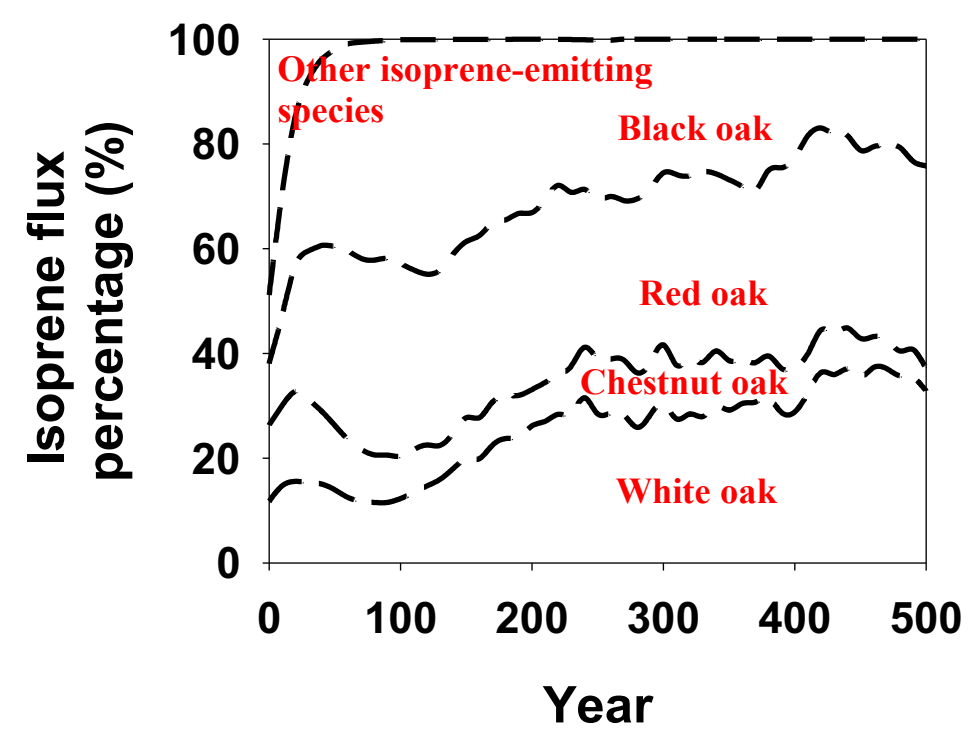

Supplementary Figure 4: Relative contribution to total isoprene emissions by individual species without $\mathrm{O}_{3}$ pressure. The interval between two lines represents the percentage of total isoprene emissions comprised by, from upper to bottom, other isoprene-emitting species, black oak, red oak, chestnut oak, and white oak, respectively. Note the biomass change of these isoprene-emitting species are basically same with their isoprene emission dynamics. Hence, the graph is not shown. 
A

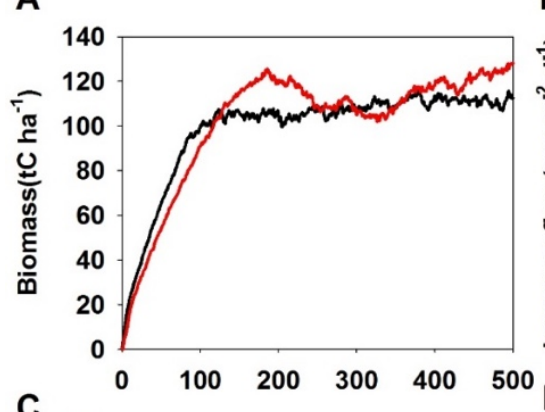

C
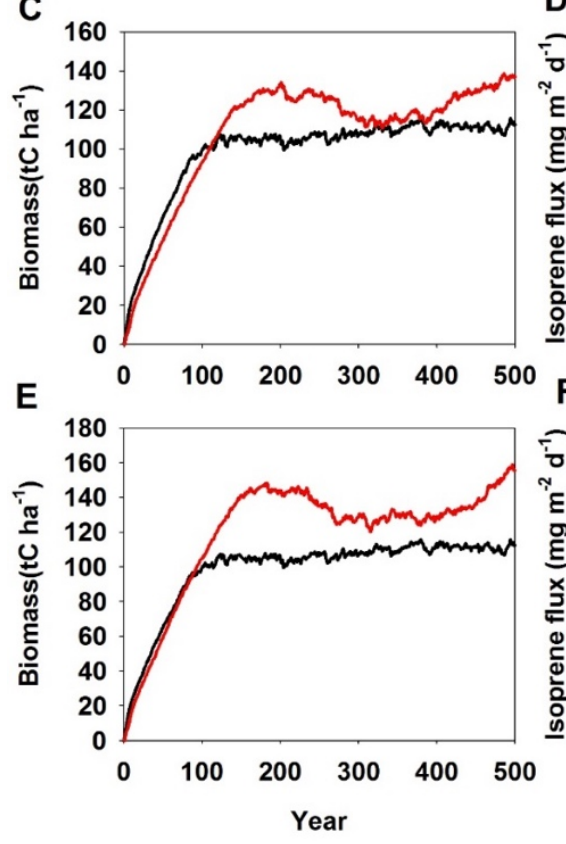

B
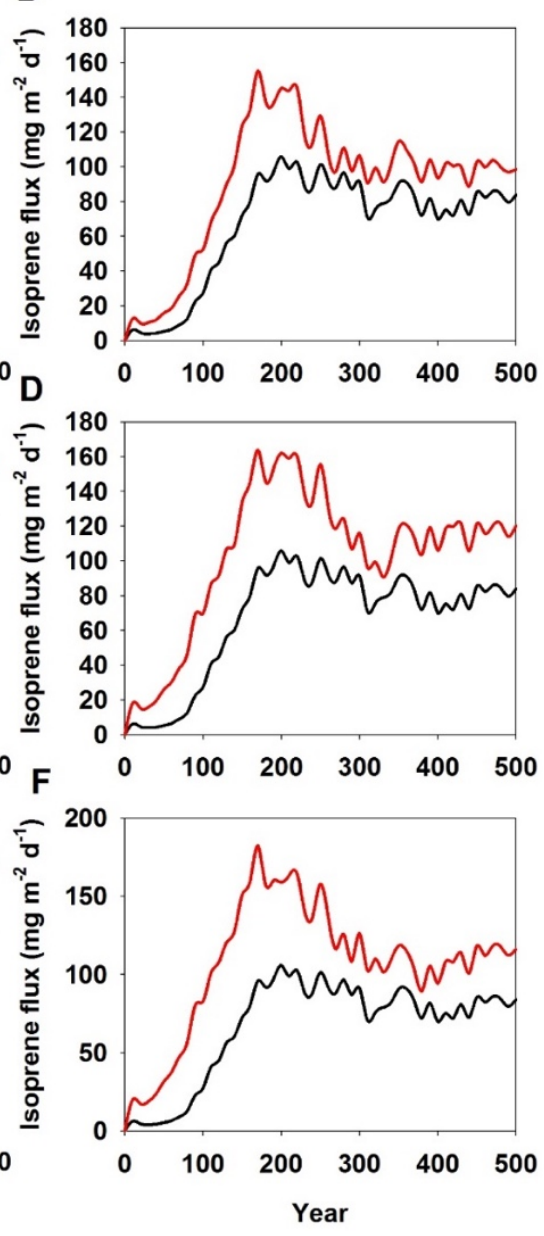

Supplementary Figure S5 Responses of biomass and isoprene flux to $\mathrm{O}_{3}$ stress of different levels. A growth reduction of $10 \%, 20 \%$, and $30 \%$ for resistant, intermediate, and sensitive species, respectively (A, B); of $10 \%, 20 \%$, and $40 \%$, respectively $(\mathbf{C}, \mathbf{D})$; and of $0,10 \%$, and $40 \%$, respectively (E, F) are applied to drive the simulations. Such various combinations of ozoneinduced growth reduction for species of different sensitivity always show unsuppressed biomass accumulation and enhanced isoprene flux. Hence, these results are presented to argue that the modelling results discussed throughout this work with a growth reduction of $0,10 \%$, and $20 \%$ for resistant, intermediate, and sensitive species, respectively, are convincing. 


\section{Chapter 5 The importance of biodiversity in mediating climate change-air quality feedbacks}

\subsection{Introduction}

Air quality change is closely linked to climate change (Jacob \& Winner 2009). Aside from the direct climatic effects initiated by the atmospheric physico-chemical processes (Jacob \& Winner 2009; Weaver et al. 2009), the biosphere plays a key role by releasing large quantities of volatile organic compounds (VOC; Guenther et al. 1995, 2006), acting as precursors of tropospheric ozone $\left(\mathrm{O}_{3}\right)$ in presence of relatively high concentration of nitrogen oxides (NOx) (Atkinson \& Arey 2003; Royal Society, 2008) and of secondary organic aerosols (SOA) (Atkinson \& Arey 2003; Kulmala et al. 2013). Climate warming-initiated effects that cascade through this climate-biosphere-atmospheric chemistry chain have received the most attention (e.g., Weaver et al. 2009; Ito et al. 2009; Pacifico et al. 2012; Fu et al. 2015). Currently, it is widely accepted that warming can enhance forest VOC emissions (e.g., Sanderson 2003; Heald et al. 2009; Pacifico et al. 2012) and thus aggravate $\mathrm{O}_{3}$ pollution (Sanderson 2003; Fu et al. 2015) and SOA formation (Kulmala et al. 2004; Paasonen et al. 2013). None of these studies, however, explicitly consider the role of terrestrial ecosystem species diversity in influencing VOC emissions.

Impacts of temperature and other factors (e.g., radiation) on phytogenic VOC production are now relatively well understood at cellular-to-leaf scales over relatively short time scales with over half a century of research (Vickers et al. 2009; Loreto and Fineschi 2015; Sharkey and Monson 2017) since the descriptions in the mid-20 $0^{\text {th }}$ century by Haagen-Smit, Went, and colleagues of plant-derived organic compounds that could contribute to $\mathrm{O}_{3}$ and haze formation (Haagen-Smit and Fox, 1954; Went, 1960). Ecosystem-level emissions have been extrapolated from this relatively good understanding of biochemical mechanisms and eco-physiological 
regulation via ecosystem models by aggregating vegetation into plant functional types (PFTs). For instance, well-defined empirically derived quantitative relationships between VOC emissions and environmental factors (notably temperature and light) have been obtained from extensive leaflevel measurements and constitute the cornerstone of regional and global VOC emissions models (Guenther et al. 1995, 2006). With the accumulation of biochemical and eco-physiological knowledge concerning phytogenic VOC production and emissions, process-based models within the dynamic global vegetation model (DGVM) schemes have also been developed (e.g., Arneth et al. 2007a). These models have been coupled with climate and atmospheric chemistry models to investigate climate-biosphere-chemistry feedbacks in the earth system. These physiologically based aggregate models produce the conclusion that climate warming enhances VOC emissions and holds a positive relationship both with $\mathrm{O}_{3}$ level (i.e., the so-called 'climate penalty'; Sanderson 2003; Ito et al. 2009; Fu et al. 2015) and SOA formation (e.g. Weaver et al. 2009). However, the lumped approach to representing vegetation in such global and regional models, either static or dynamic, cannot capture the hierarchical and dynamic nature of natural systems, neglecting the inherent interspecific heterogeneity and complex interactions (Huston et al. 1988; Purves \& Pacala 2008; Scheiter et al. 2013). This aggregation of vegetation represents one of the major uncertainties in the current modelling of climate-biosphere-chemistry feedbacks (Lerdau 2007; Purves \& Pacala 2008; Schurgers et al. 2011).

One of the longest known and most robust results from studies of phytogenic VOCs is that their production and emissions are strongly contingent on species (e.g. Lerdau et al., 1997; Monson et al. 2013). Across global biomes a mixture of emitters and non-emitters of different VOC species in an ecosystem is ubiquitous (Loreto and Fineschi 2015). Changes in ecosystem composition that involve a shift in the relative abundance of species with differing VOC emission capacity can, in 
principle, be caused by climate warming or other disturbances from global environmental changes. Such changes in diversity have the potential to significantly influence the system-level emission capacity and even dominate physiological effects (Lerdau \& Slobodkin 2002). Therefore, it is essential to explicitly incorporate the role of species diversity change when studying the effects of various environmental changes on forest VOC emissions. Among the huge number of different VOC species isoprene $\left(\mathrm{C}_{5} \mathrm{H}_{8}, 2\right.$-methyl 1-3-butadiene) is the most abundant phytogenic VOC and plays the largest role in tropospheric oxidant dynamics (Atkinson \& Arey 2000; Guenther et al. 2006; Pacifico et al. 2009). Isoprene is thus an ideal candidate for investigating impacts of forest species diversity changes on system-scale emissions.

Here we specifically examine the impacts of climate warming on forest isoprene emissions over long time scales mediated both indirectly by compositional change and directly by leaf-level response. We hypothesize that compositional changes may either enhance or counteract the direct warming effects on leaves depending on the specific forest systems. Testing this hypothesis in field studies is logistically and methodologically challenging due to the long time duration required. Instead, an experimental system of a temperate deciduous forest in the southeastern United States is built using an individual-based forest isoprene emissions model-UVAFMEVOC (v1.0) (Wang et al. 2017a), which can estimate isoprene emissions based on an explicit simulation of the size and age of different species and their competition for light, water, and nutrient in a forest community. This model has demonstrated satisfactory simulation of forest compositional and structural dynamics and ecosystem level isoprene emissions in this area (Wang et al. 2016; Wang et al. 2017a). For example, with its prominent 'individual-based' feature this model has been successfully applied to test the hypothesis that extinction of the American Chestnut (Castanea dentata) in the forests of the eastern United States in the late $19^{\text {th }}$ and early $20^{\text {th }}$ centuries 
enhanced isoprene emissions by favoring oak species (Quercus spp.) (Wang et al. 2017a). Using this individual-based experimental system of a temperate forest we investigated the impacts of climate warming on forest dynamics and isoprene emissions. The results presented here represent a pioneering work examining how biodiversity responses may meditate climate change impacts on atmospheric chemistry.

\subsection{Materials and Methods}

\subsubsection{Model description}

UVAFME-VOC (v1.0) (Wang et al. 2017a) is an individual-based forest volatile organic compounds emissions model built from the state-of-the-art forest gap model, University of Virginia Forest Model Enhanced (UVAFME), with the philosophy of IBM (individual-based model) being capable of unifying ecological theory of biodiversity and ecosystem function (Shugart 1984; Huston et al 1988; Grimm et al. 2016). UVAFME-VOC simulates VOC emissions based on an explicit modelling of forest dynamics by computing the growth, death, and regeneration of each individual tree of different species and their competition for light, moisture, and nutrient, from which system-level VOC emissions are simulated by explicitly computing and summing up each individual's emissions with an explicit simulation of radiative transfer and leaf function through the canopy (Wang et al. 2017a). It is just this individual-based modelling of forest dynamics that enables UVAFME-VOC apply explicitly species-based emission factor dynamically, distinguishing it from other PFT-based VOC models (e.g., Guenther et al. 2006; Arneth et al. 2007a).

In detail, the basic simulation unit of an individual tree is described by geometry variables

primarily including diameter at the breast height (DBH), diameter at the canopy height (DCH), 
tree height (H), and leaf area (LAI) (Fig. S6). These structural units are quantitatively linked by allometric relationships. Forest dynamics are thus simulated at an annual time step by computing the growth, mortality, and regeneration of such individual trees of different species. Tree growth is defined as an annual increment of $\mathrm{DBH}$, which is computed by multiplying the optimal growth by scalars of available light, temperature, nutrient, and soil moisture. Tree death is a stochastic process, which is simulated by calculating the annual mortality probability taking into consideration of both intrinsic mortality and environment-induced mortality. Identically, the annual establishment of new trees in terms of the number, size, and species is also a stochastic process by randomly selecting the species that establish in a given year from the candidate species pool which is comprised by the species that can survive in a given environment determined by the relative size of seedling bank of a species. See ST1 for details of model formulations.

Ecosystem-level isoprene emission, $F_{I S O}$, is calculated as a summation of the emissions from each individual tree at five canopy layers with a differentiation between sunlit and shaded leaves at an hourly time step according to the widely used empirical approach developed by Guenther et al. (1995, 2006):

$$
F_{I S O}=\sum_{i=0}^{n} \sum_{j=1}^{5} E_{S}(i) C_{T}(i)\left[L_{\text {sun }}(i j) C_{L}(i j)+L_{\text {shade }}(i j) C_{L}(i j)\right](1)
$$

where $i$ denotes one of $n$ trees in the forest, $j$ denotes one of five layers of each individual tree's canopy, Es represents the species-specific standard leaf-level emission rate of isoprene, $L_{\text {sun }}$ and $L_{\text {shade }}$ represents sunlit and shaded leaf area, and $C_{T}$ and $C_{L}$ account for light- and temperatureinduced variability, respectively, which are calculated according to Guenther et al. (1995): 


$$
\begin{gathered}
C_{T}=\frac{\exp \frac{\mathrm{C}_{\mathrm{T} 1}\left(\mathrm{~T}-T_{S}\right)}{\mathrm{R} T_{S} \mathrm{~T}}}{1+\exp \frac{C_{T 2}\left(\mathrm{~T}-\mathrm{T}_{\mathrm{M}}\right)}{\mathrm{R} T_{S} \mathrm{~T}}}(2) \\
C_{L}=\frac{\alpha C_{L 1} \mathrm{~L}}{\sqrt{1+\alpha^{2} \mathrm{~L}^{2}}}(3)
\end{gathered}
$$

where $\mathrm{R}=8.314 \mathrm{~J} \mathrm{~K}^{-1} \mathrm{~mol}^{-1}, \mathrm{C}_{\mathrm{T} 1}=95,000 \mathrm{~J} \mathrm{~mol}^{-1}, \mathrm{C}_{\mathrm{T} 2}=230,000 \mathrm{~J} \mathrm{~mol}^{-1}, \mathrm{~T}_{\mathrm{M}}=314 \mathrm{~K}, \mathrm{~T}_{\mathrm{S}}=303 \mathrm{~K}$, $\alpha=0.0027$, and $\mathrm{C}_{\mathrm{L} 1}=1.066$. $\mathrm{T}$ is hourly leaf temperature, which is assumed to be equal to hourly air temperature and constant through the canopy. $\mathrm{L}$ is hourly leaf-level PPFD $\left(\mu \mathrm{mol} \mathrm{m} \mathrm{m}^{-2} \mathrm{~s}^{-1}\right)$ at each canopy layer for sunlit and shaded leaves of each individual tree obtained with an explicit computing of light behavior within the stand and tree crown with a distinction between direct beam and diffuse radiation considering the shading by taller and surrounding trees, interception, reflection, scattering, and absorption.

Inputs required to drive this model include species-specific parameters quantifying species' fundamental silvics (including tree geometry, growth, mortality, and regeneration, as well as responses to environmental factors), site conditions (including soil physiochemical properties and topographical information), and climate data (including meteorological data of temperature and precipitation). The outputs include tree size, number, basal area, leaf area, biomass, VOC flux, as well as other biogeochemical and hydrological variables. Wang et al. (2017a) is referred to for more model details concerning the development, validation, and application of this model.

\subsubsection{Model parameterization}

We applied UVAFME-VOC to simulate the temperate deciduous forest in the eastern Tennessee, located at the southern Appalachian region in the southeastern United States. This site was chosen because long term forest dynamics and composition data are relatively rich, facilitating model validation, and species-specific isoprene data are relatively complete (Wang et al 2017a). 
Thirty-two species including both deciduous and coniferous trees native to this region are included in this simulation, among which ten species are isoprene producers. The standard isoprene emission rates of these isoprene-emitting species are listed in Table S1. All the other parameters (twenty-four in total) describing silvicultural properties of each species required as inputs are listed separately in Table S2. The sources of these parameter values are further described in ST2.

Thirty years of meteorological data for monthly precipitation $(\mathrm{mm})$ and monthly maximum and minimum temperature $\left({ }^{\circ} \mathrm{C}\right)$ ranging from 1981 to 2010 were obtained from the NOAA (National Oceanic and Atmospheric Administration) meteorological station at Oak Ridge ATDD, Tennessee, USA (GHCND: USW00003841; Latitude/Longitude: 36.0028\%-84.2486º Elevation: $275.8 \mathrm{~m}$ ) to compute monthly average precipitation, monthly maximum and minimum temperature, and their standard deviations. Soil-related parameters including organic layer carbon and nitrogen, active layer carbon and nitrogen, and base soil layer carbon are estimated according to Johnson and Van Hook (2012). Values of $25 \mathrm{~cm}$ and $12.5 \mathrm{~cm}$ were used for soil field capacity and soil permanent wilting point, respectively.

\subsubsection{Climate warming simulation}

Starting with the FORET (Shugart and West 1977) through a diverse range of versions in different forest systems (Shugart 1984; Shugart and Woodward 2011) to UVAFME used here, the capability of individual-based forest gap models in simulating climate change effects on forest dynamics has been a central topic of interest. Shugart and Woodward (2011) offer a review of the testing of these models, in many cases against independent data on climate change responses of forests. Furthermore, many of these tests are against compositional changes in forests under paleoclimate conditions or along altitudinal gradients. To examine the forest responses to climate warming, two levels of warming (temperature increase by $2^{\circ} \mathrm{C}$ and $4^{\circ} \mathrm{C}$ on the basis of base 
climate) are simulated. According to the study by Shuman et al. (2011) (which evaluated the sensitivity of Siberian larch forests to climate change using an earlier version of UVAFME), these climate changes are achieved in 200 years from year 0 to 200 in a linear way, which are followed by another 300-year simulation with these stabilized climates. See Fig. S1 for the modelled climate warming dynamics over the 500-yr simulation across the three different warming treatments.

\subsubsection{Simulation methodology}

UVAFME-VOC (and several other antecedent models) are normally evaluated by Monte Carlo simulation of a large landscape sampled by a set of independent sample plots. In these cases, each plot results from a single simulation from the model. An average of these simulation of independent plots corresponds to a shifting-mosaic steady-state landscape (Bormann and Likens 1979). Bugmann et al. (1996) have suggested that 150-200 replicate plots are needed to provide a sample which warrants a statistically quasi-stable landscape response of the forest landscape. Here we run this model with 200 independent plots of a size of $500 \mathrm{~m}^{2}$ starting from bare ground (without a spin-up) for 500 years. All the results presented are the average of such 200 simulated plots.

\subsection{Results}

\subsubsection{Forest compositional changes.}

Successional dynamics of the forest over 500 years without simulated warming effects involve changes in 10 abundant species and 22 other species (Fig.1a). Initially for a forest succession from an open plot, the 'other' species category, mostly composed of pioneer species, dominates the forest with approximately $50 \%$ of the total biomass. Soon, both Acer rubrum and 

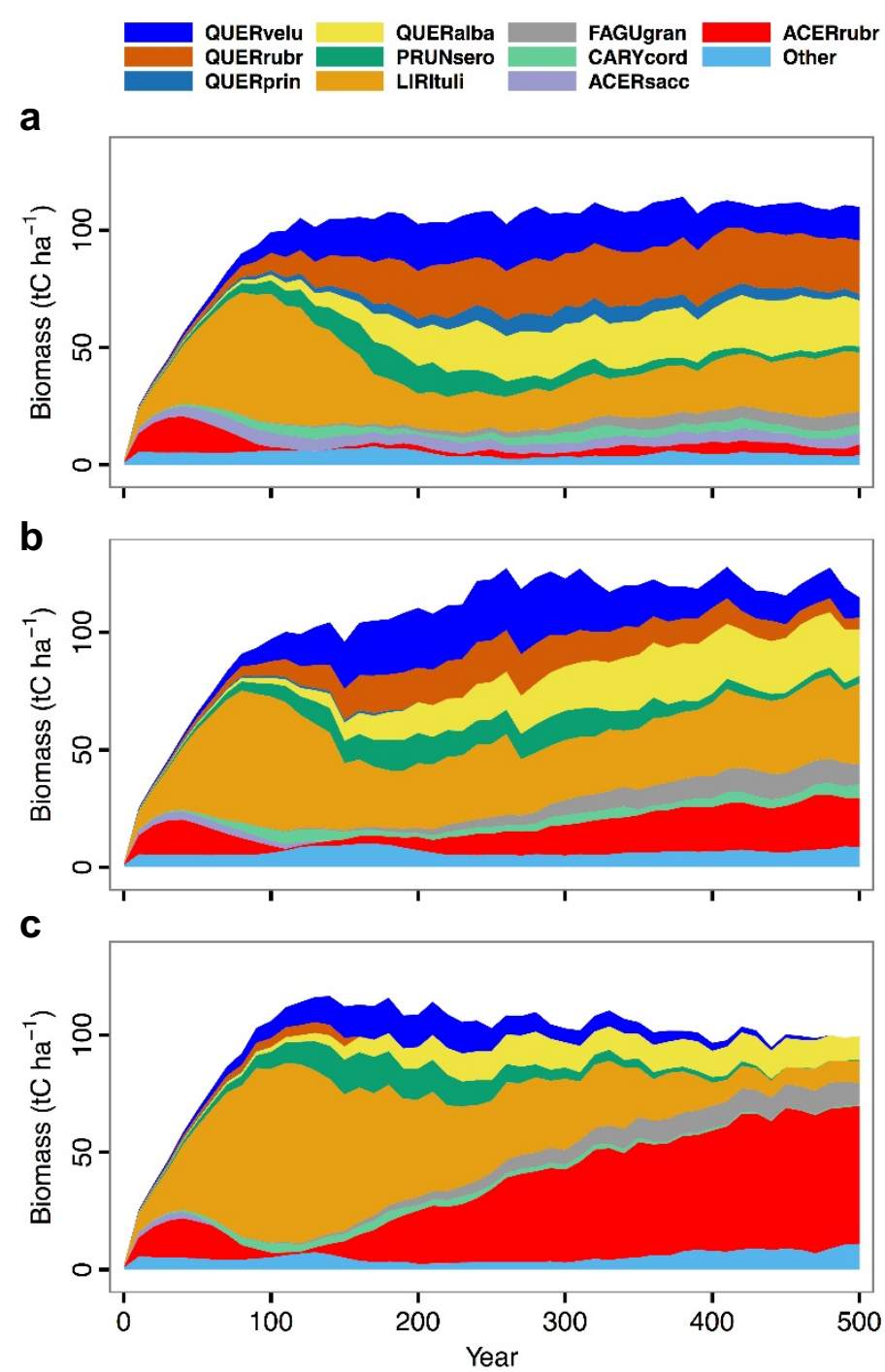

Fig.1 Forest compositional dynamics in response to warming over 500-year simulation. a-c is the base run, $2^{\circ} \mathrm{C}$, and $4{ }^{\circ} \mathrm{C}$ warming, respectively. The width of each color band represents the biomass $\left(\mathrm{tC} \mathrm{ha}^{-1}\right)$ of different species at a specific year. QUERvelu: black oak; QUERrubr: red oak; QUERprin: Chestnut oak; QUERalba: white oak; PRUNsero: black cherry; LIRItuli: yellow poplar; FAGUgran: American beech; CARYcord: bitternut hickory; CASTdent: American Chestnut; ACERsacc: sugar maple; ACERrubr: red maple; and Other: all the remaining species simulated (see Table S2). 
Liriodendron tulipifera become increasingly important, but A. rubrum eventually loses to the larger, faster-growing L. tulipifera trees, which persist and become dominant. After L. tulipifera declines over time, trees of four late-successional oak species (Quercus alba, Q. velutina, Q. rubra, and $Q$. prinus) become increasingly important, together accounting for approximately $75 \%$ of the stand biomass at year 300 . The composition of the forest stabilizes and is eventually dominated by aforementioned oaks, along with L. tulipifera and two maples (A. rubrum and A. saccharum). This simulated composition matches field survey of forest composition in the southern Appalachian mountain region both qualitatively and quantitatively (Shugart and West 1977; Wang et al. 2017a).

Climate warming (Fig. S1) exerts significant impacts on the forest dynamics in terms of species composition and structure (Fig.1b, c). Four major Quercus species $(Q$. velutina, Q. rubra, Q. prinus, and $Q$. alba), mainly late successional species, lose their position in the stand over the 500-year simulation with continuous warming. In particular, $Q$. prinus almost totally disappears from the simulation when warmed by both $2^{\circ} \mathrm{C}$ and $4^{\circ} \mathrm{C}$. These significant changes are accompanied by changes in L. tulipifera and A. rubrum. L. tulipifera, a fast-growing, shadeintolerant species, does not show an apparent change with $2^{\circ} \mathrm{C}$ warming but strong changes with $4^{\circ} \mathrm{C}$ warming when L. tulipifera dominates the stand longer and eventually loses its position severely. By contrast, A. rubrum shows a dramatic increase with continuous warming. Overall, with continuous warming this simulation presents compositional changes of an increase of red maple (A. rubrum) versus oaks (Quercus spp.) declines.

These simulated compositional changes are congruent with the dramatic changes in composition across the temperate deciduous forests in the eastern United States during the past century. Red maple, a 'super-generalist' that has characteristics of both early and late successional species (Abrams 1998), has been widely documented with a large expansion (e.g., Abrams 1998; 
Mcdonald et al. 2003; Fei and Steiner 2007), which is in stark contrast to a decline of oaks (e.g., Abrams 1998; Mcdonald et al. 2003; Crosby et al. 2014; Nowacki and Abrams 2015) and sugar maple (Iverson et al. 2008; Bishop et al. 2015). A variety of factors have been proposed to explain such changes including fire suppression, forest management, preferential browsing, insect and disease outbreaks, and climate change (Abrams 1998; Iverson et al. 2008; Pederson et al. 2014; Nowacki and Abrams 2015). This model-based study, capable of teasing out an individual factor, supports the view that climate warming contributed to these observed trends (Davis 1983; Abrams 1998; Speer et al. 2009). These temperature-induced changes are also in agreement with the relatively strong tolerance to warming by red maple that confers big competitive advantages over other species over the forest dynamic development (Fig. S2). With continuous climate warming and other disturbances in the eastern United States such changes are expected to continue.

\subsubsection{Changes in isoprene-emitting species and isoprene emissions}

Ten isoprene-emitting species are present in this simulated forest, of which seven are oak (Quercus) species (Table S1). Among these isoprene-emitting species, the four oak species of $Q$. prinus, $Q$. alba, $Q$. velutina, and $Q$. rubra mostly determine ecosystem isoprene emissions over the long term dynamics, and the remaining six species (hereafter referred to as 'others') only contribute substantially to the ecosystem isoprene emissions at very early successional stages (Fig. S3a). Climate warming-induced forest compositional dynamics alteration, as described above, presents an apparent species diversity change in terms of emitters versus non-emitters of isoprene. The relative changes of these isoprene-emitting species together are significant in the forest in terms of both leaf area and biomass (Fig. 2a; Fig. S4). After an early successional stage, forests that are warming by $2^{\circ} \mathrm{C}$ start to show a decline of isoprene-emitting species. With further warming 


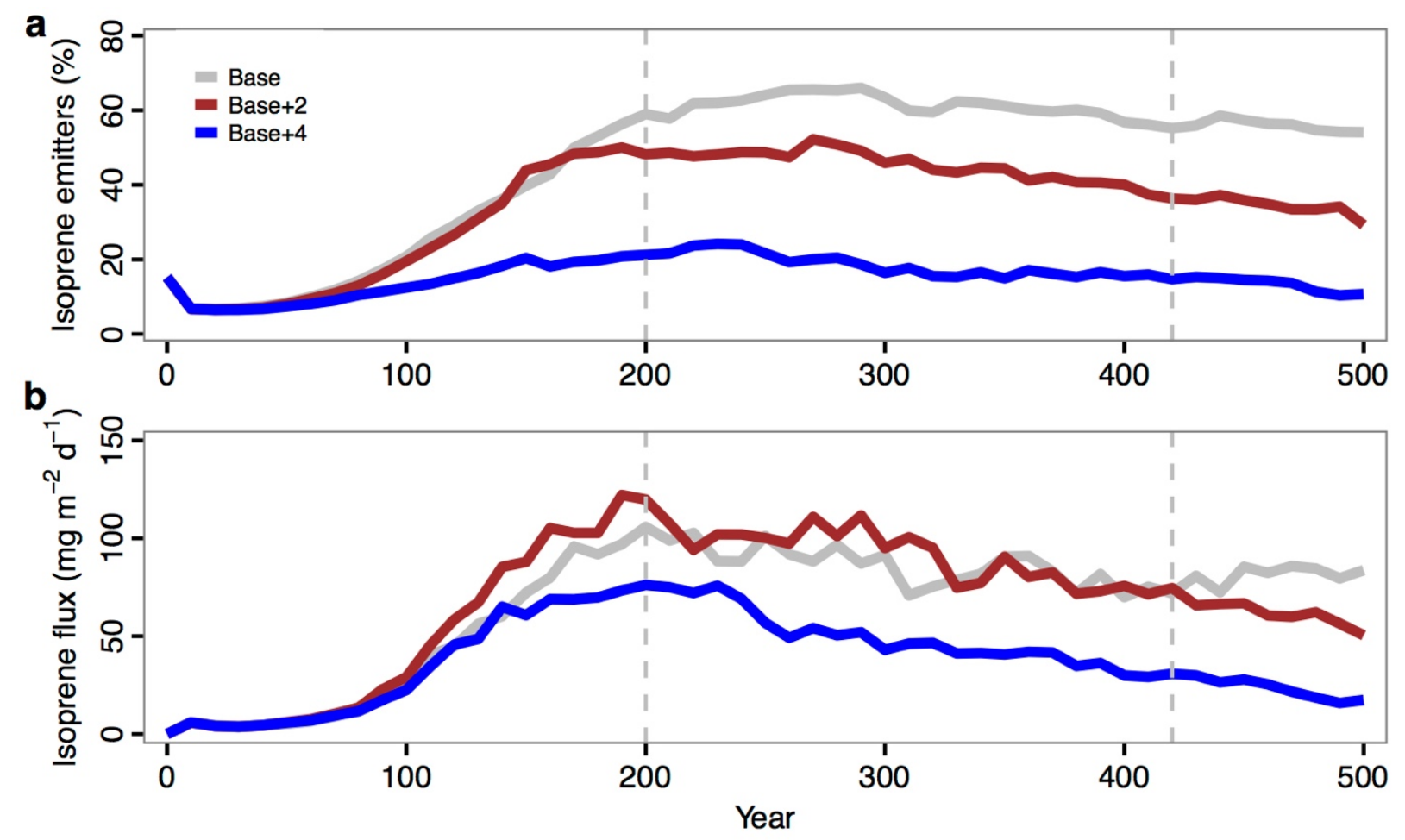

Fig.2 Dynamics of isoprene-emitting species abundance and isoprene flux in response to warming. The abundance of isoprene-emitters is calculated as the percentage of total isoprene emitters (10 species in total listed in Table $\mathrm{S} 1)$ in the forest in terms of tree biomass $\left(\mathrm{tC} \mathrm{ha}^{-1}\right)(\mathrm{a})$. The isoprene emission rate $\left(\mathrm{mg} \mathrm{m}^{-2} \mathrm{~d}^{-1}\right)$ represents the average of daily isoprene emission rate from July of each year (b).

by $4^{\circ} \mathrm{C}$, the emitters show a much earlier decline, and the percentage declines to less than $20 \%$ at a later successional stage. Moreover, warming significantly alters the relative abundance of individual species (Fig. S3b, c). With continuous warming, except for the 'others' category, $Q$. velutina and $Q$. alba become increasingly dominant, while $Q$. prinus and $Q$. rubra gradually 
disappear from the forest. Overall, climate warming significantly inhibits the presence of isopreneemitting species (Quercus spp.) at this location.

These changes in species composition mean that the forest system's isoprene emissions do not simply show an increase as expected from the direct effect of leaf-scale warming enhancement (Fig. S5). With $2^{\circ} \mathrm{C}$ warming isoprene emissions are enhanced initially until the system sees an emission reduction resulting from a decline of isoprene-emitters (Fig.2b). With the isopreneemitters further decreasing and thus warming-enhanced emissions being offset by the reduction arising from a decline of isoprene-emitters, no difference is seen between the base and $2{ }^{\circ} \mathrm{C}$ warming (Fig.2b). By later in succession, the reduction resulting from a decline of isopreneemitters starts to exceed the direct warming-enhancing effect, resulting in suppressed isoprene emissions (Fig.2b). When warmed by $4^{\circ} \mathrm{C}$, the forest's compositional change of emitters decline completely dominates the warming-enhancement effect, strongly inhibiting the isoprene production (Fig.2b). These results clearly show that, over long time scales, forest ecosystems' isoprene emission capacity is predominantly contingent on species composition.

\subsection{Discussion}

This study sheds new insights into the climate warming-air quality feedback mechanisms mediated by the terrestrial biosphere by explicitly considering forest compositional changes. Contrary to the widely seen scale-up from the temperature-dependent leaf level response (e.g., Turner et al. 1991; Sanderson et al. 2003; Heald et al. 2009; Goldstein et al. 2009; Pacifico et al. 2012), climate warming may not enhance forest ecosystems' isoprene emissions because of community-level changes in diversity. There exists a 'threshold' for the forest system examined here in terms of isoprene emission capacity in response to climate warming (Fig. 3). Prior to this 


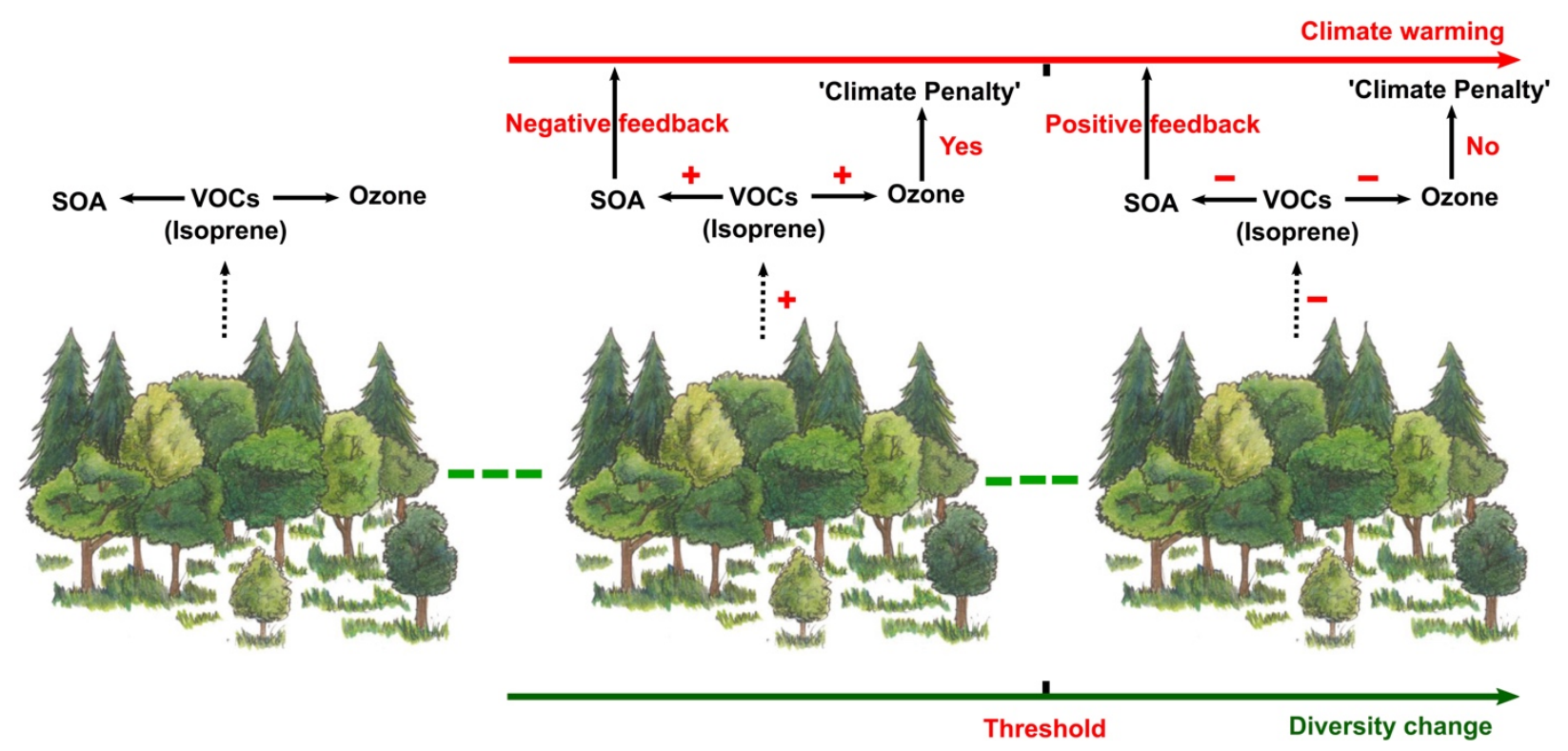

Fig.3 Schematic of climate warming impacts on atmospheric chemistry mediated by forest compositional changes. A threshold exists for forest systems in terms of isoprene production in response to climate warming, where the indirect warming effect (suppression of isoprene emissions from a decline of isoprene-emitting species) offsets the direct effect (enhancement of isoprene production and emission by increasing temperatures). Prior to and beyond this threshold, distinctive feedback mechanisms between climate and atmospheric chemistry mediated by the forests may occur at least regionally in the southeastern United States. Plus $(+)$ and minus (-) signs denote the positive and negative effect, respectively, and it is noteworthy that the isoprene- $\mathrm{O}_{3}$ relationships described here is based on a relatively high level of nitrogen oxides. Note the forest in this figure is for illustrational purpose only and does not necessarily indicate actual composition changes.

'threshold' climate warming can stimulate isoprene emissions, whereas beyond this 'threshold' isoprene emissions can be reduced because of a largely diminished occurrence of isoprene157 
emitting species. Similar 'threshold' phenomena are widely seen in ecosystem functioning under environmental disturbances (Groffman et al. 2006). Such reduced isoprene emissions under climate warming could have significant implications for the atmospheric chemical processes (Fig.3). First, climate warming may not aggravate $\mathrm{O}_{3}$ pollution because of a decline of $\mathrm{O}_{3}$ formation precursors (that is, a possible disappearance of 'climate penalty'), although the warming- $\mathrm{O}_{3}$ relationship is also influenced by other factors including $\mathrm{O}_{3}$ advection and anthropogenic NOx emissions (Atkinson \& Arey 2003; Fiore et al. 2005; Fu et al. 2015). Such a decline of $\mathrm{O}_{3}$ level induced by reduced isoprene emissions has been arguably evidenced by the study of Drewniak et al. (2014), who suggested reduced $\mathrm{O}_{3}$ formation resulting from the red maple expansion at the cost of oak shrinkage in the eastern United States. Second, declines in isoprene emissions may reduce the formation of SOA, which has a cooling effect. Goldstein et al. (2009) has suggested a significant contribution of vegetation isoprene emissions to SOA formation in the southeastern United States. Reduced isoprene emissions herein potentially form a new positive rather than negative feedback mechanism to climate warming (Kulmala et al. 2004; Goldstein et al. 2009; Paasonen et al., 2013). Moreover, methane lifetime could also be reduced by this decline of isoprene emissions (Atkinson \& Arey 2003).

In addition to the species diversity effects, impacts of climate warming on forest isoprene emissions could also be mediated by other secondary indirect pathways whose magnitudes are not yet well constrained and thus not included this modelling study. For instance, warming may both increase the atmospheric water vapor pressure deficit (VPD) and reduce soil moisture, and these changes could indirectly regulate leaf-level isoprene by reducing stomatal conductance and thus increasing leaf temperature and decreasing internal $\mathrm{CO}_{2}$ concentration (Rosenstiel et al. 2003; Seco et al. 2015). These impacts, especially VPD, are still far from being understood well enough to be 
included in VOC modeling studies, whether or not such studies consider species composition explicitly. Although it has been postulated that a VPD increase could enhance isoprene emissions (Zhang et al. 2016), empirical studies have shown varying responses of ecosystem-level isoprene emissions to soil moisture depending on the drought intensity (Seco et al. 2015). There is clearly a need for added research on drought and VPD impacts on VOC emissions.

Although this study focuses on the impacts of increasing temperatures on forest isoprene emissions, another critical factor may be the rising $\mathrm{CO}_{2}$ that drives the warming. Elevated $\mathrm{CO}_{2}$ has been shown under low temperature conditions to inhibit isoprene emissions (Arneth et al 2007b; Sharkey \& Monson 2014). However, recent work has both shown that this $\mathrm{CO}_{2}$-caused reduction in isoprene emission disappears under higher temperatures and offered convincing evidence for the mechanism underlying the temperature-dependency of the $\mathrm{CO}_{2}$-suppression (Sun et al. 2013; Potosnak et al. 2014; Niinemets and Sun 2015; Monson et al. 2016). If the current physiological mechanistic models are correct, then elevated $\mathrm{CO}_{2}$ will not suppress isoprene emissions under high temperatures. If such suppression does not, however, occur under field conditions, then the lack of warming-induced emissions increase observed in this study will occur even earlier in succession. A challenge for extrapolating from the ecosystem considered in this study lies in the dependency of the ecosystem-scale results on the responses of a few particular species. In a sense, this dependency highlights the importance of going beyond plant functional type simplifications in modeling studies.

In summary, this study highlights that both individual metabolic differences (species diversity) and community level processes (inter-specific interactions and species abundance change) in the context of global environmental changes are of great significance in influencing system-level isoprene and likely other VOC emissions and thereby atmospheric chemical 
processes and air quality. This view is also evidenced by a 13-year field warming study conducted in the subarctic ecosystems showing that warming-induced changes in vegetation composition are a major factor affecting the monoterpene and sesquiterpene emission potentials (Valolahti et al. 2015). Terrestrial ecosystems show great heterogeneity in terms of composition and structure and are simultaneously subject to strong pressure arising from a variety of global change agents besides climate warming, e.g., drought, nitrogen deposition, $\mathrm{O}_{3}$ pollution, and species invasion (Franklin et al., 2016; Wang et al. 2017b). To understand how these agents alone and in combination can affect vegetation VOC emissions at temporally long scales requires the building of a predictive science of vegetation VOC emissions, as informed by the individual-based modelling study conducted here. The next generation dynamic global vegetation model, aDGVM (Scheiter et al. 2013), built with the same philosophy with such individual-based model, may offer a good platform to conduct regional and global scale studies over long-time scales. Such large-scale individual-based ecosystem models are highly recommended to be integrated into future climatechemistry models and earth system models to investigate the complex climate-biosphere-air quality feedbacks and inform policy decisions.

\subsection{References}

Abrams M.D. (1998). The paradox of red maple. Bioscience, 48, 355-364

Arneth, A., Niinemets, Ü., Pressley, S., Bäck, J., Hari, P., Karl, T., Noe, S., Prentice, I. C., Serça, D., Hickler, T., Wolf, A., and Smith, B. (2007a) Process-based estimates of terrestrial ecosystem isoprene emissions: incorporating the effects of a direct $\mathrm{CO}_{2}$-isoprene interaction, Atmos. Chem. Phys., 7, 31-53. 
Arneth, A., P. A. Miller, M. Scholze, T. Hickler, G. Schurgers, B. Smith, and I. C. Prentice (2007b) $\mathrm{CO}_{2}$ inhibition of global terrestrial isoprene emissions: Potential implications for atmospheric chemistry, Geophys. Res. Lett., 34, L18813.

Atkinson R., Arey J., 2003. Gas-phase tropospheric chemistry of biogenic volatile organic compounds: a review. Atmos. Environ. 37, 197-219.

Bishop, D. A., Beier, C. M., Pederson, N., Lawrence, G. B., Stella, J. C., \& Sullivan, T. J. (2015).

Regional growth decline of sugar maple (Acer saccharum) and its potential causes. Ecosphere, $6,1-14$.

Bormann, F. H., Likens, G. E., (1979) Catastrophic disturbance and the steady state in northern hardwood forests. Am. Scientist 67, 660-669.

Bugmann, H., Fischlin A., Kienast F., (1996) Model convergence and state variable update inforest gap models. Ecol. Model. 89, 197-208.

Crosby, M. K., Fan, Z., Leninger, T. D., Spetich, M. A., \& Self, A. B. (2014). Spatial trends and factors associated with hardwood mortality in the southeastern United States. southeastern geographer, 54, 72-85.

Davis, M. B. (1983). Quaternary history of deciduous forests of eastern North America and Europe. Annals of the Missouri Botanical Garden, 550-563.

Drewniak, B. A., Snyder, P. K., Steiner, A. L., Twine, T. E., \& Wuebbles, D. J. (2014). Simulated changes in biogenic VOC emissions and ozone formation from habitat expansion of Acer Rubrum (red maple). Environmental Research Letters, 9(1), 014006.

Fei, S., \& Steiner, K. C. (2007). Evidence for increasing red maple abundance in the eastern United States. Forest Science, 53(4), 473-477. 
Fiore A.M., Horowitz L.W., Purves D.W., Levy H., Evans M.J., Wang Y., Li Q. \& Yantosca R.M. (2005). Evaluating the contribution of changes in isoprene emissions to surface ozone trends over the eastern United States. Journal of Geophysical Research: Atmospheres (1984-2012), 110.

Franklin, J., Serra-Diaz, J. M., Syphard, A. D., Regan, H. M., 2016. Global change and terrestrial plant community dynamics. Proc. Natl. Acad. Sci. U. S. A. 201519911.

Fu T.M., Zheng Y., Paulot F., Mao J. \& Yantosca R.M. (2015). Positive but variable sensitivity of August surface ozone to large-scale warming in the southeast United States. Nature Clim. Change. 5, 454-458.

Geron, C., Daly, R., Harley, P., Rasmussen, R., Seco, R., Guenther, A., ... \& Gu, L. (2016). Large drought-induced variations in oak leaf volatile organic compound emissions during PINOT NOIR 2012. Chemosphere, 146, 8-21.

Goldstein, A. H., Koven, C. D., Heald, C. L., \& Fung, I. Y. (2009). Biogenic carbon and anthropogenic pollutants combine to form a cooling haze over the southeastern United States. Proceedings of the National Academy of Sciences, 106, 8835-8840.

Groffman, P. M., Baron, J. S., Blett, T., Gold, A. J., Goodman, I., Gunderson, L. H., ... \& Poff, N. L. (2006). Ecological thresholds: the key to successful environmental management or an important concept with no practical application? Ecosystems, 9, 1-13.

Grimm, V., Ayllón, D., \& Railsback, S. F. (2016). Next-Generation Individual-Based Models Integrate Biodiversity and Ecosystems: Yes We Can, and Yes We Must. Ecosystems, 20, 229-236. 
Guenther, A., Hewitt, C.N., Erickson, D., Fall, R., Geron, C., Graedel, T., Harley, P.,Klinger, L., Lerdau, M., McKay, W. (1995) A global model of natural volatileorganic compound emissions. J. Geophys. Res. 100, 8873-8892.

Guenther A., Karl T., Harley P., Wiedinmyer C., Palmer P.I. \& Geron C. (2006). Estimates of global terrestrial isoprene emissions using MEGAN (Model of Emissions of Gases and Aerosols from Nature). Atmos. Chem. Phys., 6, 3181-3210.

Haagen-Smit, A. J., \& Fox, M. M. (1954). Photochemical ozone formation with hydrocarbons and automobile exhaust. Air Repair, 4, 105-136.

Heald, C. L., Wilkinson, M. J., Monson, R. K., Alo, C. A., Wang, G., \& Guenther, A. (2009). Response of isoprene emission to ambient $\mathrm{CO}_{2}$ changes and implications for global budgets. Global Change Biology, 15(5), 1127-1140.

Huston M., DeAngelis D. \& Post W. (1988). New Computer Models Unify Ecological Theory. Bioscience, 38, 682-691.

Iverson, L. R., Prasad, A. M., Matthews, S. N., \& Peters, M. (2008). Estimating potential habitat for 134 eastern US tree species under six climate scenarios. Forest Ecology and Management, 254(3), 390-406.

Ito A., Sillman S. \& Penner J.E. (2009). Global chemical transport model study of ozone response to changes in chemical kinetics and biogenic volatile organic compounds emissions due to increasing temperatures: Sensitivities to isoprene nitrate chemistry and grid resolution. Journal of Geophysical Research: Atmospheres (1984-2012), 114.

Jacob D.J. \& Winner D.A. (2009). Effect of climate change on air quality. Atmospheric Environment, 43, 51-63. 
Johnson, D.W., Van Hook R.I., 2012. Analysis of biogeochemical cycling processes in Walker Branch Watershed. Springer Verlag, New York.

Kulmala, M., Suni, T., Lehtinen, K. E. J., Dal Maso, M., Boy, M., Reissell, A., Rannik, Ü., Aalto, P., Keronen, P., Hakola, H., Bäck, J., Hoffmann, T., Vesala, T., and Hari, P.: A new feedback mechanism linking forests, aerosols, and climate, Atmos. Chem. Phys., 4, 557562.

Kulmala, M., Nieminen, T., Chellapermal, R., Makkonen, R., Bäck, J., \& Kerminen, V. M. (2013). Climate feedbacks linking the increasing atmospheric $\mathrm{CO} 2$ concentration, BVOC emissions, aerosols and clouds in forest ecosystems. In Biology, controls and models of tree volatile organic compound emissions (pp. 489-508). Springer Netherlands.

Lerdau M. 2007. A positive feedback with negative consequences. Science 316, 212-213.

Lerdau M., Guenther A. \& Monson R. (1997). Plant production and emission of volatile organic compounds. Bioscience, 373-383.

Lerdau M. \& Slobodkin L. (2002). Trace gas emissions and species-dependent ecosystem services. Trends in Ecology \& Evolution, 17, 309-312.

Loreto, F., \& Fineschi, S. (2015). Reconciling functions and evolution of isoprene emission in higher plants. New Phytologist, 206(2), 578-582.

McDonald, R. I., Peet, R. K., \& Urban, D. L. (2002). Environmental correlates of oak decline and red maple increase in the North Carolina Piedmont. Castanea, 84-95.

Monson R.K., Jones R.T., Rosenstiel T.N. \& Schnitzler J. P. (2013). Why only some plants emit isoprene. Plant, Cell \& Environment, 36, 503-516. 
Monson, R. K., Neice, A. A., Trahan, N. A., Shiach, I., McCorkel, J. T., \& Moore, D. J. (2016). Interactions between temperature and intercellular $\mathrm{CO} 2$ concentration in controlling leaf isoprene emission rates. Plant, cell \& environment, 39(11), 2404-2413.

Niinemets, Ü., \& Sun, Z. (2015). How light, temperature, and measurement and growth [CO2] interactively control isoprene emission in hybrid aspen. Journal of experimental botany, 66, 841-851.

Nowacki G.J. \& Abrams M.D. (2015). Is climate an important driver of post-European vegetation change in the Eastern United States? Global Change Biology, 21, 314-334.

Paasonen, P., Asmi, A., Petäjä, T., Kajos, M. K., Äijälä, M., Junninen, H., ... \& van der Gon, H. D. (2013). Warming-induced increase in aerosol number concentration likely to moderate climate change. Nature Geoscience, 6, 438-442.

Pacifico, F., Folberth, G. A., Jones, C. D., Harrison, S. P., and Collins, W. J.: Sensitivity of biogenic isoprene emissions to past, present, and future environmental conditions and implications for atmospheric chemistry, J. Geophys. Res., 117, D22302, (2012).

Pacifico, F., Harrison, S. P., Jones, C. D., and Sitch, S.: Isoprene emissions and climate, Atmos. Environ., 43, 6121-6135, 2009.

Potosnak, M.J., L. Lestrougeon, O. Nunez. 2014. Increasing leaf temperature reduces the suppression of isoprene emission by elevated $\mathrm{CO}_{2}$ concentration. Science of the Total Environment, 481: 352-359.

Purves D. \& Pacala S. (2008). Predictive models of forest dynamics. Science, 320, 1452-1453.

Rosenstiel, T. N., Potosnak, M. J., Griffin, K. L., Fall, R., \& Monson, R. K. (2003). Increased $\mathrm{CO}_{2}$ uncouples growth from isoprene emission in an agriforest ecosystem. Nature, 421, 256259. 
Sanderson M.G. (2003). Effect of climate change on isoprene emissions and surface ozone levels. Geophysical Research Letters, 30.

Scheiter S., Langan L. \& Higgins S.I. (2013). Next-generation dynamic global vegetation models: learning from community ecology. New Phytologist, 198, 957-969.

Schurgers, G., A. Arneth, and T. Hickler (2011), Effect of climate-driven changes in species composition on regional emission capacities of biogenic compounds, J. Geophys. Res., 116, D22304

Seco, R., Karl, T., Guenther, A., Hosman, K. P., Pallardy, S. G., Gu, L., Geron, C., Harley, P. and Kim, S. (2015), Ecosystem-scale volatile organic compound fluxes during an extreme drought in a broadleaf temperate forest of the Missouri Ozarks (central USA). Glob Change Biol, 21, 3657-3674.

Sharkey, T. D., and Monson, R. K. (2017) Isoprene research - 60 years later, the biology is still enigmatic. Plant, Cell \& Environment, doi: 10.1111/pce.12930.

Sharkey T.D. \& Monson R.K. (2014) The future of isoprene emission from leaves, canopies and landscapes. Plant, Cell \& Environment 37, 1727-1740.

Shugart H.H. (1984). A theory of forest dynamics. The ecological implications of forest succession models. Springer Verlag, New York.

Shugart H.H. \& West D.C. (1977). Development of an Appalachian deciduous forest succession model and its application to assessment of the impact of the chestnut blight. J. Environ, Manage., 5, 161-179.

Shugart, H.H., Woodward F.I., (2011) Global change and the terrestrial biosphere: achievements and challenges. John Wiley \& Sons, UK 
Shuman, J. K., Shugart, H. H., \& O'halloran, T. L. (2011). Sensitivity of Siberian larch forests to climate change. Global Change Biology, 17, 2370-2384.

Sun Z, Hüve K, Vislap V, Niinemets Ü. 2013. Elevated [CO2] magnifies isoprene emissions under heat and improves thermal resistance in hybrid aspen. Journal of Experimental Botany 64, $5509-5523$.

Speer, James H; Grission-Mayer, Henry D; Orivs, Kenneth H; Greenberg, Cathryn H: 2009. Climate response of five oak species in the eastern deciduous forest of the southern Appalachain Mountains, USA. NRC Research Press. Can J. Fox Res. 39,2009

Turner, D. P., A. G. Wones, D. Pross, and D. L. Phillips, Climate change and global isoprene emissions, Paper 91-126. 3, Global Climate Change: Papers from the 84th Annual General Meeting of the Air and Waste Management Association, June 16-21, Vancouver, 1991.

Turner, D. P., A. G. Wones, D. Pross, and D. L. Phillips, Climate change and global isoprene emissions, Paper 91 - 126. 3, Global Climate Change: Papers from the 84th Annual General Meeting of the Air and Waste Management Association, June 16-21, Vancouver, 1991.

Valolahti, H., Kivimäenpää, M., Faubert, P., Michelsen, A. and Rinnan, R. (2015), Climate change-induced vegetation change as a driver of increased subarctic biogenic volatile organic compound emissions. Glob Change Biol, 21, 3478-3488.

Vickers, C. E., Gershenzon, J., Lerdau, M. T., \& Loreto, F. (2009). A unified mechanism of action for volatile isoprenoids in plant abiotic stress. Nature Chemical Biology, 5, 283-291.

Wang, B., Shugart, H.H., Shuman, J. K., Lerdau, M.T. (2016) Forests and ozone: productivity, carbon storage, and feedbacks. Scientific Reports 6, 22133. 
Wang, B, Shugart, H.H., Lerdau, M.T., (2017a). An individual-based forest volatile organic compounds emission model—UVAFME-VOC v1.0. Ecological Modelling, 350, 69-78

Wang, B, Shugart, H.H., Lerdau, M.T., (2017b). Sensitivity of global greenhouse gas budgets to tropospheric ozone pollution mediated by the biosphere. Environmental Research Letters, 10.1088/1748-9326/aa7885.

Weaver C., Cooter E., Gilliam R., Gilliland A., Grambsch A., Grano D., Hemming B., Hunt S., Nolte C. \& Winner D. (2009). A preliminary synthesis of modeled climate change impacts on US regional ozone concentrations. Bulletin of the American Meteorological Society, 90, 1843-1863.

Went, F. W. (1960). Blue hazes in the atmosphere. Nature, 187(4738), 641-643.

Wilkinson, M. J., Monson, R. K., Trahan, N., Lee, S., Brown, E., Jackson, R. B., ... \& Fall, R. A. Y. (2009). Leaf isoprene emission rate as a function of atmospheric CO2 concentration. Global Change Biology, 15, 1189-1200.

Zhang, Y., \& Wang, Y. (2016). Climate-driven ground-level ozone extreme in the fall over the Southeast United States. Proceedings of the National Academy of Sciences, 201602563.

\subsection{Supplementary materials}




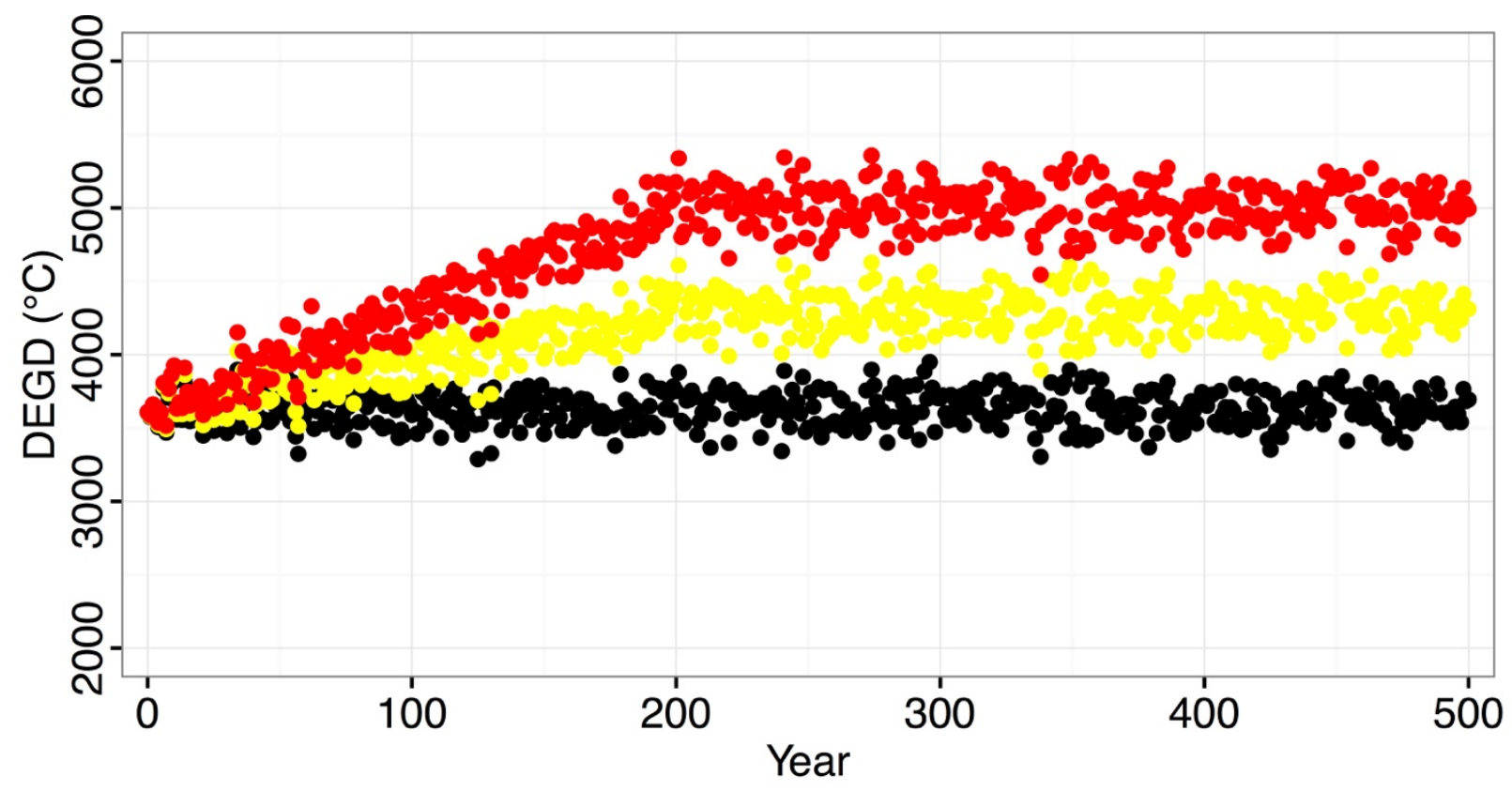

Fig. S1 Warming treatments $\left(+2{ }^{\circ} \mathrm{C}\right.$ and $\left.+4{ }^{\circ} \mathrm{C}\right)$ relative to the base climate in the simulation in terms of DEGD (growing degree days with a $5{ }^{\circ} \mathrm{C}$ base) in each year over the 500 -yr simulation. The DEGD is calculated from the daily temperature interpolated from model input of monthly mean, maximum, and minimum temperature data. The variations reflect the inter-annual variability of the climate in the simulation. 


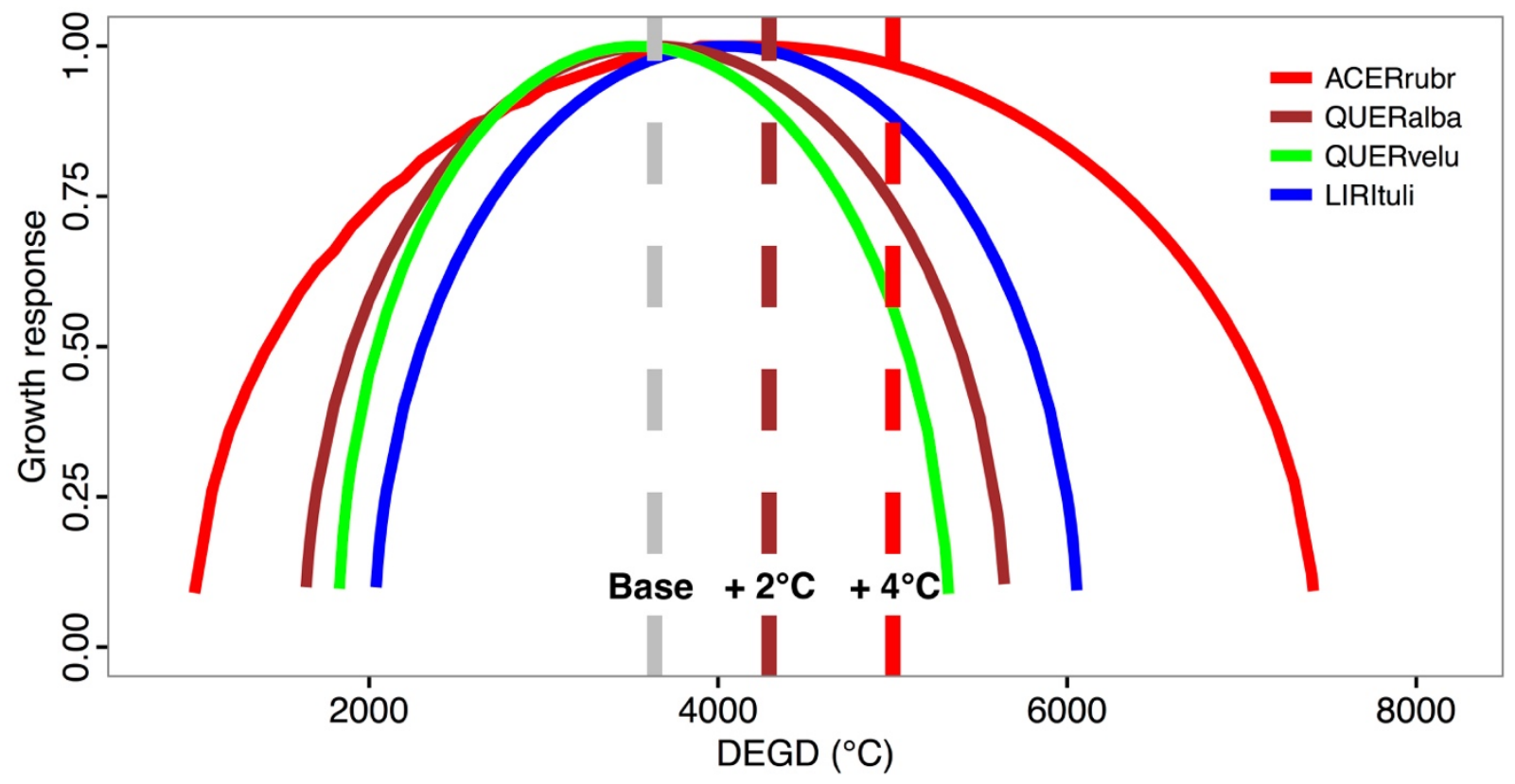

Fig.S2 Species-specific growth response to temperature as a function of DEGD. Four major species, Acer rubrum (red maple), Quercus alba (white oak), Quercus velutina (black oak), and Liriodendron tulipoplar (yellow poplar) are shown as examples. The underlying parabolic function follows:

$$
\begin{gathered}
f(x)=\left(\frac{x-d d \min }{d d o p t-d d \min }\right)^{a}\left(\frac{d d \max -x}{d d \max -d d o p t}\right)^{b} \\
a=\frac{d d o p t-d d \min }{d d \max -d d \min } \\
b=\frac{d d \max -d d o p t}{d d \max -d d \min }
\end{gathered}
$$

where $x$ is the input DEGD as shown in Supplementary Fig.1, and ddmin, ddopt, and ddmax refer to the species-specific minimum, optimal, and maximum growing degree days, respectively (see Table S2). 


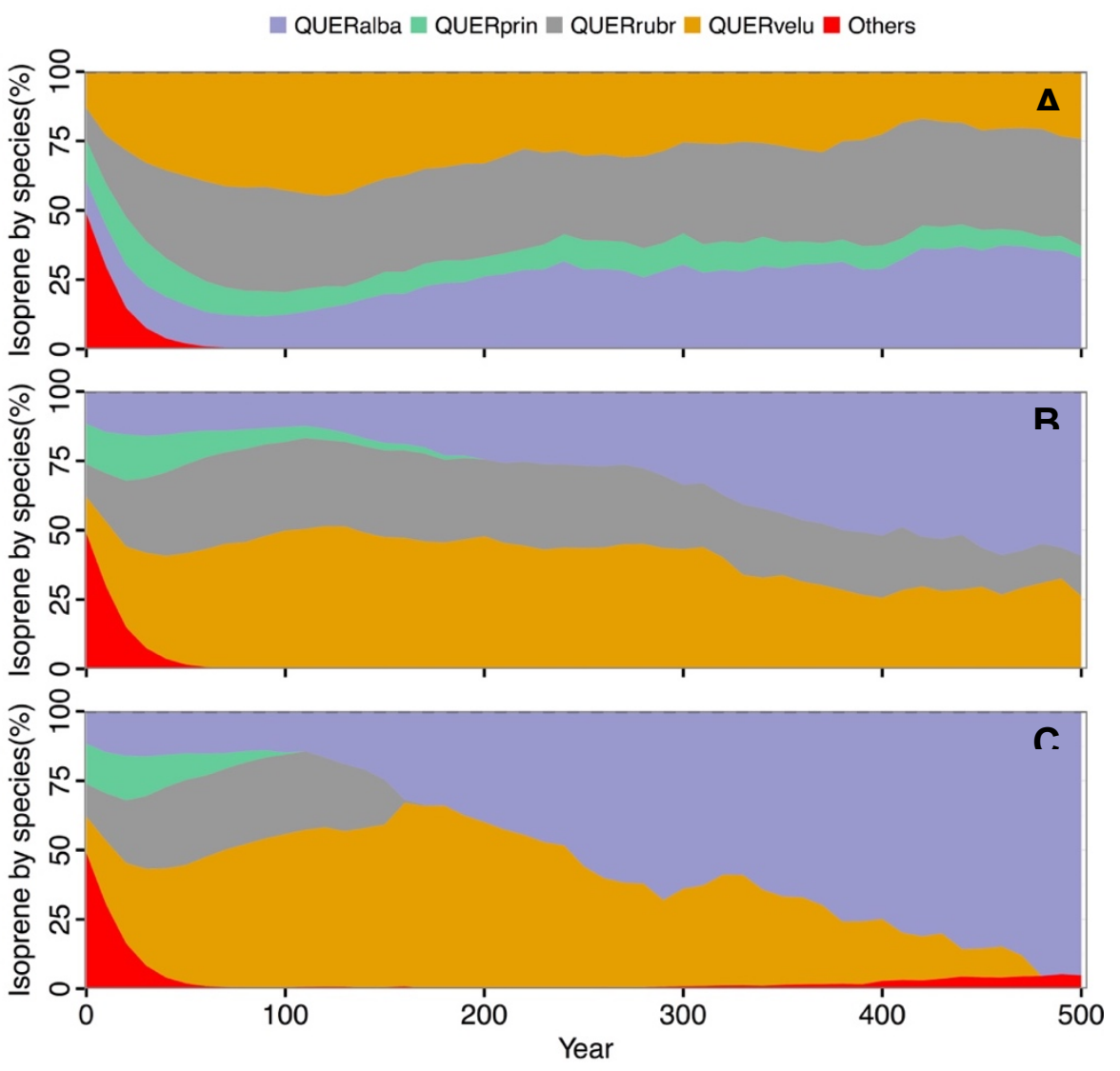

Fig.S3 Relative changes of the ten isoprene-emitting species in the simulated forest in response to climate warming. A-C is the base run, $+2^{\circ} \mathrm{C}$, and $+4{ }^{\circ} \mathrm{C}$ warming, respectively. The percentages are based on species biomass $\left(\mathrm{t} \mathrm{C} \mathrm{ha}^{-1}\right)$. See Table $\mathrm{S} 1$ for the ten species included. Four isoprene-emitting species are dominant in the forest composition, so the remaining six species are categorized into one group as 'others'. The species included in this category are in common because they are mostly early successional species. Their reappearance (e.g., in panel C) is totally because of regeneration with the death of large canopy-dominant trees, but these species consistently can't gain any dominance in the forest. As regards Quercus alba, it has relatively better performance in the southeastern US among the four major species (e.g., Shugart et al. 1977), and climate warming further intensifies its advantage. 

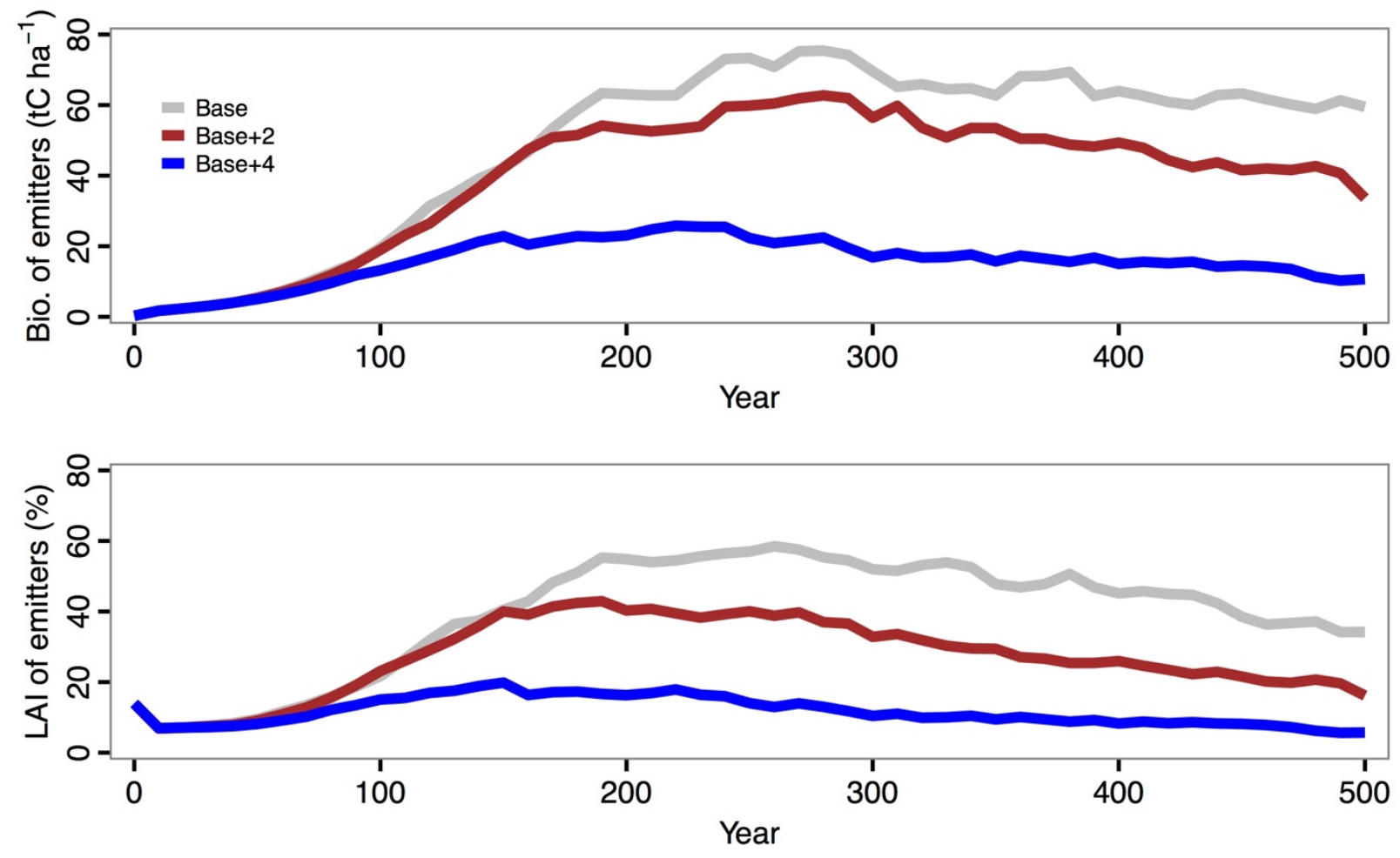

Fig. S4 Dynamic changes of the total biomass $\left(\mathrm{t} \mathrm{Cha}^{-1}\right)$ and leaf area (\%) of isoprene-emitting species in the forest in response to climate warming over the 500-yr simulation. Ten isopreneemitting species in total are included in this figure (listed in Table S1). These absolute biomass changes, combined with the relative changes (presented in Fig.2a), clearly show a decline of isoprene-emitters in the simulated forest under climate warming. The bottom panel shows the changes in total leaf area comprised by the isoprene-emitting species in response to climate warming. 


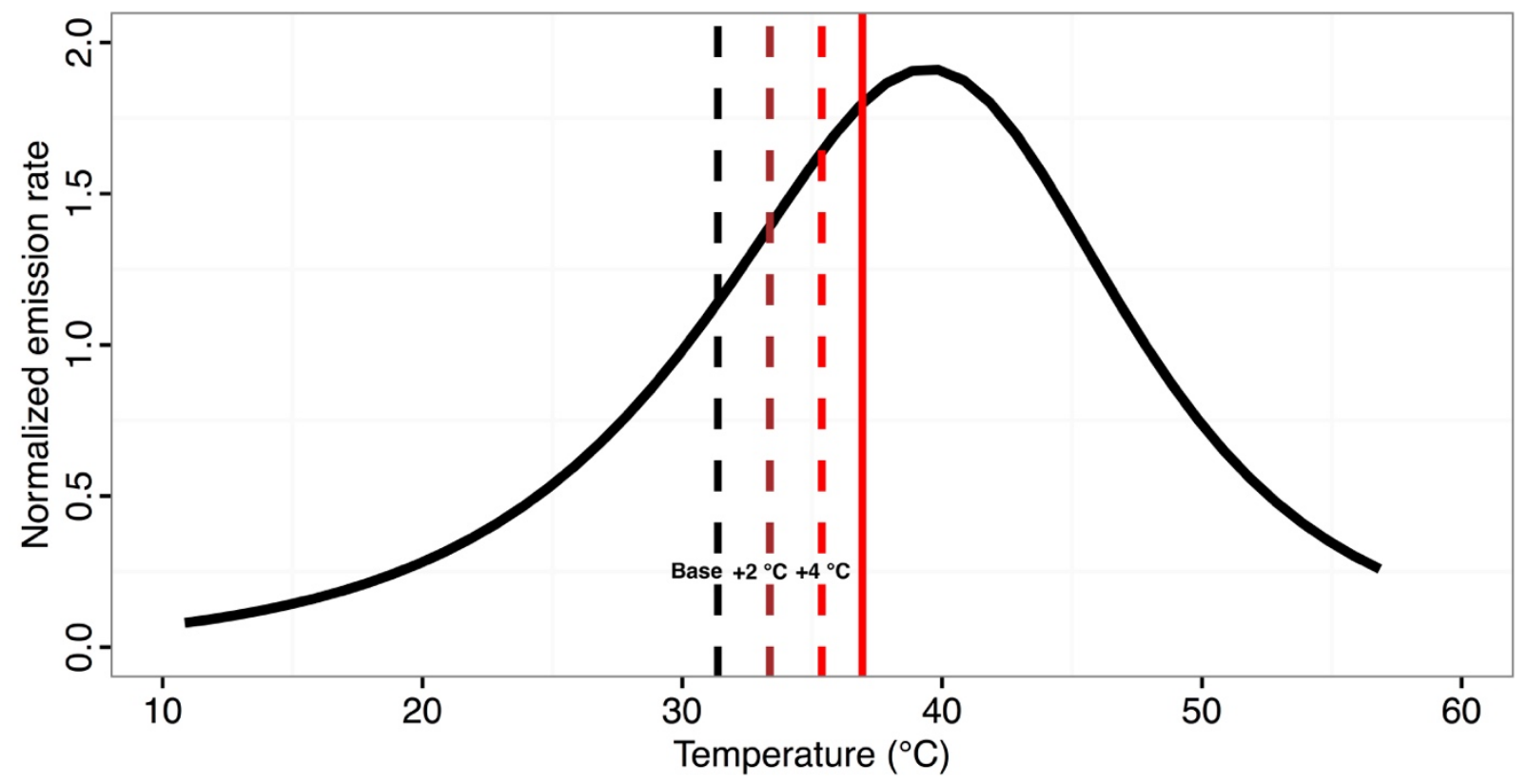

Fig. S5 Leaf-level isoprene emission rate (normalized) as a function of temperature $\left({ }^{\circ} \mathrm{C}\right)$. The underlying function of this curve follows the temperature-dependency algorithm developed by Guenther et al. (1993). Dotted lines in differing colors denote the different warming treatments (base, +2 , and $+4{ }^{\circ} \mathrm{C}$ ), and the solid red line denotes the maximum temperature reached under the $+4{ }^{\circ} \mathrm{C}$ treatment $\left(4^{\circ} \mathrm{C}\right.$ plus variation). Apparently, an experimental warming even by $4{ }^{\circ} \mathrm{C}$ still does not yet suppress leaf-level isoprene emissions, which excludes the possibility that warminginduced decline of forest system-level isoprene emissions is because of leaf-level inhibition of isoprene production. 


\section{Chapter 6 Final remarks and conclusions}

\subsection{Advantages and deficiencies of current IBM}

Starting from UVAFME-VOC, I broadly discuss some of the advantages and deficiencies of the current paradigm of IBM formulation in terms of species-specific formulations and the spatial scale, which, to my knowledge, are the two major concerns when developing, evaluating, and applying an IBM. Apparently, the fundamental advantage of IBM lies in its basic simulation unit of an individual. Thereby, which parameters to choose to depict and quantify a species will fundamentally determine the capability and complexity of an IBM. In addition, research of biosphere-atmosphere interactions always requires a spatially large scale to see implications of fine scale processes, thus making spatially large scale simulation an essential capability of IBM.

\subsubsection{Species-specific parameters and formulations}

Concerning the parameters and formulations governing the individuals of UVAFME-VOC and many other individual-based gap models (Bugmann 2001), it is best reflected by the comment from Shugart, "The simplicity of the functional relations in the models has positive and negative consequences. The positive aspects are largely involved in the ease of estimating model parameters for a large number of species; the negative aspects with a desire for more physiologically or empirically 'correct' functions." (Shugart et al. under review). We can clearly see that the parameters used as inputs to describe each individual species are a small set of variables related to species geometry, demographic properties, responses to environment, as well as other traits (see Chapter 3). These parameters (the corresponding formulations mostly based on allometric relationships) are fairly easy to estimate from sources of silvicultural books and forest inventory data (Shugart 1984; Chapter 3). In particular, in North America two silvicultural books by Fowells 
(1965) and Hardin et al. (2001) offer a synoptic compilation across the species ranges on each species' silvics.

However, a major drawback of or even criticism from ecological modelers, especially those working on large scale ecosystem models (e.g. DGVM), toward this formulation paradigm is that it is not process-based and cannot reflect the mechanistic processes of plant physiology. This forms a stark contrast to the widely adopted modelling paradigm focally represented by the Farquhar and Ball-berry photosynthesis and stomatal conductance simulation (Farquhar et al. 1980; Ball et al. 1987; Collatz et al. 1990). In response to these concerns, there do have process-based individualbased gap models developed, e.g., HYBRID (Friend et al. 1993), FORMIND for tropical forest (Fischer et al. 2016), and a very recent one, TROLL, also for tropical forests (Maréchaux and Chave 2017). However, such process-based modelling strategy requires many more speciesspecific parameters compared to the non-process-based ones that are much harder to estimate for every individual species. The overwhelming advantage of the UVAFME-type IBM makes the process-based strategy not widely accepted or applied in the forest modelling community to date (Shugart and Woodward 2011). Nevertheless, we acknowledge that without applying such process-based modelling strategy we can't even simulate or simulate well a variety of plant and ecosystem processes (e.g., $\mathrm{CO}_{2}$ fixation and water evapotranspiration). With the species-specific data becoming increasingly available we believe that more and more process-based IBM will spring up and posses a dominant position in the IBM market.

However, with either paradigm IBM provides a really flexible framework to incorporate individual level processes and examine system level responses (as exemplified by the VOC addon to the UVAFME). For further development of IBM, species-specific information from readily available plant traits could be incorporated to improve the current widely used IBM with a better 
reflection of interspecific differences and size- and age-dependent differences. This inclusion of plant traits could more completely reflect the great advancements that have been achieved in the past several decades and will be achieved in the coming decades of collecting data of different traits from species across the global biomes and of plant economic spectrum (Wright et al. 2014), such as the establishment of TRY global plant trait database (https://www.try-db.org; Kattge et al., 2011).

\subsubsection{Spatial scale}

The basic spatial extent of current IBM in general is about the size of a canopy gap created by the death of a canopy-dominant tree (that is why it is specifically called gap model, as mentioned earlier). In practice the plot size used in these models has been around 0.04 to 0.10 ha depending on sizes and heights of trees (e.g., UVAFME-VOC of $500 \mathrm{~m}^{2}$ ). The ratio of height of a gap to its width changes the illumination of the forest floor with latitude (Kuuluvainen 1992). In agreement with this pattern, the spatial unit used in gap models for models from the tropics to temperate to boreal zones have smaller plot sizes towards the equator matching the higher average sun angles there. Such a spatial scale is perfect for theoretical exploration of diversity-ecosystem functioning relationships at a local scale. This is one reason that we have seen many different versions of such IBM developed for differing forest systems over the past four decades (Shugart and Woodward 2012). As demonstrated by the progress made by UVAFME-VOC, IBM shows an overwhelming advantage in integrating explicitly the diversity into ecosystem dynamics and functions locally in the southeastern US.

An apparent concern for biosphere-atmosphere interactions is about the spatial scope limit of the current IBM. With a local scale, it seems not yet truly possible to study the global feedbacks of biosphere-atmosphere with a consideration of the system complexity. Of course, there do have 
studies beyond the local scale investigating regional or continental scale forest responses to climate change (Shugart et al. in review; Shuman et al. 2010). However, such large scale applications to regional/continental level have limitations. First, these studies are mostly limited to see the forest compositional changes responding to climate changes, lacking a closer examination of forest functions (e.g., carbon sequestration). More importantly, the modelling protocol of such IBM applications at large spatial scales are relatively inconvenient. We need an integrated biosphere model like DGVM and ESMs that have the IBM modelling strategy embedded. There have been practices in this direction that to some extent cater for these limitations. Earlier applications to global scale found a compromise between the IBM and aggregated modelling approach. This is best exemplified by the ED (Ecosystem Demographics) model developed by Moorcroft et al (2001), proposing a scaling up methodology of the gap dynamics to global scale. Simulations with this model have illustrated the importance of fine-scale heterogeneity in governing large-scale ecosystem functions. However, what is more exciting is the occurrence of a next generation DGVM, called 'aDGVM' developed by Scheiter et al. (2013), which merges the philosophy of IBM into vegetation dynamics and is built directly against the deficiencies of the PFT-based aggregate modelling strategy. These recent developments towards incorporating the system complexity following the IBM modelling strategy into large scale ecosystem simulations could be applied to study large scale feedbacks between the biosphere and atmosphere. Moreover, the rich data in the field of ecosystem ecology accumulated through the large-scale, spatially distributed eddy covariance flux towers across the planet provides a valuable, readily available resource for model validation (Williams et al. 2009). 


\subsection{Challenges of IBM-based BAIs research}

Although applications with such an IBM have obtained surprisingly new findings about the forest responses and feedbacks, to truly explore the biosphere and atmospheric chemistry interactions and even broader biosphere-atmosphere interactions using IBM or other models with the IBM methodology embedded still needs a long way to go. Feedbacks between the biosphere and atmosphere are extremely complex (e.g., Walker 1994; Arneth et al. 2010). To better elucidate the roles of the terrestrial ecosystems playing in influencing the climate and atmospheric components, even more system level processes of biogeochemical and biophysical pathways (carbon, nitrogen, water, and energy) should be investigated and simulated taking into consideration system complexity. Therefore, a rich research avenue concerning the application of IBM to regional and global scale BAIs research lies ahead but with a wide variety of big challenges. One obvious challenge is the scarcity of species-specific information, while another challenge is large scale modelling, as discussed earlier. However, these probably would not be big problems with remote sensing technology advancements enabling fast data acquisition of speciesspecific properties at spatial-temporal large scales (Shugart et al. 2015; Jetz et al. 2016; Stavros et al. 2017). By contrast, two biggest challenges toward developing next generation IBMs, to my understanding, are about the species acclimation and adaptation and the close linkage between the aboveground and belowground processes. These two challenges are likely to define a research agenda for the indefinite future not only for IBM itself but also for BAIs research broadly.

\subsubsection{Acclimation, Adaptation, and Evolution}

One grand challenge is revolving around the species acclimation, adaptation, and evolution. In a changing environment a species' metabolisms are not constantly same over time but dynamically changing, showing short-term plasticity or acclimation and relatively long-term 
adaptation (Albert et al. 2011; Keenan et al. 2013); for example, the responses of photosynthesis and plant respiration to temperature and $\mathrm{CO}_{2}$ to change over time of exposure to new or changing environmental conditions (Smith and Dukes 2013). These processes are crucial for survival of plants under global and regional environmental changes. The implications of these processes for developing and applying IBM is that species-specific parameters and formulations would have to be updated during the simulation rather than be kept consistent over the simulation. Tracing the short-term acclimation and long-term adaptation is challenging; evidence of plasticity is still limited to a few species (Albert et al. 2011). Therefore, it is basically not yet available to incorporate such species-specific properties into IBM. Some initial progress achieved in PFTbased model has clearly indicated the profound importance in including trait plasticity in modelling studies (e.g., Smith and Dukes 2013; Mastrotheodoros et al. 2017). These explorations could shed some light on the development of IBM, which, however, could not emerge until enough speciesspecific data is available. Additionally, it is anticipated that machine learning, which in a broader sense is computational techniques mimicking aspects of biological information processing for data modelling, would play a role in moving this direction forward by creating models of evolving process equations and parameters (Recknagel 2001).

\subsubsection{Aboveground-belowground linkage}

To completely understand ecosystem functioning, both the belowground system functions and in particular the close associations between the aboveground and the belowground activities must not be ignored, which are integral to the responses and feedbacks of the biosphere to changes in atmospheric conditions. Long term research of PSFs (plant-soil feedbacks) have accumulated convincing evidence showing the close interactions between the aboveground and belowground activities (e.g., Bever et al. 1994; Lau et al. 2017). In particular, system diversity has been 
increasingly being reported to play a key role in mediating PSFs; for example, very recent studies found that aboveground biodiversity affects soil microbial activities, soil-derived GHGs, and carbon storage (Lange et al. 2015). Moreover, the soil organic matter decomposition is increasingly being recognized as a process that is also strongly influenced by the microbial system composition and dynamics (Wieder et al. 2015; Melillo et al. 2017), which should be incorporated, improved, and applied in IBM (Widder et al. 2016; Allison et al. 2017). This arguably indicates that a coupled individual-based modelling of both aboveground and belowground systems is necessary. However, across the current lines of IBM the belowground processes are treated rather roughly. Take UVAFME-VOC for example. The process of organic matter decomposition is simulated using the first-order linear decay rates that are modified by environmental scalars (temperature and moisture) without considering the microbial community at all (Jenkinson et al. 1987). This rough treatment, which is understandable, primarily originates from a ubiquitous fact in the model development community that models are always developed targeting for questions of interest, usually neglecting the processes or components that "seem" not important to the processes of primary concern. Another reason might be that even for models specifically simulating soil biogeochemical cycling processes, the role of soil microbial systems was not treated explicitly until very recently (Wieder et al. 2015). However, what is encouraging is that there have been already advancements in IBM for microbial systems (Allison et al. 2017). The challenge is how to couple these two IBMs reconciling the strikingly different and wide-ranging scales/time steps of different processes.

\subsection{Conclusion}

Building a science of complex, adaptive systems of the biosphere is the prerequisite for an 
accurate understanding of BAIs in the Anthropocene Epoch. Methodological limitations, especially biosphere models with an aggregate representation of vegetation that is of overwhelmingly rich biodiversity, let alone empirical research (though having made great contributions), are hindering our achievement of this grand goal. Our initial explorations with the UVAFME-VOC of the interactions of forests and the atmospheric components mediated by diversity demonstrate that IBM is a feasible modelling strategy that can be applied to integrate diversity into ecosystem functioning in BAIs research. Confronting some big but definitely soluble challenges, I advocate more efforts to be spent in the development, validation, and application of IBM to integrate diversity into ecosystem dynamics and functions research and more broadly BAIs research. We acknowledge that it does not necessarily mean that IBM will be the only tool at least in the coming decades, but it is highly expected to play increasingly more important roles (including being embedded into Earth System Models) in addressing BAIs. This bright future is fundamentally conferred by the complexity of natural systems in the biosphere.

\subsection{References}

Albert, C. H., Grassein, F., Schurr, F. M., Vieilledent, G., \& Violle, C. (2011). When and how should intraspecific variability be considered in trait-based plant ecology?. Perspectives in Plant Ecology, Evolution and Systematics, 13, 217-225.

Allison, S. D. (2017). Building Predictive Models for Diverse Microbial Communities in Soil. In Microbial Biomass: A Paradigm Shift in Terrestrial Biogeochemistry (pp. 141-166). World Scientific.

Ball, J., Woodrow, I. \& Berry J. in Progress in Photosynthesis Research (ed. Biggens, J.) 221-224 (Martinus Nijhoff, Dordrecht, 1987). 
Bever, J. D. (1994). Feedback between plants and their soil communities in an old field community. Ecology, 75, 1965-1977.

Bugmann, H. (2001). A review of forest gap models. Climatic Change, 51(3-4), 259-305.

Collatz, G., Berry, J., Farquhar, G. \& Pierce, J. (1990) The relationship between the Rubisco reaction mechanism and models of photosynthesis. Plant Cell Environ. 13, 219-225.

DeAngelis, D. L., \& Mooij, W. M. (2005). Individual-based modeling of ecological and evolutionary processes. Annu. Rev. Ecol. Evol. Syst., 36, 147-168.

DeAngelis, D. L., \& Grimm, V. (2014). Individual-based models in ecology after four decades. F1000prime Reports, 6, 39

Dietze, M. C. (2017), Prediction in ecology: a first-principles framework. Ecol Appl, 27: 20482060.

Evans, M. R. (2012). Modelling ecological systems in a changing world. Phil. Trans. R. Soc. B, $367,181-190$.

Farquhar, G. D., von Caemmerer, S. \& Berry, J. A. (1980) A biochemical model of photosynthetic $\mathrm{CO}_{2}$ assimilation in leaves of $\mathrm{C} 3$ species. Planta $149,78-90$.

Fischer, R., Bohn, F., de Paula, M. D., Dislich, C., Groeneveld, J., Gutiérrez, A. G., ... \& Pütz, S. (2016). Lessons learned from applying a forest gap model to understand ecosystem and carbon dynamics of complex tropical forests. Ecological Modelling, 326, 124-133.

Fisher, R., McDowell, N., Purves, D., Moorcroft, P., Sitch, S., Cox, P., ... \& Ian Woodward, F. (2010). Assessing uncertainties in a second-generation dynamic vegetation model caused by ecological scale limitations. New Phytologist, 187, 666-681.

Foley, J. A., Levis, S., Costa, M. H., Cramer, W., \& Pollard, D. (2000). Incorporating dynamic vegetation cover within global climate models. Ecological Applications, 10, 1620- 
1632.

Fowells, H.A., 1965. Silvics of forest trees of the United States. Agriculture Handbook 654, US Department of Agriculture. 271

Friend, A. D., Shugart, H. H., \& Running, S. W. (1993). A physiology-based gap model of forest dynamics. Ecology, 74, 792-797.

Grimm, V., Revilla, E., Berger, U., Jeltsch, F., Mooij, W. M., Railsback, S. F., ... \& DeAngelis, D. L. (2005). Pattern-oriented modeling of agent-based complex systems: lessons from ecology. Science, 310, 987-991.

Grimm, V., Ayllón, D., \& Railsback, S. F. (2017). Next-generation individual-based models integrate biodiversity and ecosystems: yes we can, and yes we must. Ecosystems, 20, 229236.

Hardin, J.W., Leopold D.J., White F.M. (2001). Harlow and Harrar's textbook of dendrology. McGraw-Hill, New York.

Jenkinson, D. S., P. B. S. Hart, J. H. Rayner, and L. C. Parry (1987), Modelling the turnover of organic matter in long-term experiments at Rothamsted, INTECOL Bull., 15, 1-8.

Jetz, W., Cavender-Bares, J., Pavlick, R., Schimel, D., Davis, F. W., Asner, G. P., ... \& Schaepman, M. E. (2016). Monitoring plant functional diversity from space. Nature plants, 2(3).

Judson, O. P. (1994). The rise of the individual-based model in ecology. Trends in Ecology \& Evolution, 9, 9-14.

Kattge J, Diaz S, Lavorel S, Prentice IC, Leadley P,B€onisch G, Garnier E, Westoby M, Reich PB, Wright IJ et al. 2011. TRY-a global database of plant traits. Global Change Biology 17, 2905-2935.

Keenan, T. F., \& Niinemets, Ü. (2016). Global leaf trait estimates biased due to plasticity in the 
shade. Nature plants, 3 .

Kuuluvainen, T. 1992. Tree architectures adapted to efficient light utilization: is there a basis for latitudinal gradients? Oikos 65, 275-284.

Lange, M., Eisenhauer, N., Sierra, C. A., Bessler, H., Engels, C., Griffiths, R. I., ... \& Steinbeiss, S. (2015). Plant diversity increases soil microbial activity and soil carbon storage. Nature Communications, 6, 6707.

Lau, J. A., Lennon, J. T., \& Heath, K. D. (2017). Trees harness the power of microbes to survive climate change. Proceedings of the National Academy of Sciences, 201715417.

Ma, J., Shugart, H. H., Yan, X., Cao, C., Wu, S., \& Fang, J. (2017). Evaluating carbon fluxes of global forest ecosystems by using an individual tree-based model FORCCHN. Science of The Total Environment, 586, 939-951.

Maréchaux, I. and Chave, J. (2017), An individual-based forest model to jointly simulate carbon and tree diversity in Amazonia: description and applications. Ecol Monogr. doi:10.1002/ecm.1271

Mastrotheodoros, T., Pappas, C., Molnar, P., Burlando, P., Keenan, T. F., Gentine, P., ... \& Fatichi, S. (2017). Linking plant functional trait plasticity and the large increase in forest water use efficiency. Journal of Geophysical Research: Biogeosciences. 122, 2393-2408

Melillo, J. M., Frey, S. D., DeAngelis, K. M., Werner, W. J., Bernard, M. J., Bowles, F. P., ... \& Grandy, A. S. (2017). Long-term pattern and magnitude of soil carbon feedback to the climate system in a warming world. Science, 358(6359), 101-105.

Moorcroft, P. R., Hurtt, G. C., \& Pacala, S. W. (2001). A method for scaling vegetation dynamics: the ecosystem demography model (ED). Ecological monographs, 71, 557-586. 
Moorcroft, P. R. (2003). Recent advances in ecosystem-atmosphere interactions: an ecological perspective. Proceedings of the Royal Society of London B: Biological Sciences, 270, 1215-1227.

Moorcroft, P. R. (2006). How close are we to a predictive science of the biosphere? Trends in Ecology \& Evolution, 21, 400-407.

Recknagel, F. (2001). Applications of machine learning to ecological modelling. Ecological Modelling, 146, 303-310.

Scheiter, S., Langan, L., \& Higgins, S. I. (2013). Next-generation dynamic global vegetation models: learning from community ecology. New Phytologist, 198(3), 957-969.

Schurgers, G., A. Arneth, and T. Hickler (2011), Effect of climate-driven changes in species composition on regional emission capacities of biogenic compounds, J. Geophys. Res., 116, D22304

Shugart, H. H., \& West, D. C. (1980). Forest succession models. BioScience, 30, 308-313.

Shugart, H. H. (1984). A theory of forest dynamics. The ecological implications of forest succession models. Springer-Verlag.

Shugart, H.H., Woodward F.I., (2011) Global change and the terrestrial biosphere: achievements and challenges. John Wiley \& Sons, UK

Shugart, H. H., Asner, G. P., Fischer, R., Huth, A., Knapp, N., Le Toan, T., \& Shuman, J. K. (2015). Computer and remote-sensing infrastructure to enhance large-scale testing of individual-based forest models. Frontiers in Ecology and the Environment, 13, 503-511.

Shugart, H. H., Bin Wang, Andreas Huth, Rico Fischer, Xiaodong Yan, Amanda Armstrong (under review) Gap models and their individual-based relatives in the assessment of the consequences of global change. Environmental Research Letters 
Smith, N. G. and Dukes, J. S. (2013), Plant respiration and photosynthesis in global-scale models: incorporating acclimation to temperature and $\mathrm{CO}_{2}$. Glob Change Biol, 19, 45-63.

Smith, B., Prentice, I. C., \& Sykes, M. T. (2001). Representation of vegetation dynamics in the modelling of terrestrial ecosystems: comparing two contrasting approaches within European climate space. Global Ecology and Biogeography, 10, 621-637.

Stavros, E. N., Schimel, D., Pavlick, R., Serbin, S., Swann, A., Duncanson, L., ... \& Schweiger, A. (2017). ISS observations offer insights into plant function. Nature Ecology \& Evolution, 1,1584

Stillman, R. A., Railsback, S. F., Giske, J., Berger, U., \& Grimm, V. (2015). Making predictions in a changing world: the benefits of individual-based ecology. BioScience, 65, 140-150.

Valolahti, H., Kivimäenpää, M., Faubert, P., Michelsen, A. and Rinnan, R. (2015), Climate change-induced vegetation change as a driver of increased subarctic biogenic volatile organic compound emissions. Glob Change Biol, 21, 3478-3488.

Wieder, W. R., Allison, S. D., Davidson, E. A., Georgiou, K., Hararuk, O., He, Y., ... \& ToddBrown, K. (2015). Explicitly representing soil microbial processes in Earth system models. Global Biogeochemical Cycles, 29, 1782-1800.

Widder, S., Allen, R. J., Pfeiffer, T., Curtis, T. P., Wiuf, C., Sloan, W. T., ... \& Kettle, H. (2016). Challenges in microbial ecology: building predictive understanding of community function and dynamics. The ISME journal, 10, 2557.

Williams, M., Richardson, A. D., Reichstein, M., Stoy, P. C., Peylin, P., Verbeeck, H., Carvalhais, N., Jung, M., Hollinger, D. Y., Kattge, J., Leuning, R., Luo, Y., Tomelleri, E., Trudinger, C. M., and Wang, Y.-P.: Improving land surface models with FLUXNET data, Biogeosciences, 6, 1341-1359 
Wright, I. J., Reich, P. B., Westoby, M., \& Ackerly, D. D. (2004). The worldwide leaf economics spectrum. Nature, 428, 821-827.

Zak, D. R., Pregitzer, K. S., Kubiske, M. E. \& Burton, A. J. (2011) Forest productivity under elevated $\mathrm{CO}_{2}$ and $\mathrm{O}_{3}$ : positive feedbacks to soil $\mathrm{N}$ cycling sustain decade-long net primary productivity enhancement by $\mathrm{CO}_{2}$. Ecol. Lett. 14, 1220-1226. 